\title{
Estudo de correlação das internações hospitalares por câncer, poluição relacionada ao tráfego e nível sócio-econômico no município de São Paulo
}

André de Almeida Ribeiro

Dissertação apresentada ao Programa de PósGraduação em Saúde Pública da Faculdade de Saúde Pública da Universidade de São Paulo para obtenção do título de Mestre em Ciências.

Área de Concentração: Saúde Ambiental

Orientador: Prof. Dr. Adelaide Cassia Nardocci

São Paulo

2011 
É expressamente proibida a comercialização deste documento, tanto na sua forma impressa como eletrônica. Sua reprodução total ou parcial é permitida exclusivamente para fins acadêmicos e científicos, desde que na reprodução figure a identificação do autor, título, instituição e ano da dissertação. 


\section{DEDICATÓRIA}

Dedico este trabalho

a meus pais, Fernando e Elsy,

à minha companheira, Cristiane, e aos meus irmãos, Bruno e Marcos. 


\title{
AGRADECIMENTOS
}

\begin{abstract}
À Professora Adelaide Cássia Nardocci. Sem a sua persistência e orientação, não seria possível a realização deste trabalho.
\end{abstract}

Ao estagiário Samuel Luna de Almeida, pela inestimável contribuição na confecção dos mapas e no georreferenciamento das internações hospitalares. 
Ribeiro AA. Estudo de correlação das internações hospitalares por câncer, poluição relacionada ao tráfego e nível sócio-econômico no município de São Paulo [dissertação de mestrado]. São Paulo: Faculdade de Saúde Pública da USP; 2011.

\section{Resumo}

Introdução - A exposição à poluição do ar é responsável por diversos efeitos à saúde e se distribui de forma diferenciada na população conforme o nível sócio-econômico. Objetivos - Explorar relações entre internações hospitalares por tipos de câncer e indicadores ambientais e sócioeconômico, na escala de áreas de pequeno tamanho, no município de São Paulo. Métodos - Revisaram-se estudos ecológicos sobre desigualdades sócio-econômicas em câncer e estudos sobre os efeitos da poluição ambiental do ar relacionada ao tráfego sobre o risco de câncer, publicados entre 1998 e 2008. Empreendeu-se a seguir estudo ecológico, com uso de unidade delimitada por grid (500 por 500 metros) e setor censitário, englobando todos os indivíduos internados em hospitais públicos ou privados com diagnóstico principal de neoplasia primária invasiva, no período de 2004 a 2006. As internações foram georreferenciadas e alocadas às unidades de estudo, sendo cada caso contado apenas uma vez. A densidade de tráfego foi calculada para cada unidade da grid a partir de dados de contagem veicular. Utilizaram-se modelos de regressão logística para explorar as associações entre densidade de tráfego, Índice de Desenvolvimento Humano e taxas de internação hospitalar. Resultados - $\mathrm{O}$ estudo de revisão mostrou que o nível sócio-econômico se associou de modo distinto de acordo com o tipo de neoplasia maligna. A maioria dos estudos observaram associação positiva da poluição ambiental do ar com câncer, com achados mais consistentes para exposição a material particulado inalável e câncer de pulmão. Do estudo ecológico verificou-se risco aumentado de internação por neoplasias respiratórias em adultos e hematológicas em crianças e adolescentes associado a morar em áreas com maior densidade de tráfego por veículos totais, movidos a gasolina e a diesel, com claro gradiente dose-resposta. O nível sócio-econômico da área 
de moradia esteve associado positivamente e em gradiente com as medidas de densidade de tráfego e com os cânceres de mama e de próstata. Conclusões - Investigações se fazem necessárias em megacidades de países em desenvolvimento sobre os riscos à saúde relacionados à poluição ambiental do ar devida ao tráfego e sobre o modo como se desenvolveu a rede viária e o tráfego de veículos em sua relação com os locais ocupados historicamente pelas diferentes classes sociais. Estudos que contornem as limitações aqui encontradas poderão fornecer estimativas mais precisas e acuradas.

Descritores: poluição do ar; tráfego; câncer; fatores sócio-econômicos; desigualdades em saúde. 
Ribeiro AA. Estudo de correlação das internações hospitalares por câncer, poluição do ar relacionada ao tráfego e nível sócio-econômico no município de São Paulo [dissertation]. São Paulo (BR): Faculdade de Saúde Pública da Universidade de São Paulo; 2011.

\section{Abstract}

Introduction - Exposure to air pollution is responsible for various health effects and is distributed differently in the population according to socioeconomic status. Objectives - To explore relationships between hospital admissions for cancers and socio-economic and environmental indicators, on a small-area scale, in São Paulo city. Methods - First we reviewed ecological studies on socioeconomic inequalities in cancer and studies on the effects of traffic-related air pollution on the risk of cancer, published between 1998 and 2008. Then an ecological study was undertaken, using a unit defined by grid ( 500 by 500 meters) and census tract, and embraced all individuals admitted to public or private hospitals with a main diagnosis of primary invasive cancer during the period 2004 to 2006. Hospitalizations were georeferenced and allocated to units of study, each case counted only once. The traffic density was calculated for each grid unit from vehicle count data. We used logistic regression models to explore the associations between traffic density, Human Development Index and rates of hospitalization. Results - The review showed that the socioeconomic status was associated differently according to the type of malignancy. Most studies found a positive association of environmental air pollution with cancer, the most consistent findings for exposure to inhalable particulate matter and lung cancer. The ecological study found an increased risk of hospitalization for respiratory cancers in adults and for hematologic cancers in children and adolescents associated with living in areas with higher total, gasoline and diesel traffic density, with a clear dose-response gradient. The socioeconomic status of the living area was positively associated in gradient with measures of traffic density and with breast and prostate cancers. 
Conclusions - Investigations are necessary in megacities of developing countries about the health risks of traffic-related environmental air pollution and about how the development of the road network and vehicle traffic relates to sites historically occupied by different social classes. Studies that circumvent the limitations found here may provide more precise and accurate estimates.

Descriptors: air pollution; traffic; cancer; socioeconomic factors; health inequalities. 


\section{ÍNDICE}

1 INTRODUÇÃO 19

2 OBJETIVOS 24

2.1 OBJETIVO GERAL 24

2.2 OBJETIVOS ESPECÍFICOS 24

3 MÉTODO 25

3.1 ESTUDO DE REVISÃO 25

3.2 ESTUDO ECOLÓGICO 26

3.2.1 Caracterização da Área de Estudo 26

3.2.2 População de Estudo 29

3.2.3 Bases de Dados 30

3.3 VARIÁVEIS DE ESTUDO 35

3.4 ANÁLISE DE DADOS 35

4 RESULTADOS 38

4.1 ESTUDO DE REVISÃO 38

4.1.1 Desigualdades Sócio-econômicas e Câncer 38

4.1.2 Poluição Ambiental do Ar e Câncer 50

4.2 ESTUDO ECOLÓGICO 61

5 DISCUSSÃO 84

6 CONCLUSÕES E CONSIDERAÇÕES FINAIS 99

7 REFERÊNCIAS BIBLIOGRÁFICAS 102

ANEXOS

Anexo 1

Anexo 2

Anexo $3 \quad 140$

Anexo $4 \quad 159$

CURRÍCULOS LATTES 171 


\section{Lista de Figuras}

Figura 1 - Tendência temporal da concentração média anual de $\mathrm{MP}_{2,5}\left(\mathrm{em} \mu \mathrm{g} / \mathrm{m}^{3}\right)$. Município de São Paulo 2000-2006

Figura 2 - Tendência temporal da concentração média anual de $\mathrm{MP}_{10}\left(\mathrm{em} \mu \mathrm{g} / \mathrm{m}^{3}\right.$ ). Município de São Paulo 1997-2008

Figura 3 - Tendência temporal da concentração média anual de $\mathrm{NO}_{2}\left(\mathrm{em} \mu \mathrm{g} / \mathrm{m}^{3}\right)$. Município de São Paulo 1997-2008.

Figura 4 - Histograma de freqüência de densidade veicular total por célula da grid. Município de São Paulo, 2008

Figura 5 - Densidade de tráfego veicular total por célula da grid. Município de São Paulo, 2008

Figura 6 - Densidade de tráfego por veículos movidos a diesel por célula da grid. Município de São Paulo, 2008

Figura 7 - Densidade de tráfego de veículos movidos a gasolina por célula da grid. Município de São Paulo, 2008

Figura 8 - Índice de Desenvolvimento Humano Municipal por célula da grid. Município de São Paulo, 2000

Figura 9 - Índice de Desenvolvimento Humano Municipal por setor censitário. Município de São Paulo, 2000 


\section{Lista de Quadros}

Quadro 1 - Relação de estudos ecológicos nacionais sobre câncer. 1998-2008

Quadro 2 - Relação de estudos ecológicos internacionais de desigualdades sócio-econômicas em câncer. 19982008

Quadro 3 - Relação de estudos sobre os efeitos da poluição do ar relacionada ao tráfego sobre o risco de câncer em adultos. 1998-2008

Quadro 4 - Relação de estudos sobre os efeitos da poluição do ar sobre o risco de câncer em crianças e adolescentes. 1998-2008

Quadro 5 - Relação de estudos ecológicos nacionais sobre câncer. 1998-2008.

Quadro 6 - Relação de estudos ecológicos internacionais de desigualdades sócio-econômicas em câncer. 19982008

Quadro 7 - Relação de estudos sobre os efeitos da poluição do ar sobre o risco de câncer em adultos. 1998-2008

Quadro 8 - Relação de estudos sobre os efeitos da poluição do ar sobre o risco de câncer em crianças e adolescentes. 1998-2008 


\section{Lista de Tabelas}

Tabela 1 - Matriz de correlação das concentrações médias anuais de $\mathrm{MP}_{10}$. Município de São Paulo, 1997-2008

Tabela 2 - Percentis, valores mínimo e máximo, média e desvio padrão de população, IDH-M e indicadores de tráfego por célula da grid. Município de São Paulo, 2000, 2008

Tabela 3 - Número e porcentagem das internações hospitalares por tipos de neoplasia maligna, segundo as bases de dados original e georreferenciada com e sem duplicatas. Município de São Paulo, 2004-2006

Tabela 4 - Número e porcentagem das internações hospitalares e mortes por tipos de neoplasias malignas. Município de São Paulo, 2004-2006

Tabela 5 - Odds Ratio para taxas de internação hospitalar por neoplasias totais, respiratórias em maiores de 20 anos e hematológicas em menores de 20 anos e densidades veiculares por célula da grid. Município de São Paulo, 2004-2006

Tabela 6 - Odds Ratio para taxas de internação hospitalar por neoplasias e densidade veicular total por célula da grid, após exclusão de áreas com menos de 20 habitantes. Município de São Paulo, 2004-2006

Tabela 7 - Odds Ratio para densidades veiculares e IDH-M por célula da grid. Município de São Paulo, 2000, 2008 
Tabela 8 - Odds Ratio para taxas de internação hospitalar por neoplasias e IDH-M por setor censitário. Município de São Paulo, 2004-2006

Tabela 9 - Percentis, valores mínimo e máximo, média e desvio padrão de população, IDH-M e indicadores de tráfego por célula da grid. Centro expandido do município de São Paulo, 2000, 2008

Tabela 10 - Odds Ratio para densidades veiculares e IDH-M por célula da grid. no centro expandido do Município de São Paulo, 2000, 2008.

Tabela 11 - Odds Ratio e Intervalo de Confiança de 95\% para internações por neoplasias respiratórias em maiores de 20 anos e densidades veiculares por célula da grid. Município de São Paulo, 2004 a 2006. 


\section{Siglas Utilizadas}
$\mathrm{AlH}-$
Autorização de Internação Hospitalar
CEP - $\quad$ Código de Endereçamento Postal
CETESB - $\quad$ Companhia de Tecnologia de Saneamento Ambiental
ClH - Comunicação de Internação Hospitalar
CET - $\quad$ Companhia de Engenharia de Tráfego
CID-10 - Classificação Internacional de Doenças (10ª Revisão)
CO - Monóxido de carbono
$\mathrm{CO}_{2}-\quad$ Dióxido de carbono
DATASUS - Departamento de Informática do SUS
DETRAN-SP - Departamento Estadual de Trânsito de São Paulo
EUA - $\quad$ Estados Unidos da América
FSP-USP - $\quad$ Faculdade de Saúde Pública da Universidade de São Paulo
HPA - Hidrocarbonetos Policíclicos Aromáticos
HEI - $\quad$ Health Effects Institute
IARC - Internacional Agency for Research on Cancer
IBGE - $\quad$ Instituto Brasileiro de Geografia e Estatística
IC95\% - Intervalo de Confiança de 95 porcento 


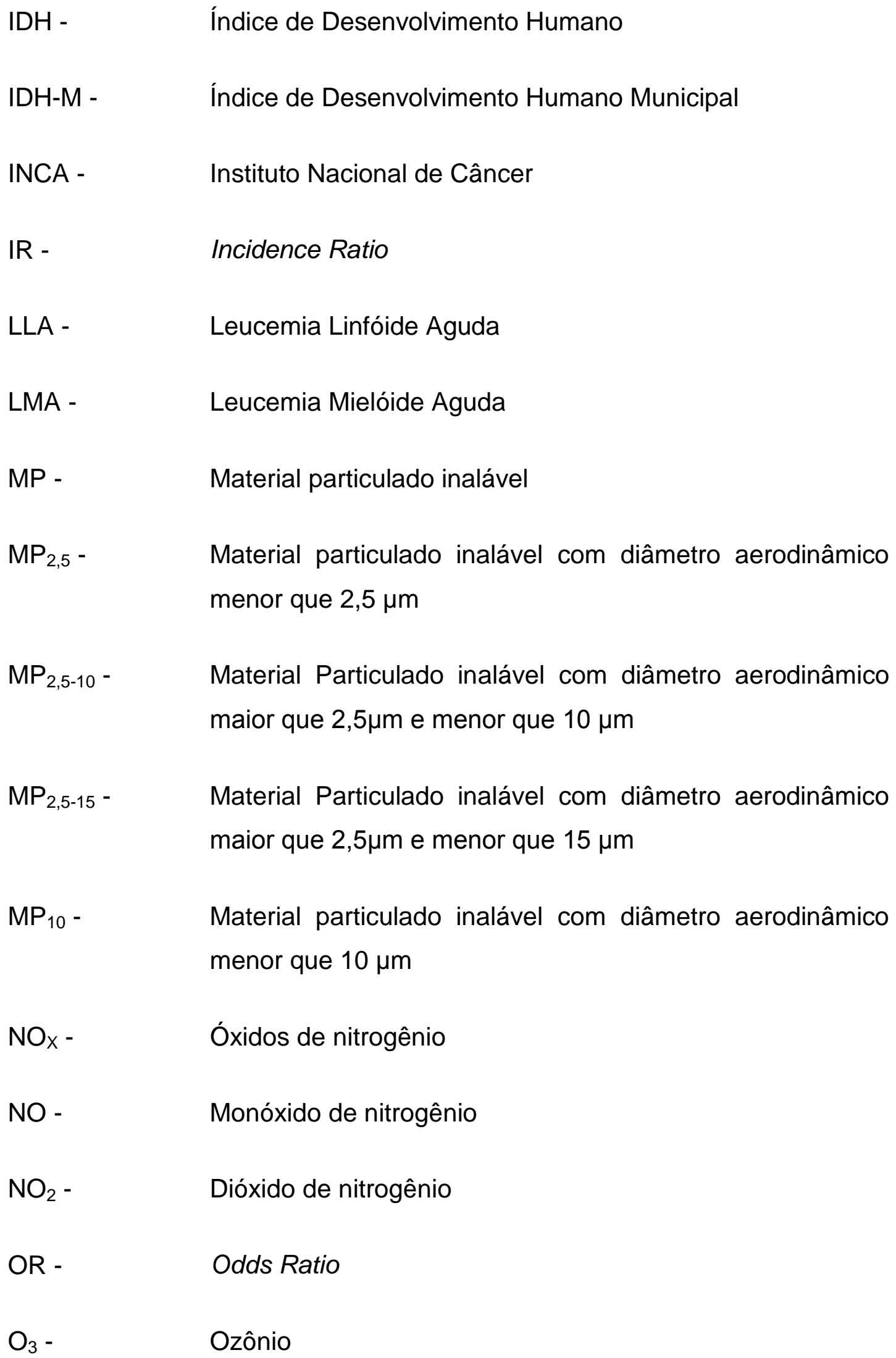




\begin{tabular}{|c|c|}
\hline PNUD - & Programa das Nações Unidas para o Desenvolvimento \\
\hline PSA - & Prostate-Specific Antigen \\
\hline PTS - & Partículas Totais em Suspensão \\
\hline RMSP - & Região Metropolitana de São Paulo \\
\hline SEADE - & Fundação Sistema Estadual de Análise de Dados \\
\hline SES - & Secretaria de Estado de Saúde \\
\hline SNC - & Sistema Nervoso Central \\
\hline SUS - & Sistema Único de Saúde \\
\hline $\mathrm{SO}_{\mathrm{x}}-$ & Óxidos de enxofre \\
\hline $\mathrm{SO}_{2}-$ & Dióxido de enxofre \\
\hline $\mathrm{SO}_{4}^{-}-$ & Sulfato \\
\hline RR - & Risco Relativo \\
\hline SIR - & Standardized Incidence Ratio \\
\hline TGI - & Trato Gastrintestinal \\
\hline WHO - & World Health Organization \\
\hline
\end{tabular}




\section{INTRODUÇÃO}

Efeitos adversos à saúde humana da exposição à poluição do ar têm sido mostrados em vários estudos. Exposições agudas estão associadas com os desfechos agudos de morbidade e mortalidade geral, respiratória e cardiovascular. Entre suas conseqüências estão incluídos a diminuição da função pulmonar, o aumento dos sintomas respiratórios, do absenteísmo escolar, dos episódios de pneumonia, doença isquêmica cardíaca, acidente vascular cerebral, transtornos da condução e arritmias, exacerbação de asma e doença respiratória obstrutiva crônica, assim como o aumento de procura a serviços de urgência e emergência médica, de internações hospitalares e mortes por essas e outras moléstias (GOUVEIA et al., 2003; $\mathrm{HEl}, 2009)$.

As exposições de longo prazo têm sido associadas com desfechos crônicos de morbidade e mortalidade geral, respiratória, cardiovascular, e possivelmente neoplásica, como aceleração da progressão, aumento da incidência e da mortalidade por doença pulmonar obstrutiva crônica, doença isquêmica cardíaca, transtornos de condução e arritmias, insuficiência cardíaca, câncer de pulmão, déficit do crescimento da função pulmonar em crianças e adolescentes, diminuição da função pulmonar em adultos e da expectativa de vida, entre outros (LADEN et al., 2006; POPE e DOCKERY, 2006; GÖTSCHI et al., 2008; HEI, 2009; POPE et al., 2009). Desfechos relacionados com a exposição à poluição do ar durante a gestação, como baixo peso ao nascimento, mortalidade intra-uterina, prematuridade e crescimento intra-uterino retardado, ainda não estão bem estabelecidos, mas recentes estudos têm somado evidências a seu favor (POPE e DOCKERY, 2006; HEI, 2009).

DANAEl et al. (2005) estimaram que 5\% das mortes por cânceres de pulmão, laringe e traquéia seriam atribuídos à poluição do ar urbana, o que corresponderia a 64 mil mortes anuais no mundo. Estimativas mais recentes 
apontam que o material particulado fino (com diâmetro aerodinâmico menor que 2,5 $\mu \mathrm{m}-\mathrm{MP}_{2,5}$ ) está associado a $8 \%$ das mortes por câncer de pulmão, $5 \%$ das mortes por doenças cardiovasculares e 3\% das mortes por infecção respiratória em todo mundo (WHO, 2009).

Os veículos motorizados são uma importante e crescente fonte de poluição do ar e as emissões veiculares incluem compostos tóxicos, mutagênicos e cancerígenos, que se diferenciam enormemente em suas propriedades físicas e químicas. São compostos orgânicos e inorgânicos, que se apresentam como gases ou partículas sólidas, que podem sofrer transformações físico-químicas após sua emissão. Entre os compostos emitidos por veículos automotivos associados com efeitos adversos à saúde e ao ambiente, citam-se $\mathrm{CO}_{2}$ (dióxido de carbono), $\mathrm{CO}$ (monóxido de carbono), hidrocarbonetos, $\mathrm{NO}_{\mathrm{x}}$ (óxidos de nitrogênio), material particulado inalável (especialmente $\mathrm{MP}_{2,5}$ e $\mathrm{MP}_{10}$ ), $\mathrm{SO}_{2}$ (dióxido de enxofre), benzeno, formaldeído, acetaldeído, 1,3-butadieno e chumbo (onde ainda se utiliza gasolina com chumbo tetraetila). Partículas de sulfato e ozônio $\left(\mathrm{O}_{3}\right)$ são subprodutos secundários decorrentes das transformações atmosféricas de poluentes primários ( $\mathrm{HEl}, 2009)$. Entretanto, a maioria desses compostos também é emitida por outras fontes como indústrias, queima de biomassa, entre outras.

Em áreas urbanas, a população passa tempo considerável próxima ou em vias com alto tráfego de veículos. O crescimento da população urbana, da frota de veículos e dos congestionamentos do tráfego, entre outros fatores, sugerem que a exposição à poluição veicular exercerá um papel cada vez mais importante na exposição a poluentes ambientais nas áreas urbanas e metropolitanas, apesar das medidas de controle adotadas nas últimas décadas para diminuir as emissões (HEI, 2009).

Desse modo, estudos que investiguem os efeitos adversos à saúde da poluição relacionada ao tráfego tem se tornado importantes e oportunos na atualidade, tanto para o dimensionamento dos impactos à saúde das pessoas como também para sensibilizar os gestores na implementação de 
medidas adequadas que reduzam a poluição veicular nos grandes centros urbanos e a população na adesão e apoio a essas medidas.

O município de São Paulo não foge dessa realidade e tendência mundiais. Uma das maiores e mais populosas cidades do mundo, possui uma frota de mais de 6 milhões de veículos e cerca de 18 mil quilômetros de vias, além de um transporte público ainda muito centrado no ônibus, cuja frota diária chega a 15000 veículos movidos a diesel.

Muitos estudos sobre os efeitos à saúde da poluição relacionada ao tráfego têm sido realizados, em especial envolvendo doenças respiratórias e cardiovasculares em grupos vulneráveis (idosos e crianças), mas muito poucos sobre poluição relacionada ao tráfego e efeitos de longo prazo, como câncer. Embora este tema ainda seja controverso e inconclusivo, estudos ecológicos podem auxiliar na compreensão da amplitude dos efeitos dessa exposição sobre a saúde humana.

Um aspecto relevante para os estudos sobre os efeitos da poluição relacionada ao tráfego é a consideração da distribuição desigual da exposição sobre a população, podendo afetar de forma desigual diferentes áreas e estratos socioeconômicos. O estudo dessas desigualdades na exposição à poluição do tráfego demanda o uso de unidades de análise em escalas intra-urbanas e tem sido também utilizado como forma de avaliação da chamada justiça ambiental, definida por Sexton e Anderson, citados por SEXTON e ADGATE (1999), como a provisão de proteção adequada contra riscos ambientais para todas as pessoas, independentemente de idade, raça, etnia, gênero, classe social ou estado de saúde.

Os estudos que tratam da questão da justiça ambiental têm evidenciado que populações com menores níveis sócio-econômicos tendem a experimentar exposição a maiores níveis de poluentes ambientais, devido especialmente à proximidade de suas residências a fontes poluentes (indústrias, vias de tráfego intenso etc) (HAVARD et al., 2009; DEGUEN e ZMIROU-NAVIER, 2010). Entre as explicações desse fenômeno se destacam a dinâmica do mercado imobiliário e o baixo poder de decisão política e econômica das comunidades com menor nível sócio-econômico, 
que, de um lado, fariam com que as vias de alto tráfego e indústrias poluidoras se instalassem preferencialmente próximas a essas comunidades e, por outro, com que a população mais pobre ocupe áreas próximas a essas vias e indústrias (O’NEILL et al., 2003).

Essa população também tende a apresentar suscetibilidade aumentada aos efeitos deletérios da poluição do ar, o que evidencia o efeito modificador do nível sócio-econômico sobre os efeitos adversos à saúde relacionados à poluição. Nesse sentido, o nível sócio-econômico funciona como indicador de fatores proximais que determinam o estado de saúde e a vulnerabilidade potencial à poluição do ar (SAMET e WHITE, 2004).

Entre os fatores suspeitos de aumentarem a suscetibilidade à essa exposição, fatores esses mais prevalentes nas populações com menor nível sócio-econômico, enumeram-se: a co-exposição a outras fontes de poluição, especialmente as intra-domiciliares e ocupacionais, maior nível de estresse psicossocial, menor ingestão de frutas e vegetais, acesso reduzido a serviços de saúde, características desfavoráveis da vizinhança do local de residência, baixa qualidade da moradia, condições médicas (como diabetes, asma, doença pulmonar obstrutiva crônica, doenças cardíacas crônicas), características genéticas (como traço falcêmico) e comportamentais (como tabagismo) (O’NEILL et al., 2003).

Por meio desses dois mecanismos - a maior exposição e suscetibilidade - estudos em várias cidades têm mostrado que a poluição do ar parece afetar com maior intensidade a saúde de grupos com baixo status sócio-econômico em relação àqueles com melhores condições sócioeconômicas. No entanto, apesar dos efeitos da poluição do ar à saúde serem mais intensos em determinados grupos da população, eles se distribuem por toda a sociedade, em gradiente e, usualmente, de forma crescente dos estratos mais pobres aos mais afluentes.

Ademais, se as desigualdades sócio-econômicas atuam modificando os efeitos à saúde causados por essa exposição, também se observa que uma fração das desigualdades em saúde devidas às diferenças sócioeconômicas é atribuída aos efeitos da poluição do ar. Desse modo, enquanto 
as variáveis sócio-econômicas podem confundir a relação entre poluição do ar e os desfechos de saúde, a poluição do ar pode atuar como fator de confusão nas medidas de nível sócio-econômico e os desfechos de interesse, o que tem sido ignorado em muitos estudos focados nos determinantes sociais da saúde (O’NEILL et al., 2003; JERRET et al., 2005b).

Portanto, o estudo das desigualdades em saúde vem se constituindo em importante área de pesquisa do campo das ciências da saúde ambiental (SEXTON e ADGATE, 1999; HAVARD et al., 2009) e além de permitir reconhecer possíveis mecanismos causais das doenças, informar 0 planejamento de cuidados de saúde e a prevenção em saúde pública, pode propiciar a identificação de oportunidades de intervenção para reduzir essas desigualdades (FAGGIANO et al, 1997; KOGEVINAS et al., 1997).

No Brasil, e em São Paulo, contextos de elevadas desigualdades sócio-econômicas, a relevância de estudos focados nessa temática é marcante e ainda são raros. A maior parte deles são estudos ecológicos e que utilizam dados de mortalidade, em que o menor nível de desagregação é o de distrito em grandes cidades.

Desta forma, este trabalho se propõe à abordagem de dois temas atuais relevantes: investigar a correlação entre a poluição relacionada ao tráfego e efeito de longo prazo sobre o câncer e a distribuição das internações hospitalares por câncer e status socioeconômico no município de São Paulo, por meio de estudo ecológico, utilizando pequenas áreas intra-urbanas como unidades de análise. 


\section{OBJETIVOS}

\subsection{OBJETIVO GERAL}

Investigar as relações entre internações hospitalares por câncer total e seus tipos e poluição relacionada ao tráfego e status sócio-econômico na escala ecológica de áreas de pequeno tamanho, no município de São Paulo.

\subsection{OBJETIVOS ESPECÍFICOS}

a) Estudo de revisão da literatura sobre: (1) poluição do ar e câncer; e (2) desigualdades sócio-econômicas e câncer.

b) Investigar associações entre internações hospitalares por câncer total e alguns de seus tipos e a densidade de tráfego, em escala intraurbana, formada por unidades de área de pequena extensão.

d) Investigar associações entre internações hospitalares por câncer total e alguns de seus tipos e indicadores sócio-econômicos, em escala intra-urbana, tomando o setor censitário como unidade de análise.

c) Investigar associações entre indicadores sócio-econômicos e densidade de tráfego, em escala intra-urbana, formada por unidades de área de pequena extensão. 


\section{MÉTODO}

\subsection{ESTUDO DE REVISÃO}

Na consulta às bases bibliográficas, as palavras-chave utilizadas para levantamento das referências sobre desigualdades sócio-econômicas e câncer foram (CANCER or NEOPLASMS) and (SOCIOECONOMIC FACTORS or SOCIOECONOMIC FACTOR or SOCIOECONOMIC STATUS); (CANCER or NEOPLASMS) and INDUSTRIALIZATION. As bases bibliográficas pesquisadas foram LILACS, OPAS/OMS, WHOLIS, MEDLINE e Pubmed, no período de 1998 a 2008. Procuramos incluir na revisão todos os estudos ecológicos nacionais que tratavam de câncer, por serem poucos os que tratavam das desigualdades sócio-econômicas em câncer. Quanto à literatura internacional, focalizou-se nesta temática específica. Foram excluídos estudos de caso-controle, de coorte, de intervenção, estudos que tratavam da relação da poluição industrial na vizinhança com câncer, assim como estudos em outros idiomas que não o português, inglês e espanhol. Artigos encontrados nas referências relevantes à dissertação foram incluídos na revisão, assim como dissertações e teses, quando disponíveis e pertinentes. Excepcionalmente, incluíram-se estudos de 2009.

No estudo de revisão sobre poluição do ar e poluição do tráfego e sua relação com câncer, as palavras-chave utilizadas foram CANCER and TRAFFIC; CANCER and AIR POLLUTION; CHILDHOOD CANCER and TRAFFIC; CHILDHOOD CANCER and AIR POLLUTION. As bases bibliográficas pesquisadas foram LILACS, OPAS/OMS, WHOLIS, MEDLINE e Pubmed, no período de 1998 a 2008. Procuramos incluir na revisão todos os estudos relevantes sobre a temática encontrados na pesquisa, assim como aqueles considerados importantes retirados das referências dos artigos pesquisados. Incluíram-se teses e dissertações, quando disponíveis 
e pertinentes. Foram excluídos artigos em outras línguas que não o inglês, espanhol e português e os que tratavam da relação do câncer especificamente com fontes industriais. Os estudos sobre câncer em adultos e em crianças e adolescentes foram descritos separadamente. Excepcionalmente, incluímos uma dissertação de mestrado de 2010 por conter um dos poucos estudos exploratórios nacionais sobre a temática.

$\mathrm{Na}$ análise dos estudos, foi considerada associação consistente quando a maioria dos estudos sobre o desfecho apontava na mesma direção, positiva quando o risco do desfecho fosse maior nos estratos mais ricos e negativa quando maior nos mais pobres.

\subsection{ESTUDO ECOLÓGICO}

Para análise em escala intra-urbana foram utilizadas duas unidades de área:

(1) Dividiu-se o município em uma grade com células de 500 × 500 metros, totalizando-se 6385 unidades de área, de acordo com método proposto em projeto FAPESP PPP/SUS 61616-5 (Cardoso, 2010).

(2) Malha de setor censitário do IBGE - Censo 2000 que dividiu o município em 13278 unidades de área.

\subsubsection{Caracterização da Área de Estudo}

O município de São Paulo é o mais populoso do Brasil, com população estimada em cerca de 11 milhões de habitantes em 2009 compreendida em uma área de 1523 km² (IBGE, 2009). Maior cidade do país e capital do estado de São Paulo constitui-se no centro da maior região metropolitana do país e de uma das maiores do mundo. 
Economicamente, é o município brasileiro que apresenta o maior Produto Interno Bruto (PIB) municipal, contribuindo com $12 \%$ do total de riquezas produzidas no país em 2007, sendo o principal pólo industrial nacional (IBGE, 2007).

Em relação à sua dinâmica populacional, tem-se verificado declínio progressivo da sua taxa anual de crescimento populacional, que passou de $1,1 \%$, em 1980, para a projeção atual de 0,5\%, graças, em grande parte, à reversão do fluxo migratório, com saldos negativos desde as duas últimas décadas do século $X X$. Nesse período, também se observou diminuição progressiva da taxa de fecundidade, que, em 1980, era de 3,2 filhos por mulher e que, em 2007, não passou de 2, e da razão de dependência, com aumento da proporção de idosos. Ao lado do envelhecimento da população, notou-se diminuição expressiva dos índices de mortalidade infantil (SEADE, 2007).

O município apresentou Índice de Desenvolvimento Humano Municipal (IDH-M) de 0,841 em 2000, encontrando-se entre os 20 maiores entre os municípios do estado de São Paulo e entre os 70 maiores do Brasil (PNUD, 2003), porém apenas 6 distritos, todos localizados na região sudoeste do município, apresentaram IDH-M acima de 0,8, considerado alto pelo Programa das Nações Unidas para o Desenvolvimento (PNUD), enquanto que, em 38 distritos, o valor do índice foi abaixo de 0,5, baixo para os padrões adotados (SECRETARIA MUNICIPAL DE PLANEJAMENTO, 2006). Tais indicadores captam os elevados níveis de heterogeneidade sócio-econômica de sua população e de desigualdades sócio-territoriais, expressas pelos imensos contrastes de situações de riqueza e pobreza e pela fragmentação dos espaços urbanos.

Quanto ao perfil epidemiológico, o câncer constitui-se na segunda causa de óbito no município, com mortalidade proporcional crescente nas últimas décadas. Em 2001, 17,4\% dos óbitos foram a ele atribuídos. Já em 2008, tal proporção se elevara a 19,8\%. Nesse ano, contabilizaram-se 12440 mortes por neoplasias malignas. No sexo masculino, os cânceres com maiores taxas de mortalidade (ajustadas por idade pela população mundial, 
por 100.000 homens) foram, em ordem decrescente, o de pulmão, traquéia e brônquios $(21,3)$, o de próstata $(14,4)$, o de estômago (13), de cólon e reto $(12,8)$ e as leucemias $(11,4)$. Já no sexo feminino, as taxas de mortalidade (ajustadas por idade, pela população mundial, por 100.000 mulheres) por câncer de mama $(16,7)$, de cólon e reto $(9,6)$, de pulmão, traquéia e brônquios $(8,7)$, de leucemias $(7,5)$ e de estômago $(5,4)$ foram as mais elevadas. Em 2008, estima-se que tenham ocorrido 44060 novos casos de câncer. Nos homens, as neoplasias malignas mais incidentes foram, em ordem decrescente, as de pele não-melanoma (4650 novos casos), de próstata (4170), de cólon e reto (1730), de pulmão, traquéia e brônquios (1600) e de estômago (1240). Nas mulheres, as neoplasias malignas de mama (5.940), de pele não-melanoma (4.020), de cólon e reto (2.020), de colo de útero (1.260) e de pulmão, traquéia e brônquios (880) foram as mais incidentes. De modo geral, o câncer no município de São Paulo segue padrões epidemiológicos e evolução semelhantes aos do Brasil e do mundo, embora sua magnitude seja mais elevada em relação ao país e ao mundo como um todo (SECRETARIA MUNICIPAL DE SAÚDE, 2009).

Além dos graves problemas relacionados às desigualdades sociais, a cidade de São Paulo enfrenta também sérias questões relacionadas à poluição ambiental, especialmente a do ar. Os principais causadores da importante poluição aérea no município são os veículos automotivos, que foram responsáveis, em 2008, na Região Metropolitana de São Paulo (RMSP), por 98\% das emissões de CO, 97\% de hidrocarbonetos, 96\% de $\mathrm{NO}_{x}, 40 \%$ de Material Particulado (MP) e 33\% de óxidos de enxofre $\left(\mathrm{SO}_{\mathrm{x}}\right)$ (CETESB, 2009). Possuidora da maior frota municipal veicular do Brasil, em crescimento contínuo, com cerca de 6,7 milhões de veículos registrados em novembro de 2009 , $74 \%$ dos quais automóveis, a cidade enfrenta, há décadas, frequentes congestionamentos de tráfego e lentidão crescente do trânsito, que contribuem adicionalmente para o aumento da poluição do ar (DETRAN-SP, 2009). A malha viária do município é estimada em cerca de 18000 quilômetros de vias, por onde trafegam também cerca de 15000 ônibus movidos a diesel utilizados no transporte público de passageiros. 
Desde a década de 70, a Companhia de Tecnologia de Saneamento Ambiental (CETESB) mantém redes de monitoramento da qualidade do ar para avaliar os níveis de poluição atmosférica no estado de São Paulo. Inicialmente, o monitoramento era efetuado exclusivamente por estações manuais. Em 1981, foi iniciado o monitoramento automático que, além de ampliar o número de poluentes medidos, permitiu o acompanhamento dos resultados em tempo real. Em 2008, a RMSP contou com medições em 22 estações fixas e uma móvel para monitoramento automático e 14 estações de monitoramento manual. Já o município de São Paulo, no mesmo ano, contou com 13 estações fixas e uma móvel para monitoramento automático e 9 estações de monitoramento manual, a maioria concentrada na região central da cidade. A atual rede mede as concentrações de $\mathrm{MP}_{2,5}, \mathrm{MP}_{10}, \mathrm{SO}_{2}$, $\mathrm{CO}, \mathrm{O}_{3}$, óxidos de nitrogênio $\left(\mathrm{NO}, \mathrm{NO}_{2}, \mathrm{NO}_{\mathrm{x}}\right)$, enxofre reduzido total, fumaça e partículas totais em suspensão (PTS), além de variáveis meteorológicas (CETESB, 2009).

Embora a qualidade do ar no município de São Paulo, segundo os dados de monitoramento da CETESB, vem apresentando melhoras sistemáticas nos últimos anos, a cidade convive há décadas com altos valores de concentração de poluentes atmosféricos.

\subsubsection{População de Estudo}

Todos os indivíduos internados em hospitais públicos ou privados do município de São Paulo com diagnóstico principal de neoplasia primária invasiva de todo o tipo, no período de 2004 a 2006, residentes neste município, foram considerados casos (C00 a $\mathrm{C} 97$ da 10 $0^{\underline{a}}$ Revisão da Classificação Internacional de Doenças - CID-10) (OMS, 2003). Registros de internação múltiplos para um mesmo caso, devido a erros nos procedimentos de registro ou a múltiplas hospitalizações, foram contabilizados apenas uma vez, correspondendo à primeira internação no 
período do estudo, para que se assegurasse que a cada caso correspondesse apenas um diagnóstico de câncer, considerando-se como remota a hipótese de mais de um tipo de câncer detectado ou sob tratamento no mesmo paciente no relativamente curto período do estudo. Tal procedimento visou a transformar as internações em uma aproximação de casos incidentes. Na análise, foram incluídos somente os casos com endereços residenciais georreferenciados e não moradores de áreas correspondentes a setores censitários formados por quartéis, bases militares, penitenciárias, presídios ou cadeias, por conterem populações com características muito singulares.

\subsubsection{Bases de Dados}

3.2.3.1 Dados de Internações Hospitalares por Câncer Georreferenciados

Os dados das internações hospitalares do Município de São Paulo, georreferenciados pelo endereço do paciente, foram obtidos do "Estudo da relação entre doenças respiratórias e cardiovasculares e poluição veicular nas regiões metropolitanas do Estado de São Paulo, com a finalidade de subsidiar a estruturação das atividades do programa de vigilância em saúde e qualidade do ar", desenvolvido pela Faculdade de Saúde Pública da Universidade de São Paulo (FSP-USP), em parceria com a Secretaria de Estado da Saúde e os municípios dessas regiões (Projeto FAPESP/PPPSUS 2006/61616-5) (CARDOSO, 2010).

As bases de dados de internações hospitalares, tanto de hospitais públicos ou privados conveniados ao Sistema Único de Saúde (Autorização de Internação Hospitalar - AlH) quanto de hospitais privados não 
conveniados (Comunicação de Internação Hospitalar - $\mathrm{ClH}$ ), foram obtidas da Secretaria de Estado da Saúde. Devido à necessidade do endereço do paciente para o georreferenciamento das internações, foi assinado um termo de compromisso de sigilo das informações de acordo com os requisitos éticos da Comissão Nacional de Ética em Pesquisa (CONEP). Os dados georreferenciados compreendem o período de 2004 a 2006.

$\mathrm{O}$ método de georreferenciamento das $\mathrm{AlHs}$ e $\mathrm{ClHs}$ utilizado no projeto FAPESP-PPP/SUS 61616-5 consistiu das seguintes etapas:

a) Adequação e melhoria na consistência das bases de dados tabulares: as bases de dados de $\mathrm{AlH}$ e $\mathrm{ClH}$ foram padronizadas (no formato e na distribuição das variáveis) para qualificar seu ingresso no banco de dados geográficos (BDG). As internações que possuíam endereços idênticos aos registrados no Cadastro Nacional de Estabelecimentos de Saúde (CNES) foram excluídas através de linkage entre essa base de dados e as de $\mathrm{AlH}$ e $\mathrm{ClH}$. Este procedimento é necessário pela constatação, na literatura especializada e em trabalhos de campo, de que, no momento do cadastramento das internações no sistema, em alguns casos, o serviço administrativo do hospital registra o endereço do próprio estabelecimento quando desconhece o endereço do paciente, viabilizando, dessa forma, a continuação do cadastramento da internação no banco de dados;

b) Tratamento dos dados: utilizou-se, no seu tratamento, algoritmo específico de verificação da qualidade do endereço e do Código de Endereçamento Postal (CEP) preenchidos nas AlHs e ClHs, através de linkage com a base digital de logradouros. Este procedimento visou minimizar perdas na geocodificação de endereços inconsistentes (especialmente por erros de digitação);

c) Geoprocessamento: a geocodificação das bases tabulares foi realizada somente através do endereço completo do paciente, pois a localização por CEP poderia interferir nos resultados devido à sua falta de precisão.

Além do endereço utilizado no georreferenciamento, foram extraídas das $\mathrm{AlH}$ e $\mathrm{ClH}$ as informações relativas ao gênero, data de nascimento e de 
internação e diagnóstico principal de internação dos participantes que atenderam aos critérios de inclusão relatados na seção "População de Estudo".

O georreferenciamento das internações hospitalares foi feito com 0 uso do programa ArcGIS 9.3. (2008, ESRI; Redlands, Califórnia, EUA).

\subsubsection{Dados Demográficos e IDH por Setor Censitário}

O setor censitário é a menor unidade territorial construída para dar organização e sustentação espacial às atividades de planejamento operacional, coleta, apuração de dados e divulgação de resultados do Censo Demográfico 2000. Tal unidade é definida de acordo com o número de domicílios, que variam de 250 a 350 na área urbana e de 150 a 250 na área rural. Para esse Censo, o Instituto Brasileiro de Geografia e Estatística (IBGE) dividiu o município de São Paulo em 13278 setores censitários contíguos, respeitando-se os limites da divisão político-administrativa, do quadro urbano e rural legal e de outras estruturas territoriais de interesse (IBGE, 2003; PEDROSO, 2003). Para cada um dos setores, são disponibilizados dados sobre população total, características dos domicílios (abastecimento de água, esgotamento sanitário, destinação de lixo etc), sexo, idade e alfabetização dos moradores, anos de estudo e rendimento dos responsáveis por domicílios particulares permanentes, entre inúmeras outras variáveis (IBGE, 2003).

Do conjunto de arquivos "Agregados por Setor Censitário dos Resultados do Universo", disponibilizados na página do IBGE na internet rede mundial de computadores) foi extraída a pasta referente à Região Metropolitana de São Paulo (RMSP), composta de 21 planilhas em formato MS-Excel, contendo dados de mais de 3200 variáveis para todos os setores censitários de todos os municípios dessa região metropolitana. Limitamo-nos aos dados referentes aos setores do município de São Paulo e do total de 
variáveis disponíveis escolhemos algumas dezenas para a determinação da contagem da população, da estrutura etária e de gênero para cada uma dessas pequenas unidades geográficas. Tais dados foram utilizados diretamente, quando a unidade de investigação era o setor censitário, e indiretamente, quando era a célula da grid, a fim de se calcularem as taxas de internações.

O Índice de Desenvolvimento Humano (IDH) foi criado no início da década de 1990 pelo Programa das Nações Unidas para o Desenvolvimento (PNUD), com o objetivo de mensurar e comparar o desenvolvimento humano das nações combinando três componentes básicos, a saber, a longevidade, a renda e a educação. Cada um desses componentes são transformados em índices, que são fundidos para formar um indicador síntese, que varia entre 0 e 1 . Quanto mais próximo de 1 o valor calculado para o indicador, melhor será o nível de desenvolvimento humano do país ou região. Como o IDH foi concebido para ser aplicado a países e grandes regiões, criou-se o Índice de Desenvolvimento Humano Municipal (IDH-M) para utilização em níveis municipal e intra-municipal, tendo sido necessárias algumas adaptações metodológicas e conceituais, como substituição das variáveis usadas para cálculo dos índices constituintes do indicador.

No presente estudo, utilizamos o IDH-M do setor censitário calculado segundo a metodologia exposta no projeto de pesquisa FAPESP/PPP-SUS 2006/61616-5 (CARDOSO, 2010).

\subsubsection{Cálculo das densidades de tráfego}

Os dados de densidade de tráfego por unidade de grid de $500 \times 500 \mathrm{~m}$ foram obtidas do projeto FAPESP/PPP-SUS 2006/61616-5 (CARDOSO, 2010).

O cálculo da densidade de tráfego por unidade de área foi feito pela soma do produto do volume horário de veículos multiplicado pelo 
comprimento de todos os respectivos seguimentos de via dentro da célula, dividida pela área da grid (Cardoso, 2010). Foi calculada a densidade de tráfego total utilizando-se o volume total de veículos, a densidade de veículos a gasolina considerando-se a soma do volume de veículos mais motos e a densidade de tráfego de veículos a diesel a soma do volume de caminhões e ônibus.

Nesse projeto, parte dos dados de contagem veicular no município de São Paulo foi obtida da Companhia de Engenharia de Tráfego (CET), que realiza medições contínuas em 30 pontos, além de medições avulsas, nas vias de maior volume de tráfego localizadas no centro expandido, categorizadas por tipo de veículo. Outra parte foi obtida por meio da contagem de veículos nas vias por agentes de saúde pertencentes aos quadros das Supervisões de Vigilância em Saúde (SUVIS) das regiões norte, sul, leste e sudeste da Secretaria Municipal de Saúde e, na região centro-oeste, a contagem de veículos envolveu técnicos do nível central da Coordenação de Vigilância em Saúde (COVISA) e da FSP-USP, tendo sido realizada entre os dias $1^{\circ}$ e 5 de dezembro de 2008.

As contagens, em 105 pontos das diversas regiões da cidade, foram realizadas nos horários de pico de tráfego de veículos, pela manhã e à tarde, no período de 15 minutos cronometrados em cada ponto, sendo contados separadamente carros, ônibus, caminhões e motos e multiplicados os valores obtidos por 4 para cálculo dos volumes horários.

Todos os dados horários medidos foram georreferenciados na malha de logradouros fornecida pela CET, que contém as informações de classificação das vias. Para os segmentos de ruas que não dispunham de dados de contagem de volume veicular foram atribuídos valores médios do volume por categoria de veículos, segundo a classificação de tipo de via da CET: Trânsito Rápido, Arterial 1, Arterial 2, Arterial 3, Coletora 1, Coletora 2 e Local. (Cardoso, 2010) 


\subsection{VARIÁVEIS DE ESTUDO}

Segundo Cardoso (2010), a população por célula da grid foi calculada a partir da soma dos produtos das densidades demográficas dos setores censitários constituintes pelas suas respectivas áreas no interior da unidade de estudo. As populações desagregadas por gênero e faixa etária foram calculadas da mesma forma. O IDH-M para cada unidade da grid considerou a média ponderada desses índices dos setores censitários constituintes pelas suas respectivas áreas no interior dessa unidade.

Por meio da sobreposição das internações hospitalares georreferenciadas por endereço com a grid ou malha de setor censitário foi calculado o número de casos em cada unidade de área e, em seguida, calculadas as taxas, correspondendo à proporção de número de casos entre 2004 e 2006 sobre a população da mesma área no ano 2000, para câncer total e certos tipos e grupos de neoplasias, delimitados ou não por faixas etárias, escolhidos a partir dos resultados do estudo de revisão da literatura sobre poluição do ar e câncer. Desse modo, foram calculadas taxas de internação para câncer total (C00 a C97, conforme CID-10) e para as neoplasias malignas respiratórias em maiores de 20 anos (C32 a C34) e hematológicas em menores de 20 anos (C81 a C96).

As taxas de internação por setor censitário foram calculadas para neoplasias malignas do lábio, cavidade oral e faringe ( $\mathrm{C} 00$ a $\mathrm{C} 14$, conforme CID-10), dos órgãos digestivos (C15 a C26), do cólon e reto (C18 a C20), da mama (C50) e da próstata (C61).

\subsection{ANÁLISE DOS DADOS}

As células da grid foram classificadas em categorias das medidas de densidade de tráfego, formadas a partir de percentis da distribuição de todas as células do município de São Paulo. Cada medida de densidade de tráfego 
foi assim agrupada em 5 categorias: baixa exposição ( $\leq$ percentil 25), exposição média (do percentil 26 ao 50), exposição média alta (do percentil 51 ao 75 ) e exposição alta (> percentil 76). As taxas de internação, como variáveis dicotômicas, foram classificadas em duas categorias: menores ou iguais ao percentil 90 e maiores que esse percentil. Para a análise estatística, foram excluídas células da grid com população total ou das faixas etárias delimitadas iguais a zero. Foram calculadas Odds Ratio (e respectivos intervalos de confiança de 95\%) das taxas de internação hospitalar para cada grupo ou tipo de câncer analisado e as medidas de densidade de tráfego, utilizando-se modelo de regressão logística, em que o IDH-M foi introduzido como co-variável a ser ajustada. Os desfechos investigados foram: câncer total, neoplasias respiratórias em maiores de 20 anos e hematológicas em menores de 20 anos.

As células da grid também foram classificadas em categorias de IDH$\mathrm{M}$, formadas a partir de percentis da distribuição de todas as células do município. Foram agrupadas em 5 categorias: IDH-M baixo ( $\leq$ percentil 25$)$, médio (do percentil 26 ao 50), médio alto (do percentil 51 ao 75), alto (do percentil 76 ao 90) e muito alto (> percentil 90). As densidades veiculares, como variáveis dicotômicas, foram classificadas em duas categorias: menores ou iguais ao percentil 90 e maiores que esse percentil. A seguir, foram excluídas as células com população igual a zero. Através de modelo de regressão logística, foram calculadas Odds Ratio (e respectivos intervalos de confiança de $95 \%$ ) das medidas de densidade veicular e IDH-M. Os desfechos investigados foram densidade veicular total, a gasolina e a diesel.

Por fim, os setores censitários foram também agrupados em 5 categorias de IDH-M, do mesmo modo que o foram as células da grid. As taxas de internação, como variáveis dicotômicas, foram classificadas em duas categorias: menores ou iguais ao percentil 90 e maiores que esse percentil Após exclusão de setores censitários sem população, foram calculadas Odds Ratio (e respectivos intervalos de confiança de 95\%) das taxas de internação hospitalar para cada grupo ou tipo de câncer investigado e IDH-M, através de modelo de regressão logística. Os desfechos 
investigados foram: taxas de internação hospitalar por câncer digestivo, colorretal, de lábios, cavidade oral e faringe, de mama e de próstata.

O centro expandido do município de São Paulo foi também separadamente analisado quanto à associação entre o IDH-M e as medidas de densidade veicular, assim como entre essas medidas de tráfego e as internações hospitalares, com as mesmas estratégias estatísticas supracitadas. As unidades geográficas determinadas pela grid, no entanto, foram agrupadas em 4 categorias de IDH-M, devido ao menor número dessas unidades.

As análises foram feitas utilizando-se do programa estatístico STATA 10.0. for Windows (2007, Stata Corporation; College Station, Texas, EUA). 


\section{RESULTADOS}

\subsection{ESTUDOS DE REVISÃO}

\subsubsection{Desigualdades Sócio-econômicas e Câncer}

As desigualdades em saúde refletem as desigualdades sociais. Embora mais aparentes nos estratos sócio-econômicos desfavorecidos, as desigualdades em saúde operam através de toda a sociedade. Em relação ao câncer, as diferenças sócio-econômicas se manifestam em diversos aspectos do seu perfil epidemiológico (KOGEVINAS et al., 1997).

As evidências acumuladas vêm demonstrando que os grupos de níveis sócio-econômicos mais baixos têm apresentado maior incidência de câncer em geral; maior proporção de diagnóstico tardio de neoplasias passíveis de detecção em estágios iniciais por meio de rastreamento; maior dificuldade de acesso ao diagnóstico e tratamento adequado; menor uso do sistema de saúde para fins preventivos; pior prognóstico e menor sobrevida após o diagnóstico de câncer; maior proporção de incapacidade adquirida em decorrência da doença e de cuidados paliativos insuficientes; maior risco de óbito por câncer em geral e por tipos de câncer potencialmente curáveis (WÜNSCH FILHO et al., 2008).

Em relação à incidência de câncer, sua variação reflete diferenças de risco, embora parte de tal variação possa ser artefactual, atribuível a diferenças na definição de caso, à subnotificação e ao acesso diferencial aos serviços de saúde de diagnóstico e tratamento (WÜNSCH FILHO et al., 2008). Programas de prevenção primária e secundária também podem resultar em alterações nas taxas de incidência (PARKIN et al, 2005). De modo geral, a maior incidência de câncer entre os grupos sociais mais 
desfavorecidos decorre da sua maior exposição a diversos fatores de risco importantes na sua gênese que os grupos mais favorecidos. Por exemplo, o consumo de tabaco, o principal fator isolado para câncer, o consumo excessivo de bebidas alcoólicas, a dieta pobre em frutas e vegetais, as exposições ocupacionais e ambientais a carcinógenos, as infecções crônicas (por exemplo, aos vírus das Hepatites B e C e ao Helicobacter pylorı) são mais prevalentes nos grupos com baixo nível sócio-econômico, de forma consistente em todo mundo. Por sua vez, os fatores reprodutivos determinantes de cânceres reprodutivos femininos são mais comuns nas mulheres com alto nível sócio-econômico (KOGEVINAS et al., 1997). Já o excesso de peso é mais comum nos grupos com desvantagens sociais nas sociedades mais ricas e o inverso é observado nos países em desenvolvimento (WÜNSCH FILHO et al., 2008).

Já a variação na mortalidade sofre a influência de diferenças na incidência e na sobrevivência por câncer. Esta é determinada pelo acesso heterogêneo ao diagnóstico precoce e ao tratamento efetivo, pelas comorbidades do paciente e pelos riscos das causas competitivas de morte (ANTUNES et al., 2008). Programas de prevenção primária e secundária podem influir em suas taxas (PARKIN et al, 2005). Desse modo, a maior mortalidade por câncer nos estratos sociais mais baixos é determinada pela maior incidência de câncer nesses grupos, mas também pela sua menor sobrevida após o diagnóstico. Entre as causas dessa menor sobrevida, destaca-se o acesso restrito aos serviços de saúde, que implica em demora do diagnóstico, detecção tardia de tumores, traduzindo-se em pior prognóstico e maior mortalidade. Nesse sentido, a menor participação das mulheres de baixo nível sócio-econômico em programas de rastreamento para câncer de colo uterino e de mama é determinante na sua menor sobrevida, ao serem detectados em estágios mais avançados (WÜNSCH FILHO et al., 2008).

Em relação à incidência e mortalidade por tipos específicos de câncer, FAGGIANO et al. (1997), em revisão sistemática de estudos de casocontrole e coorte, entre 1966 a 1994, observaram maior risco, para homens 
de estratos sociais mais baixos, de todos os tipos de cânceres respiratórios (cavidades nasais, laringe, pulmão), de cânceres de cavidade oral e faringe, esôfago. estômago e, possivelmente, fígado. Para as mulheres de menor nível sócio-econômico, maior risco foi encontrado para os cânceres de esôfago, estômago, colo do útero e, com menos consistência, para o de fígado. Já os homens de estratos sociais mais altos apresentaram excesso de risco para os cânceres de cólon e melanoma maligno e as mulheres desses estratos maior risco para cânceres de cólon, melanoma maligno, mama e ovário.

Por sua vez, as diferenças sócio-econômicas na sobrevivência por câncer após o diagnóstico se manifestam de forma consistente para todos os tipos de câncer em favor das classes mais ricas, conforme revisão sistemática de KOGEVINAS e PORTA (1997). Cânceres de bom prognóstico, como os de mama, colorretal, corpo uterino e bexiga, foram os que apresentaram as maiores diferenças de sobrevivência.

Baseando-se em dados da Inglaterra e País de Gales de 1911 a 1981, FAGGIANO et al. (1997) verificaram tendência de ampliação das desigualdades, ao longo do tempo, entre as classes sociais, em prejuízo das menos favorecidas, para a mortalidade por câncer em geral, cânceres de pulmão, laringe e estômago, nos homens, e por câncer em geral e de colo de útero, nas mulheres Estudos mais recentes nas mesmas nações sugerem que as desigualdades sócio-econômicas em câncer continuam a se ampliar, especialmente a mortalidade por câncer em geral, nos homens, (MACKENBACH et al., 2003), e a incidência de câncer de pulmão, em ambos os sexos, em prejuízo das classes mais pobres (ROWAN, 2007). No caso do câncer de próstata, tem se verificado ampliação da desigualdade na sua incidência, em prejuízo das classes mais abastadas (ROWAN, 2007). Entretanto, alguns países, como o Canadá, experimentaram uma diminuição dessas desigualdades em relação ao câncer de colo de útero entre as décadas de 70 e de 90 (NG et al., 2004).

Em relação ao Brasil, encontramos, em nossa pesquisa bibliográfica, catorze estudos utilizando o desenho ecológico para avaliar o câncer. Todos 
os estudos encontrados tratavam da mortalidade por câncer geral ou específico. Os dados sobre as mortes foram obtidos de instituições oficiais que rotineiramente os disponibilizam. Não se encontraram estudos ecológicos que utilizassem medidas de morbidade. A maioria deles foi realizada no Estado de São Paulo (dez estudos), sendo seis no município de São Paulo e quatro na Baixada Santista. Metade utilizou unidades de agregação de município ou maiores e a outra metade unidades menores que o município. Destes, seis foram realizados na cidade de São Paulo e um em Belo Horizonte. Oito estudos utilizaram taxas ou razão de taxas de mortalidade padronizadas por idade como método estatístico preferencial. Dos demais, cinco usaram métodos variados de regressão e um empreendeu análise espacial. A maioria dos estudos (doze) procedeu a ajuste para idade. Em relação às medidas sócio-econômicas utilizadas, oito compararam áreas definidas com base em critérios administrativos, geográficos ou histórico-sociais pré-determinados. O restante se utilizou de variáveis ou índices sócio-econômicos para a determinação das áreas de comparação.

Dos estudos acima descritos que tratam da relação entre câncer e variáveis sócio-econômicas, observamos que a direção da associação com o nível sócio-econômico pode variar de acordo com a unidade de agregação utilizada. No caso de câncer oral, quando se utiliza o município e a região geográfica como unidade de estudo, o nível sócio-econômico se correlacionou positivamente com esses cânceres (WÜNSCH FILHO e MONCAU, 2002; BORGES et al., 2009). Já em nível distrital, no caso do município de São Paulo, a correlação para o mesmo câncer foi negativa (ANTUNES et al., 2001, 2008a). Porém, os cânceres de mama e colo de útero apresentaram a mesma direção de associação em relação às variáveis sócio-econômicas, nos níveis de agregação de região geográfica, territórios supradistritais e distrito municipal (REIS, 2001; PRADO, 2002; WÜNSCH FILHO e MONCAU, 2002), em que o risco do primeiro tipo de câncer foi mais comum nas áreas mais afluentes e o segundo nas áreas mais pobres. 
Após a descrição dos estudos internacionais sobre desigualdades sócio-econômicas em câncer, discutiremos os resultados dos estudos nacionais em conjunto com eles.

No quadro 1 abaixo, apresentamos as principais informações resumidas dos estudos ecológicos nacionais descritos. Informações adicionais sobre número de casos, fonte de dados, análise estatística, medidas de avaliação de nível sócio-econômico e ajustes para potenciais variáveis de confusão nos estudos revisados estão contidas no quadro e texto do ANEXO 1.

Quadro 1 - Relação de estudos ecológicos nacionais sobre câncer. 19982008.

\begin{tabular}{|c|c|c|c|c|}
\hline $\begin{array}{c}\text { Autores e } \\
\text { ano de } \\
\text { publicação }\end{array}$ & $\begin{array}{l}\text { Local e } \\
\text { período }\end{array}$ & $\begin{array}{l}\text { Desfecho(s) } \\
\text { estudado(s) }\end{array}$ & $\begin{array}{c}\text { Nível de } \\
\text { agregação }\end{array}$ & Resultados \\
\hline $\begin{array}{l}\text { Faria et al., } \\
1999\end{array}$ & $\begin{array}{l}\text { Baixada } \\
\text { Santista; } \\
1980-1993\end{array}$ & $\begin{array}{l}\text { Mortalidade } \\
\text { por Câncer } \\
\text { em geral }\end{array}$ & $\begin{array}{l}\text { Município } \\
\text { conjunto } \\
\text { municípios }\end{array}$ & $\begin{array}{l}\text { Risco maior nos } \\
\text { municípios e conjunto } \\
\text { de municípios com } \\
\text { maior desenvolvimento } \\
\text { econômico } \\
\text { industrialização }\end{array}$ \\
\hline $\begin{array}{l}\text { Drummond } \\
\text { Jr e Barros, } \\
1999\end{array}$ & $\begin{array}{l}\text { Município de } \\
\text { São Paulo, } \\
\text { 1990-1992 }\end{array}$ & \begin{tabular}{l}
\multicolumn{2}{l}{ Mortalidade } \\
por diversos \\
tipos de \\
Câncer
\end{tabular} & $\begin{array}{l}\text { Distrito } \\
\text { municipal }\end{array}$ & $\begin{array}{l}\text { Risco maior de câncer } \\
\text { de esôfago, estômago, } \\
\text { laringe e colo uterino } \\
\text { nos estratos mais } \\
\text { pobres, e de câncer de } \\
\text { mama, pulmão e cólon } \\
\text { nos mais ricos. }\end{array}$ \\
\hline $\begin{array}{l}\text { Faria et al., } \\
2000\end{array}$ & $\begin{array}{l}\text { Baixada } \\
\text { Santista; } \\
\text { 1980-1993 }\end{array}$ & $\begin{array}{l}\text { Mortalidade } \\
\text { por Câncer do } \\
\text { SNC }\end{array}$ & $\begin{array}{l}\text { Município } \\
\text { conjuntos } \\
\text { municípios }\end{array}$ & $\begin{array}{l}\text { Risco maior nos } \\
\text { municípios e conjunto } \\
\text { de municípios com } \\
\text { maior desenvolvimento } \\
\text { econômico } \\
\text { industrialização }\end{array}$ \\
\hline \begin{tabular}{ll|} 
Ishitani & e \\
França, & \\
2000 &
\end{tabular} & $\begin{array}{l}\text { Região } \\
\text { centro-sul do } \\
\text { município de } \\
\text { Belo } \\
\text { Horizonte; } \\
1996 \\
\end{array}$ & $\begin{array}{l}\text { Mortalidade } \\
\text { por Câncer } \\
\text { em Geral e } \\
\text { alguns tipos }\end{array}$ & $\begin{array}{l}\text { Conjunto } \\
\text { bairros } \\
\text { conjunto } \\
\text { favelas }\end{array}$ & $\begin{array}{l}\text { Risco maior de câncer } \\
\text { em geral, de pulmão e } \\
\text { estômago no conjunto } \\
\text { de favelas que no de } \\
\text { bairros }\end{array}$ \\
\hline $\begin{array}{l}\text { Antunes et } \\
\text { al., } 2001\end{array}$ & $\begin{array}{l}\text { Município de } \\
\text { São Paulo; } \\
\text { 1991-1998 }\end{array}$ & $\begin{array}{l}\text { Mortalidade } \\
\text { por Câncer de } \\
\text { Lábio e } \\
\text { Cavidade Oral }\end{array}$ & $\begin{array}{l}\text { Distrito } \\
\text { municipal }\end{array}$ & \begin{tabular}{|lrl} 
Associação & entre \\
indicadores & sócio- \\
econômicos & \\
desfavoráveis e & o \\
desfecho sob estudo.
\end{tabular} \\
\hline
\end{tabular}




\begin{tabular}{|c|c|c|c|c|}
\hline $\begin{array}{l}\text { Faria et al.. } \\
2001\end{array}$ & $\begin{array}{l}\text { Baixada } \\
\text { Santista; } \\
\text { 1980-1993 }\end{array}$ & $\begin{array}{l}\text { Mortalidade } \\
\text { por Câncer de } \\
\text { Estômago e } \\
\text { Colorretal }\end{array}$ & $\begin{array}{lr}\text { Município } & \mathrm{e} \\
\text { conjuntos } & \mathrm{de} \\
\text { municípios } & \end{array}$ & $\begin{array}{l}\text { Risco maior nos } \\
\text { municípios e conjunto } \\
\text { de municípios com } \\
\text { maior desenvolvimento } \\
\text { econômico } \\
\text { industrialização }\end{array}$ \\
\hline Reis, 2001 & $\begin{array}{l}\text { Município de } \\
\text { São Paulo, } \\
1997\end{array}$ & \begin{tabular}{l}
\multicolumn{2}{l}{ Mortalidade } \\
por diversos \\
tipos de \\
Câncer
\end{tabular} & $\begin{array}{l}\text { Distrito } \\
\text { Municipal }\end{array}$ & $\begin{array}{l}\text { Risco maior de câncer } \\
\text { de pulmão e cólon, em } \\
\text { homens, e de mama e } \\
\text { cólon, nas mulheres } \\
\text { residentes dos distritos } \\
\text { mais ricos }\end{array}$ \\
\hline $\begin{array}{l}\text { Prado, } \\
2002\end{array}$ & $\begin{array}{l}\text { Município de } \\
\text { São Paulo, } \\
1985-1999\end{array}$ & $\begin{array}{l}\text { Mortalidade } \\
\text { por Câncer de } \\
\text { Mama e por } \\
\text { Câncer de } \\
\text { Colo de Útero }\end{array}$ & $\begin{array}{l}\text { Territórios } \\
\text { supradistritais }\end{array}$ & $\begin{array}{l}\text { Risco maior de câncer } \\
\text { de mama nos } \\
\text { territórios mais ricos e } \\
\text { de câncer de colo } \\
\text { uterino nos territórios } \\
\text { mais pobres }\end{array}$ \\
\hline $\begin{array}{l}\text { Wünsch } \\
\text { Filho } \\
\text { Moncau, } \\
2002\end{array}$ & $\begin{array}{l}\text { Brasil; 1980- } \\
1995\end{array}$ & $\begin{array}{l}\text { Mortalidade } \\
\text { por Câncer } \\
\text { em Geral e os } \\
\text { principais } \\
\text { tipos }\end{array}$ & $\begin{array}{l}\text { Região } \\
\text { geográfica }\end{array}$ & $\begin{array}{l}\text { Risco maior de câncer } \\
\text { em geral e dos } \\
\text { principais tipos nas } \\
\text { regiões com melhores } \\
\text { indicadores sócio- } \\
\text { econômicos, com } \\
\text { exceção do de colo de } \\
\text { útero }\end{array}$ \\
\hline $\begin{array}{l}\text { Zago et al., } \\
2005\end{array}$ & $\begin{array}{l}\text { Baixada } \\
\text { Santista;1980- } \\
1999\end{array}$ & $\begin{array}{l}\text { Mortalidade } \\
\text { por Câncer de } \\
\text { mama }\end{array}$ & Município & $\begin{array}{l}\text { Risco aumentado em } \\
\text { Santos, o município } \\
\text { mais industrializado da } \\
\text { Baixada Santista, que } \\
\text { nos demais municípios } \\
\text { da região }\end{array}$ \\
\hline $\begin{array}{l}\text { Antunes et } \\
\text { al., 2008a }\end{array}$ & $\begin{array}{l}\text { Municípios de } \\
\text { São Paulo e } \\
\text { Barcelona; } \\
\text { 1995-2003 }\end{array}$ & $\begin{array}{l}\text { Mortalidade } \\
\text { por Câncer de } \\
\text { Lábio, } \\
\text { Cavidade Oral } \\
\text { e Faringe }\end{array}$ & $\begin{array}{l}\text { Distrito } \\
\text { municipal }\end{array}$ & $\begin{array}{l}\text { Risco maior nos } \\
\text { distritos mais pobres. } \\
\text { Associação negativa } \\
\text { entre indicadores } \\
\text { sócio-econômicos } \\
\text { favoráveis e o } \\
\text { desfecho sob estudo. }\end{array}$ \\
\hline $\begin{array}{l}\text { Antunes et } \\
\text { al., 2008b }\end{array}$ & $\begin{array}{l}\text { Municípios de } \\
\text { São Paulo e } \\
\text { Barcelona; } \\
\text { 1995-2003 }\end{array}$ & $\begin{array}{l}\text { Mortalidade } \\
\text { por Câncer de } \\
\text { Pulmão }\end{array}$ & $\begin{array}{l}\text { Distrito } \\
\text { municipal }\end{array}$ & $\begin{array}{l}\text { Risco maior nos } \\
\text { distritos mais ricos de } \\
\text { São Paulo, para } \\
\text { homens e mulheres. }\end{array}$ \\
\hline $\begin{array}{l}\text { Cavalini e } \\
\text { De Leon, } \\
2008\end{array}$ & Brasil; 2001 & $\begin{array}{l}\text { Mortalidade } \\
\text { por Câncer } \\
\text { em geral }\end{array}$ & Município & $\begin{array}{l}\text { Associação positiva } \\
\text { entre indicadores } \\
\text { sócio-econômicos } \\
\text { favoráveis } \\
\text { municípios dos } \\
\text { desfecho sob estudo }\end{array}$ \\
\hline $\begin{array}{l}\text { Borges et } \\
\text { al., } 2009\end{array}$ & $\begin{array}{l}\text { Capitais do } \\
\text { Brasil; 1998- } \\
2002\end{array}$ & $\begin{array}{l}\text { Mortalidade } \\
\text { por Câncer de } \\
\text { Cavidade Oral }\end{array}$ & $\begin{array}{l}\text { Região } \\
\text { geográfica }\end{array}$ & $\begin{array}{l}\text { Associação positiva } \\
\text { entre indicadores } \\
\text { sócio-econômicos } \\
\text { favoráveis } \\
\text { municípios dos } \\
\text { desfecho sob estudo }\end{array}$ \\
\hline
\end{tabular}


Em relação à literatura estrangeira, foram pesquisados estudos ecológicos que focalizavam a análise descritiva e/ou espacial da relação entre status sócio-econômico e a mortalidade ou a incidência por cânceres dos mais diversos tipos. Porém, quando existentes, foram incluídos estudos com o mesmo desenho sobre desigualdades sócio-econômicas em fatores prognósticos de câncer, como estadiamento ou grau histológico, por estarem intimamente relacionados com a sobrevivência e, por conseguinte, com a mortalidade.

A revisão resultou em vinte e seis estudos, dos quais quinze realizados na América do Norte (catorze nos Estados Unidos da América e um no Canadá), sete na Europa (cinco no Reino Unido e dois na Espanha) e o restante na Argentina, na Nova Zelândia e no Japão. A maioria (quinze) investigou exclusivamente a incidência pelos mais variados tipos de câncer, cinco se detiveram somente sobre fatores prognósticos e quatro só sobre a mortalidade. Os dois restantes investigaram mais de uma dessas medidas de desfecho. Quanto à dimensão das unidades geográficas de estudo, a maioria (dezoito) se utilizou de unidades com pequena dimensão e população inferior a 5.000 habitantes, como census tract, census block group e zip code (no caso do EUA), census tract (no Canadá), meshblock (na Nova Zelândia), radio censale (na Argentina), postcode (na Escócia), census ward, electoral ward e lower super output area (na Inglaterra). Desses, oito utilizaram áreas com população de até 1.000 habitantes.

Em relação às fontes dos dados dos casos de câncer, vinte e dois estudos buscaram-nos em registros de câncer de base populacional e os georreferenciaram. Dois (um no Canadá e outro na Argentina) georreferenciaram as mortes devidas ao câncer investigado a partir de atestados de óbito e os outros dois restantes se valeram de estatísticas de mortalidade fornecidas por instituições oficiais. Para a análise estatística, catorze fizeram uso de métodos de regressão (em sua maioria, de Poisson), oito de taxas ou razão de taxas de incidência ou mortalidade, três de análise espacial e um de mais de um desses métodos. Todos procederam a ajuste para idade e alguns adicionalmente para outras variáveis. Quanto à medida 
sócio-econômica, doze estudos fizeram uso de variáveis de renda, educação, ocupação ou de pobreza e onze de índices sócio-econômicos os mais variados (Carstairs, Townsend, Yost etc). Dois usaram categorias sociais oriundas de análise de cluster e um fatores obtidos por análise fatorial.

Nos homens, verificou-se associação positiva e consistente do nível sócio-econômico da área de residência com a mortalidade por câncer de cólon e a incidência por cânceres de próstata e melanoma maligno. A mortalidade por câncer de fígado e a incidência de linfoma de Hodgkin também se mostraram positivamente associados, mas cada desfecho foi investigado por somente um estudo.

Nas mulheres, observou-se associação positiva e consistente entre 0 nível sócio-econômico da área de residência e a mortalidade por cânceres de mama e cólon e a incidência por cânceres de mama e melanoma maligno. As taxas de incidência de cânceres de ovário, corpo uterino e linfoma de Hodgkin mostraram-se também associadas positivamente, porém cada um desses desfechos foi investigado por apenas um estudo.

No sexo masculino, associação negativa e consistente foi encontrada para a mortalidade por câncer total, esôfago, estômago, laringe e cavidade oral. A incidência de câncer total foi investigada uma única vez, com resultados semelhantes aos da mortalidade.

Nas mulheres, associação negativa e consistente com o status sócioeconômico da área de residência foi encontrada para a mortalidade por câncer em geral, de esôfago, estômago e colo uterino, e a incidência por câncer de colo uterino. A incidência de câncer total foi investigada apenas uma vez e se mostrou negativamente associada ao nível sócio-econômico.

Nos estudos que não apresentaram estratificação por gênero, observou-se associação negativa e consistente com o nível sócio-econômico para a incidência por câncer de estômago. Para a incidência de cânceres de vesícula biliar, cavidade oral e leucemia, associação positiva ocorreu no único estudo que os investigou. 
Ausência de associação foi encontrada para o câncer de pâncreas, encéfalo, rim e bexiga.

Achados inconsistentes, no sexo masculino, foram encontrados para o câncer de pulmão, cuja mortalidade se associou positivamente com o nível sócio-econômico em São Paulo e negativamente em Barcelona, e cuja incidência se associou negativamente na Inglaterra e País de Gales.

Também no sexo feminino, ocorreram achados inconsistentes para o câncer de pulmão, com mortalidade associada positivamente com o nível sócio-econômico em São Paulo, e incidência negativamente associada na Inglaterra e País de Gales. A mortalidade por câncer de laringe mostrou associação negativa em um estudo e ausente em outro, ambos em São Paulo.

Por sua vez, os fatores prognósticos (estadiamento e grau histológico) favoráveis dos cânceres de próstata, mama, colorretal se associaram positiva e consistentemente com o nível sócio-econômico da área. O mesmo ocorreu para o câncer total, de pulmão e de colo de útero, analisados somente por um estudo.

O quadro 2 a seguir contêm as principais informações dos estudos ecológicos internacionais. Informações adicionais sobre número de casos, fonte de dados, análise estatística, medidas de avaliação de nível sócioeconômico e ajustes para potenciais variáveis de confusão dos estudos revisados estão contidas no quadro e texto do ANEXO 2. 
Quadro 2 - Relação de estudos ecológicos internacionais de desigualdades sócio-econômicas em câncer. 1998-2008.

\begin{tabular}{|c|c|c|c|c|}
\hline $\begin{array}{l}\text { Autores e } \\
\text { ano de } \\
\text { publicação }\end{array}$ & $\begin{array}{l}\text { Local e } \\
\text { período }\end{array}$ & $\begin{array}{l}\text { Desfecho(s) } \\
\text { estudado(s) }\end{array}$ & $\begin{array}{l}\text { Nível de } \\
\text { agregação }\end{array}$ & Resultados \\
\hline $\begin{array}{l}\text { Harrison et } \\
\text { al., } 1998\end{array}$ & $\begin{array}{l}\text { EUA; } \\
1993\end{array}$ & $\begin{array}{l}\text { Incidência de } \\
\text { Melanoma } \\
\text { Maligno }\end{array}$ & Condado & $\begin{array}{lr}\text { Associação positiva } \\
\text { entre indicadores } \\
\text { sócio-econômicos } \\
\text { favoráveis } \\
\begin{array}{l}\text { condados dos } \\
\text { desfecho e }\end{array}\end{array}$ \\
\hline $\begin{array}{l}\text { Liu et al., } \\
1998\end{array}$ & $\begin{array}{lr}\text { Los } & \text { Angeles, } \\
\text { EUA; } & 1972- \\
1992 & \end{array}$ & $\begin{array}{l}\text { Incidência } \\
\text { Câncer de } \\
\text { Mama, de } \\
\text { Ovário, Corpo } \\
\text { e Colo de } \\
\text { Útero } \\
\end{array}$ & $\begin{array}{l}\text { Census tract } \\
\text { (com } \\
\text { população } \\
\text { média de } \\
4000 \\
\text { residentes) } \\
\end{array}$ & $\begin{array}{l}\text { Risco maior de câncer } \\
\text { de mama, ovário e } \\
\text { corpo de útero nos } \\
\text { estratos mais ricos e } \\
\text { de colo de útero nos } \\
\text { estratos mais pobres }\end{array}$ \\
\hline $\begin{array}{l}\text { Prehn e e } \\
\text { West, } 1998\end{array}$ & $\begin{array}{l}\text { Baía de } \\
\text { Francisco } r \text { e } \\
\text { arredores, } \\
\text { EUA; } 1988- \\
1992\end{array}$ & $\begin{array}{ll}\text { Incidência } & \text { de } \\
\text { Câncer } & \text { de } \\
\text { Mama } & \end{array}$ & $\begin{array}{l}\begin{array}{l}\text { Census block } \\
\text { group (com } \\
\text { população } \\
\text { média de } \\
1000 \\
\text { residentes) }\end{array} \\
\end{array}$ & $\begin{array}{l}\text { Associação positiva } \\
\text { entre indicadores } \\
\text { sócio-econômicos } \\
\text { favoráveis e o } \\
\text { desfecho }\end{array}$ \\
\hline $\begin{array}{l}\text { Liu et al., } \\
2001\end{array}$ & $\begin{array}{lr}\text { Los } & \text { Angeles, } \\
\text { EUA; } & 1972- \\
1997 & \end{array}$ & $\begin{array}{l}\text { Incidência e } \\
\text { estadiamento } \\
\text { de Câncer de } \\
\text { Próstata }\end{array}$ & $\begin{array}{l}\text { Census tract } \\
\text { (com } \\
\text { população } \\
\text { média de } \\
4000 \\
\text { residentes) }\end{array}$ & $\begin{array}{l}\text { Incidência maior nos } \\
\text { estratos sócio- } \\
\text { econômicos mais ricos } \\
\text { e estádio mais } \\
\text { avançado nos estratos } \\
\text { mais pobres a partir de } \\
1987 \\
\end{array}$ \\
\hline $\begin{array}{l}\text { Yost et al., } \\
2001\end{array}$ & $\begin{array}{l}\text { Estado da } \\
\text { Califórnia, } \\
\text { EUA; 1988- } \\
1992\end{array}$ & $\begin{array}{ll}\text { Incidência } & \text { de } \\
\text { Câncer } & \text { de } \\
\text { Mama } & \end{array}$ & 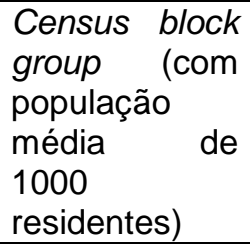 & $\begin{array}{lr}\text { Risco maior } & \text { nos } \\
\text { estratos } & \text { sócio- } \\
\text { econômicos } & \text { mais } \\
\text { ricos, com gradiente } \\
\text { dose-resposta }\end{array}$ \\
\hline $\begin{array}{l}\text { Merkin et } \\
\text { al., } 2002\end{array}$ & $\begin{array}{lr}\text { Cidade } & \text { de } \\
\text { Nova } & \text { York, } \\
\text { EUA; } & 1986- \\
1995 & \\
\end{array}$ & $\begin{array}{l}\text { Estadiamento } \\
\text { de Câncer de } \\
\text { Mama }\end{array}$ & Zip code & $\begin{array}{l}\text { Estádio mais } \\
\text { avançado em estratos } \\
\text { sócio-econômicos } \\
\text { mais pobres }\end{array}$ \\
\hline $\begin{array}{l}\text { Schwartz et } \\
\text { al., } 2003\end{array}$ & \begin{tabular}{ll}
\multicolumn{2}{l}{ Área } \\
Metropolitana \\
de $\quad$ Detroit, \\
EUA; 1988- \\
1992
\end{tabular} & $\begin{array}{l}\text { Estadiamento } \\
\text { de Câncer } \\
\text { Colorretal, de } \\
\text { Próstata, } \\
\text { Pulmão, } \\
\text { Mama e Colo } \\
\text { de Útero } \\
\end{array}$ & $\begin{array}{l}\text { Census block } \\
\text { group (com } \\
\text { população } \\
\text { média de } \\
1000 \\
\text { residentes) }\end{array}$ & $\begin{array}{l}\text { Estádio mais } \\
\text { avançado em estratos } \\
\text { sócio-econômicos } \\
\text { mais pobres }\end{array}$ \\
\hline $\begin{array}{l}\text { Klassen et } \\
\text { al., } 2004\end{array}$ & $\begin{array}{l}\text { Estado de } \\
\text { Maryland, } \\
\text { EUA; 1992- } \\
1997\end{array}$ & $\begin{array}{l}\text { Estadiamento } \\
\text { e Grau } \\
\text { Histológico de } \\
\text { Câncer de } \\
\text { Próstata }\end{array}$ & $\begin{array}{l}\text { Census block } \\
\text { group, census } \\
\text { tract, condado }\end{array}$ & $\begin{array}{lr}\text { Estádio } & \text { mais } \\
\text { avançado e pior } & \text { grau } \\
\text { histológico } & \text { em } \\
\text { moradores de } & \text { census } \\
\text { block group } & \text { mais } \\
\text { pobres } & \end{array}$ \\
\hline
\end{tabular}




\begin{tabular}{|c|c|c|c|c|}
\hline $\begin{array}{l}\text { McFadden } \\
\text { et al., } 2004\end{array}$ & $\begin{array}{l}\text { Nova Zelândia; } \\
\text { 1988-1998 }\end{array}$ & $\begin{array}{ll}\text { Incidência } & \text { de } \\
\text { Câncer } & \text { de } \\
\text { Colo de Útero }\end{array}$ & $\begin{array}{l}\text { Meshblock } \\
\text { (com } \\
\text { população } \\
\text { mediana de } \\
90 \text { residentes) }\end{array}$ & $\begin{array}{l}\text { Risco maior entre os } \\
\text { estratos mais pobres, } \\
\text { com gradiente }\end{array}$ \\
\hline $\begin{array}{l}\mathrm{Ng} \text { et al., } \\
2004\end{array}$ & $\begin{array}{l}\text { Canadá, } 1971, \\
1986,1991 \text { e } \\
1996\end{array}$ & $\begin{array}{l}\text { Mortalidade } \\
\text { por Câncer de } \\
\text { colo de útero }\end{array}$ & Census tract & $\begin{array}{l}\text { Risco maior entre os } \\
\text { estratos mais pobres, } \\
\text { com gradiente }\end{array}$ \\
\hline $\begin{array}{l}\text { Ocaña- } \\
\text { Riola et al., } \\
2004\end{array}$ & $\begin{array}{l}168 \text { municípios } \\
\text { da Província de } \\
\text { Granada, } \\
\text { Espanha; } \\
\text { 1985-1996 }\end{array}$ & $\begin{array}{l}\text { Incidência dos } \\
\text { mais diversos } \\
\text { tipos de } \\
\text { Câncer }\end{array}$ & Município & $\begin{array}{l}\text { Associação positiva } \\
\text { entre indicadores } \\
\text { desfavoráveis e câncer } \\
\text { de cavidade oral, } \\
\text { estômago e esôfago, e } \\
\text { negativa com câncer } \\
\text { de próstata, mama, } \\
\text { vesícula biliar e } \\
\text { melanoma }\end{array}$ \\
\hline $\begin{array}{l}\text { Suarez- } \\
\text { Varela } \\
\text { al., 2004 }\end{array}$ & $\begin{array}{lr}50 & \text { províncias } \\
\text { da } & \text { Espanha; } \\
1989-1997\end{array}$ & $\begin{array}{l}\text { Mortalidade } \\
\text { por Câncer de } \\
\text { Colo de Útero } \\
\end{array}$ & Província & $\begin{array}{lll}\text { Associação } & \text { negativa } \\
\text { dentre PIB e } & \text { o } \\
\text { desfecho. } & & \\
\end{array}$ \\
\hline $\begin{array}{ll}\text { Clarke } & \text { et } \\
\text { al., } 2005 & \end{array}$ & $\begin{array}{l}\text { Estado ra } \\
\text { Califórnia, } \\
\text { EUA; 1988- } \\
1992\end{array}$ & $\begin{array}{ll}\text { Incidência } & \text { de } \\
\text { Linfoma } & \text { de } \\
\text { Hodgkin } & \end{array}$ & 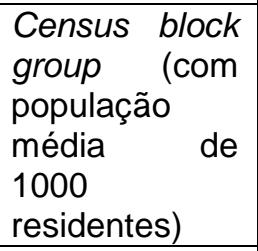 & $\begin{array}{l}\text { Risco maior nos } \\
\text { estratos mais ricos, } \\
\text { com gradiente, na } \\
\text { faixa etária de } 15 \text { a } 44 \\
\text { anos. }\end{array}$ \\
\hline $\begin{array}{l}\text { Fukuda et } \\
\text { al., } 2005\end{array}$ & $\begin{array}{l}\text { Japão; 1993- } \\
1998\end{array}$ & $\begin{array}{|lr|}\text { Mortalidade } \\
\text { por Câncer de } \\
\text { Pulmão re } \\
\text { Cólon } \quad(e m \\
\text { homens) e de } \\
\begin{array}{lr}\text { Mama } \\
\text { mulheres) }\end{array}\end{array}$ & Município & $\begin{array}{l}\text { Risco maior de câncer } \\
\text { de mama feminina e } \\
\text { cólon masculino em } \\
\text { clusters de municípios } \\
\text { com características } \\
\text { sócio-econômicas } \\
\text { favoráveis e urbanas. }\end{array}$ \\
\hline $\begin{array}{l}\text { Shipp et al., } \\
2005\end{array}$ & $\begin{array}{l}\text { Estado de } \\
\text { Alabama, EUA; } \\
\text { 1996-1999 }\end{array}$ & $\begin{array}{ll}\text { Incidência } & \text { de } \\
\text { Câncer } & \text { de } \\
\text { Cólon } & \\
\text { Intestinal } & \end{array}$ & Condado & $\begin{array}{l}\text { Associação positiva } \\
\text { entre indicadores de } \\
\text { acesso a cuidados de } \\
\text { saúde e sócio- } \\
\text { econômicos favoráveis } \\
\text { e o desfecho }\end{array}$ \\
\hline $\begin{array}{l}\text { Ueda et al., } \\
2005\end{array}$ & $\begin{array}{l}\text { Área } \\
\text { metropolitana } \\
\text { de } \quad \text { Osaka, } \\
\text { Japão; } 1995- \\
1999\end{array}$ & $\begin{array}{lr}\text { Incidência, } & \\
\text { Mortalidade e } \\
\text { Sobrevida } & \text { de } \\
\text { Câncer rem } \\
\text { geral }\end{array}$ & Município & $\begin{array}{l}\text { Associação negativa } \\
\text { entre indicadores } \\
\text { sócio-econômicos } \\
\text { favoráveis e a } \\
\text { incidência } \\
\text { mortalidade, e positiva } \\
\text { entre tais indicadores } \\
\text { e a sobrevida }\end{array}$ \\
\hline $\begin{array}{l}\text { Lancaster } \\
\text { et al., } 2006\end{array}$ & $\begin{array}{ll}\text { Norte } & \text { da } \\
\text { Inglaterra; } & \\
1993-1996 & \end{array}$ & $\begin{array}{ll}\text { Incidência } & \text { de } \\
\text { Câncer } & \text { de } \\
\text { Pulmão } & \end{array}$ & $\begin{array}{l}\text { Distrito de } \\
\text { Autoridade } \\
\text { Local }\end{array}$ & $\begin{array}{l}\text { Associação negativa } \\
\text { entre indicadores } \\
\text { sócio-econômicos } \\
\text { favoráveis e o } \\
\text { desfecho }\end{array}$ \\
\hline
\end{tabular}




\begin{tabular}{|c|c|c|c|c|}
\hline $\begin{array}{l}\text { Oliver et al., } \\
2006\end{array}$ & $\begin{array}{l}\text { Estado da } \\
\text { Virgínia, EUA; } \\
\text { 1990-1999 }\end{array}$ & $\begin{array}{ll}\text { Incidência } & \text { de } \\
\text { Câncer } & \text { de } \\
\text { Próstata } & \end{array}$ & $\begin{array}{l}\text { Census tract } \\
\text { (com } \\
\text { população } \\
\text { média } \\
4000 \\
\text { residentes) de } \\
\text { condado }\end{array}$ & $\begin{array}{l}\text { Associação positiva } \\
\text { entre variáveis sócio- } \\
\text { econômicas favoráveis } \\
\text { e o desfecho, } \\
\text { especialmente em } \\
\text { brancos }\end{array}$ \\
\hline $\begin{array}{l}\text { Pollack et } \\
\text { al., } 2006\end{array}$ & $\begin{array}{l}\text { Estado da } \\
\text { Califórnia, } \\
\text { EUA; 1996- } \\
2000\end{array}$ & $\begin{array}{l}\text { Estadiamento } \\
\text { de Câncer } \\
\text { Colorretal }\end{array}$ & $\begin{array}{l}\text { Census } \\
\text { group (com } \\
\text { população } \\
\text { média de } \\
1000 \\
\text { residentes) } \\
\end{array}$ & $\begin{array}{l}\text { Risco maior de } \\
\text { estágios avançados do } \\
\text { câncer nos estratos } \\
\text { mais pobres, com } \\
\text { gradiente. }\end{array}$ \\
\hline $\begin{array}{l}\text { Alazraqui et } \\
\text { al., } 2007\end{array}$ & $\begin{array}{l}\text { Município de } \\
\text { Lanús, } \\
\text { Argentina; } \\
\text { 1995-2002 }\end{array}$ & $\begin{array}{l}\text { Mortalidade } \\
\text { por Câncer de } \\
\text { Mama }\end{array}$ & $\begin{array}{l}\text { Radios } \\
\text { censales (com } \\
200 \text { a } 400 \\
\text { domicílios } \\
\text { urbanos) }\end{array}$ & $\begin{array}{l}\text { Risco maior nos } \\
\text { estratos } \\
\text { econômicos } \\
\text { ricos, com gradiente } \\
\text { dose-resposta }\end{array}$ \\
\hline $\begin{array}{l}\text { Brown et } \\
\text { al., } 2007\end{array}$ & $\begin{array}{l}\text { Escócia; 1991- } \\
2000\end{array}$ & $\begin{array}{ll}\text { Incidência } & \text { de } \\
\text { Câncer } & \text { de } \\
\text { Mama } & \end{array}$ & Postcode & $\begin{array}{lr}\text { Risco maior } & \text { nos } \\
\text { estratos } & \text { mais } \\
\text { afluentes, } & \text { com } \\
\text { gradiente } & \\
\end{array}$ \\
\hline $\begin{array}{l}\text { DeChello e } \\
\text { Sheehan, } \\
2007\end{array}$ & $\begin{array}{lr}\text { Estado } \quad \text { de } \\
\text { Massachusetts, } \\
\text { EUA; 1995- } \\
1998\end{array}$ & $\begin{array}{l}\text { Incidência de } \\
\text { Câncer } \\
\text { Colorretal }\end{array}$ & $\begin{array}{l}\text { Census tract } \\
\text { (com } \\
\text { população } \\
\text { média de } \\
4000 \\
\text { residentes) }\end{array}$ & \begin{tabular}{lr} 
Fatores & \multicolumn{2}{r}{ sócio- } \\
econômicos & e \\
urbanização & estão \\
relacionados & ao \\
desfecho &
\end{tabular} \\
\hline $\begin{array}{l}\text { Rowan, } \\
2007\end{array}$ & $\begin{array}{l}\text { Inglaterra e } \\
\text { País de Gales; } \\
\text { 1990-2002 }\end{array}$ & $\begin{array}{ll}\text { Incidência } & \text { de } \\
\text { Cânceres } & \text { de } \\
\text { Pulmão, } & \\
\text { Mama } & \text { e } \\
\text { Próstata } & \end{array}$ & Census ward & $\begin{array}{l}\text { Risco maior de câncer } \\
\text { de mama e próstata } \\
\text { nos estratos mais ricos } \\
\text { e de câncer de pulmão } \\
\text { nos estratos mais } \\
\text { pobres }\end{array}$ \\
\hline $\begin{array}{l}\text { Xiao et al., } \\
2007\end{array}$ & $\begin{array}{l}\text { Estado da } \\
\text { Flórida, EUA; } \\
\text { 1990-2001 }\end{array}$ & $\begin{array}{l}\text { Estadiamento } \\
\text { e Grau } \\
\text { Histológico de } \\
\text { Câncer de } \\
\text { Próstata }\end{array}$ & $\begin{array}{l}\text { Census tract } \\
\text { (com } \\
\text { população } \\
\text { média de } \\
4000 \\
\text { residentes) } \\
\end{array}$ & $\begin{array}{l}\text { Estádio mais } \\
\text { avançado e pior grau } \\
\text { histológico nos } \\
\text { estratos mais pobres }\end{array}$ \\
\hline $\begin{array}{l}\text { Downing et } \\
\text { al., } 2008\end{array}$ & $\begin{array}{l}\text { Região de } \\
\text { Yorkshire, } \\
\text { Inglaterra; } \\
\text { 1983-2003 }\end{array}$ & $\begin{array}{l}\text { Incidência de } \\
\text { Câncer de } \\
\text { Pulmão, } \\
\text { Estômago, } \\
\text { Esôfago, } \\
\text { Pâncreas, } \\
\text { Bexiga e Rim } \\
\end{array}$ & $\begin{array}{l}\text { Electoral ward } \\
\text { (com } \\
\text { população } \\
\text { média de } \\
5000 \\
\text { residentes) }\end{array}$ & \begin{tabular}{lr} 
Associação & \multicolumn{2}{c}{ positiva } \\
entre indicador de \\
privação e cânceres \\
de pulmão \\
estômago, \\
gradiente
\end{tabular} \\
\hline $\begin{array}{ll}\text { Shack } & \text { et } \\
\text { al., } 2008 & \end{array}$ & $\begin{array}{l}\text { Inglaterra; } \\
\text { 1998-2003 }\end{array}$ & $\begin{array}{l}\text { Incidência de } \\
\text { Câncer de } \\
\text { Pulmão, } \\
\text { Mama, Colo } \\
\text { de Útero e } \\
\text { Melanoma } \\
\text { Maligno }\end{array}$ & $\begin{array}{l}\begin{array}{l}\text { Lower super } \\
\text { output area }\end{array} \\
\text { (com } \\
\text { população } \\
\text { média de } \\
1500 \\
\text { residentes) }\end{array}$ & $\begin{array}{l}\text { Risco maior de câncer } \\
\text { de mama e melanoma } \\
\text { nos estratos mais ricos } \\
\text { e de câncer de colo de } \\
\text { útero e de pulmão nos } \\
\text { estratos mais pobres }\end{array}$ \\
\hline
\end{tabular}

EUA: Estados Unidos da América 


\subsubsection{Poluição do Ar e Câncer}

Segundo a International Agency for Research on Cancer (IARC, 1989), a emissão de motores a diesel é provavelmente carcinogênica para seres humanos, classificada no grupo $2 \mathrm{~A}$, e a emissão de motores a gasolina é possivelmente carcinogênica para os mesmos, incluída no grupo 2B, a partir de evidências de estudos em animais e investigações epidemiológicas em grupos ocupacionalmente expostos. Compostos considerados cancerígenos para o homem pela IARC, com diferentes níveis de certeza, são encontrados nas emissões veiculares, como benzeno, hidrocarbonetos policíclicos aromáticos, formaldeído, acetaldeído e 1,3butadieno, entre outros. Estudos in vitro têm demonstrado a capacidade de poluentes da exaustão de diesel de causar formação de adutos de DNA, oxidação de bases, deleções e aberrações cromossômicas, entre outros efeitos, que poderiam levar a amplo espectro de mutações. Estudos em animais, por sua vez, têm mostrado a habilidade de altas concentrações de poluentes da exaustão de gasolina e diesel de provocar câncer em alguns animais. Embora, tais classificações e dados a favor de um papel causal da poluição relacionada ao tráfego em relação ao câncer, as evidências epidemiológicas em populações expostas a essa poluição em ambientes não ocupacionais têm-se demonstrado inadequadas e insuficientes para essa inferência (HEI, 2009).

Em revisão recente da associação entre poluição do ar e câncer infantil, na qual a quase totalidade dos estudos tratavam da poluição relacionada ao tráfego, avaliaram-se 8 estudos caso-controle e 7 ecológicos, observando-se na maioria deles resultados negativos, e que os poucos achados positivos foram encontrados em estudos com pequeno número de casos, métodos de avaliação da exposição não validados e outras limitações metodológicas. De forma inversa, os estudos com maior poder estatístico, métodos validados de avaliação da exposição e com menor potencial para viés de seleção e confundimento proveram as mais fortes evidências contra 
a associação. De tal modo, os autores concluíram que o peso das evidências indica risco não aumentado de câncer infantil associada à exposição à poluição do ar pelo tráfego, porém, devido ao pequeno número de estudos, às suas limitações metodológicas e à ausência de consistência dos resultados, uma firme conclusão de não efeito não era possível (RAASCHOU-NIELSEN e REYNOLDS, 2006).

Em outra recente revisão, feita pelo Health Effects Institute (Instituto de Efeitos à Saúde) (HEI, 2009), analisando-se estudos que tratavam da associação potencial entre poluição veicular e câncer, concluiu-se que poucos dados e estudos estão disponíveis para todos os tipos de câncer que não o de pulmão e o infantil. Em relação a esses, embora mais estudos estejam disponíveis do que para os outros tipos, a evidência da exposição geral ao tráfego foi considerada insuficiente e inadequada para inferência causal.

A revisão da literatura sobre os efeitos da poluição do ar sobre o risco de câncer no adulto resultou em vinte e um estudos, dos quais oito realizados nos Estados Unidos da América, três na Holanda, três na Noruega, dois no Brasil, um no Canadá, França, Japão e Suécia e.um europeu multicêntrico. Ou seja, nove na Europa, nove na América do Norte, dois no Brasil e um no Japão. Cabe destacar que os estudos brasileiros corresponderam a dissertações de mestrado e não foram publicados sob a forma de artigo em revistas científicas.

Ao todo, foram doze estudos de coorte, cinco ecológicos e quatro caso-controle. Porém, os estudos de coorte corresponderam a sete populações diversas e os de caso-controle a três, pois há artigos que investigam a mesma população sob aspectos diferentes. As coortes acompanhadas foram: três norte-americanas correspondentes aos estudos dos adventistas do $7^{\circ}$ dia da Califórnia (Adventist Health Study of Smog), das 6 cidades (Harvard Six Cities Study) e da Sociedade Americana de Câncer (American Cancer Society); duas norueguesas, sendo uma iniciada em 1972 e outra em 1992; uma francesa e outra holandesa (Netherlands Cohort on Diet and Cancer). O número de casos, nos estudos de coorte, variou de 36 
incidentes e 30 mortes por câncer de pulmão, na coorte dos adventistas do $7^{\circ}$ dia, a 2183 incidentes e 1888 mortes pelo mesmo câncer, na coorte holandesa. Já os estudos caso-controle chegaram a estudar 1042 casos incidentes de câncer de pulmão e 1168 de câncer de mama.

Foram utilizados como método principal de avaliação da exposição à poluição do ar, a partir da classificação proposta por JERRET et al. (2005a), a média da concentração do poluente, medido por estação de monitoramento do ar ou por equação de regressão a partir de medidas de visibilidade do ar para determinada unidade geográfica de estudo (nove estudos), os modelos de dispersão (cinco), a interpolação estatística (cinco), modelos híbridos (dois) e modelo de proximidade com o tráfego (um). As medidas de exposição investigadas foram as concentrações de $\mathrm{MP}_{2,5}, \mathrm{MP}_{10}$, $\mathrm{MP}_{2,5-10}, \mathrm{MP}_{2,5-15}, \mathrm{MP}_{10}$ (material particulado com diâmetro aerodinâmico, respectivamente, menor que $2,5 \mu \mathrm{m}$ e $10 \mu \mathrm{m}$, entre $2,5 \mu \mathrm{m}$ e $10 \mu \mathrm{m}$, e entre $2,5 \mu \mathrm{m}$ e $15 \mu \mathrm{m}$ ), partículas de sulfato, PTS (partículas totais em suspensão), $\mathrm{NO}_{2}$ (dióxido de nitrogênio), $\mathrm{NO}_{x}$ (óxidos de nitrogênio), $\mathrm{SO}_{2}$ (dióxido de enxofre), $\mathrm{O}_{3}$ (ozônio), Carbono Elementar e Hidrocarbonetos Policíclicos Aromáticos (HPA), além de medidas de intensidade de tráfego. Os desfechos investigados foram incidência e mortalidade por câncer de pulmão (treze estudos), incidência por câncer de mama (dois) e o restante mortalidade ou incidência por câncer total ou por mais de um tipo (seis).

Apesar da dificuldade de se comparar os resultados dos estudos acima descritos, devido a diferenças no desenho, nas condições locais, nos métodos de avaliação da exposição e nos poluentes mensurados, a maioria deles revelaram uma associação positiva entre as concentrações de diversos poluentes particulados e gasosos e o câncer de pulmão.

A maioria dos estudos que avaliaram a exposição a $\mathrm{NO}_{2}$ ou $\mathrm{NO}_{x}$ revelaram uma associação positiva desse poluentes com a mortalidade e a incidência de câncer de pulmão (oito estudos) e alguns demonstraram associação negativa (três). Por outro lado, os achados da associação do poluente $\mathrm{SO}_{2}$ com esses desfechos foram inconsistentes, com alguns estudos mostrando ausência ou associação negativa (seis estudos) e outros 
associação positiva (quatro). Já a maioria dos estudos revisados que exploraram a associação de $\mathrm{MP}_{10}$ com esses desfechos revelaram associação positiva (cinco) e somente um negativa. Em relação ao $\mathrm{MP}_{2,5}$, todos os estudos (seis) apontaram para uma associação positiva com a mortalidade por câncer de pulmão. Porém o único que avaliou a relação dessa medida com a incidência de câncer de pulmão mostrou associação negativa.

O câncer de mama foi avaliado por poucos estudos e se mostrou associado positivamente aos níveis de PTS, de hidrocarbonetos policíclicos aromáticos e de $\mathrm{MP}_{10}$. As demais medidas de exposição e desfechos foram abordados por muito poucos estudos e não permitiram análise comparativa.

Portanto, as associações positivas mais consistentes foram encontradas para exposições ao $\mathrm{NO}_{2} / \mathrm{NO}_{x}, \mathrm{MP}_{2,5}, \mathrm{MP}_{10}$ na determinação do câncer de pulmão. É provável, porém, que a exposição aos agentes gasosos $\mathrm{NO}_{2}$ e $\mathrm{NO}_{\mathrm{x}}$ não seja causa verdadeira responsável por esse desfecho, mas seja apenas indicadora da exposição a agentes carcinógenos, isolados ou adsorvidos a partículas, encontrados na poluição do ar (NAFSTAD et al., 2003). Por sua vez, há evidências epidemiológicas que indicam que a maior parte dos efeitos exercidos por $\mathrm{MP}_{10}$ seja atribuído à sua fração $\mathrm{MP}_{2,5}$, o que é plausível com várias considerações toxicológicas e fisiológicas (POPE e DOCKERY, 2006).

O quadro 3 a seguir contêm as principais informações dos estudos revisados, publicados entre 1998 e 2008, que tratam dos efeitos da poluição do ar sobre o risco de câncer em adultos. Informações adicionais sobre número de participantes e casos, métodos e medidas de exposição, resultados e ajustes para potenciais variáveis de confusão nos estudos revisados estão contidas no quadro e texto do ANEXO 3. 
Quadro 3 - Relação de estudos sobre os efeitos da poluição do ar sobre o risco de câncer em adultos. 1998-2008.

\begin{tabular}{|c|c|c|c|c|c|}
\hline $\begin{array}{l}\text { Autores e } \\
\text { ano de } \\
\text { publicação }\end{array}$ & $\begin{array}{c}\text { Local, } \\
\text { período e } \\
\text { desenho do } \\
\text { estudo }\end{array}$ & $\begin{array}{l}\text { Desfecho(s) } \\
\text { estudado(s) }\end{array}$ & $\begin{array}{c}\text { Número } \\
\text { de casos } \\
\text { e } \\
\text { controles }\end{array}$ & $\begin{array}{l}\text { Medidas } \\
\text { de } \\
\text { exposição }\end{array}$ & Resultados \\
\hline $\begin{array}{l}\text { Beeson et } \\
\text { al., } 1998\end{array}$ & $\begin{array}{l}\text { Estado da } \\
\text { Califórnia, } \\
\text { EUA; 1977- } \\
\text { 1992; coorte } \\
\text { prospectiva }\end{array}$ & $\begin{array}{l}\text { Incidência } \\
\text { de Câncer } \\
\text { de Pulmão }\end{array}$ & 36 casos & $\begin{array}{l}\mathrm{NO}_{2}, \quad \mathrm{SO}_{2} \\
\mathrm{MP}_{10} \text { e } \mathrm{O}_{3}\end{array}$ & $\begin{array}{l}\text { Associação positiva e } \\
\text { significante entre o } \\
\text { desfecho e os níveis de } \\
\mathrm{MP}_{10} \text { e } \mathrm{SO}_{2} \text {, em homens, } \\
\text { e de } \mathrm{SO}_{2} \text {, nas mulheres. }\end{array}$ \\
\hline $\begin{array}{l}\text { Abbey et al., } \\
1999\end{array}$ & $\begin{array}{l}\text { Estado da } \\
\text { Califórnia, } \\
\text { EUA; 1977- } \\
\text { 1992; coorte } \\
\text { prospectiva }\end{array}$ & $\begin{array}{l}\text { Mortalidade } \\
\text { por Câncer } \\
\text { de Pulmão }\end{array}$ & 30 casos & $\begin{array}{l}\mathrm{NO}_{2}, \quad \mathrm{SO}_{2} \\
\mathrm{MP}_{10} \text { e } \mathrm{O}_{3}\end{array}$ & $\begin{array}{l}\text { Associação positiva e } \\
\text { significante entre o } \\
\text { desfecho e os níveis de } \\
\mathrm{MP}_{10} \text { e } \mathrm{SO}_{2} \text {, em homens, } \\
\text { e de } \mathrm{NO}_{2} \text { e } \mathrm{SO}_{2} \text {, nas } \\
\text { mulheres. }\end{array}$ \\
\hline $\begin{array}{l}\text { Cangerana- } \\
\text { Pereira, } \\
2000\end{array}$ & $\begin{array}{l}12 \text { Distritos } \\
\text { do } \text { Município } \\
\text { der São } \\
\text { Paulo, Brasil; } \\
\text { 1997; } \\
\text { ecológico } \\
\end{array}$ & $\begin{array}{l}\text { Incidência } \\
\text { de Câncer } \\
\text { em geral e } \\
\text { de vários } \\
\text { tipos }\end{array}$ & $\begin{array}{l}70 \text { casos } \\
\text { (laringe) e } \\
507 \text { casos } \\
\text { (pele) }\end{array}$ & $\begin{array}{l}\mathrm{NO}_{2}, \mathrm{NO}_{x} \\
\mathrm{SO}_{2}, \mathrm{MP}_{10} \\
\mathrm{O}_{3} \text { e } \mathrm{CO}\end{array}$ & $\begin{array}{l}\text { Associação positiva } \\
\text { significante entre os } \\
\text { cânceres de laringe e } \\
\text { pele e os níveis de } \mathrm{O}_{3} \text {. }\end{array}$ \\
\hline $\begin{array}{l}\text { Mcdonnell } \\
\text { et al., } 2000\end{array}$ & $\begin{array}{l}\text { Estado da } \\
\text { Califórnia, } \\
\text { EUA; 1977- } \\
\text { 1992; coorte } \\
\text { prospectiva }\end{array}$ & $\begin{array}{l}\text { Mortalidade } \\
\text { por Câncer } \\
\text { de Pulmão }\end{array}$ & $24 \mathrm{c}$ & $\begin{array}{l}\mathrm{MP}_{2,5} \\
\mathrm{MP}_{2,5-10} \quad \mathrm{e} \\
\mathrm{MP}_{10}\end{array}$ & $\begin{array}{l}\text { Associação positiva e } \\
\text { não significante entre o } \\
\text { desfecho e os níveis de } \\
\mathrm{MP}_{2,5}, \mathrm{MP}_{2,5-10} \text { e } \mathrm{MP}_{10}\end{array}$ \\
\hline $\begin{array}{ll}\text { Nyberg } & \text { et } \\
\text { al., } 2000 & \end{array}$ & $\begin{array}{l}\text { Estocolmo, } \\
\text { Suécia; } \\
\text { 1985-1990; } \\
\text { caso } \\
\text { controle de } \\
\text { base } \\
\text { populacional }\end{array}$ & $\begin{array}{l}\text { Incidência } \\
\text { de Câncer } \\
\text { de Pulmão }\end{array}$ & $\begin{array}{l}1042 \\
\text { casos e } \\
2364 \\
\text { controles }\end{array}$ & $\mathrm{NO}_{2} \mathrm{e} \mathrm{SO}_{2}$ & $\begin{array}{l}\text { Associação positiva e } \\
\text { não significante entre o } \\
\text { desfecho e os níveis de } \\
\mathrm{NO}_{2}\end{array}$ \\
\hline $\begin{array}{l}\text { Pope et al., } \\
2002\end{array}$ & $\begin{array}{l}\text { Áreas } \\
\text { metropolitan } \\
\text { as dos EUA: } \\
\text { 1982-1998; } \\
\text { coorte } \\
\text { prospectiva }\end{array}$ & $\begin{array}{l}\text { Mortalidade } \\
\text { por Câncer } \\
\text { de Pulmão }\end{array}$ & $\begin{array}{l}\text { Não } \\
\text { disponível }\end{array}$ & $\begin{array}{l}\mathrm{MP}_{2,5}, \\
\mathrm{MP}_{2,5-15}, \\
\mathrm{MP}_{10} \quad \mathrm{NO}_{2}, \\
\mathrm{SO}_{2}, \quad \mathrm{O}_{3}, \\
\mathrm{CO}, \\
\text { partículas } \\
\text { de } \mathrm{SO}_{4}^{-}\end{array}$ & $\begin{array}{l}\text { Associação positiva } \\
\text { significante entre o } \\
\text { desfecho e as níveis de } \\
\mathrm{MP}_{2,5} \text { e partículas de } \\
\mathrm{SO}_{4}{ }^{-}\end{array}$ \\
\hline $\begin{array}{l}\text { Nafstad et } \\
\text { al., 2003 }\end{array}$ & $\begin{array}{l}\text { Oslo, } \\
\text { Noruega; } \\
\text { 1972-1998; } \\
\text { coorte } \\
\text { prospectiva }\end{array}$ & $\begin{array}{l}\text { Incidência } \\
\text { de Câncer } \\
\text { de Pulmão }\end{array}$ & 418 casos & $\mathrm{NO}_{x}$ e $\mathrm{SO}_{2}$ & $\begin{array}{l}\text { Associação positiva } \\
\text { significante } \\
\text { entre } \\
\text { desfecho e os níveis de } \\
\mathrm{NO}_{x}\end{array}$ \\
\hline $\begin{array}{l}\text { Nafstad et } \\
\text { al., } 2004\end{array}$ & $\begin{array}{l}\text { Oslo, } \\
\text { Noruega; } \\
\text { 1972-1998; } \\
\text { coorte } \\
\text { prospectiva }\end{array}$ & $\begin{array}{l}\text { Mortalidade } \\
\text { por Câncer } \\
\text { de Pulmão }\end{array}$ & 382 casos & $\mathrm{NO}_{x}$ e $\mathrm{SO}_{2}$ & $\begin{array}{l}\text { Associação positiva e } \\
\text { significante entre } \\
\text { desfecho e os níveis de } \\
\mathrm{NO}_{x}\end{array}$ \\
\hline $\begin{array}{l}\text { Visser et al., } \\
2004\end{array}$ & $\begin{array}{l}\text { Amsterdã, } \\
\text { Holanda; } \\
\text { 1989-1997; } \\
\text { ecológico }\end{array}$ & $\begin{array}{l}\text { Incidência } \\
\text { de Câncer } \\
\text { em geral e } \\
\text { dos seus } \\
\text { principais } \\
\text { grupos }\end{array}$ & $\begin{array}{l}378 \text { casos } \\
\text { (TGl em } \\
\text { homens), } \\
\text { e } 148 \\
\text { casos } \\
\text { (hematoló- } \\
\text { gicos em } \\
\text { mulheres) } \\
\end{array}$ & $\begin{array}{l}\text { Distância } \\
\text { da } \\
\text { residência } \\
\text { a vias de } \\
\text { alto tráfego }\end{array}$ & $\begin{array}{l}\text { Associação } \\
\text { significante } \\
\text { neoplasias do } \\
\text { (homens) } \\
\text { hematológicas } \\
\text { (mulheres) e } \\
\begin{array}{l}\text { próximo a vias de alto } \\
\text { tráfego }\end{array} \\
\end{array}$ \\
\hline
\end{tabular}




\begin{tabular}{|c|c|c|c|c|c|}
\hline $\begin{array}{l}\text { Bonner et } \\
\text { al., } 2005\end{array}$ & $\begin{array}{l}\text { Oeste do } \\
\text { Estado de } \\
\text { Nova lorque, } \\
\text { EUA; 1996- } \\
2001 ; \text { caso } \\
\text { controle de } \\
\text { base } \\
\text { populacional }\end{array}$ & $\begin{array}{l}\text { Incidência } \\
\text { de Câncer } \\
\text { de Mama }\end{array}$ & $\begin{array}{l}1166 \\
\text { casos e } \\
2105 \\
\text { controles }\end{array}$ & PTS & $\begin{array}{l}\text { Associação positiva e } \\
\text { significante entre câncer } \\
\text { de mama pós- } \\
\text { menopáusico e a } \\
\text { exposição acumulada } \\
\text { durante toda a vida a } \\
\text { níveis de PTS }\end{array}$ \\
\hline $\begin{array}{l}\text { Filleul et al., } \\
2005\end{array}$ & $\begin{array}{l}24 \text { áreas de } \\
7 \text { cidades da } \\
\text { França; } \\
1974-1998 ; \\
\text { coorte } \\
\text { prospectiva }\end{array}$ & $\begin{array}{l}\text { Mortalidade } \\
\text { por Câncer } \\
\text { de Pulmão }\end{array}$ & 178 casos & $\begin{array}{l}\mathrm{NO}_{2}, \quad \mathrm{NO}, \\
\mathrm{SO}_{2}, \mathrm{PTS}, \\
\text { Carbono } \\
\text { elementar }\end{array}$ & $\begin{array}{lc}\text { Associação } & \text { positiva } \\
\text { significante } & \text { entre } \\
\text { desfecho e os níveis de } \\
\mathrm{NO}_{2}\end{array}$ \\
\hline $\begin{array}{l}\text { Iwai et al., } \\
2005\end{array}$ & $\begin{array}{l}\text { Japão, 2000; } \\
\text { ecológico }\end{array}$ & $\begin{array}{l}\text { Mortalidade } \\
\text { por diversos } \\
\text { tipos de } \\
\text { Câncer }\end{array}$ & $\begin{array}{l}1462 \\
\text { casos } \\
\text { (pulmão } \\
\text { em } \\
\text { mulheres), } \\
9171 \\
\text { (mama), } \\
3532 \\
\text { (útero), } \\
3993 \\
\text { (ovário) }\end{array}$ & $\mathrm{MP}_{10}$ & $\begin{array}{l}\text { Associação positiva e } \\
\text { significante entre câncer } \\
\text { de pulmão (mulheres), } \\
\text { de mama, de endométrio } \\
\text { e de ovário e os níveis } \\
\text { de } \mathrm{MP}_{10}\end{array}$ \\
\hline $\begin{array}{l}\text { Jerret et al., } \\
2005 a\end{array}$ & $\begin{array}{l}\text { Hamilton, } \\
\text { Canadá; } \\
\text { 1985-1994; } \\
\text { ecológico }\end{array}$ & $\begin{array}{l}\text { Mortalidade } \\
\text { por Câncer } \\
\text { em geral }\end{array}$ & $\begin{array}{l}\text { Não } \\
\text { disponível }\end{array}$ & PTS & $\begin{array}{l}\text { Associação positiva e } \\
\text { significante entre } \\
\text { desfecho e os níveis de } \\
\text { PTS }\end{array}$ \\
\hline $\begin{array}{l}\text { Jerret et al., } \\
2005 b\end{array}$ & $\begin{array}{l}\text { Los Angeles, } \\
\text { EUA; 1982- } \\
2000 ; \text { coorte } \\
\text { prospectiva }\end{array}$ & $\begin{array}{l}\text { Mortalidade } \\
\text { por Câncer } \\
\text { de Pulmão e } \\
\text { Digestivo }\end{array}$ & 434 casos & $\begin{array}{l}\mathrm{MP}_{2,5}, \mathrm{O}_{3}, \\
\text { distância } \\
\text { da } \\
\text { residência } \\
\text { a vias de } \\
\text { alto tráfego }\end{array}$ & $\begin{array}{l}\text { Associação positiva e } \\
\text { não significante entre os } \\
\text { desfechos e os níveis de } \\
\mathrm{MP}_{2,5} \text {, após controle para } \\
\text { confundimento }\end{array}$ \\
\hline $\begin{array}{l}\text { Laden et al., } \\
2006\end{array}$ & $\begin{array}{l}6 \text { cidades do } \\
\text { nordeste dos } \\
\text { EUA; 1974- } \\
1998\end{array}$ & $\begin{array}{l}\text { Mortalidade } \\
\text { por Câncer } \\
\text { de Pulmão }\end{array}$ & 226 casos & $\mathrm{MP}_{2,5}$ & $\begin{array}{l}\text { Associação positiva e } \\
\text { não significante entre o } \\
\text { desfecho e as níveis de } \\
\mathrm{MP}_{2,5}\end{array}$ \\
\hline $\begin{array}{l}\text { Vineis et al., } \\
2006\end{array}$ & $\begin{array}{l}\text { Europa (10 } \\
\text { países); } \\
\text { caso- } \\
\text { controle } \\
\text { aninhado de } \\
\text { base } \\
\text { populacional }\end{array}$ & $\begin{array}{l}\text { Incidência } \\
\text { de Câncer } \\
\text { de Pulmão }\end{array}$ & $\begin{array}{l}197 \text { casos } \\
\text { de e } 556 \\
\text { controles }\end{array}$ & $\begin{array}{l}\mathrm{NO}_{2}, \mathrm{SO}_{2}, \\
\mathrm{MP}_{10} ; \\
\text { distância } \\
\text { da } \\
\text { residência } \\
\text { a vias de } \\
\text { alto tráfego }\end{array}$ & $\begin{array}{l}\text { Associação } \\
\text { significante entre o } \\
\text { desfecho e níveis de } \\
\mathrm{NO}_{2} \text {, e não significante } \\
\text { entre o desfecho e morar } \\
\text { próximo a vias de alto } \\
\text { tráfego e níveis de } \mathrm{SO}_{2}\end{array}$ \\
\hline $\begin{array}{l}\text { Naess et al., } \\
2007\end{array}$ & $\begin{array}{l}\text { Oslo, } \\
\text { Noruega; } \\
\text { 1992-1998; } \\
\text { coorte } \\
\text { prospectiva }\end{array}$ & $\begin{array}{l}\text { Mortalidade } \\
\text { por Câncer } \\
\text { de Pulmão }\end{array}$ & $\begin{array}{l}1453 \\
\text { casos }\end{array}$ & $\begin{array}{l}\mathrm{NO}_{2}, \mathrm{MP}_{2,5} \\
\text { e } \mathrm{MP}_{10}\end{array}$ & $\begin{array}{l}\text { Associação positiva e } \\
\text { significante entre o } \\
\text { desfecho e os níveis de } \\
\mathrm{NO}_{2}, \mathrm{MP}_{2,5} \text {, e } \mathrm{MP}_{10} \text { para } \\
\text { mulheres }\end{array}$ \\
\hline $\begin{array}{l}\text { Nie et al., } \\
2007\end{array}$ & $\begin{array}{l}\text { Oeste do } \\
\text { Estado de } \\
\text { Nova lorque, } \\
\text { EUA; 1996- } \\
2001 ; \text { caso- } \\
\text { controle de } \\
\text { base } \\
\text { populacional }\end{array}$ & $\begin{array}{l}\text { Incidência } \\
\text { de Câncer } \\
\text { de Mama }\end{array}$ & $\begin{array}{l}1068 \\
\text { casos e } \\
1944 \\
\text { controles }\end{array}$ & HPA & $\begin{array}{l}\text { Associação positiva e } \\
\text { significante entre câncer } \\
\text { de mama pós- } \\
\text { menopáusico e níveis de } \\
\text { HAP na época do } \\
\text { nascimento do primeiro } \\
\text { filho }\end{array}$ \\
\hline
\end{tabular}




\begin{tabular}{|c|c|c|c|c|c|}
\hline $\begin{array}{l}\text { Bellen et al., } \\
2008 a\end{array}$ & $\begin{array}{l}\text { Holanda; } \\
\text { 1987-1996; } \\
\text { coorte } \\
\text { prospectiva }\end{array}$ & $\begin{array}{l}\text { Mortalidade } \\
\text { por Câncer } \\
\text { de Pulmão }\end{array}$ & $\begin{array}{l}1888 \\
\text { (coorte) e } \\
1059 \\
\text { (caso- } \\
\text { coorte) }\end{array}$ & $\begin{array}{l}\mathrm{NO}_{2}, \mathrm{SO}_{2}, \\
\mathrm{MP}_{2,5}, \\
\text { Carbono } \\
\text { Elementar; } \\
\text { medidas } \\
\text { de } \\
\text { intensidad } \\
\text { e de } \\
\text { tráfego }\end{array}$ & $\begin{array}{l}\text { Associação positiva e } \\
\text { não significante entre o } \\
\text { desfecho e os níveis de } \\
\text { Carbono Elementar e } \\
\mathrm{MP}_{2,5} \text { e morar próximo a } \\
\text { vias de alto tráfego. }\end{array}$ \\
\hline $\begin{array}{l}\text { Bellen et al., } \\
2008 b\end{array}$ & $\begin{array}{l}\text { Holanda; } \\
\text { 1987-1996; } \\
\text { coorte } \\
\text { prospectiva }\end{array}$ & $\begin{array}{l}\text { Incidência } \\
\text { de Câncer } \\
\text { de Pulmão }\end{array}$ & $\begin{array}{l}2183 \\
\text { (coorte) e } \\
1295 \\
\text { (caso- } \\
\text { coorte) }\end{array}$ & $\begin{array}{l}\mathrm{NO}_{2}, \mathrm{SO}_{2}, \\
\mathrm{MP}_{2,5}, \\
\text { Carbono } \\
\text { Elementar; } \\
\text { medidas } \\
\text { de } \\
\text { intensidad } \\
\text { e de } \\
\text { tráfego }\end{array}$ & $\begin{array}{l}\text { Associação negativa e } \\
\text { não significante entre o } \\
\text { desfecho e os níveis dos } \\
\text { poluentes. Associação } \\
\text { positiva } \\
\text { significante entre não } \\
\text { desfecho e o morar } \\
\text { próximo a vias de alto } \\
\text { tráfego. }\end{array}$ \\
\hline $\begin{array}{l}\text { Yanagi, } \\
2010\end{array}$ & $\begin{array}{l}11 \text { Distritos } \\
\text { do município } \\
\text { de São } \\
\text { Paulo, Brasil; } \\
\text { 1997-2005; } \\
\text { ecológico }\end{array}$ & $\begin{array}{l}\text { Incidência e } \\
\text { Mortalidade } \\
\text { por diversos } \\
\text { tipos de } \\
\text { Câncer }\end{array}$ & $\begin{array}{l}36534 \\
\text { casos de } \\
\text { Câncer; } \\
12934 \\
\text { mortes por } \\
\text { Câncer }\end{array}$ & $M P_{10}$ & $\begin{array}{l}\text { Associação positiva e } \\
\text { significante entre a } \\
\text { incidência por câncer de } \\
\text { pele e de pulmão e a } \\
\text { mortalidade por câncer } \\
\text { de pulmão e os níveis de } \\
\text { MP }_{10 .}\end{array}$ \\
\hline
\end{tabular}

EUA: Estados Unidos da América; HPA: Hidrocarbonetos Policíclicos Aromáticos; PTS: Partículas Totais em Suspensão; $\mathrm{MP}_{2,5}$ : Material Particulado inalável com diâmetro aerodinâmico menor que 2,5 $\mu \mathrm{m} ; \mathrm{MP}_{2,5-10}$ : Material Particulado inalável com diâmetro aerodinâmico maior que 2,5 $\mu \mathrm{m}$ e menor que $10 \mu \mathrm{m} ; \mathrm{MP}_{2,5-15}$ : Material Particulado inalável com diâmetro aerodinâmico maior que 2,5 $\mu \mathrm{m}$ e menor que $15 \mu \mathrm{m} ; \mathrm{MP}_{10}$ : Material Particulado inalável com diâmetro aerodinâmico menor que 10 $\mu \mathrm{m}$; $\mathrm{NO}_{2}$ : Dióxido de Nitrogênio; $\mathrm{NOx}$ : Óxidos de Nitrogênio; $\mathrm{O}_{3}$ : Ozônio; $\mathrm{SO}_{2}$ : Dióxido de Enxofre; $\mathrm{SO}_{4}$ : Sulfato; TGI: Trato Gastrintestinal.

Foram selecionados no total dezesseis estudos que tratavam dos efeitos da poluição do ar sobre o risco de câncer na infância ou adolescência. A maioria deles foi realizada nos Estados Unidos da América (sete), especialmente no estado da Califórnia (cinco), quatro no Reino Unido e um na Dinamarca, Itália, França, Holanda e Taiwan. Portanto, sete estudos feitos na América do Norte, oito na Europa e um em Taiwan.

Nove deles eram caso-controle, seis ecológicos e um se valeu dos dois desenhos. Três estudos ecológicos utilizaram análise de migração. $O$ número de casos nos estudos caso-controle variou de 97 a 1728 incidentes de leucemia, o tipo de câncer mais investigado.

Quanto aos métodos de exposição utilizados, onze fizeram uso de modelos de proximidade da fonte poluente, quatro de modelos de dispersão, um da média aritmética da concentração do poluente medido por estação de monitoramento do ar, para determinada unidade geográfica de estudo. As 
medidas de exposição utilizadas foram as de tráfego as mais diversas e as concentrações de benzeno, $\mathrm{NO}_{2}$ e 1,3-butadieno. Os desfechos investigados foram: incidência ou mortalidade por câncer em geral, leucemia ou leucemia aguda e seus subtipos linfóide aguda e mielóide aguda, linfoma e seus subtipos não Hodgkin e doença de Hodgkin, e neoplasias do SNC.

Sendo o câncer na faixa etária infantil e adolescente, mesmo os seus tipos mais comuns, de ocorrência relativamente rara na atualidade em comparação com certos tipos de câncer no adulto, estudos de coorte visando investigar o papel da poluição do ar sobre esse desfecho na infância são operacionalmente complexos e de custos muito elevados, apesar de seu menor tempo de latência. Provavelmente, devido a esses fatores, entre outros, não encontramos na literatura científica sobre o assunto em questão estudos de coorte, mas somente estudos nos formatos caso-controle e ecológico.

Além disso, a maioria das investigações sobre o assunto utiliza-se ainda de modelos de proximidade com a fonte poluente, o que revela 0 estágio inicial e exploratório em que se encontra sua literatura (JERRET et al., 2005a). Porém, gradativamente, os estudos vêm se utilizando das medidas de concentração de poluentes e de métodos de avaliação da exposição mais complexos, revelando que é possível que tal estágio já se encontre em seu final (JERRET et al., 2005a).

Deve-se destacar a dificuldade de se comparar os resultados dos estudos sobre o câncer na faixa etária infantil e adolescente, devido a diferenças no desenho, nas condições locais, nos métodos de avaliação da exposição e desfechos investigados. De modo geral, a maioria dos estudos demonstrou associação positiva entre as medidas de exposição e a incidência de leucemia ou algum dos seus subtipos de modo significante (três estudos) ou não (seis). Entretanto, três estudos demonstraram ausência ou associação negativa da exposição com esse desfecho. Os dois únicos estudos caso-controle que se valeram de modelos de dispersão para avaliar a exposição apresentaram resultados discordantes quanto a esse desfecho (RAASCHOU-NIELSEN et al., 2001; CROSIGNANI et al., 2004), 
sendo que o que mostrou ausência de associação foi o único com modelo de exposição validado (RAASCHOU-NIELSEN et al., 2001). A incidência de câncer em geral mostrou associação positiva significante (um estudo) ou não (dois) e associação negativa (dois) em relação à exposição ao tráfego.

Outros desfechos estudados foram a mortalidade por câncer em geral, com risco elevado nos três estudos de KNOX (2005a, 2005b, 2006); mortalidade por leucemia aguda, com achado positivo e significante no estudo de WENG et al. (2008); incidência de neoplasias do SNC, com risco elevado não significante em dois estudos e ausência ou associação negativa em outros dois; e a incidência de linfoma de Hodgkin, com achados positivos não significantes nos dois estudos que o investigaram.

Portanto, os dois desfechos mais estudados, incidência de câncer em geral e de leucemia e seus subtipos, demonstraram resultados inconsistentes. Novos estudos com métodos de exposição sofisticados são necessários para melhor se avaliar a sua associação potencial com a exposição ao tráfego. Quanto aos outros desfechos, poucos estudos estão disponíveis para se chegar a qualquer conclusão.

O quadro 4 a seguir contêm as principais informações dos estudos revisados, publicados entre 1998 e 2008, que tratam dos efeitos da poluição do ar sobre o risco de câncer em crianças e adolescentes. Informações adicionais sobre número de participantes e casos, métodos e medidas de exposição, resultados e ajustes para potenciais variáveis de confusão nos estudos revisados estão contidas no quadro e texto do ANEXO 4. 
Quadro 4 - Relação de estudos sobre os efeitos da poluição do ar sobre o risco de câncer em crianças e adolescentes. 1998-2008.

\begin{tabular}{|c|c|c|c|c|c|}
\hline $\begin{array}{c}\text { Autores e } \\
\text { ano de } \\
\text { publicação }\end{array}$ & $\begin{array}{c}\text { Local, período e } \\
\text { desenho do } \\
\text { estudo }\end{array}$ & $\begin{array}{l}\text { Desfecho(s) } \\
\text { estudado(s) }\end{array}$ & $\begin{array}{c}\text { Número de } \\
\text { casos e } \\
\text { controles } \\
\end{array}$ & $\begin{array}{c}\text { Medidas } \\
\text { de } \\
\text { exposição } \\
\end{array}$ & Resultados \\
\hline $\begin{array}{l}\text { Harrison et } \\
\text { al.; } 1999\end{array}$ & $\begin{array}{l}\text { Região de West } \\
\text { Midlands, Reino } \\
\text { Unido; } 1990- \\
\text { 1994; caso- } \\
\text { controle de base } \\
\text { populacional e } \\
\text { ecológico }\end{array}$ & $\begin{array}{l}\text { Incidência } \\
\text { de Leucemia }\end{array}$ & $\begin{array}{l}130 \text { casos e } \\
251 \\
\text { controles }\end{array}$ & $\begin{array}{l}\text { Medida de } \\
\text { intensidade } \\
\text { de tráfego }\end{array}$ & $\begin{array}{l}\text { Associação } \\
\text { positiva e não } \\
\text { significante entre o } \\
\text { desfecho e a } \\
\text { proximidade da } \\
\text { residência a vias } \\
\text { de alto tráfego }\end{array}$ \\
\hline $\begin{array}{l}\text { Pearson et } \\
\text { al., } 2000\end{array}$ & $\begin{array}{l}\text { Área } \\
\text { metropolitana de } \\
\text { Denver, EUA; } \\
\text { 1976-1983; caso- } \\
\text { controle de base } \\
\text { populacional }\end{array}$ & $\begin{array}{l}\text { Incidência } \\
\text { de Câncer } \\
\text { em geral e } \\
\text { Leucemia }\end{array}$ & $\begin{array}{l}320 \text { casos } \\
\text { de Câncer } \\
(97 \text { casos } \\
\text { de } \\
\text { Leucemia) e } \\
259 \\
\text { controles }\end{array}$ & $\begin{array}{l}\text { Medida de } \\
\text { intensidade } \\
\text { de tráfego }\end{array}$ & $\begin{array}{l}\text { Associação } \\
\text { positiva } \\
\text { significante entre } \\
\text { câncer e leucemia } \\
\text { e a proximidade } \\
\text { da residência a } \\
\text { vias de alto } \\
\text { tráfego, } \\
\text { gradiente }\end{array}$ \\
\hline $\begin{array}{l}\text { Raaschou- } \\
\text { Nielsen et } \\
\text { al., } 2001\end{array}$ & $\begin{array}{l}\text { Dinamarca; } \\
\text { 1968-1991; caso- } \\
\text { controle de base } \\
\text { populacional }\end{array}$ & $\begin{array}{l}\text { Incidência } \\
\text { de Câncer } \\
\text { em geral, } \\
\text { Leucemia, } \\
\text { Neoplasias } \\
\text { do SNC e } \\
\text { Linfoma }\end{array}$ & $\begin{array}{l}1989 \text { casos } \\
\text { de Câncer } \\
(986 \text { de } \\
\text { Leucemia, } \\
740 \text { do SNC } \\
\text { e } 263 \text { de } \\
\text { Linfoma) e } \\
5506 \\
\text { controles. }\end{array}$ & $\begin{array}{l}\mathrm{NO}_{2}, \\
\text { benzeno e } \\
\text { medida de } \\
\text { intensidade } \\
\text { de tráfego }\end{array}$ & $\begin{array}{lr}\text { Ausência } & \text { da } \\
\text { associação entre } \\
\text { câncer, leucemia e } \\
\text { neoplasias do } \\
\text { SNC e as medidas } \\
\text { de exposição. } \\
\text { Associação } \\
\text { positiva } \\
\text { significante entre } \\
\text { linfoma } \\
\text { Hodgkin e os } \\
\text { níveis de } \mathrm{NO}_{2} \text { e de } \\
\text { benzeno, } \\
\text { gradiente }\end{array}$ \\
\hline $\begin{array}{l}\text { Langholz et } \\
\text { al., } 2002\end{array}$ & $\begin{array}{l}\text { Los Angeles, } \\
\text { EUA; 1978-1984; } \\
\text { caso-controle de } \\
\text { base } \\
\text { populacional }\end{array}$ & $\begin{array}{l}\text { Incidência } \\
\text { de Leucemia }\end{array}$ & $\begin{array}{l}212 \text { casos e } \\
202 \\
\text { controles }\end{array}$ & $\begin{array}{l}\text { Medida de } \\
\text { intensidade } \\
\text { de tráfego }\end{array}$ & $\begin{array}{l}\text { Associação } \\
\text { positiva e não } \\
\text { significante entre o } \\
\text { desfecho e a } \\
\text { proximidade da } \\
\text { residência a vias } \\
\text { de alto tráfego, } \\
\text { sem gradiente }\end{array}$ \\
\hline $\begin{array}{l}\text { Reynolds et } \\
\text { al., } 2002\end{array}$ & $\begin{array}{l}\text { Estado } \quad \text { da } \\
\text { Califórnia, EUA; } \\
\text { 1988-1994; } \\
\text { ecológico }\end{array}$ & $\begin{array}{l}\text { Incidência } \\
\text { de Câncer, } \\
\text { Leucemia e } \\
\text { Glioma }\end{array}$ & $\begin{array}{l}6988 \text { casos } \\
\text { de Câncer, } \\
2443 \text { de } \\
\text { Leucemia e } \\
1351 \text { de } \\
\text { Glioma }\end{array}$ & $\begin{array}{l}\text { Medidas de } \\
\text { intensidade } \\
\text { de tráfego }\end{array}$ & \begin{tabular}{lr}
\multicolumn{2}{l}{ Associação } \\
positiva e & não \\
significante & entre \\
incidência & de \\
câncer, leucemia e \\
glioma e \\
densidade \\
tráfego, \\
gradiente
\end{tabular} \\
\hline $\begin{array}{l}\text { Reynolds et } \\
\text { al., } 2003\end{array}$ & $\begin{array}{l}\text { Estado } \quad \text { da } \\
\text { Califórnia, EUA; } \\
\text { 1988-1994; } \\
\text { ecológico }\end{array}$ & $\begin{array}{l}\text { Incidência } \\
\text { de Câncer, } \\
\text { Leucemia e } \\
\text { Glioma }\end{array}$ & $\begin{array}{l}6989 \text { casos } \\
\text { de Câncer, } \\
2443 \text { de } \\
\text { Leucemia e } \\
1351 \text { de } \\
\text { Glioma }\end{array}$ & $\begin{array}{l}25 \\
\text { poluentes } \\
\text { combinado } \\
\mathrm{s}\end{array}$ & $\begin{array}{lr}\text { Associação } \\
\text { positiva e não } \\
\text { significante entre } \\
\text { os desfechos e os } \\
\text { níveis } \\
\text { exposição } \\
\text { poluentes, } \\
\text { gradiente }\end{array}$ \\
\hline
\end{tabular}




\begin{tabular}{|c|c|c|c|c|c|}
\hline $\begin{array}{l}\text { Crosignani } \\
\text { et al., } 2004\end{array}$ & $\begin{array}{l}\text { Província de } \\
\text { Varese, Itália; } \\
\text { 1978-1997; caso- } \\
\text { controle de base } \\
\text { populacional }\end{array}$ & $\begin{array}{l}\text { Incidência } \\
\text { de Leucemia }\end{array}$ & $\begin{array}{l}120 \text { casos e } \\
480 \\
\text { controles }\end{array}$ & $\begin{array}{l}\text { Benzeno e } \\
\text { medida de } \\
\text { intensidade } \\
\text { de tráfego }\end{array}$ & $\begin{array}{l}\text { Associação } \\
\text { positiva } \\
\text { significante entre o } \\
\text { desfecho e a } \\
\text { proximidade da } \\
\text { residência a vias } \\
\text { de alto tráfego e } \\
\text { os níveis de } \\
\text { benzeno, com } \\
\text { gradiente }\end{array}$ \\
\hline $\begin{array}{l}\text { Reynolds et } \\
\text { al., } 2004\end{array}$ & $\begin{array}{l}\text { Estado da } \\
\text { Califórnia, EUA; } \\
\text { 1988-1997; caso- } \\
\text { controle de base } \\
\text { populacional }\end{array}$ & $\begin{array}{l}\text { Incidência } \\
\text { de Câncer } \\
\text { em geral, } \\
\text { Leucemia e } \\
\text { Neoplasias } \\
\text { do SNC }\end{array}$ & $\begin{array}{lr}4396 & \text { casos } \\
\text { de Câncer } \\
(1728 \text { de } \\
\text { Leucemia e } \\
746 \text { do } \\
\text { SNC) re } \\
8730 \\
\text { controles }\end{array}$ & $\begin{array}{l}\text { Medidas de } \\
\text { intensidade } \\
\text { de tráfego }\end{array}$ & $\begin{array}{lr}\text { Associação } \\
\text { negativa não } \\
\text { significante entre } \\
\text { câncer e leucemia } \\
\text { e as medidas de } \\
\text { exposição. } \\
\text { Associação } \\
\text { positiva e não } \\
\text { significante entre } \\
\text { neoplasias } \\
\begin{array}{l}\text { SNC do } \\
\text { densidade } \\
\text { tráfego, de } \\
\text { gradiente }\end{array} \\
\end{array}$ \\
\hline $\begin{array}{l}\text { Steffen } \\
\text { al., } 2004\end{array}$ & $\begin{array}{ll}\text { Nancy, } & \text { Lille, } \\
\text { Lyon e } & \text { Paris, } \\
\text { França; } & 1995- \\
\text { 1999; } & \text { caso- } \\
\text { controle de base } \\
\text { hospitalar }\end{array}$ & $\begin{array}{l}\text { Incidência } \\
\text { de Leucemia } \\
\text { Aguda }\end{array}$ & $\begin{array}{l}280 \text { casos e } \\
285 \\
\text { controles }\end{array}$ & $\begin{array}{l}\text { Medida de } \\
\text { intensidade } \\
\text { de tráfego }\end{array}$ & $\begin{array}{l}\text { Ausência } \\
\text { associação entre } \\
\text { o desfecho e a } \\
\text { proximidade da } \\
\text { residência a vias } \\
\text { de alto tráfego }\end{array}$ \\
\hline $\begin{array}{l}\text { Visser et al., } \\
2004\end{array}$ & $\begin{array}{l}\text { Amsterdã, } \\
\text { Holanda; 1989- } \\
\text { 1997; ecológico }\end{array}$ & $\begin{array}{l}\text { Incidência } \\
\text { de Câncer } \\
\text { em geral e } \\
\text { dos seus } \\
\text { principais } \\
\text { grupos }\end{array}$ & $\begin{array}{l}5 \text { casos de } \\
\text { Leucemia } \\
\text { Linfóide } \\
\text { Aguda }\end{array}$ & $\begin{array}{l}\text { Medida de } \\
\text { intensidade } \\
\text { de tráfego }\end{array}$ & $\begin{array}{l}\text { Associação } \\
\text { positiva e não } \\
\text { significante entre } \\
\text { neoplasias } \\
\text { hematológicas e } \\
\text { Leucemia Linfóide } \\
\text { Aguda e a } \\
\text { proximidade da } \\
\text { residência a vias } \\
\text { de alto tráfego }\end{array}$ \\
\hline Knox, 2005a & $\begin{array}{l}\text { Reino Unido; } \\
\text { 1966-1980; } \\
\text { ecológico }\end{array}$ & $\begin{array}{l}\text { Mortalidade } \\
\text { por Câncer } \\
\text { em geral }\end{array}$ & $\begin{array}{l}11312 \\
\text { casos }\end{array}$ & $\begin{array}{l}\text { Distância } \\
\text { da } \\
\text { residência } \\
\text { a fontes de } \\
\mathrm{CO}, \mathrm{MP}_{10}, \\
\mathrm{NO}_{\mathrm{x}} \mathrm{e} 1,3- \\
\text { butadieno }\end{array}$ & $\begin{array}{l}\text { Associação } \\
\text { positiva entre o } \\
\text { desfecho e a } \\
\text { proximidade da } \\
\text { residência a tais } \\
\text { fontes } \\
\text { poluentes }\end{array}$ \\
\hline Knox, 2005b & $\begin{array}{l}\text { Reino Unido; } \\
\text { 1955-1980; } \\
\text { ecológico }\end{array}$ & $\begin{array}{l}\text { Mortalidade } \\
\text { por Câncer } \\
\text { em geral }\end{array}$ & $\begin{array}{l}12018 \\
\text { casos }\end{array}$ & $\begin{array}{l}\text { Distância } \\
\text { da } \\
\text { residência } \\
\text { a rodovias } \\
\text { de alto } \\
\text { tráfego }\end{array}$ & $\begin{array}{lr}\text { Ausência } & \text { de } \\
\text { associação entre o } \\
\text { desfecho e a } \\
\text { proximidade da } \\
\text { residência } \\
\text { rodovias de alto } \\
\text { tráfego }\end{array}$ \\
\hline Knox, 2006 & $\begin{array}{l}\text { Reino Unido; } \\
\text { 1955-1980; } \\
\text { ecológico }\end{array}$ & $\begin{array}{l}\text { Mortalidade } \\
\text { por Câncer } \\
\text { em geral }\end{array}$ & $\begin{array}{l}12017 \\
\text { casos }\end{array}$ & $\begin{array}{l}\text { Distância } \\
\text { da } \\
\text { residência } \\
\text { a rodovias } \\
\text { de } \\
\text { intensidade } \\
\text { variada de } \\
\text { tráfego }\end{array}$ & $\begin{array}{l}\text { Associação } \\
\text { positiva } \\
\text { significante entre o } \\
\text { desfecho e a } \\
\text { proximidade } \\
\text { residência } \\
\text { rodovias a } \\
\text { moderada intensi- } \\
\text { dade de tráfego }\end{array}$ \\
\hline
\end{tabular}




\begin{tabular}{|c|c|c|c|c|c|}
\hline $\begin{array}{l}\text { Von Behren } \\
\text { et al., } 2008\end{array}$ & $\begin{array}{l}\text { Estado da } \\
\text { Califórnia, EUA; } \\
\text { 1995-2002; caso- } \\
\text { controle de base } \\
\text { populacional }\end{array}$ & $\begin{array}{l}\text { Incidência } \\
\text { de Leucemia } \\
\text { Linfoblástica } \\
\text { Aguda }\end{array}$ & $\begin{array}{l}310 \text { casos e } \\
396 \\
\text { controles }\end{array}$ & $\begin{array}{l}\text { Medida de } \\
\text { intensidade } \\
\text { de tráfego }\end{array}$ & $\begin{array}{l}\text { Associação } \\
\text { positiva e não } \\
\text { significante entre o } \\
\text { desfecho e a } \\
\text { proximidade da } \\
\text { residência a vias } \\
\text { de alto tráfego, } \\
\text { sem gradiente } \\
\text { para a maioria dos } \\
\text { períodos de } \\
\text { exposição }\end{array}$ \\
\hline $\begin{array}{l}\text { Whitworth et } \\
\text { al., } 2008\end{array}$ & $\begin{array}{l}8 \text { condados do } \\
\text { nordeste } \\
\text { estado do Texas, } \\
\text { EUA; 1995-2004; } \\
\text { ecológico }\end{array}$ & $\begin{array}{l}\text { Incidência } \\
\text { de } \\
\text { Leucemia, } \\
\text { LLA, LMA e } \\
\text { Linfoma }\end{array}$ & $\begin{array}{l}670 \text { casos } \\
\text { de } \\
\text { Leucemia, } \\
510 \text { de LLA, } \\
92 \text { de LMA, } \\
283 \text { de } \\
\text { Linfoma }\end{array}$ & $\begin{array}{l}\text { Benzeno e } \\
\text { 1,3- } \\
\text { butadieno }\end{array}$ & $\begin{array}{l}\text { Associação } \\
\text { positiva } \\
\text { significante entre } \\
\text { leucemia e LMA e } \\
\text { os níveis de } \\
\text { benzeno, e entre } \\
\text { leucemia e os } \\
\text { níveis de } \\
\text { butadieno. } \\
\text { Gradiente dose- } \\
\text { resposta para } \\
\text { leucemia }\end{array}$ \\
\hline $\begin{array}{l}\text { Weng et al., } \\
2008\end{array}$ & $\begin{array}{l}\text { Taiwan; } 1995- \\
2005 ; \quad \text { caso- } \\
\text { controle de base } \\
\text { populacional }\end{array}$ & $\begin{array}{l}\text { Mortalidade } \\
\text { por } \\
\text { Leucemia }\end{array}$ & $\begin{array}{l}308 \text { casos e } \\
308 \\
\text { controles }\end{array}$ & $\mathrm{NO}_{2}$ & $\begin{array}{l}\text { Associação } \\
\text { positiva } \\
\text { significante entre o } \\
\text { desfecho e os } \\
\text { níveis de } \mathrm{NO}_{2}, \\
\text { com gradiente }\end{array}$ \\
\hline
\end{tabular}

EUA: Estados Unidos da América; LLA: Leucemia Linfoblástica Aguda; LMA: Leucemia Mielóide Aguda

\subsection{ESTUDO ECOLÓGICO}

A qualidade do ar na cidade de São Paulo já atingiu níveis muito elevados de concentração de poluentes e apesar de melhoras observadas na última década, as concentrações médias anuais ainda superam os valores recomendados pela OMS para efeitos de longo prazo, como pode ser observado nas figuras 1,2 e 3 , para os poluentes $\mathrm{MP}_{2,5}, \mathrm{MP}_{10}$ e $\mathrm{NO}_{2}$ respectivamente.

Pode ser observada uma tendência temporal de queda contínua nas concentrações de todos os poluentes. Para $\circ \mathrm{MP}_{2,5}$, com medições sistemáticas por apenas três estações de monitoramento do ar no município, as suas concentrações diminuíram de $24 \mu \mathrm{g} / \mathrm{m}^{3}$ em 2000 para cerca de 20 
$\mu \mathrm{g} / \mathrm{m}^{3}$ em 2006. Entretanto, este valor é ainda o dobro do preconizado pelas últimas recomendações da WHO (2005), que é de $10 \mu \mathrm{g} / \mathrm{m}^{3}$. Os dois outros poluentes foram medidos por um número bem maior de estações de monitoramento do ar, especialmente o $\mathrm{MP}_{10}$, cujas concentrações caíram de $61 \mu \mathrm{g} / \mathrm{m}^{3}$ em 1997 para quase $39 \mu \mathrm{g} / \mathrm{m}^{3}$ em 2008, quase o dobro ainda do recomendado pela mesma organização $\left(20 \mu \mathrm{g} / \mathrm{m}^{3}\right)$. Já o $\mathrm{NO}_{2}$ teve suas concentrações diminuídas de $68 \mu \mathrm{g} / \mathrm{m}^{3}$ em 1997 para pouco mais de 45 $\mu \mathrm{g} / \mathrm{m}^{3}$ em 2008, um pouco acima do recomendado $\left(40 \mu \mathrm{g} / \mathrm{m}^{3}\right)$.

Figura 1 - Tendência temporal da concentração média anual de $\mathrm{MP}_{2,5}$ (em $\mu \mathrm{g} / \mathrm{m}^{3}$ ). Município de São Paulo, 2000-2006.

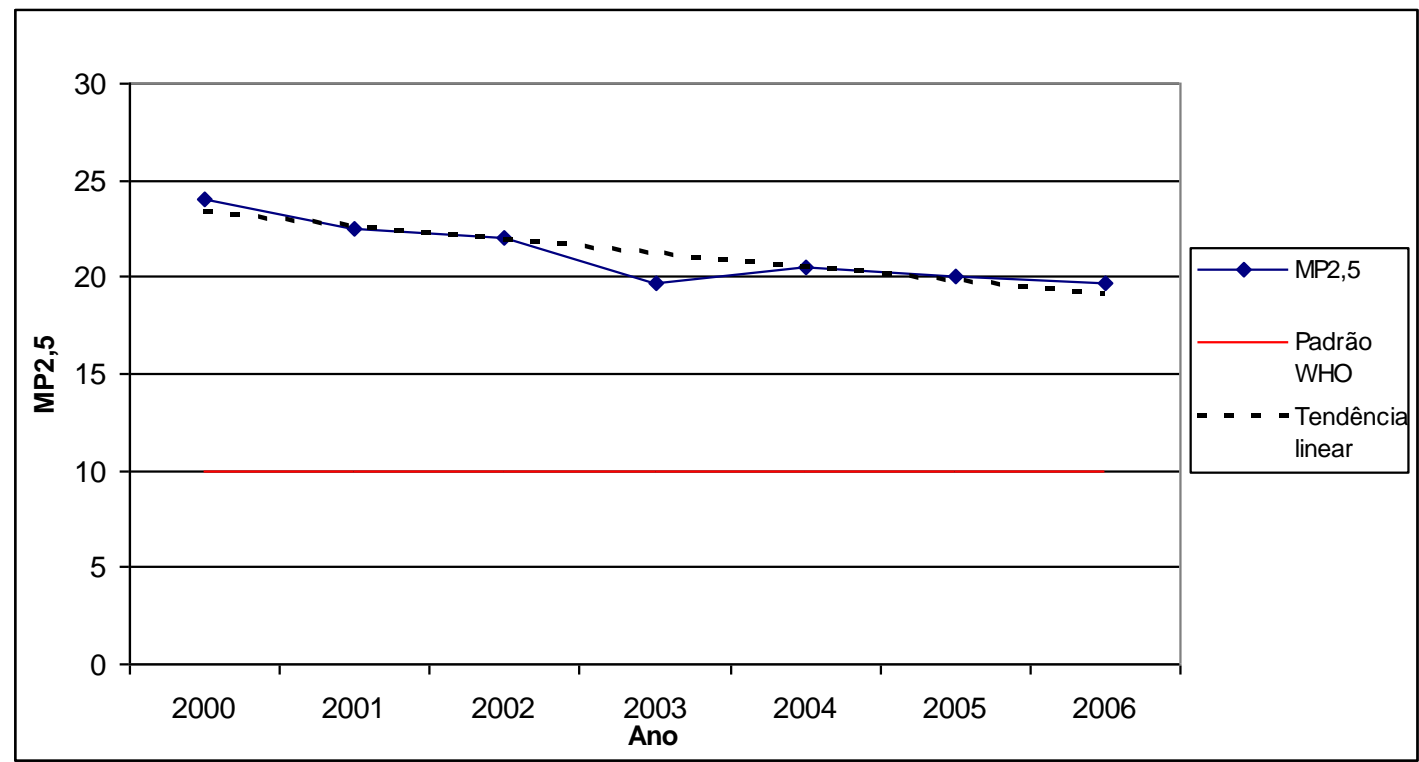

MP2,5: Material particulado inalável dom diâmetro aerodinâmico menor que $2,5 \mu \mathrm{g} / \mathrm{m}^{3}$; Padrão WHO: concentração anual média máxima recomendada pela World Health Organization (WHO, 2005).

Fonte: CETESB, 2000-2006 
Figura 2 - Tendência temporal da concentração média anual de $\mathrm{MP}_{10}(\mathrm{em}$ $\left.\mu \mathrm{g} / \mathrm{m}^{3}\right)$. Município de São Paulo, 1997-2008.

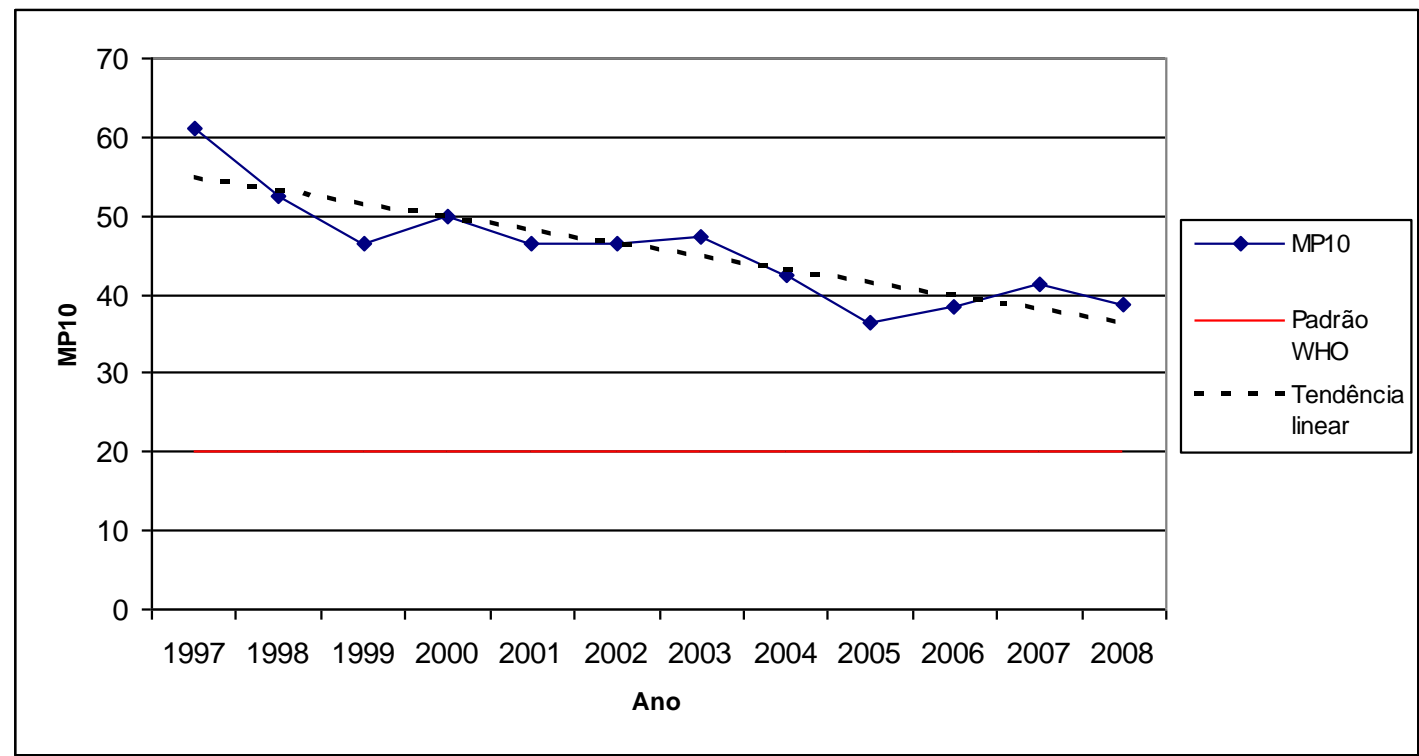

MP10: Material particulado inalável com diâmetro aerodinâmico menor que $10 \mu \mathrm{g} / \mathrm{m}^{3}$; Padrão WHO: concentração média anual máxima recomendada pela World Health Organization (WHO, 2005).

Fonte: CETESB, 1997-2008

Figura 3 - Tendência temporal da concentração média anual de $\mathrm{NO}_{2}$ (em $\mu \mathrm{g} / \mathrm{m}^{3}$ ). Município de São Paulo, 1997-2008.

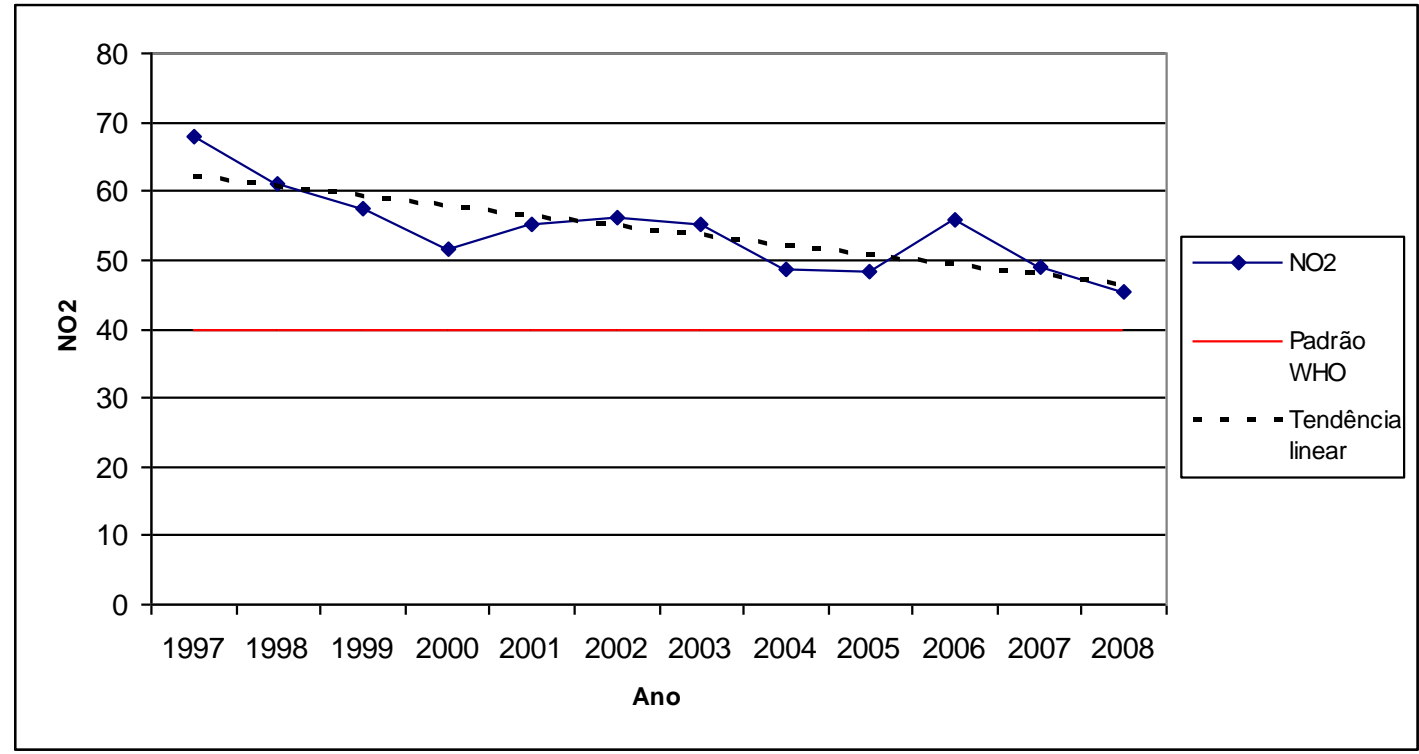

NO2: dióxido de nitrogênio; Padrão WHO: concentração média anual máxima recomendada pela World Health Organization (WHO, 2005).

Fonte: CETESB, 1997-2008 
Na tabela 1, observam-se os resultados dos testes de correlação de Spearman feitos para as concentrações médias anuais de $\mathrm{MP}_{10}$ obtidas de 7 estações de monitoramento do ar do município que continham dados desse poluente para todos os anos do período de 1997 a 2008. As concentrações médias do poluente de vários anos apresentaram correlação forte $(r>0,7)$ e significante $(p<0.05)$ ou marginalmente significante $(p<0,10)$ entre diversos pares de anos, ainda que temporalmente distantes.

Tabela 1 - Matriz de correlação das concentrações médias anuais de $\mathrm{MP}_{10}$. Município de São Paulo, 1997-2008.

\begin{tabular}{|c|c|c|c|c|c|c|c|c|c|c|c|c|}
\hline & 1997 & 1998 & 1999 & 2000 & 2001 & 2002 & 2003 & 2004 & 2005 & 2006 & 2007 & 2008 \\
\hline 1997 & 1 & & & & & & & & & & & \\
\hline 1998 & 0,54 & 1 & & & & & & & & & & \\
\hline 1999 & 0,65 & 0,64 & 1 & & & & & & & & & \\
\hline 2000 & $\underset{* \star}{0,71}$ & 0,42 & $\underset{* \star}{0,91}$ & 1 & & & & & & & & \\
\hline 2001 & $\underset{* *}{0,74}$ & $\underset{* \star}{0,85}$ & $\underset{* *}{0,90}$ & $\underset{* *}{0,77}$ & 1 & & & & & & & \\
\hline 2002 & 0,49 & 0,52 & $\underset{* *}{0,82}$ & $\underset{* *}{0,87}$ & $\underset{* *}{0,72}$ & 1 & & & & & & \\
\hline 2003 & $\underset{*}{0,64}$ & 0,36 & $\underset{* *}{0,74}$ & $\underset{* *}{0,84}$ & 0,55 & $\underset{* *}{0,81}$ & 1 & & & & & \\
\hline 2004 & 0,50 & 0,60 & 0,39 & 0,43 & 0,47 & 0,33 & 0,43 & 1 & & & & \\
\hline 2005 & 0,20 & 0,57 & 0,29 & 0,36 & 0,44 & 0,57 & 0,22 & 0,62 & 1 & & & \\
\hline 2006 & $\underset{*}{0,70}$ & 0,93 & 0,62 & 0,48 & $\underset{* *}{0,87}$ & 0,56 & 0,38 & 0,48 & 0,56 & 1 & & \\
\hline 2007 & $\underset{\star}{0,64}$ & 0,38 & $\underset{* *}{0,79}$ & $\underset{\star *}{0,84}$ & $\underset{* *}{0,73}$ & 0,59 & 0,47 & 0,47 & 0,38 & 0,42 & 1 & \\
\hline 2008 & 0,31 & 0,28 & $\underset{*}{0,68}$ & $\underset{* *}{0,81}$ & 0,49 & $\underset{* *}{0,77}$ & $\underset{*}{0,61}$ & 0,56 & 0,60 & 0,20 & $\underset{* *}{0,77}$ & 1 \\
\hline
\end{tabular}

${ }^{* *} p<0,05 ;{ }^{*} p<0,10$

Fonte: CETESB, 1997-2008

Para o cálculo da densidade de tráfego, o município de São Paulo foi dividido em 6385 unidades geográficas pela grid de 500 por 500 metros e a tabela 2 apresenta os dados descritivos dos parâmetros calculados. A média e a mediana de IDH-M são quase coincidentes, com uma distribuição tendendo à curva de normalidade. Por outro lado, grande parte das células geográficas apresenta densidade de tráfego total e por categorias de combustível com valores próximos ou iguais a 0 , o que é sobretudo devido a 
regiões geográficas de baixa densidade populacional localizadas nos extremos das periferias. A figura 4 mostra a distribuição em histograma de freqüência da densidade veicular total, corroborando o referido acima. Para as categorias por combustível, os histogramas são semelhantes a este e por isso não foram mostrados.

Tabela 2 - Percentis, valores mínimo e máximo, média e desvio padrão de população, IDH-M e indicadores de tráfego por célula da grid. Município de São Paulo.

\begin{tabular}{|c|c|c|c|c|c|c|c|c|c|}
\hline Variáveis & $10 \%$ & $25 \%$ & $50 \%$ & $75 \%$ & $90 \%$ & $\operatorname{Min}^{a}$ & Máx & Média & $D P^{c}$ \\
\hline $\begin{array}{l}\text { População } \\
\text { total (2000) } \\
\text { (habitantes) }\end{array}$ & 4 & 30 & 717 & 2998 & 4466 & 0 & 14390 & 1629 & 1918 \\
\hline $\begin{array}{l}\text { IDH-M }^{\mathrm{d}} \\
(2000)\end{array}$ & 0,631 & 0,657 & 0,696 & 0,743 & 0,809 & 0 & 0,931 & 0,702 & 0,09 \\
\hline $\begin{array}{l}\text { Densidade } \\
\text { Veicular } \\
\text { Total }(2008) \\
\left(\mathrm{m} / \mathrm{m}^{2}\right)\end{array}$ & 0 & 0,483 & 4,300 & 9,640 & 23,896 & 0 & 163.03 & 8,772 & 14,243 \\
\hline $\begin{array}{l}\text { Densidade } \\
\text { Veicular a } \\
\text { Diesel (2008) } \\
\left(\mathrm{m} / \mathrm{m}^{2}\right)\end{array}$ & 0 & 0,095 & 0,924 & 2,042 & 4,082 & 0 & 20,655 & 1,510 & 2,036 \\
\hline $\begin{array}{l}\text { Densidade } \\
\text { Veicular a } \\
\text { Gasolina } \\
(2008)\left(\mathrm{m} / \mathrm{m}^{2}\right)\end{array}$ & 0 & 0,380 & 3,320 & 7,717 & 19,926 & 0 & 142,48 & 7,269 & 12,297 \\
\hline
\end{tabular}


Figura 4 - Histograma de freqüência de densidade veicular total por célula da grid. Município de São Paulo, 2008.

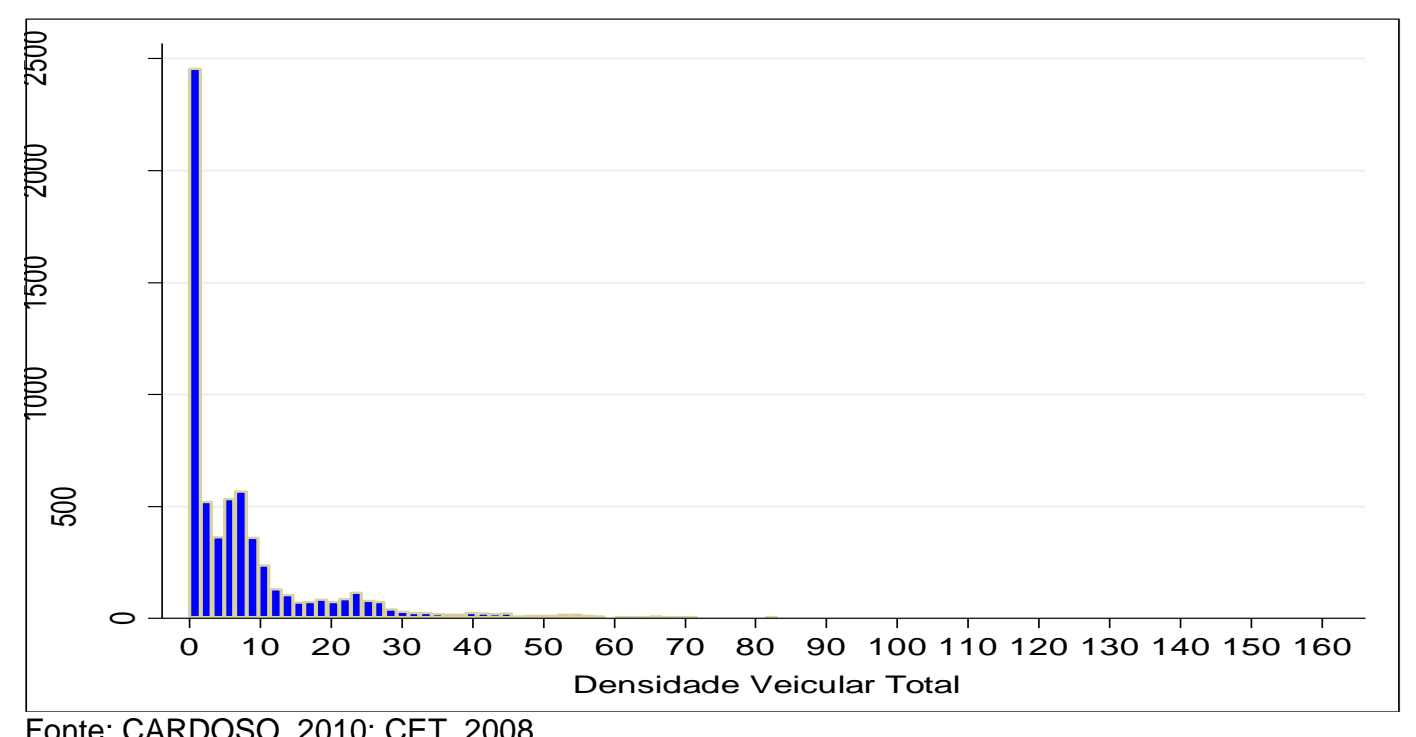

A seguir se visualizam as figuras 5, 6 e 7, que ilustram a variabilidade da densidade de tráfego total e de veículos movidos a diesel e a gasolina, por unidade da grid, no município de São Paulo.

$\mathrm{Na}$ figura 5 , observa-se que a densidade de tráfego total se concentra na região central do município, formando uma área quase contínua de alta densidade veicular. Dessa área partem formações lineares centrífugas correspondentes a avenidas e rodovias com alta circulação de veículos, em meio a uma grande área circular concêntrica de moderada intensidade de tráfego ao redor da primeira. Por fim, nos extremos das zonas norte, leste e sul, há regiões de baixa a muita baixa intensidade de tráfego, intercaladas entre si. Na zona sul, pode-se até distinguir uma rede de vias de baixa circulação em meio a uma área de tráfego ainda menor. Rodovias importantes cruzam essas regiões extremas, especialmente na zona norte. 
Figura 5 - Densidade de tráfego veicular total por célula da grid. Município de São Paulo, 2008.

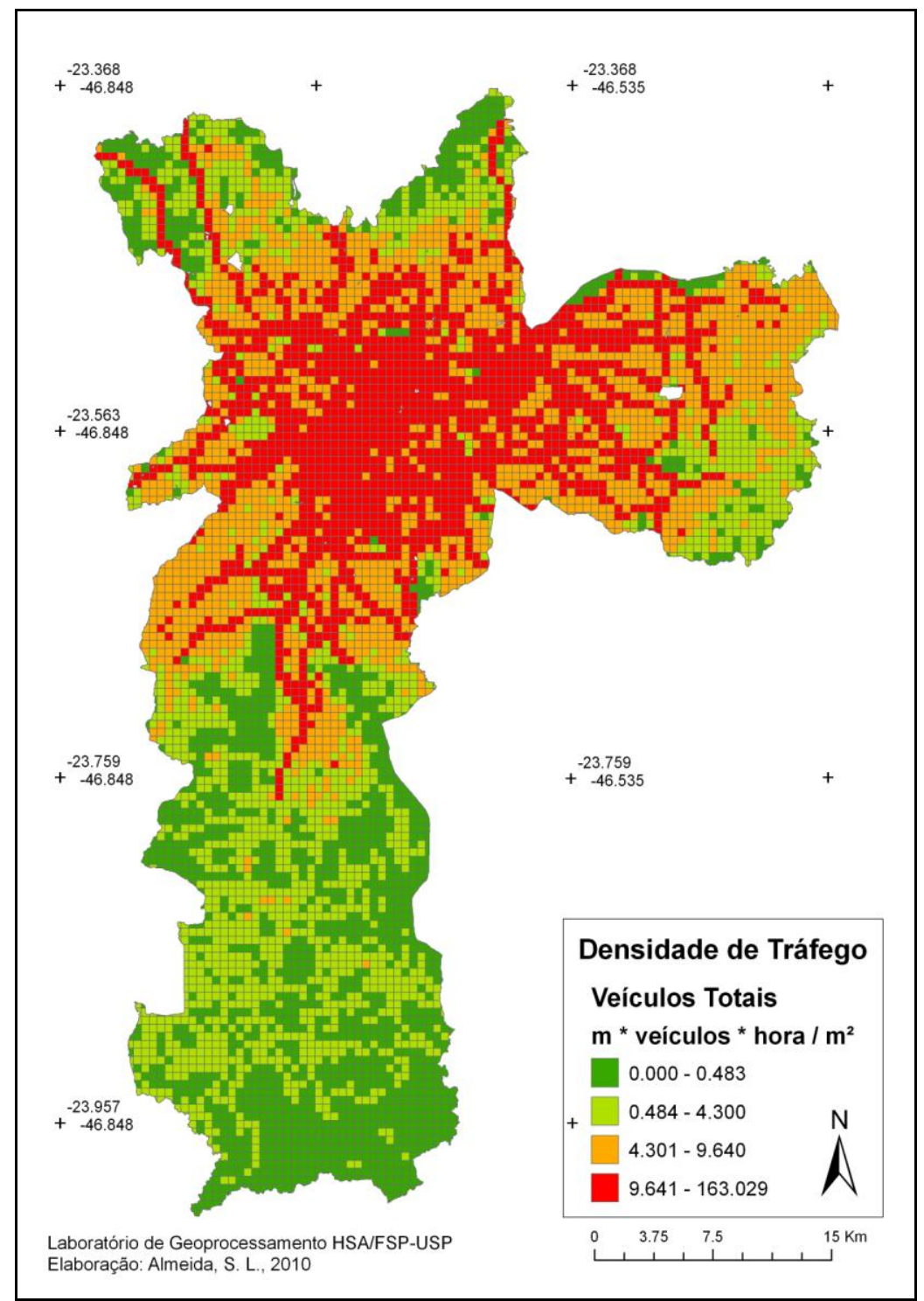

Fonte: CARDOSO, 2010; CET, 2008

A figura 6 mostra que a densidade veicular a diesel apresenta uma distribuição menos centralizada, com uma rede de alta densidade localizada na região central e na região concêntrica ao seu redor, em meio a uma área de moderada intensidade de tráfego, tornando tais regiões muito semelhantes entre si quanto a essa variável. Esse aspecto reticular, com múltiplas formações lineares, revela que o tráfego desses veículos se concentra em certas vias altamente utilizadas por eles. Nos extremos das 
zonas norte, leste e sul do município, o seu tráfego é bem menor, exceto nas rodovias que as cortam.

Figura 6 - Densidade de tráfego por veículos movidos a diesel por célula da grid. Município de São Paulo, 2008.

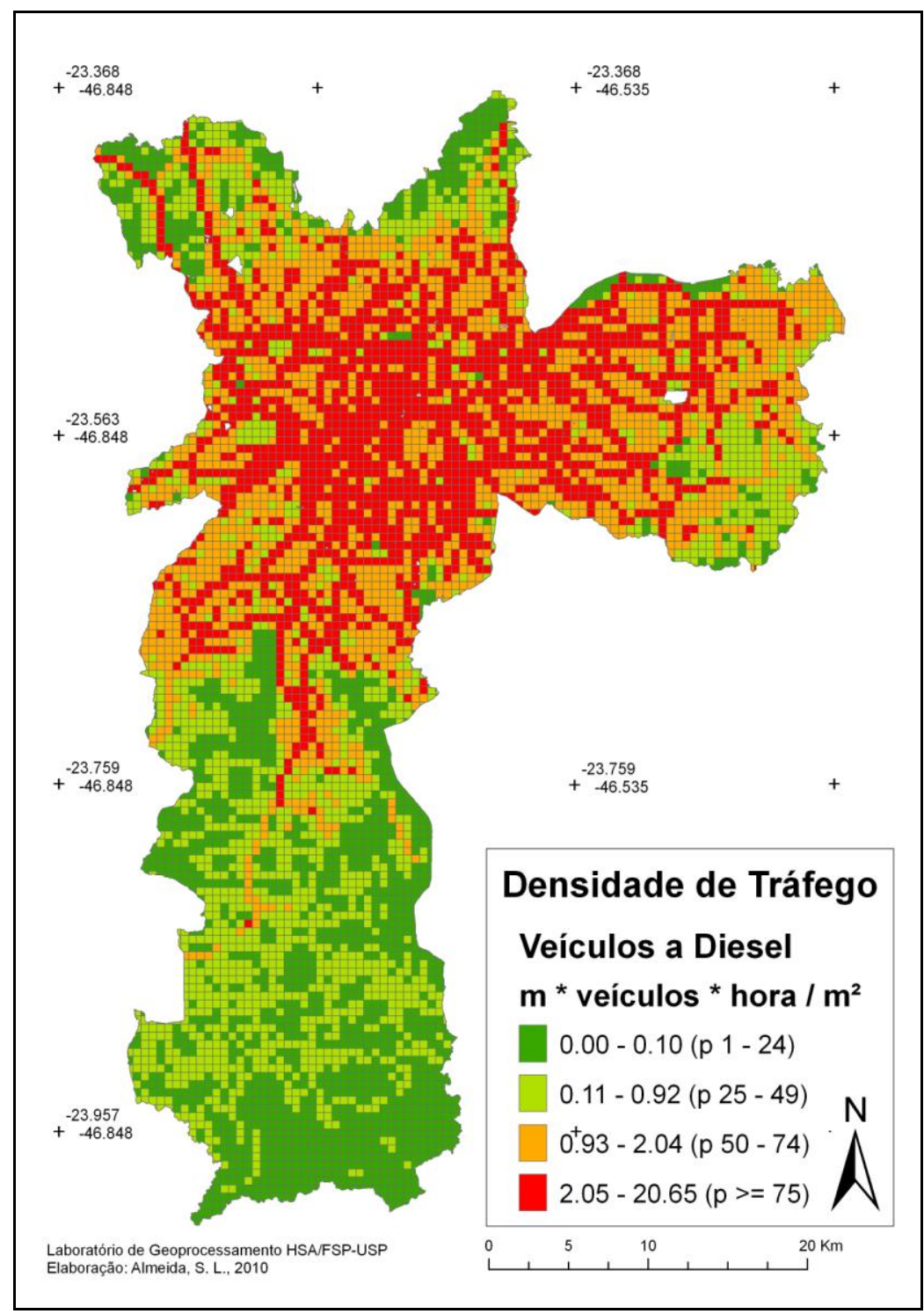

Fonte: CARDOSO, 2010; CET, 2008

Verifica-se, na figura 7, que a densidade de tráfego por veículos a gasolina é extremamente centralizada, com a região central e parte da que se localiza ao seu redor exibindo alta intensidade de tráfego. A área de moderada intensidade é cruzada por formações lineares de alto tráfego. A 
região mais periférica apresenta principalmente áreas com densidade veicular baixa entremeadas com áreas de densidade muito baixa.

Figura 7 - Densidade de tráfego de veículos movidos a gasolina por célula da grid. Município de São Paulo, 2008.

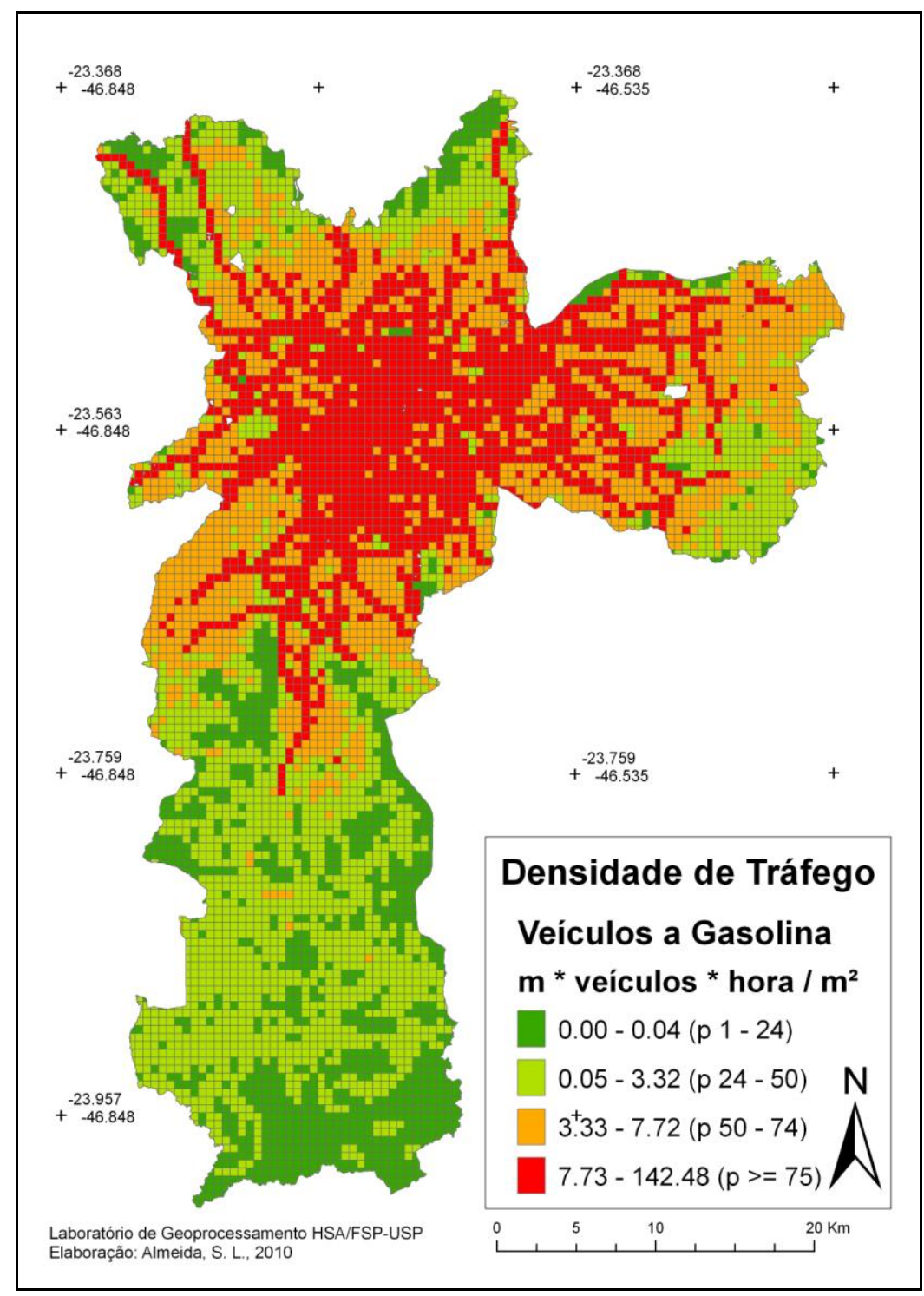

Fonte: CARDOSO, 2010; CET, 2008

A figura 8 mostra o IDH para cada célula da grid, enquanto a figura 9 a mesma medida para cada setor censitário no município de São Paulo. $\mathrm{Na}$ figura 8 , observa-se que na região centro-sul da cidade se concentram as áreas com os maiores índices que se estendem em ramificações até certos pontos das zonas norte, leste, sul e oeste. Ao seu redor se apresentam 
áreas com índices um pouco menores, que por sua vez são envolvidas por outras com índices ainda menores em direção à periferia. As áreas com os menores IDHs se localizam nos extremos periféricos do município.

Figura 8 - Índice de Desenvolvimento Humano Municipal por célula da grid. Município de São Paulo, 2000.

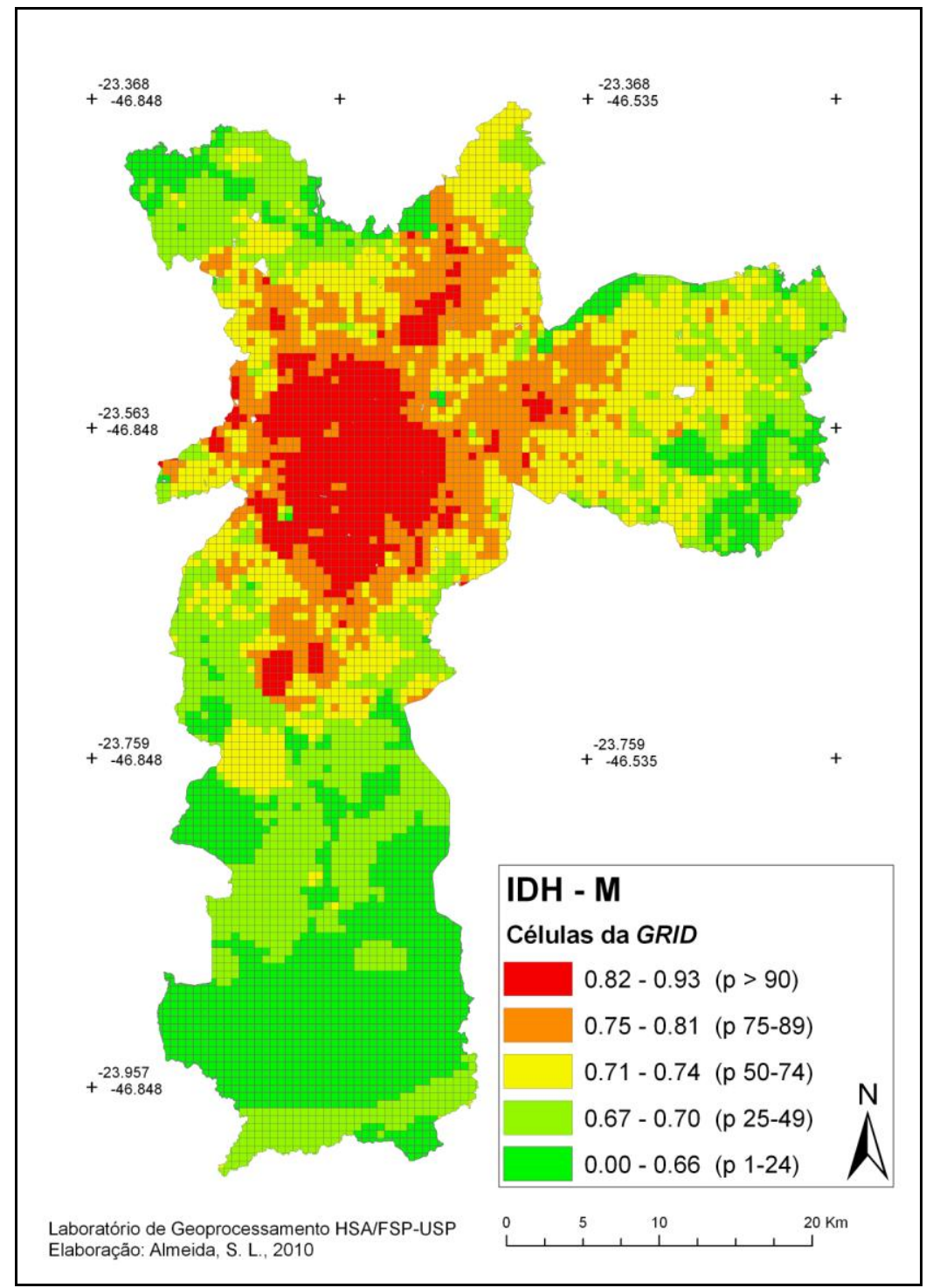

Fonte: CARDOSO, 2010

A distribuição do IDH por setor censitário apresenta maior detalhamento do que a do IDH por célula da grid, resultado da transformação por que passou essa variável para adaptação à grid. $\mathrm{Na}$ figura 9, pode-se melhor observar que as áreas com os maiores IDHs 
ocupam parte da região central, estendendo-se pelo vetor centro-sudoeste, com algumas ramificações de pequena área em direção às zonas norte, leste, sul e oeste. Áreas com IDHs um pouco menores se localizam ao redor das áreas mais desenvolvidas em direção à periferia. Nos extremos periféricos do município se localizam as áreas compostas dos setores censitários com os piores índices.

Figura 9 - Índice de Desenvolvimento Humano Municipal por setor censitário. Município de São Paulo, 2000.

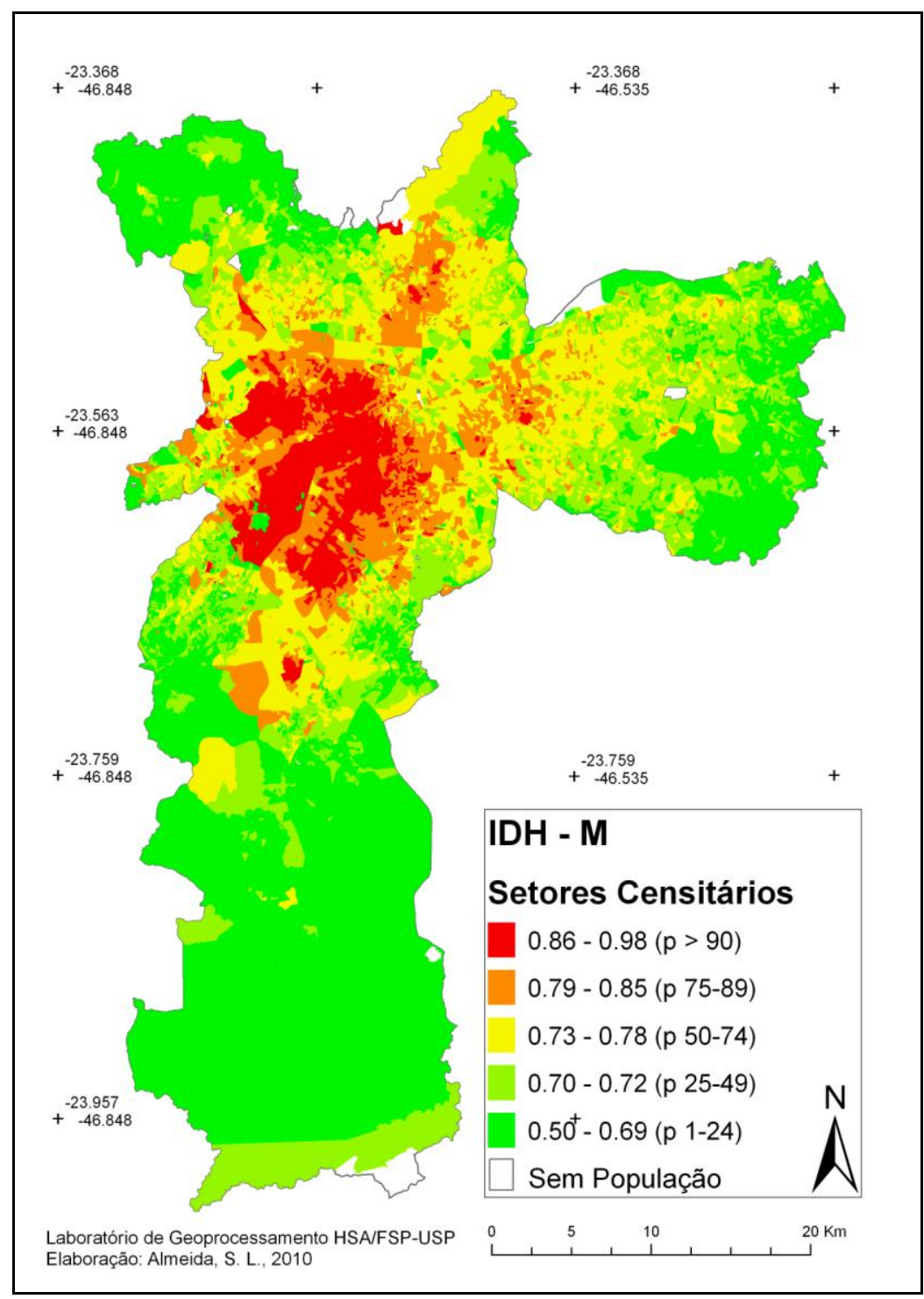

Fonte: CARDOSO, 2010 
A base de dados de internações hospitalares por câncer de residentes no município de São Paulo, ocorridas no mesmo município entre 2004 e 2006, continha 90.373 internações por meio de AlH $(65,1 \%)$ e 48.457 via $\mathrm{CIH} \mathrm{(34,9 \% ),} \mathrm{num} \mathrm{total} \mathrm{de} 138.830$ internações. Desse montante, foram georreferenciadas $55.405 \mathrm{AlHs}(61,2 \%)$ e $35.104 \mathrm{CIHs}$ (38.8\%), totalizando 90.509 internações. Portanto, foi possível georreferenciar somente $61,32 \%$ das AlHs e $72,45 \%$ das $\mathrm{ClHs}$, perfazendo $65,2 \%$ internações totais por câncer. Foi considerada para a análise final somente a primeira internação de cada indivíduo, o que resultou em 46.934 AlHs (63.7\%), $23.736 \mathrm{ClHs}$ $(36,3 \%)$ e 73.670 internações totais.

$\mathrm{Na}$ tabela 3, observa-se o número de internações hospitalares dos residentes do município, ocorridas no período entre 2004 e 2006, devido a diversos tipos de neoplasia maligna. A base original refere-se ao total de internações composto por AlHs e ClHs. A base georreferenciada com duplicatas ao conjunto de internações localizadas e a georreferenciada sem duplicatas a este conjunto após se excluir todas as internações ocorridas após a primeira de cada indivíduo. Apesar de importante parte das internações não ter sido georreferenciada, não houve grandes diferenças na distribuição dos tipos de câncer entre as bases original e a georreferenciada com duplicatas, do que se conclui que as internações não localizadas se distribuem uniformemente entre os diversos tipos de câncer. No entanto, observam-se na comparação entre a primeira base e a georreferenciada sem duplicatas, diferenças importantes na frequência das neoplasias hematológicas e de próstata, reflexo das exclusões das internações múltiplas. 
Tabela 3 - Número e porcentagem das internações hospitalares por tipos de neoplasia maligna, segundo as bases de dados original e georreferenciada com e sem duplicatas. Município de São Paulo, 2004-2006.

\begin{tabular}{|c|c|c|c|c|c|c|}
\hline \multirow[t]{2}{*}{$\begin{array}{c}\text { Tipos de neoplasia } \\
\text { maligna }\end{array}$} & \multicolumn{2}{|c|}{ Base original } & \multicolumn{2}{|c|}{$\begin{array}{c}\text { Base georreferenciada } \\
\text { com duplicatas }\end{array}$} & \multicolumn{2}{|c|}{$\begin{array}{c}\text { Base georreferenciada } \\
\text { sem duplicatas }\end{array}$} \\
\hline & $n$ & $\%$ & $n$ & $\%$ & $n$ & $\%$ \\
\hline Mama & 18853 & 13,58 & 12403 & 13,7 & 10613 & 14,41 \\
\hline Colorretal & 11229 & 8,09 & 7613 & 8,41 & 6024 & 8,18 \\
\hline Prostata & 6817 & 4,91 & 4605 & 5,09 & 4222 & 5,73 \\
\hline Leucemia & 6817 & 4,91 & 4513 & 4,99 & 2637 & 3,58 \\
\hline $\begin{array}{l}\text { Lábio, cavidade oral e } \\
\text { faringe }\end{array}$ & 6358 & 4,58 & 3943 & 4,36 & 3343 & 4,54 \\
\hline $\begin{array}{l}\text { Traquéia, brônquios e } \\
\text { pulmões }\end{array}$ & 5828 & 4,2 & 3844 & 4,25 & 3138 & 4,26 \\
\hline Estômago & 5595 & 4,03 & 3579 & 3,95 & 3082 & 4,18 \\
\hline Corpo do útero & 5008 & 3,61 & 3199 & 3,53 & 2721 & 3,69 \\
\hline Pele não-melanoma & 4825 & 3,48 & 2930 & 3,24 & 2771 & 3,76 \\
\hline Linfoma não-Hodgkin & 4771 & 3,44 & 3390 & 3,75 & 1996 & 2,71 \\
\hline Encéfalo & 4448 & 3,2 & 2921 & 3,23 & 2435 & 3,31 \\
\hline Colo do útero & 4357 & 3,14 & 2635 & 2,91 & 2374 & 3,22 \\
\hline Bexiga & 3660 & 2,64 & 2483 & 2,74 & 2105 & 2,86 \\
\hline Ovário & 2822 & 2,03 & 1907 & 2,11 & 1464 & 1,99 \\
\hline Laringe & 2801 & 2,02 & 1719 & 1,9 & 1440 & 1,95 \\
\hline Esôfago & 2582 & 1,86 & 1660 & 1,83 & 1347 & 1,83 \\
\hline $\begin{array}{l}\text { Fígado e vias biliares } \\
\text { intra-hepáticas }\end{array}$ & 2335 & 1,68 & 1534 & 1,69 & 1204 & 1,63 \\
\hline Pâncreas & 1846 & 1,33 & 1390 & 1,54 & 1161 & 1,58 \\
\hline Melanoma maligno & 1605 & 1,16 & 1036 & 1,14 & 880 & 1,19 \\
\hline Doença de Hodgkin & 1163 & 0,84 & 803 & 0,89 & 432 & 0,59 \\
\hline Total & 138830 & 100 & 90509 & 100 & 73670 & 100 \\
\hline
\end{tabular}

A tabela 4 permite a comparação entre a distribuição de mortes e de internações hospitalares, ocorridas no município durante o mesmo período de tempo, pelos diversos tipos de câncer. Primeiramente, o número de internações foi quase 4 vezes maior que o número de mortes. Para alguns tipos, a diferença foi ainda maior, especialmente para o câncer de pele (mais de 18 vezes), corpo e partes não especificadas do útero (mais de 8 vezes), mama, colo de útero e leucemia (mais de 5 vezes). Para outros, porém, a diferença foi menor que 2 vezes, especialmente para o câncer de pâncreas (1,02 vezes), traquéia, brônquios e pulmões $(1,3)$, fígado e vias biliares intra- 
hepáticas $(1,6)$ e estômago $(1,82)$. Essas diferenças refletem as de prognóstico entre os tipos de neoplasias malignas, com aquelas com melhor prognóstico e maior sobrevivência apresentando múltiplas internações por indivíduo, como as de pele, mama e útero, e as de pior prognóstico e curta sobrevida com pouca ou nenhuma internação por indivíduo, como as de pâncreas, pulmão e fígado. As neoplasias malignas que mais levaram à internação, em ordem decrescente, foram: mama (13,58\%), cólon, reto e ânus $(8,64 \%)$, próstata $(4.91 \%)$, leucemia $(4,91 \%)$ e pele $(4,63 \%)$. Por outro lado, as que mais levaram ao óbito foram: traquéia, brônquios e pulmões $(12,19 \%)$, cólon, reto e ânus $(10,28 \%)$, mama $(9,17 \%)$, estômago $(8,4 \%)$ e próstata $(5,88 \%)$. É provável que o número de internações por tipos de neoplasia maligna reflete a sua incidência e a sobrevivência, no sentido de os tipos mais incidentes e de melhor prognóstico apresentarem maiores taxas de internações. Já a mortalidade reflete a incidência e a letalidade, com os tipos mais incidentes e de pior prognóstico com maiores taxas de óbito. 
Tabela 4 - Número e porcentagem das internações hospitalares e mortes por tipos de neoplasias malignas. Município de São Paulo, 2004-2006.

\begin{tabular}{|c|c|c|c|c|}
\hline \multirow[t]{3}{*}{ Tipos de neoplasias } & \multicolumn{2}{|c|}{ Internação Hospitalar } & \multicolumn{2}{|c|}{ Mortalidade } \\
\hline & & & \multirow[t]{2}{*}{$n$} & \multirow[t]{2}{*}{$\%$} \\
\hline & $n$ & $\%$ & & \\
\hline Mama & 18853 & 13,58 & 3350 & 9,17 \\
\hline Cólon, reto e ânus & 11996 & 8,64 & 3754 & 10,28 \\
\hline Prostata & 6817 & 4,91 & 2418 & 5,88 \\
\hline Leucemia & 6817 & 4,91 & 1232 & 3,37 \\
\hline Pele & 6430 & 4,63 & 352 & 0,96 \\
\hline Lábio, cavidade oral e faringe & 6358 & 4,58 & 1291 & 3,53 \\
\hline Traquéia, brônquios e pulmões & 5828 & 4,2 & 4454 & 12,19 \\
\hline Estômago & 5595 & 4,03 & 3069 & 8,4 \\
\hline $\begin{array}{l}\text { Corpo e partes não } \\
\text { especificadas do útero }\end{array}$ & 5574 & 4,01 & 683 & 1,87 \\
\hline $\begin{array}{l}\text { Meninges, encéfalo e outras } \\
\text { partes do SNC }\end{array}$ & 5099 & 3,67 & 1438 & 3,94 \\
\hline Linfoma não-Hodgkin & 4771 & 3,44 & 1034 & 2,83 \\
\hline Colo do útero & 4357 & 3,14 & 821 & 2,25 \\
\hline Bexiga & 3660 & 2,64 & 796 & 2,18 \\
\hline Ovário & 2822 & 2,03 & 802 & 2,2 \\
\hline Laringe & 2801 & 2,02 & 897 & 2,46 \\
\hline Esôfago & 2582 & 1,86 & 1272 & 3,48 \\
\hline $\begin{array}{l}\text { Fígado e vias biliares intra- } \\
\text { hepáticas }\end{array}$ & 2335 & 1,68 & 1457 & 3,99 \\
\hline Pâncreas & 1846 & 1,33 & 1813 & 4,96 \\
\hline Total & 138830 & 100 & 36534 & 100 \\
\hline
\end{tabular}

Fonte: Fontes: Autorização de Internação Hospitalar e Comunicação de Internação Hospitalar, 2004-2006. Sistema de Informações sobre Mortalidade, 2004-2006

As Odds Ratio (OR) para as taxas de internações hospitalares por neoplasias totais, neoplasias respiratórias em maiores de 20 anos e hematológicas em menores de 20 anos, obtidas por modelos de regressão logística com ajuste para IDH-M, são mostradas na tabela 5 .

Para as internações por neoplasias totais, as OR se mostraram significantemente elevadas na segunda e quarta categorias mais altas de densidade veicular total, a diesel e a gasolina, embora padrão dose-resposta não tenha sido verificado.

Já para as neoplasias respiratórias em maiores de 20 anos, as OR das taxas de internação mostraram elevação de risco nas 3 categorias mais altas de densidade de tráfego total, a diesel e a gasolina, com claro 
gradiente dose-resposta. As estimativas de risco foram muito semelhantes dentro de cada categoria das densidades de veículos a diesel e a gasolina, exceto para o quartil mais elevado, em que a densidade por veículos a gasolina mostrou OR um pouco maior que a por veículos a diesel, embora com amplos intervalos de confiança.

As internações hospitalares por neoplasias hematológicas em menores de 20 anos mostraram estimativas de risco com padrão semelhante ao das neoplasias respiratórias, mas com magnitude um pouco menor. As estimativas são igualmente imprecisas, devido ao relativamente pequeno número de casos desses dois grupos de neoplasias.

Tabela 5 - Odds Ratio para taxas de internação hospitalar por neoplasias totais, respiratórias em maiores de 20 anos e hematológicas em menores de 20 anos e densidades veiculares por célula da grid. Município de São Paulo, 2004-2006.

\begin{tabular}{|c|c|c|c|}
\hline $\begin{array}{l}\text { Densidade } \\
\left(\mathrm{m} / \mathrm{m}^{2}\right)\end{array}$ & $\begin{array}{c}\text { Neoplasias Totais } \\
\text { OR }(\text { IC95\%) }\end{array}$ & $\begin{array}{c}\text { Neoplasias } \\
\text { Respiratórias >20a } \\
\text { OR }(\text { IC95\%) }\end{array}$ & $\begin{array}{c}\text { Neoplasias } \\
\text { Hematológicas < 20a } \\
\text { OR }(\text { IC } 95 \%)^{a}\end{array}$ \\
\hline \multicolumn{4}{|l|}{ Densidade total } \\
\hline$\leq 25 p(0-0,483)$ & 1,00 & 1,00 & 1.00 \\
\hline $26-50 p(0,484-4,300)$ & $5,66(4,03-7,96)$ & 6,28 (3.61 - 10,89) & $5,44(3,06-9,69)$ \\
\hline $51-75 p(4,301-9,640)$ & $1,40(0,94-2,10)$ & $9,07(5,23-15,74)$ & $7,40(4,16-13,16)$ \\
\hline$>76 p(9,641-163,03)$ & $3,67(2,51-5,37)$ & $15,19(8,76-26,35)$ & $13,36(7,55-23,65)$ \\
\hline \multicolumn{4}{|l|}{ Densidade a Diesel } \\
\hline$\leq 25 p(0-0,095)$ & 1,00 & 1,00 & 1,00 \\
\hline $26-50 p(0,096-0,924)$ & $5,09(3,64-7,12)$ & $6,59(3,80-11.41)$ & $5,69(3.21-10,12)$ \\
\hline $51-75 p(0,925-2,042)$ & $1,98(1,35-2,90)$ & $9,10(5.26-15,75)$ & $8,14(4,60-14,40)$ \\
\hline$>76 p(2,043-20,655)$ & $3,27(2,26-4,75)$ & $13,68(7,91-23,66)$ & $11,47(6,50-20,25)$ \\
\hline \multicolumn{4}{|l|}{ Densidade a Gasolina } \\
\hline$\leq 25 p(0-0,380)$ & 1,00 & 1,00 & 1,00 \\
\hline $26-50 p(0,381-3,320)$ & $5,69(4,05-8,01)$ & $6,21(3,58-10,79)$ & $5,55(3,12-9,88)$ \\
\hline $51-75 p(3,321-7,717)$ & $1,43(0,95-2,13)$ & $8,96(5,16-15,55)$ & $7,34(4,13-13,04)$ \\
\hline$>76 p(7,718-19,934)$ & $3,57(2,44-5,22)$ & $15,57(8,97-27,01)$ & $13,09(7,40-23,17)$ \\
\hline
\end{tabular}

${ }^{a}$ OR: Odds Ratio ajustado por IDH-M; IC95\%: Intervalo de Confiança de 95\% 
$\mathrm{Na}$ tabela 6 , estão os resultados de uma análise de sensibilidade em que foram excluídas todas as unidades geográficas com população menor que 20 indivíduos, visando eliminar o efeito causado por aquelas com populações muito pequenas localizadas, em geral, nos extremos das periferias. Disso resultou a exclusão de 1431 áreas $(22,4 \%$ do total), tendo sido mantidas 4964. As Odds Ratio diminuíram em magnitude, mas o gradiente dose-resposta se manteve para as neoplasias respiratórias e hematológicas, em relação às densidades veiculares total e segundo modalidade de combustível (não mostradas na tabela).

Tabela 6 - Odds Ratio para taxas de internação hospitalar por neoplasias e densidade veicular total por célula da grid, após exclusão de áreas com menos de 20 habitantes. Município de São Paulo, 2004-2006.

\begin{tabular}{lll}
\hline $\begin{array}{l}\text { Densidade veicular total } \\
\left(m / m^{2}\right)\end{array}$ & $O R^{a}$ & $I C 95 \%$ \\
\hline Câncer total & 1,00 & \\
$\leq 25 p(0-1.913)$ & 1,07 & $0,80-1,43$ \\
$26-50 p(0,1914-6,500)$ & 0,50 & $0,35-0,71$ \\
$51-75 p(6,501-12,134)$ & 1,01 & $0,73-1,40$ \\
$>76 p(12,135-163,029)$ & & \\
& & \\
Neoplasias respiratórias em & 1,00 & \\
$>20$ anos & 1,95 & $1,34-2,83$ \\
$\leq 25 p(0-1.913)$ & 2,20 & $1,49-3,26$ \\
$26-50 p(0,1914-6,500)$ & 3,31 & $2,26-4,87$ \\
$51-75 p(6,501-12,134)$ & & \\
$>76 p(12,135-163,029)$ & & \\
& 1,00 & \\
Neoplasias hematológicas & 1,21 & $1,09-2,44$ \\
em < 20 anos & 1,63 & \\
$\leq 25 p(0-1.913)$ & 2,35 & \\
$26-50 p(0,1914-6,500)$ & $12,134)$ &
\end{tabular}

${ }^{a}$ OR: Odds Ratio ajustado por IDH-M; IC95\%: Intervalo de Confiança de 95\%

A associação entre a densidade veicular e o IDH-M da área de moradia é mostrada na tabela 7. Nela se observa que quanto maior o IDH-M 
maior a densidade veicular total, a diesel e a gasolina, com evidente gradiente dose-resposta e amplos intervalos de confiança especialmente para as categorias superiores do índice. A magnitude das estimativas são maiores para os veículos a diesel, sugerindo importante proximidade das áreas mais ricas da cidade em relação às vias com alto fluxo desses veículos.

Tabela 7 - Odds Ratio para densidades veiculares e IDH-M por célula da grid. Município de São Paulo, 2000, 2008.

\begin{tabular}{|c|c|c|}
\hline Densidade veicular /IDH-M & $\overline{O R}$ & $1 C 95 \%$ \\
\hline \multicolumn{3}{|l|}{ Densidade total } \\
\hline IDH-M1 p1-24 (0 - 6,57) & 1,00 & \\
\hline IDH-M2 p25-49 (0,658 - 0,696) & 1,58 & $1,02-2,44$ \\
\hline IDH-M3 p50-74 (0,697 - 0,743) & 5,30 & $3,64-7,73$ \\
\hline IDH-M4 p75-89 (0,744 - 0,809) & 12,89 & $8,88-18,71$ \\
\hline IDH-M5 p90 + (0,810 - 0,931) & 17,66 & $12,05-25,85$ \\
\hline \multicolumn{3}{|l|}{ Densidade a Diesel } \\
\hline IDH-M1 p1-24 $(0-6,57)$ & 1,00 & \\
\hline IDH-M2 p25-49 (0,658 - 0,696) & 2,03 & $1,24-3,33$ \\
\hline IDH-M3 p50-74 (0,697 - 0,743) & 8,39 & $5,45-12,92$ \\
\hline IDH-M4 p75-89 (0,744 - 0,809) & 19,51 & $12,69-30,00$ \\
\hline IDH-M5 p90 + (0,810 - 0,931) & 23,05 & $14,84-35,80$ \\
\hline \multicolumn{3}{|l|}{ Densidade a Gasolina } \\
\hline IDH-M1 p1-24 $(0-6,57)$ & 1,00 & \\
\hline IDH-M2 p25-49 (0,658 - 0,696) & 1,55 & $1,01-2,37$ \\
\hline IDH-M3 p50-74 (0,697 - 0,743) & 4,80 & $3,32-6,94$ \\
\hline IDH-M4 p75-89 (0,744 - 0,809) & 12,01 & $8,34-17,29$ \\
\hline IDH-M5 p90 + (0,810 - 0,931) & 17,17 & $11,83-24,93$ \\
\hline
\end{tabular}

OR: Odds Ratio; IC95\%: Intervalo de Confiança de 95\%; IDH-M: Índice de Desenvolvimento Humano Municipal

$\mathrm{Na}$ tabela 8, são mostrados os resultados da regressão logística envolvendo as taxas de internação hospitalar por diversos grupos ou tipos de neoplasias e o IDH-M, em nível de setor censitário. 
Observa-se que o câncer digestivo, englobando os diversos órgãos constitutivos do trato gastrintestinal, apresenta risco aumentado para as 4 categorias superiores de IDH-M, entretanto sem a presença de gradiente dose-resposta. Realmente é a terceira categoria intermediária é a que demonstra o maior risco $(2,92)$.

Por sua vez, evidencia-se também para o câncer colorretal risco aumentado nas 4 categorias superiores de IDH-M. Certo gradiente doseresposta se apresenta, mas é ainda a terceira categoria intermédia a de maior risco $(2,78)$.

Para o câncer de lábio, cavidade oral e faringe, risco aumentado de pequena magnitude é observado na segunda, terceira e quarta categorias superiores de IDH-M. Não se verifica risco aumentado na categoria com os índices mais elevados.

Já para os cânceres de mama e próstata, o risco se eleva com 0 aumento do IDH-M, com claro gradiente dose-resposta ao longo das categorias consideradas, especialmente para o de próstata, que apresenta as estimativas de maior magnitude. 
Tabela 8 - Odds Ratio para taxas de internação hospitalar por neoplasias e IDH-M por setor censitário. Município de São Paulo, 2004-2006.

\begin{tabular}{|c|c|c|}
\hline$I D H-M$ & $O R$ & IC 95\% \\
\hline \multicolumn{3}{|l|}{ Câncer Digestivo } \\
\hline IDH-M1 p1-24 (0,497 - 0,687) & 1,00 & \\
\hline IDH-M2 p25-49 (0,688 - 0,723) & 1,90 & $1,73-2,10$ \\
\hline IDH-M3 p50-74 (0,724 - 0,783) & 2,92 & $2,64-3,23$ \\
\hline IDH-M4 p75-89 (0,784 - 0,847) & 2,12 & $1,90-2,38$ \\
\hline IDH-M5 p90 + $(0,848-0,979)$ & 1,91 & $1,68-2,18$ \\
\hline \multicolumn{3}{|l|}{ Câncer Colorretal } \\
\hline IDH-M1 p1-24 (0,497 - 0,687) & 1,00 & \\
\hline IDH-M2 p25-49 (0,688 - 0,723) & 1,76 & $1,57-1,98$ \\
\hline IDH-M3 p50-74 (0,724 - 0,783) & 2,78 & $2,49-3,12$ \\
\hline IDH-M4 p75-89 (0,784 - 0,847) & 2,49 & $2,19-2,82$ \\
\hline IDH-M5 p90 + (0,848 - 0,979) & 2,50 & $2,16-2,88$ \\
\hline \multicolumn{3}{|l|}{$\begin{array}{l}\text { Câncer de Lábio, Cavidade Oral } \\
\text { e Faringe }\end{array}$} \\
\hline IDH-M1 p1-24 (0,497 - 0,687) & 1,00 & \\
\hline IDH-M2 p25-49 (0,688 - 0,723) & 1,29 & $1,13-1,46$ \\
\hline IDH-M3 p50-74 (0,724 - 0,783) & 1,66 & $1,47-1,88$ \\
\hline IDH-M4 p75-89 (0,784 - 0,847) & 1,22 & $1,06-1,42$ \\
\hline IDH-M5 p90 + $(0,848-0,979)$ & 0,92 & $0,77-1,11$ \\
\hline \multicolumn{3}{|l|}{ Câncer de Mama } \\
\hline IDH-M1 p1-24 (0,497 - 0,687) & 1,00 & \\
\hline IDH-M2 p25-49 (0,688 - 0,723) & 1,89 & $1,71-2,09$ \\
\hline IDH-M3 p50-74 (0,724 - 0,783) & 2,69 & $2,43-2,97$ \\
\hline IDH-M4 p75-89 (0,784 - 0,847) & 2,64 & $2,35-2,96$ \\
\hline IDH-M5 p90 + (0,848 - 0,979) & 2,73 & $2,39-3,11$ \\
\hline \multicolumn{3}{|l|}{ Câncer de Próstata } \\
\hline IDH-M1 p1-24 (0,497 - 0,687) & 1,00 & \\
\hline IDH-M2 p25-49 (0,688 - 0,723) & 1,89 & $1,66-2,16$ \\
\hline IDH-M3 p50-74 (0,724 - 0,783) & 2,56 & $2,25-2,91$ \\
\hline IDH-M4 p75-89 (0,784 - 0,847) & 2,91 & $2,53-3,35$ \\
\hline IDH-M5 p90 + (0,848 - 0,979) & 3,96 & $3,40-4,61$ \\
\hline
\end{tabular}

OR: Odds Ratio; Intervalo de Confiança de 95\%; IDH-M: Índice de Desenvolvimento Humano Municipal 
Recortaram-se as 661 células correspondentes à área do chamado centro expandido do município de São Paulo para análise. Os resultados obtidos são mostrados na tabela 9. Os valores das médias das variáveis no centro expandido foram maiores que as do município como um todo, o que revela a grande concentração populacional, de volume de tráfego e as condições sócio-econômicas superiores nessa importante área.

Tabela 9 - Percentis, valores mínimo e máximo, média e desvio padrão de população, IDH-M e indicadores de tráfego por célula da grid. Centro expandido do município de São Paulo, 2000, 2008.

\begin{tabular}{|c|c|c|c|c|c|c|c|c|c|}
\hline Variáveis & $10 \%$ & $25 \%$ & $50 \%$ & $75 \%$ & $90 \%$ & $\operatorname{Min}^{a}$ & $M a ́ x^{b}$ & Média & $D P^{c}$ \\
\hline $\begin{array}{l}\text { População } \\
\text { total (2000) } \\
\text { (habitantes) }\end{array}$ & 357 & 867 & 1961 & 3280 & 4910 & 35 & 10384 & 2356 & 1864 \\
\hline $\begin{array}{l}\text { IDH-M }^{\mathrm{d}} \\
(2000)\end{array}$ & 0,737 & 0,763 & 0,806 & 0,854 & 0,880 & 0,582 & 0,920 & 0,807 & 0,055 \\
\hline $\begin{array}{l}\text { Densidade } \\
\text { Veicular Total } \\
(2008)\left(\mathrm{m} / \mathrm{m}^{2}\right)\end{array}$ & 8,141 & 11,532 & 20,676 & 33,582 & 62,571 & 0 & 163,03 & 27,960 & $\begin{array}{l}24,05 \\
5\end{array}$ \\
\hline $\begin{array}{l}\text { Densidade } \\
\text { Veicular a } \\
\text { Diesel (2008) } \\
\left(\mathrm{m} / \mathrm{m}^{2}\right)\end{array}$ & 1,371 & 2,034 & 3,522 & 5,395 & 8,766 & 0 & 20,655 & 4,286 & 3,107 \\
\hline $\begin{array}{l}\text { Densidade } \\
\text { Veicular a } \\
\text { Gasolina } \\
(2008)\left(\mathrm{m} / \mathrm{m}^{2}\right)\end{array}$ & 6,799 & 9,451 & 17,464 & 28,162 & 55,131 & 0 & 142,48 & 23,743 & $\begin{array}{l}21,03 \\
7\end{array}$ \\
\hline
\end{tabular}

A associação entre a densidade veicular e o IDH-M da área de moradia no centro expandido do município é mostrada na tabela 10. Diferentemente do gradiente crescente das densidades veiculares com o aumento do IDH-M observado no município, verificou-se no centro expandido que os três quartis com maiores IDH-M foram os que apresentaram menores densidades veiculares, porém sem gradiente doseresposta. O terceiro quartil mais elevado do índice foi o que apresentou associação negativa mais robusta. A densidade por veículos a gasolina também apresentou a mais forte associação negativa, sugerindo importante 
proximidade de áreas mais pobres de vias com maior fluxo desses veículos no centro expandido.

Tabela 10- Odds Ratio para densidades veiculares e IDH-M por célula da grid. no centro expandido do Município de São Paulo, 2000, 2008.

\begin{tabular}{lll}
\hline Densidade veicular/IDH-M & OR & IC 95\% \\
\hline Densidade total & 1,00 & \\
IDH-M1 p1-24 (0,582 - 0,762) & 0,37 & $0,19-0,72$ \\
IDH-M2 p25-49 (0,763 - 0,805) & 0,23 & $0,11-0,50$ \\
IDH-M3 p50-74 (0,806 - 0,853) & 0,29 & $0,14-0,59$ \\
IDH-M4 p75+ (0,854 - 0,920) & & \\
Densidade a Diesel & 1,00 & \\
IDH-M1 p1-24 (0,582 - 0,762) & 0,40 & $0,20-0,80$ \\
IDH-M2 p25-49 (0,763 - 0,805) & 0,30 & $0,14-0,64$ \\
IDH-M3 p50-74 (0,806 - 0,853) & 0,47 & $0,24-0,91$ \\
IDH-M4 p75+ (0,854 - 0,920) & & \\
Densidade a Gasolina & 1,00 & \\
IDH-M1 p1-24 (0,582 - 0,762) & 0,37 & $0,19-0,72$ \\
IDH-M2 p25-49 (0,763 - 0,805) & 0,23 & $0,11-0,50$ \\
IDH-M3 p50-74 (0,806 - 0,853) & 0,29 & $0,14-0,59$ \\
IDH-M4 p75+ (0,854 - 0,920)
\end{tabular}

OR: Odds Ratio; IC95\%: Intervalo de Confiança de 95\%; IDH-M: Índice de Desenvolvimento Humano Municipal

Não se observaram associações significantes nem gradiente doseresposta para os três grupos de câncer investigados, quando se analisou a relação entre densidade de tráfego e internações hospitalares no centro expandido do município. A tabela 11 mostra os resultados para as internações por neoplasias respiratórias em maiores de 20 anos, que são similares aos dos dois outros grupos de câncer. 
Tabela 11 - Odds Ratio e Intervalo de Confiança de 95\% para internações por neoplasias respiratórias em maiores de 20 anos e densidades veiculares por célula da grid. Município de São Paulo, 2004 a 2006.

\begin{tabular}{lcc}
\hline Densidade veicular $\left(\mathrm{m} / \mathrm{m}^{2}\right)$ & $O R^{\mathrm{a}}$ & $I C 95 \%$ \\
\hline Densidade total & 1 & \\
$\leq 25 p(0-11,532)$ & 1,87 & $0,91-3,86$ \\
$26-50 p(11,533-20,676)$ & 1,22 & $0,57-2,63$ \\
$51-75 p(20,677-33,582)$ & 0,98 & $0,44-2,19$ \\
$>76 p(33,583-163.03)$ & & \\
& & \\
Densidade a Diesel & 1 & $0,99-4,33$ \\
$\leq 25 p(0-2,034)$ & 2,07 & $0,69-3,19$ \\
$26-50 p(2,035-3,522)$ & 1,48 & $0,48-2,46$ \\
$51-75 p(3,523-5,395)$ & 1,09 & \\
$>76 p(5,396-20,655)$ & & \\
& & \\
Densidade a Gasolina & 1 & $0,78-3,23$ \\
$\leq 25 p(0-9,451)$ & 1,58 & $0,37-1,84$ \\
$26-50 p(9,452-17,464)$ & 1,20 & \\
$51-75 p(17,465-28,162)$ & 0,82 & \\
$>76 p(28,163-142,48)$ & & \\
\hline
\end{tabular}

a OR: Odds Ratio ajustado por IDH-M; IC95\%: Intervalo de Confiança de 95\% 


\section{DISCUSSÃO}

Este estudo explorou as relações existentes entre variáveis sócioeconômicas e de tráfego e as taxas de internação por câncer no município de São Paulo, utilizando como unidade de análise uma pequena área geográfica de $25.000 \mathrm{~m}^{2}$. É o primeiro estudo nacional a avaliar tais relações fazendo uso de pequenas unidades de área. Em revisão da literatura publicada na última década sobre os efeitos da poluição do ar na saúde da população do município de São Paulo, TOLEDO (2010) observou que quase todos os estudos encontrados sobre a temática eram ecológicos, de série temporal, avaliavam efeitos agudos da poluição à saúde, utilizavam dados das estações de monitoramento da qualidade do ar na caracterização da exposição e atribuíam para toda a área da cidade valores médios das concentrações dos poluentes considerados.

Nosso estudo com desenho ecológico, utilizando dados de exposição ao tráfego e taxas de internações por câncer agregados por unidades da grid, permitiu o conhecimento das diferenças e especificidades locais existentes no interior do município, inserindo-se em uma nova vertente da literatura nacional sobre os efeitos à saúde devidos à poluição do tráfego que busca preencher importantes lacunas no conhecimento sobre efeitos de longo prazo associados à poluição relacionada ao tráfego.

Verificou-se risco aumentado e significante de internação por neoplasias respiratórias em adultos e hematológicas em crianças e adolescentes associado a morar em áreas com maior densidade de tráfego por veículos totais, movidos a gasolina e a diesel, com claro gradiente doseresposta, após ajuste para o nível sócio-econômico de área. Além disso, o nível sócio-econômico da área de moradia esteve associado positivamente e em gradiente com as medidas de densidade de tráfego e com certos tipos de câncer, especialmente o de mama e o de próstata. 
A observação de maior risco de internação por neoplasias respiratórias e hematológicas em moradores de áreas com maiores densidades de tráfego, após ajuste para o nível sócio-econômico de moradia, pode ser tomada como sugestiva de que a poluição relacionada ao tráfego possa estar contribuindo para o aumento da incidência desses grupos de neoplasias.

REYNOLDS et al. (2002), em estudo ecológico observaram correlações moderadamente altas entre a densidade de tráfego e as concentrações de benzeno $[r=0,69 ; p<0,01]$ e de 1,3 -butadieno $[r=0,57$; $p<0,01]$, reconhecidos carcinógenos presentes nas emissões veiculares, mensurados em uma área de 500 metros ao redor de 20 estações de monitoramento do ar. Apesar do contexto geográfico diferente, é possível que correlações semelhantes existam no município de São Paulo, explicando como a densidade de tráfego, por meio de emissão de compostos cancerígenos, se associa à incidência de determinados tipos de câncer.

Além disso, o município de São Paulo vivencia há décadas uma situação de altas concentrações de poluentes na atmosfera. $O \mathrm{MP}_{2,5}$ e $\mathrm{O}$ $\mathrm{MP}_{10}$, os poluentes que mais têm sido associados à mortalidade por câncer de pulmão em estudos recentes, têm apresentado durante a última década concentrações duas a três vezes maiores que as recomendadas pela WHO (2006). Concentrações ainda maiores de tais poluentes eram encontradas em décadas anteriores. Embora até a década de 1980, as fontes industriais eram as principais emissoras de poluentes aéreos e somente na década de 1990 o tráfego passou a ser a fonte emissora predominante (TOLEDO, 2010), é provável que ele tenha contribuído com importante parcela de $\mathrm{MP}_{2,5}$ e $\mathrm{MP}_{10}$ nos últimos 20 a 30 anos, o período etiologicamente relevante para o nosso estudo.

Deve ser lembrado que os valores recomendados pela WHO (2005) representam os menores níveis em que a mortalidade cardiovascular ou por câncer de pulmão demonstrou aumento de risco com mais de $95 \%$ de intervalo de confiança em resposta à exposição crônica a $\mathrm{MP}_{2,5}$ e $\mathrm{MP}_{10}$. 
Desta forma, a ocorrência de risco aumentado de neoplasias malignas respiratórias associado a morar em áreas com alta densidade de tráfego, importante fonte de tais poluentes, é plausível no contexto do município de São Paulo nas últimas décadas.

Estudo publicado recentemente verificou que, mesmo em períodos considerados como de boa qualidade do ar no centro do município de São Paulo, em que os picos de concentração de $\mathrm{MP}_{10}$ não ultrapassam $60 \mu \mathrm{g} / \mathrm{m}^{3}$, partículas ultrafinas (com diâmetro aerodinâmico menor que 0,1 $\mu \mathrm{m}$ ) provenientes do tráfego são capazes de se depositar com eficiência e em magnitude significativa nos alvéolos dos pulmões de quem aí se encontre, podendo determinar impactos à saúde (MARTINS et al., 2010). Tais achados são consistentes com os da revisão de POPE e DOCKERY (2006) que observaram que a forma da função concentração ambiental de MP resposta têm se apresentado, ao longo dos estudos recentes, como linear, sem um nível limiar seguro bem definido.

Mesmo as diretrizes da WHO (2006) alerta que limiares seguros não foram ainda identificados pelas pesquisas, e que as concentrações-limite recomendadas podem não proteger completamente a saúde humana. Essas considerações reforçam a tese de que os atuais e pregressos níveis de poluição relacionada ao tráfego do município de São Paulo podem causar e ter causado importantes danos à saúde.

Os resultados deste estudo em relação aos cânceres do sistema respiratório são consistentes com os encontrados por todos os estudos publicados entre 1998 e 2008 que examinaram a associação de medidas de intensidade de tráfego com câncer no adulto. VISSER et al. (2004) observou risco aumentado de desenvolvimento de neoplasias do sistema respiratório em mulheres, mas não em homens, associado a morar próximo de vias de alto fluxo veicular em Amsterdã, Holanda. BELLEN et al. (2008b), no mesmo país, e VINEIS et al. (2006), na Europa, também verificaram risco aumentado de desenvolver câncer de pulmão relacionado a residir próximo de vias de alto tráfego. Por sua vez, JERRET et al. (2005b) e BELLEN et al. (2008a) demonstraram elevação do risco de morte por câncer de pulmão 
relacionado a essa proximidade na Holanda e em Los Angeles (EUA) respectivamente. Os riscos relativos obtidos em todas essas investigações tiveram incremento entre $11 \%$ e $46 \%$ e não foram estatisticamente significativos. Nos estudos de BELLEN et al. (2008a, 2008b) e de JERRET et al. (2005b), as medidas de intensidade de tráfego tiveram estimativas de risco mais elevadas do que as baseadas na concentração de poluentes atmosféricos concomitantemente avaliados, enquanto que no de VINEIS et al. (2006) a medida de tráfego teve estimativa menor que a da concentração de $\mathrm{NO}_{2}$.

Quanto às neoplasias do sistema hematológico em menores de 20 anos, observamos associação positiva e significante com a exposição ao tráfego. Nosso resultado foi concordante com o obtido por PEARSON et al. (2000) para leucemia, que verificou magnitude de risco de até 8,28, embora com amplo intervalo de confiança. Dos nove estudos restantes, publicados entre 1998 e 2008, que investigaram a associação de diversos tipos de neoplasias hematológicas com o tráfego, sete verificaram associação positiva e não significante, com medidas de risco variando entre 1,1 e 2,09, e somente dois deles não verificaram associação positiva (RAASCHOUNIELSEN et al., 2001; REYNOLDS et al., 2004). A incidência de leucemia foi o desfecho investigado por nove estudos e somente um se focou na incidência de neoplasias hematológicas (VISSER et al., 2004), que também mostrou associação positiva não significativa.

Entretanto, especialmente no caso do câncer do pulmão, não se pode excluir que fatores outros relacionados às áreas com densidades de tráfego elevadas sejam os verdadeiros responsáveis por essas associações, como a idade, os relacionados ao estilo de vida, especialmente o tabagismo, e outras exposições ambientais. Por outro lado, o aumento das internações por câncer poderia ser principalmente devido ao incremento de internações por outras doenças associadas ao câncer, mas não conseqüentes a ele, também desencadeadas ou causadas pela poluição do ar, como as doenças respiratórias e cardiovasculares. No entanto, essa alternativa pode ser considerada remota, pois necessitaria de grande número de erros de 
preenchimento do diagnóstico primário por parte dos médicos. . Muitos erros semelhantes no preenchimento dos diagnósticos nas $\mathrm{AlHs}$ e $\mathrm{ClHs}$ seriam necessários e, além disso, a consideração de somente as internações com diagnóstico principal de câncer feita neste trabalho reduz este viés.

Quando se restringiu a análise à região do centro expandido do município de São Paulo, não se observou associação significante linear entre as medidas de tráfego e as internações hospitalares pelos grupos de câncer estudados. Há várias explicações plausíveis para o ocorrido. As diferenças na exposição aos poluentes oriundos do tráfego no interior de uma área com reconhecida alta concentração de volume de tráfego podem ter sido insuficientes a ponto de não se observar associações positivas com gradiente. Dentro desse raciocínio, a dispersão dos gases e partículas das vias de tráfego para locais mais ou menos distantes pode também ter contribuído para uma exposição menos heterogênea da população residente no interior dessa área. Outra explicação poderia ser uma hipotética diminuição do viés de seleção de internação ocasionado pelo acesso menos desigual aos serviços hospitalares de internação, devido à sua menor distância para a população residente no centro expandido, onde estão concentrados, e a uma possível menor desigualdade social no interior da área.

De modo geral, nosso estudo soma evidências em favor da hipótese de existência de uma associação entre a poluição causada pelo tráfego e certos tipos de câncer.

A associação positiva entre a densidade de tráfego e o nível sócioeconômico da área de residência no município de São Paulo é interessante e difere da maioria dos estudos internacionais, em que associação negativa é encontrada entre medidas diversas de poluição de ar e nível sócioeconômico (HAVARD et al., 2009; DEGUEN e ZMIROU-NAVIER, 2010). Historicamente, o estabelecimento e a expansão dos territórios das elites paulistanas seguiram o vetor centro-oeste, localizando-se atualmente na região centro-sudoeste da cidade. Já os imigrantes e operários pobres se estabeleceram ao redor dessa região em áreas cada vez mais distantes 
(PRADO, 2002), de tal modo que se observa, ainda que não uniformemente, um gradiente negativo de nível sócio-econômico em direção às áreas mais periféricas do município.

A dinâmica histórica da formação e distribuição do tráfego de veículos no município fez com que ele se concentrasse em suas regiões centrais, onde se localizam grande parte dos serviços urbanos, comércio, sedes de empresas, repartições públicas, aparelhos culturais, estabelecimentos de ensino superior, escritórios e, sobretudo, empregos, com infra-estrutura urbana bem desenvolvida. Tais áreas correspondem em grande parte às de moradia das populações com maior nível sócio-econômico, possuidora muitas vezes de mais de um carro por residência. Veículos pertencentes aos seus moradores, os provindos de áreas mais periféricas, em importante influxo e refluxo diário entre as duas áreas, e os de transporte de mercadorias, de passagem pelo município ou abastecendo-o, são responsáveis pela alta intensidade de tráfego nesses territórios.

Os veículos movidos a diesel (ônibus e caminhões) apresentam-se mais associados a essas regiões que os movidos a gasolina, o que evidencia a importância dessas áreas em termos de passagem para 0 transporte de mercadorias e de passageiros dentro e através do município.

Portanto, é possível que, pelo seu próprio desenvolvimento urbano e localização, as regiões mais ricas do município tenham criado e propiciado tal concentração do tráfego em seu interior. Por sua vez, as áreas mais periféricas, com urbanização menos desenvolvida, apresentam menor volume de tráfego, pois é provável que grande parte de seus moradores não possuam carro e trabalhem nas regiões centrais, deslocando-se através de transporte público.

No centro expandido, verificou-se associação negativa, mas não linear, entre o nível sócio-econômico da área de residência e a densidade de tráfego. Tal área apresenta densidade veicular total média por unidade da grid mais de 3 vezes maior que a do município, o que demonstra a grande concentração de tráfego em seu interior. Por outro lado, embora tal área apresente IDH-M médio maior que o do restante do município, ela não é 
homogênea do ponto de vista sócio-econômico. Fenômenos mais importantes que o da atração acima mencionada exercida por áreas mais ricas sobre o tráfego devem estar ocorrendo no interior dessa área. Entre eles, o da desvalorização imobiliária ocorrida nas últimas décadas em regiões tradicionalmente habitadas por populações de maior renda causada, entre outros fatores, pelo aumento do tráfego e da poluição sonora e do ar, determinando a emigração de populações de maior renda para áreas ricas com menor tráfego e a sua substituição por populações pobres e de menor renda, adensadas em cortiços e habitações mal conservadas.

Nosso estudo também observou risco aumentado de câncer de mama, próstata e colorretal associado a morar em áreas com maior nível sócio-econômico, com gradiente dose-resposta através das categorias consideradas.

O câncer digestivo mostrou risco aumentado nas quatro categorias superiores de IDH-M em relação à de referência, porém sem gradiente doseresposta. Deve-se salientar que sob a designação de câncer digestivo estão contidas as neoplasias de esôfago, estômago, fígado, pâncreas, vesícula e vias biliares, intestinos delgado e grosso. Os três primeiros tipos geralmente se associam com baixo nível e o de colón com alto nível sócio-econômico. A maior representatividade deste (cerca de 6024 casos) em relação àqueles (cerca de 5633 casos) pode explicar, pelo menos em parte, a associação do câncer digestivo com alto nível sócio-econômico. Viés de seleção em direção a maior representatividade de internações hospitalares de indivíduos de classes sociais mais altas pode ser uma explicação alternativa. A falta de gradiente, por sua vez, pode ser devida à miscelânea de neoplasias que o constituem, apresentando agentes etiológicos diversos que se relacionam de forma distinta com o nível sócio-econômico.

Já o câncer colorretal se mostrou positivamente associado com o nível sócio-econômico neste estudo, com certo gradiente dose-resposta não linear. O câncer de cólon também apresentou associação positiva na nossa e na revisão de FAGGIANO et al. (1997). Hábitos alimentares, como o baixo consumo de frutas e vegetais e o alto consumo de carne vermelha e de 
gorduras, sedentarismo, obesidade, alto consumo de álcool têm sido apontados como principais fatores de risco para o câncer de cólon (SHIPP et al., 2005; DECHELLO e SHEEHAN, 2007). É possível que a maior parte desses fatores, entre outros, esteja associado com altos níveis sócioeconômicos, o que explica a associação positiva desses níveis com o câncer de cólon. Já para o câncer de reto tem-se demonstrado apresentar aspectos clínicos e epidemiológicos diversos do de cólon. A revisão de FAGGIANO et al. (1997), por exemplo, encontrou achados inconsistentes em relação à sua associação com o nível sócio-econômico. Esse pode ser um dos motivos porque a nossa análise do câncer colorretal não mostrou gradiente linear. Entretanto, como a maior parte do câncer colorretal é formada pelo de cólon, é plausível a ocorrência da associação positiva verificada.

Poucos fatores de risco estão bem estabelecidos para o câncer de próstata, entre eles a história familiar. Em relação à sua associação com o nível sócio-econômico, achados inconsistentes foram encontrados pela revisão de FAGGIANO et al. (1997), cujos estudos analisaram o desfecho em algum segmento de tempo entre 1906 e 1987. Porém, em nossa revisão encontramos associação positiva entre a incidência desse câncer e o nível sócio-econômico em 4 estudos que o investigaram em algum intervalo de tempo entre 1985 e 2002. Entre eles, o de LIU et al. (2001) não observou associação entre a sua incidência e o status sócio-econômico no período entre 1972 e 1987, mas verificou associação positiva no período de 1988 a 1997. Atribuiu tal associação ao uso diferenciado e disseminado do exame de PSA (Prostate-Specific Antigen) a partir do final da década de 1980. É possível que esse fator explique as diferenças encontradas entre os resultados dessas duas revisões temporalmente distintas, assim como o observado no nosso estudo.

A associação entre a incidência de câncer de mama e nível sócioeconômico elevado tem sido explicada pela maior prevalência de fatores reprodutivos nas classes mais ricas, como menor idade na menarca, menor paridade, idade maior no nascimento do primeiro filho e na menopausa (KOGEVINAS et al., 1997; KAWACHI e KROENKE, 2006). É possível que 
esses fatores, entre outros, como o uso de terapia de reposição hormonal, certos hábitos alimentares, sejam mais prevalentes nas classes sociais mais abastadas e em gradiente crescente com o nível sócio-econômico ao longo de toda a sociedade, no município de São Paulo.

Os cânceres da cavidade oral, boca e faringe têm sido relacionados principalmente aos hábitos de tabagismo, consumo de álcool e à dieta pobre em frutas e vegetais, em geral mais prevalentes nas classes mais pobres (HASHIBE et al., 2007; KOGEVINAS et al., 1997). Na nossa revisão e na de FAGGIANO et al. (1997), observou-se associação negativa entre esses cânceres e o nível sócio-econômico no sexo masculino, com especial destaque para os estudos ecológicos de ANTUNES et al. (2001, 2008b) realizados no município de São Paulo em nível distrital. Porém no nosso estudo, tal achado não se confirmou. Risco maior foi encontrado na terceira categoria de IDH-M e os riscos nas categorias extremas foram menores e semelhantes entre si. Algumas hipóteses para explicar estes resultados podem ser o viés de seleção decorrente de perda diferencial de casos no sentido de sub-representação de casos internados com menor nível sócioeconômico e a influência da menor unidade de área utilizada em nosso estudo.

Portanto, observamos que os cânceres colorretal, de mama e de próstata se associaram positivamente com a moradia em áreas com maior nível sócio-econômico. Esses achados parecem estar de acordo com o que já foi encontrado anteriormente no município de São Paulo e na literatura internacional. É possível que as diferenças na prevalência de fatores de risco e de exames de rastreamento entre as classes sociais sejam os determinantes dos resultados encontrados, mas outros estudos são necessários para ampliar o conhecimento sobre essas diferenças no município de São Paulo.

Deve ser enfatizado que o desenho ecológico utilizado neste estudo apresenta como vantagens a grande heterogeneidade e amplitude de exposições ao tráfego e de situações sócio-econômicas existentes no interior do município, permitindo comparações valiosas dos níveis de 
exposições a que estão sujeitos os indivíduos da população. Outros pontos fortes do estudo foram: a determinação dos valores das medidas de exposições sócio-econômicas e ambientais das unidades da grid independentemente do conhecimento dos valores das medidas do desfecho, o que impossibilita a introdução de viés sistemático de aferição da exposição relacionada ao desfecho; a abordagem pioneira, em nível nacional, de utilização de uma medida aproximada da incidência de câncer, como se procurou configurar e transformar a taxa de internação, uma vez que, em nosso meio, dados de incidência a partir de registros de câncer não estão facilmente disponíveis; o uso de unidades geográficas com pequenas áreas e/ou populações, como as células da grid ou os setores censitários.

Dentre as limitações podem se citadas as referentes ao desenho, à determinação das medidas de nível sócio-econômico, de exposição ao tráfego e de desfecho, e ao controle das potenciais variáveis de confusão.

Os estudos ecológicos representam uma abordagem essencial em epidemiologia e saúde pública, mas estão sujeitos a certas limitações, especialmente à falácia ecológica, que resulta da utilização de dados agregados ao invés de individuais, limitando a transposição automática de conclusões obtidas em agregados populacionais para o indivíduo e viceversa. Entretanto, esse viés pode ser minimizado com o uso de unidades geográficas de análise cada vez menores (WHITWORTH et al., 2008), como foi o caso do presente estudo.

O uso da grid como unidade de análise pode ter contribuído para a geração de instabilidade nas taxas de internação por neoplasias malignas em algumas poucas células de regiões pouco povoadas, que revelaram altas taxas de internação. Devido ao pequeno número de moradores no interior dessas células, pequeno número de casos pode ter determinado elevadas taxas. Outra explicação é a indicação freqüente, por parte dos casos residentes nessas regiões, de endereços mais conhecidos e de mais fácil identificação, próximos à suas residências, comumente referidos pela população local. Entretanto, o efeito dessas poucas células sobre estimativas de risco não parece ter sido relevante. 
Por outro lado, a grande quantidade de células com poucos moradores pode também ter levado a taxas de internação muito pequenas. Uma vez que tais células se localizavam especialmente em áreas de baixa densidade de tráfego e baixo nível sócio-econômico, isso resultou em estimativas de risco muito elevadas para as associações das taxas com as variáveis independentes de interesse, devido a essa peculiaridade que a análise das taxas individuais das células realça. Entretanto, a existência de gradiente dose-resposta é um fator que favorece a interpretação de que a associação seja verdadeira e não fruto desse artifício. Do mesmo modo, a eliminação de células com poucos habitantes diminuiu o risco estimado, mas não eliminou o gradiente dose-resposta verificado.

A literatura tem sugerido que as características sócio-econômicas da comunidade ou vizinhança podem afetar de modo importante a saúde das pessoas, independentemente de suas características socioeconômicas individuais. Nesse sentido, medidas agregadas que representam nível sócioeconômico de uma área são somente parcialmente confundidas pelas individuais correspondentes, permanecendo efeito atribuível a peculiaridades da área de moradia. Esse efeito é mediado por fatores de risco relacionados ao acesso a serviços de saúde e de tratamento, a estabelecimentos educacionais, de assistência social e aparelhos culturais, à qualidade da habitação, às condições do ambiente físico local (como a qualidade do ar) e de segurança pública da comunidade, a hábitos culturais e sociais, entre inúmeros outros (MERKIN et al., 2002; OLIVER et al., 2006). Portanto, as medidas agregadas de status sócio-econômico utilizadas em nosso estudo representam uma combinação de efeitos individuais e de área, não passíveis de serem separados em nossa análise.

Além, disso, as medidas socioeconômicas utilizadas neste estudo podem não ser necessariamente representativas do grupo sócio-econômico atual ou prévio de todo paciente e dos fatores de risco associados ao desfecho, de tal forma que se dilui a força das associações em nível individual entre medidas de morbidade de câncer e variáveis ecológicas de status sócio-econômico (SHACK et al., 2008). 
Entretanto, as medidas sócio-econômicas agregadas de unidades geográficas de pequena área, como as do estudo, aproximam-se mais das medidas individuais correspondentes que as unidades com áreas maiores, embora efeito residual de área ainda permaneça. Essas pequenas unidades ainda captam desigualdades sócio-econômicas não passíveis de detecção por grandes agregados heterogêneos, como os distritos administrativos ou as subprefeituras, no caso da cidade de São Paulo, o que tenderia a diminuir a magnitude do viés relacionado ao nível sócio-econômico (PEDROSO, 2003).

Quanto ao Índice de Desenvolvimento Humano Municipal, a falta de dados que permitam o cálculo da expectativa de vida e, por conseguinte, do índice de longevidade, em nível de setor censitário, pode reduzir a habilidade do IDH-M de captar diferenças entre setores censitários muito próximos, o que pode ser relevante em um município como São Paulo, em que áreas extremamente pobres podem se localizar ao lado de áreas muito ricas, introduzindo viés na medição desse índice. Essa conseqüência também se aplica às unidades da grid, com a agravante de que a transformação do índice de setores censitários para essas unidades pode ter aumentado esse viés. Entretanto, é provável que esse viés seja nãodiferencial, diminuindo a magnitude das associações entre IDH-M e internações por câncer ou medidas de tráfego.

A escala espacial ótima para estimar as exposições relevantes relacionadas ao tráfego não é conhecida (VON BEHREN et al., 2008) e podem existir variações consideráveis de tráfego no interior das células da grid de tal forma que as medidas agregadas de exposição podem não corresponder a medidas individuais, diminuindo a força das associações em nível individual entre medidas de morbidade de câncer e as variáveis ecológicas de tráfego.

O uso da densidade de tráfego da área de residência no momento da internação, como indicador indireto da exposição aos poluentes relacionados à emissão veicular, pode não ser representativo da exposição de longo prazo dos indivíduos. A possibilidade de migração de outros estados e de 
outros municípios do estado de São Paulo para tratamento no município de São Paulo, grande pólo médico-hospitalar, assim como o inverso, não pode ser excluída, além da mobilidade residencial no interior do próprio município. No entanto, deve ser destacado que algumas destas limitações perdem força no caso dos cânceres ocorridos em crianças e adolescentes, especialmente as neoplasias hematológicas. Em primeiro lugar, elas apresentam relativamente curto período de latência, o pode diminuir o viés de classificação da exposição ao tráfego, decorrente da mobilidade residencial e das mudanças temporais no ordenamento relativo das vias quanto à intensidade de tráfego. Além disso, as crianças costumam passar a maior parte de seu tempo no interior das residências, o que pode contribuir na diminuição desse viés, e ainda não há possibilidade de história pregressa de exposição em ambiente ocupacional.

Outro aspecto a ser mencionado é o cálculo da densidade de tráfego com dados medidos em 2008, diferente do período utilizado na determinação do desfecho (2004 a 2006) e, especialmente, do que é etiologicamente importante para o desfecho (décadas antes da ocorrência deste). Porém, é provável que esse problema potencial não limite seriamente os resultados, porquanto não parecem ter ocorrido alterações importantes nos padrões espaciais de intensidade de tráfego nos últimos 10 a 20 anos, ainda que o volume de tráfego no município tenha aumentado ao longo desse período. Os resultados da análise de correlação de Spearman mostraram alta correlação significante das concentrações de $\mathrm{MP}_{10}$ entre diversos anos entre 1997 e 2008, o que permite inferir que a intensidade de tráfego possa ter mantido padrão espacial semelhante e que alterações importantes no seu ordenamento espacial não tenham ocorrido ao longo das últimas décadas.

Os poluentes do ar individuais se dispersam de modos diferentes e suas concentrações variam com as condições geográficas, topográficas e meteorológicas, como o relevo, direção do vento, temperatura, pressão atmosférica, umidade relativa do ar e radiação solar. A configuração das edificações das ruas também pode influir nas concentrações desses 
poluentes, o chamado street canyon effect. Esses fatores, entre outros, não foram incorporados na nossa análise. No entanto, as concentrações costumam ser maiores próximas às vias e diminuem com a distância destas.

O uso de dados populacionais do censo 2000 como base para o cálculo dos denominadores das taxas de internações também deve ser mencionado, uma vez que podem ter ocorrido alterações demográficas no interior dos setores censitários no intervalo entre esse censo e os anos do estudo (2004 a 2006), resultando em erros nos cálculos das taxas de internações.

Quanto à determinação dos numeradores das taxas de internações, destaca-se o fato de somente $65,2 \%$ dos endereços residenciais dos casos de internação por câncer terem sido localizados. A acurácia do geoprocessamento depende de se ter o endereço residencial completo e correto, do mapa utilizado de referência das vias e de regras hierárquicas na escolha entre múltiplos endereços (POLLACK et al., 2006). Além disso, a inexistência de certos endereços no mapa de referência, especialmente dos localizados em favelas, pode ter impossibilitado adicionalmente 0 georreferenciamento de vários casos.

O acesso diferencial a serviços hospitalares de diagnóstico e tratamento, resultando em menor representatividade das classes sociais mais desfavorecidas, também poderia introduzir viés de seleção na avaliação das desigualdades sócio-econômicas em câncer, no sentido de aumento nas estimativas de risco de alguns cânceres associados à riqueza e na diminuição nas estimativas daqueles associados à pobreza. No entanto, o fato dos serviços de diagnóstico e tratamento de câncer serem oferecidos integralmente pelo SUS amplia o acesso das classes sociais mais baixas, diminuindo tal viés.

A transformação da taxa "bruta" de internações hospitalares em uma medida aproximada de incidência não pode ser tomada como uma boa medida indireta de incidência, uma vez que tal taxa "bruta" sofre influência de diversos fatores relacionados ao acesso à assistência hospitalar, à incidência e prognóstico da doença. 
Outra limitação inerente aos estudos com desenho ecológico é a dificuldade de se controlar o efeito de potenciais variáveis de confusão. $\mathrm{Na}$ avaliação da relação entre as medidas de tráfego e os desfechos, somente se ajustou para o nível sócio-econômico na análise estatística. Entretanto, outras variáveis, se associadas à exposição e ao desfecho, poderiam atuar como variáveis de confusão, como, por exemplo, a fumaça proveniente do cigarro.

Em relação às neoplasias malignas hematológicas em menores de 20 anos, além da idade e sexo, poucos fatores de risco estão bem estabelecidos, entre eles certas alterações genéticas herdadas, a exposição intrauterina e pós-natal à radiação ionizante e a certos quimioterápicos, o uso de dietilestilbestrol e a infecção pelo vírus Epstein-Barr durante a gestação (RAASCHOU-NIELSEN e REYNOLDS, 2006).

Porém, em relação aos cânceres respiratórios a situação é mais complexa. Esse grupo é composto pelo câncer de pulmão, brônquios e traquéia, que apresenta como principais fatores de risco o tabagismo ativo e passivo, as exposições ocupacionais, ao radônio, entre outros, e o câncer de laringe, em que tabagismo e o álcool são os principais fatores de risco. Há evidências de que a dieta rica em vegetais e frutas funcione como fator de proteção para todas essas neoplasias. 


\section{CONCLUSÕES E CONSIDERAÇÕES FINAIS}

Da revisão de literatura, devem ser destacadas as seguintes conclusões:

-Associação positiva e consistente entre exposições ao $\mathrm{NO}_{2} / \mathrm{NO}_{x}$, ao $\mathrm{MP}_{2,5}$, ao $\mathrm{MP}_{10}$ e o câncer de pulmão.

-Associação inconsistente entre exposição ao tráfego e a poluentes do ar e diversos tipos de câncer infantil.

-Associação positiva e consistente com o nível sócio-econômico da área de moradia para os cânceres de próstata e melanoma maligno, nos homens, e para os cânceres de mama e melanoma maligno, nas mulheres.

-Associação negativa e consistente com o nível sócio-econômico da área de moradia para os cânceres de esôfago, estômago, laringe e cavidade oral, nos homens, e para os de esôfago, estômago e colo uterino, nas mulheres.

Do estudo ecológico destacam-se as seguintes conclusões:

-Aumento significante do risco de internação hospitalar por neoplasias respiratórias em maiores de 20 anos associado a morar em áreas com alta densidade de tráfego, com claro gradiente dose-resposta, após ajuste para o nível sócio-econômico de área.

-Aumento significante do risco de internação hospitalar por neoplasias hematológicas em menores de 20 anos associado a morar em áreas com 
alta exposição ao tráfego, com claro gradiente dose-resposta, após ajuste para o nível sócio-econômico de área.

-Risco aumentado e significante de internação por câncer de mama e de próstata associado a morar em áreas com alto IDH-M, com evidente padrão dose-resposta.

-Risco aumentado e significante de exposição ao tráfego em áreas com alto IDH-M, com evidente gradiente dose-resposta, no município de São Paulo como um todo.

-Risco diminuído e significante de exposição ao tráfego em áreas com alto IDH-M, sem gradiente dose-resposta, no centro expandido do município.

-Ausência de associação significante e de padrão dose-resposta entre internação hospitalar por neoplasias respiratórias e hematológicas e a exposição ao tráfego da área de moradia, no centro expandido do município.

Os resultados enfatizam a importância de investigações sobre os riscos à saúde relacionados à poluição relacionada ao tráfego em megacidades de países em desenvolvimento, caracterizadas por altos níveis de poluição ambiental do ar, muito acima dos observados em cidades de países desenvolvidos. Dado ao caráter incipiente do conhecimento da relação entre essa exposição e o desfecho câncer no Brasil, estudos ecológicos exploratórios ainda se fazem importantes. Porém em uma etapa seguinte, desenhos outros que o ecológico serão desejáveis para avançar o conhecimento, especialmente devido ao longo tempo de latência requerido para o desenvolvimento desse desfecho.

Deve ser destacado que áreas com alta densidade de tráfego corresponderam, em grande parte, às com maior nível sócio-econômico, o que não coincidiu com a maioria dos estudos já realizados sobre o assunto, 
concentrados em cidades de países desenvolvidos. Estudos sobre o assunto em megacidades de países em desenvolvimento são praticamente ausentes, sendo provável que o desenvolvimento histórico-social diferenciado determine padrões distintos de localização dos diferentes estratos sócioeconômicos e do tráfego de veículos em relação aos predominantes em cidades dos países desenvolvidos.

Na realidade do município de São Paulo, investigações sociológicas e históricas se fazem necessárias sobre o modo como se desenvolveu a rede viária e o tráfego de veículos em sua relação com os locais ocupados historicamente pelas diferentes classes sociais. Como a distribuição do tráfego influenciou a localização das populações e como esta influenciou aquela são questões que necessitam de melhor entendimento na busca de uma solução mais equitativa dos problemas ambientais causados pela poluição do ar decorrente do fluxo veicular excessivo.

Ressaltamos ainda, quanto a aspectos metodológicos, a necessidade de melhoria da qualidade dos registros de saúde para redução de perda e aumento da eficácia do geoprocessamento dos dados. 


\section{REFERÊNCIAS BIBLIOGRÁFICAS}

Abbey DE, Nishino N, McDonnell WF, Burchette RJ, Knutsen SF, Beeson L, et al. Long-term inhalable particles and other air pollutants related to mortality in nonsmokers. Am J Respir Crit Care Med. 1999;159:373-82.

Alazraqui M, Mota E, Spinelli H, Guevel C. Desigualdades em salud y desigualdades sociales: un abordaje epidemiológico en un município urbano de Argentina. Rev Panam Salud Publica. 2007;21(1):1-10.

Antunes JLF, Biazevic MGH, Araujo ME, Tomita NE, Chinellato LEM, Narvai PC. Trends and spatial distribution of oral cancer mortality in São Paulo, Brazil, 1980-1998. Oral Oncol. 2001;37:345-50.

Antunes JLF, Borrell C, Pérez G, Boing AF, Wünsch-Filho V. Inequalities in mortality of men by oral and pharyngeal cancer in Barcelona, Spain and São Paulo, Brazil, 1995-2003. Int J Equity Health. Jun. 2008a;7:14.

Antunes JLF, Borrell C, Rodriguez-Sanz M, Pérez G, Biazevic MGH, Wünsch-Filho V. Sex and socioeconomic inequalities of lung cancer mortality in Barcelona, Spain and São Paulo, Brazil. Eur J Cancer Prev. Oct. 2008b;17:399-405.

Beelen R, Hoek G, van den Brandt PA, Goldbohm RA, Fischer P, Schouten $L J$, et al. Long-term effects of traffic-related air pollution on mortality in a Dutch cohort (NLCS-AIR study). Environ Health Perspect. Feb. 2008a;116(2):196-202.

Beelen R, Hoek G, van den Brandt PA, Goldbohm RA, Fischer P, Schouten LJ, et al. Long-term exposure to traffic-related air pollution and lung cancer risk. Epidemiology. Sep. 2008b;19(5):702-10.

Beeson WL, Abbey DE, Knutsen SF. Long term concentrations of ambient air pollutants and incident lung cancer in California adults: results from the AHSMOG study. Environ Health Perspect. 1998;106(12):813-22.

Bonner MR, Han D, Nie J, Rogerson P, Vena JE, Muti P, et al. Breast cancer risk and exposure in early life to polycyclic aromatic hydrocarbons using total suspended particulates as a proxy measure. Cancer Epidemiol Biomakers Prev. 2005;14(1):53-60. 
Borges DML, Sena MF, Ferreira MAF, Roncalli AG. Mortalidade por câncer de boca e condição sócio-econômica no Brasil. Cad Saúde Pública. 2009;25(2):321-7.

Brown SBF, Hole DJ, Cooke TG. Breast cancer incidence trends in deprived and affluent Scottish women. Breast Cancer Res Treat. 2007;103:233-8.

Cangerana-Pereira FA. Estudo exploratório da influência da poluição do ar na incidência de câncer nos distritos do município de São Paulo [dissertação de mestrado]. São Paulo: Faculdade de Saúde Pública da USP; 2000.

Cardoso MRA. Estudo da relação entre doenças respiratórias e cardiovasculares nas regiões metropolitanas do estado de São Paulo com a finalidade de subsidiar a estruturação das atividades do programa de vigilância em saúde e qualidade do ar. São Paulo; mar. 2010.

Cavalini LT, De Leon ACMP. Morbidity and mortality in Brazilian municipalities: a multilevel study of the association between socioeconomic and healthcare indicators. Int J Epidemiol. 2008;37:775-85.

CETESB - Companhia de Tecnologia de Saneamento Ambiental. Relatório de qualidade do ar no estado de São Paulo 2008. São Paulo; 2009. Disponível em: http://www.cetesb.sp.gov.br/Ar/publicacoes.asp

Clarke CA, Glaser SL, Keegan THM, Stroup A. Neighborhood socioeconomic status and Hodgkin's lymphoma incidence in California. Cancer Epidemiol Biomakers Prev. 2005;14(6):1441-7.

Crosignani P, Tittarelli A, Borgini A, Codazzi T, Rovelli A, Porro E, et al. Childhood leukemia and road traffic: a population-based case-control study. Int J Cancer. 2004; 108(4):596-9.

Danaei G, Hoorn SV, Lopes AD, Murray CJL. Ezzati M. Causes of cancer in the world: comparative risk assessment of nine behavioural and environmental risk factors. Lancet. 2005;366:1784-93.

DATASUS - Departamento de Informática do SUS. Sistema de Informações sobre Mortalidade 1979 - 2006: dados de declaração de óbito. Brasília; 2006 [acesso em 22 jun 2009]. Disponível em: http://www.datasus.gov.br

DeChello LM, Sheehan, TJ. Spatial analysis of colorectal cancer incidence and proportion of late-stage in Massachusetts residents: 1995-1998. Int J Health Geogr. 2007;6:20. 
Deguen S, Zmirou-Navier D. Social inequalities resulting from health risks related to ambient air quality - A European review. Eur J Public Health. 2010;20(1):27-35.

DETRAN-SP - Departamento Estadual de Trânsito de São Paulo. Frota de veículos. São Paulo; [s.d] [acesso em 5 fev. 2010]. Disponível em: http://www.detran.sp.gov.br./frota/frota2009.asp

Downing A, Forman D, Gilthorpe MS, Edwards KL, Manda SOM. Joint disease mapping using six cancers in the Yorkshire region of England. Int $\mathrm{J}$ Health Geogr. 2008;7:41.

Drummond Jr M, Barros MBA. Desigualdades socioespaciais na mortalidade do adulto no município de São Paulo. Rev Bras Epidemiol. 1999; 2(1-2):3449.

Faggiano $F$, Partanen $T$, Kogevinas M, Boffetta P. Socioeconomic differences in cancer incidence and mortality. In: Kogevinas M, Pearce N, Susser M, Boffetta P, editors. Social inequalities and cancer. Lyon, France: IARC Sci Publ; 1997. v. 138, p. 65-176.

Faria MAM, Almeida JWR, Zanneta DMT. Mortalidade por câncer na região urbano-industrial da Baixada Santista, SP (Brasil). Rev Saúde Pública. 1999; 33(3):255-61.

Faria MAM, Almeida JWR, Zanneta DMT, Gattás, GJF. Nervous system cancer mortality in an industrialized area of Brazil 1980-1993. Arq Neuropsiquiatr. 2000;58(2B):412-7.

Faria MAM, Almeida JWR, Zanneta DMT. Gastric and colorectal cancer mortality in an urban and industrialized area of Brazil. Rev Hosp Clin Fac Med Sao Paulo. 2001;56(2):47-52.

Filleul L, Rondeau V, Vandentorren S, Moual NL, Cantagrel A, AnnesiMaesano I, et al. Twenty five year mortality and air pollution: results from the French PAARC survey. Occup Environ Med. 2005;62:453-60.

Fukuda Y, Umezaki M, Nakamura K, Takano T. Variations in societal characteristics of spatial disease clusters: examples of colon, lung and breast cancer in Japan. Int J Health Geogr. 2005;4:16.

Götschi T, Heinrich J, Sunyer J, Künzli N. Long-term effects of ambient air pollution on lung function: a review. Epidemiology. 2008;19(5):690-701.

Gouveia N, Mendonça GAS, De Leon AP, Correia JEM, Junger WL, Freitas $\mathrm{CU}$, et al. Poluição do ar e efeitos na saúde nas populações de duas grandes metrópoles brasileiras. Epidemiol Serv Saude. 2003;12(1):29-40. 
Guerra MR, Gallo CVM, Mendonça GAS. Risco de Câncer no Brasil: tendências e estudos epidemiológicos mais recentes. Revista Brasileira de Cancerologia. 2005;51(3):227-34.

Havard S, Deguen S, Zmirou-Navier D, Schillinger C, Bard D. Traffic-related air pollution and socioeconomic status: a spatial autocorrelation study to assess environmental equity on a small-area scale. Epidemiology; 2009;20(2):223-30.

Harrison RA, Haque AU, Roseman JM, Soong SJ. Socioeconomic characteristics and melanoma incidence. Ann Epidemiol. 1998;8(5):327-33.

Harrison RM, Leung PL, Somervaille L, Smith R, Gilman E. Analysis of incidence of childhood cancer in the West Midlands of the United Kingdom in relation to proximity to main roads and petrol stations. Occup Environ Med. 1999;56(11):774-80.

Hashibe M, Brennan P, Benhamou S, Castellsague X, Chen C, Curado MP et al. Alcohol drinking in never users of tobacco, cigarette smoking in never drinkers, and the risk of head and neck cancer: pooled analysis in the International Head and Neck Cancer Epidemiology Consortium. J Natl Cancer Inst. 2007;99:777-89.

HEI - Health Effects Institute. Traffic-related air pollution: a critical review of the literature on emissions, exposure, and health effects. Boston, Massachusetts; May 2009. (Special Report 17).

IARC - Internacional Agency for Research on Cancer. Diesel and gasoline engine exhausts and some nitrosarenes. Lyon, France: IARC Sci Publ; 1989. v. 46. (IARC monographs on the evaluation of carcinogenic risks to humans).

IBGE - Instituto Brasileiro de Geografia e Estatística. Censo demográfico 2000 agregado por setores censitários dos resultados do universo. 2. ed. Rio de Janeiro; 2003. Disponível em: http://www.ibge.com.br

IBGE - Instituto Brasileiro de Geografia e Estatística. Produto Interno Bruto dos Municípios 2002-2005. Rio de Janeiro; 2007. Disponível em: http://www.ibge.com.br

IBGE - Instituto Brasileiro de Geografia e Estatística. Estimativas das populações residentes, em $1^{\text {o }}$ de julho de 2009 , segundo os municípios. Rio de Janeiro; 2009 [acesso em 22 jun. 2009]. Disponível em: http://www.ibge.com.br/home/estatistica/populacao/estimativa2009/POP_200 9_TCU.pdf 
Ishitani LH, França E. Desigualdades socioespaciais e mortes precoces de adultos na região centro-sul do município de Belo Horizonte em 1996. Inf Epidemiol Sus. 2000:9(4):229-39.

Iwai K, Mizuno S, Miyasaka Y, Mori T. Correlation between suspended particles in the environmental air and causes of disease among inhabitants: cross-sectional studies using the vital statistics and air pollution data in Japan. Environ Res. 2005;99:106-17.

Jerret M, Arain A, Kanaroglou P, Beckerman B, Potoglou D, Sahsuvaroglu T, et al. A review and evaluation of intraurban air pollution exposure models. J Expo Anal Environ Epidemiol. 2005a;15(2):185-204.

Jerrett M, Buzzelli M, Burnett RT, DeLuca PF. Particulate air pollution, social confounders, and mortality in small areas of an industrial city. Soc Sci Med. 2005b;60:2845-63.

Jerret M, Burnett RT, Ma R, Pope III CA, Krewski D, Newbold KB, et al. Spatial analysis of air pollution and mortality in Los Angeles. Epidemiology. 2005c;16(6):727-36.

Kawachi I, Kroenke C. Socioeconomic disparities in cancer incidence and mortality. In: Schottenfeld D, Fraumeni Jr JF, editors. Cancer epidemiology and prevention. $3^{\text {rd }}$ edition. New York: Oxford University Press; 2006. p. 174188.

Klassen AC, Curriero FC, Hong JH, Williams C, Kulldorff M, Meissner HI, et al. The role of area-level influences on prostate cancer grade and stage at diagnosis. Prev Med. 2004:39:441-8.

Knox EG. Childhood cancers and atmospheric carcinogens. J Epidemiol Community Health. 2005;59:101-5.

Knox EG. Oil combustion and childhood cancers. J Epidemiol Community Health. 2005;59:755-60.

Knox EG. Roads, railways, and childhood cancers. J Epidemiol Community Health. 2006;60:136-41.

Kogevinas M, Pearce N, Susser M, Boffetta P. Social inequalities and cancer. Lyon, France: IARC Sci Publ; 1997. v. 138. Social inequalities and cancer; p. 1-15.

Kogevinas M, Porta M. Socioeconomic differences in cancer survival: a review of the evidence. In: Kogevinas M, Pearce N, Susser M, Boffetta P, editors. Social inequalities and cancer. Lyon, France: IARC Sci Publ; 1997. v. 138, p. 177-84. 
Laden F, Schwartz J, Speizer FE, Dockery DW. Reduction in fine particulate air pollution and mortality: extended follow-up of the Harvard Six Cities study. Am J Respir Crit Care Med. 2006;173:667-72.

Lancaster GA, Green M, Lane S. Linkage of survey data with district-level lung cancer registrations: a method of bias reduction in ecological studies. $J$ Epidemiol Community Health. 2006;60:1093-8.

Langholz B, Ebi KL, Thomas DC, Peters JM, London SJ. Traffic density and the risk of childhood leukemia in a Los Angeles case-control study. Ann Epidemiol. 2002;12(7):482-7.

Liu L, Deapen D, Bernstein L. Socioeconomic status and cancers of the female breast and reproductive organs: a comparison across racial/ethnic populations in Los Angeles County, California (United States). Cancer Causes Control. 1998;9:369-80.

Liu L, Cozen W, Bernstein L, Ross RK, Deapen D. Changing relationship between socioeconomic status and prostate cancer incidence. J Natl Cancer Inst. 2001;93:705-9.

Mackenbach JP, Bos V, Andersen O, Cardano M, Costa G, Harding S, et al. Widening socioeconomic inequalities in six Western European countries. Int J Epidemiol. 2003;32:830-7.

Martins LD. Martins JA, Freitas ED, Mazzoli CR, Gonçalves FLT, Ynoue RY, et al. Potential health impact of ultrafine particles under clean and polluted urban atmospheric conditions: a model-based study. Air Qual Atmos Health. 2010; 3:29-39.

Mcdonnell WF, Nishino-Ishikawa N, Petersen FF, Chen LH, Abbey DE. Relationships of mortality with the fine and coarse fractions of long-term ambient $\mathrm{PM}_{10}$ concentrations in nonsmokers. J Expo Anal Environ Epidemiol. 2000;10:427-36.

McFadden K, McConnell D, Salmond C, Crampton P, Fraser J. Socioeconomic deprivation and the incidence of cancer in New Zealand : 1988-1998. N Z Med J. 2004;117(1206).

Merkin SS, Stevenson L, Powe N. Geographic socioeconomic status, race, and advanced-stage breast cancer in New York city. Am J Public Health. 2002;92(1):64-70.

Naess O, Nafstad P, Aamodt G, Claussen B, Rosland P. Relation between concentration of air pollution and cause-specific mortality: four-year 
exposures to nitrogen dioxide and particulate matter pollutants in 470 neighborhoods in Oslo, Norway. Am J Epidemiol. 2007;165(4):435-43.

Nafstad P, Haheim LL, Oftedal B, Gram F, Holme I, Hjermann I, et al. Lung cancer and air pollution: a 27 year follow up of 16.209 Norwegian men. Thorax. 2003;58:1071-6.

Nafstad P, Haheim LL, Wisleff T, Gram F, Oftedal B, Holme I, et al. Urban air pollution and mortality in a cohort of Norwegian men. Environ Health Perspect. 2004; 112(5):610-5.

Ng E, Wilkins R, Fung MFK, Berthelot JM. Cervical cancer mortality by neighbourhood income in urban Canada from 1971 to 1976. CMAJ. 2004;170(10):1545-9.

Nie J, Beyea J, Bonner MR, Han D, Vena JE, Rogerson P, et al. Exposure to traffic emissions throughout life and risk of breast cancer: the Western New York Exposures and Brest Cancer (WEB) study. Cancer Causes Control. 2007;18:947-55.

Nyberg F, Gustavsson P, Järup L, Bellander T, Berglind N, Jakobsson R, et al. Urban air pollution and lung cancer in Stockholm. Epidemiology. 2000;11(5):487-95.

Ocaña-Riola R, Sánchez-Cantalejo C, Rosell J, Sánchez-Cantalejo E, Daponte A. Socio-economic level, farming activities and risk of cancer in small areas of Southern Spain. Eur J Epidemiol. 2004;19:643-50.

Oliver MN, Smith E, Siadaty M, Hauck FR, Pickle LW. Spatial analysis of prostate cancer incidence and race in Virginia, 1990-1999. Am J Prev Med. 2006;30(2S):S67-S75.

OMS - Organização Mundial da Saúde. Centro Colaborador da OMS para a Classificação de Doenças em Português. Classificação estatística internacional de doenças e problemas relacionados à saúde. Décima revisão. 9. ed. rev. São Paulo: Editora da Universidade de São Paulo; 2003.

O'Neill MS, Jerrett M, Kawachi I, Levy JI, Cohen AJ, Gouveia N, et al. Health, wealth, and air pollution: advancing theory and methods. Environ Health Perspect. 2003;111(16):1861-70.

Parkin DM, Bray F, Ferlay J, Pisani P. Global cancer statistics, 2002. CA Cancer J Clin. 2005;55(2):74-108.

Parkin DM. The evolution of the population-based cancer registry. Nat Rev Cancer. 2006;6:603-12. 
Pearson RL, Watchel H, Ebi KL. Distance-weighted traffic density in proximity to a home is a risk factor for leukemia and other childhood cancers. J Air Waste Manage Assoc. 2000;50(2):175-80.

Pedroso MM. Desenvolvimento humano no município de São Paulo (2000): uma cartografia socioeconômica como contribuição ao planejamento de políticas públicas [dissertação de mestrado]. São Paulo: Pontifícia Universidade Católica de São Paulo; 2003.

PNUD - Programa das Nações Unidas para o Desenvolvimento. Atlas do desenvolvimento humano no Brasil, versão 1.0.0 [software na internet]. Brasília; 2003 [acesso em 18 set. 2008]. Disponível em: http://www.pnud.org.br/atlas/

Pollack LA, Gotway CA, Bates JH, Parikh-Patel A, Richards TB, Seeff LC, et al. Use of spatial scan statistic to identify geographic variations in late stage colorectal cancer in California (United States). Cancer Causes Control. 2006;17:449-57.

Pope CA III, Burnett RT, Thun MJ, Calle EE, Krewski D, Ito K, et al. Lung cancer, cardiopulmonary mortality, and long-term exposure to fine particulate air pollution. JAMA. 2002;287(9):1132-41.

Pope CA III, Dockery DW. Health effects of fine particulate air pollution: lines that connect. J Air Waste Manage Assoc. 2006;56:709-42.

Pope CA III, Ezzati M, Dockery DW. Fine-particulate air pollution and life expectancy in the United States. N Engl J Med. 2009;360(4):376-86.

Prado COM. Câncer feminino: evolução da mortalidade por câncer de mama e do colo do útero em distritos do município de São Paulo, 1985-1999 [tese de doutorado]. São Paulo: Faculdade de Saúde Pública da USP; 2002.

Prehn AW, West DW. Evaluating local differences in breast cancer incidence rates: a census-based methodology (United States). Cancer Causes Control. 1998;9:511-7.

Raaschou-Nielsen $\mathrm{O}$, Hertel $\mathrm{O}$, Thomsen $\mathrm{BL}$, Olsen $\mathrm{JH}$. Air pollution from traffic at the residence of children with cancer. Am J Epidemiol. 2001; 153(5):433-43.

Raaschou-Nielsen O, Reynolds P. Air pollution and childhood cancer: a review of the epidemiological literature. Int J Cancer. 2006;118:2920-9.

Reis DO. Diferenças socioeconômicas na mortalidade por neoplasias malignas no município de São Paulo, 1997 [dissertação de mestrado]. São Paulo: Faculdade de Saúde Pública da USP; 2001. 
Reynolds P, Von Behren J, Gunier RB, Goldberg DE, Hertz A, Smith D. Traffic patterns and childhood cancer incidence rates in California, United States. Cancer Causes Control. 2002;13(7):665-73.

Reynolds P, Von Behren J, Gunier RB, Goldberg DE, Hertz A, Smith D. Childhood cancer incidence rates and hazardous air pollutants in California: an exploratory analysis. Environ Health Perspect. 2003;111(4):663-8.

Reynolds P, Von Behren J, Gunier RB, Goldberg DE, Hertz A. Residential exposure to traffic in California and childhood cancer. Epidemiology. 2004;15(1):6-12.

Rowan S. Trends in cancer incidence by deprivation, England and Wales, 1990-2002. Health Stat Q. 2007;36:24-35.

Samet JM, White $\mathrm{RH}$. Urban air pollution, health, and equity [editorial]. Epidemiol Community Health. 2004;58:3-5

Schwartz KL, Croosley-May H, Vigneau FD, Brown K, Banerjee M. Race, socioeconomic status and stage at diagnosis for five common malignancies. Cancer Causes Control. 2003;14:761-6.

SEADE - Fundação Sistema Estadual de Análise de Dados. Perfil do paulistano em 2007. São Paulo; jan. 2007 [acesso em 18 set. 2008] Disponível em: http://www.seade.gov.br/produtos/pdf/paulistano_2007.pdf

Secretaria Municipal de Planejamento. Município em mapas 2006. São Paulo; 2006. (Série temática: índices sociais). Disponível em: http://www9.prefeitura.sp.gov.br/sempla/mm/

Secretaria Municipal de Saúde. Coordenação de Epidemiologia e Informação. O impacto do câncer no município de São Paulo. São Paulo; nov. 2009. p. 32. (Boletim CEinfo Análise n. 3).

Sexton K; Adgate JL. Looking at environmental justice from an environmental health perspective. J Expo Anal Environ Epidemiol. 1999;9(1):3-8.

Shack L, Jordan C, Thomson CS, Mak V, Moller H. Variation in incidence of breast, lung and cervical cancer and malignant melanoma of skin by socioeconomic group in England. BMC Cancer. 2008;8:271.

Shipp MPL, Desmond R, Accortt N, Wilson RJ, Fouad M, Eloubeidi MA. Population-based study of the geographic variation in colon cancer incidence in Alabama: relationship to socioeconomic status indicators and physician density. South Med J. 2005;98(11):1076-81. 
Steffen C, Auclerc MF, Auvrignon A, Baruchel A, Kebaili K, Lambilliotte A, et al. Acute childhood leukaemia and environmental exposure to potential sources of benzene and other hydrocarbons: a case-control study. Occup Environ Med. 2004;61(9):773-8.

Suarez-Varela MMM, Jiménez-López MC, Llópis-González A. Socioeconomic factors and cervical cancer mortality in Spain during the period 1989-1997. Arch Gynecol Obstet. 2004;269:99-103.

Toledo GIFM. Avaliação da exposição á poluição relacionada ao tráfego na cidade de São Paulo, 2010 [tese de doutorado]. São Paulo: Faculdade de Saúde Pública da USP; 2010.

Ueda K, Tsukuma H, Ajiki W, Oshima A. Socioeconomic factors and cancer incidence, mortality, and survival in a metropolitan area of Japan: a crosssectional ecological study. Cancer Sci. 2005:96(10):684-8.

Vineis P, Hoek G, Krzyzanowsky, Vigna-Taglianti F, Veglia F, Airoldi L, et al. Air pollution and risk of lung cancer in a prospective study in Europe. Int $\mathrm{J}$ Cancer. 2006; 119:169-74.

Visser O, van Wijnen JH, van Leeuwen FE. Residential traffic density and cancer incidence in Amsterdam, 1989-1997. Cancer Causes Control. 2004;15:331-9.

Von Behren J, Reynolds P, Gunier RB, Rull RP, Hertz A, Urayama KY, et al. Residential traffic density and childhood leukemia risk. Cancer Epidemiol Biomarkers Prev. 2008;17(9):2298-301.

Weng $\mathrm{HH}$, Tsai SS, Chen CC, Chiu HF, Wu TN, Yang CY. Childhood leukemia development and correlation with traffic air pollution in Taiwan using nitrogen dioxide as an air pollutant marker. J Toxicol Environ Health A. 2008;71:434-8.

Whitworth KW, Symanski E, Coker AL. Childhood lymphohematopoietic cancer incidence and hazardous air pollutants in Southeast Texas, 19952004. Environ Health Perspect. 2008;116(11):1576-80.

WHO - World Health Organization. WHO air quality guidelines for particulate matter, ozone, nitrogen dioxide and sulfur dioxide: global update 2005. Geneva, Switzerland: WHO; 2006.

WHO - World Health Organization. Global health risks: mortality and burden of disease attributable to selected major risks. Geneva, Switzerland: WHO, 2009. 
Wünsch Filho V, Antunes JLF, Boing AF, Lorenzi RL. Perspectivas da investigação sobre determinantes sociais em câncer. Physis. 2008;18(3):427-50.

Wünsch Filho V, Moncau JE. Mortalidade por câncer no Brasil 1980-1995: padrões regionais e tendências temporais. Rev Assoc Med Bras. 2002; 48(3):250-7.

Xiao H, Gwede CK, Kiros G, Milla K. Analysis of prostate cancer incidence using geographic information system and multilevel modeling. J Natl Med Assoc. 2007:99(3):218-25.

Yanagi Y. Estudo da influência do material particulado na incidência e mortalidade por câncer na cidade de São Paulo [dissertação de mestrado]. São Paulo: Faculdade de Saúde Pública da USP; 2010.

Yost K, Perkins C, Cohen R, Morris C, Wright W. Socioeconomic status and breast cancer incidence in California for different race/ethnic groups. Cancer Causes Control. 2001;12:703-11.

Zago A, Pereira LAA, Braga ALF, Bousquat A. Mortalidade por câncer de mama em mulheres na Baixada Santista, 1980 a 1999. Rev Saúde Pública. 2005;39(4):641-5. 


\section{Anexo 1}

Quadro 5- Relação de estudos ecológicos nacionais sobre câncer. 1998-2008.

\begin{tabular}{|c|c|c|c|c|c|c|c|c|}
\hline $\begin{array}{c}\text { Autores e } \\
\text { ano de } \\
\text { publicação }\end{array}$ & $\begin{array}{l}\text { Local e } \\
\text { período }\end{array}$ & $\begin{array}{l}\text { Desfecho(s) } \\
\text { estudado(s) }\end{array}$ & $\begin{array}{c}\text { Nível de } \\
\text { agregação }\end{array}$ & $\begin{array}{c}\text { Número e } \\
\text { idade de } \\
\text { casos } \\
\end{array}$ & $\begin{array}{c}\text { Fonte de } \\
\text { dados dos } \\
\text { casos } \\
\end{array}$ & $\begin{array}{c}\text { Análise } \\
\text { estatística }\end{array}$ & $\begin{array}{l}\text { Variáveis sócio- } \\
\text { econômicas }\end{array}$ & Comentários \\
\hline $\begin{array}{l}\text { Faria et al., } \\
1999\end{array}$ & $\begin{array}{l}\text { Baixada } \\
\text { Santista; 1980- } \\
1993\end{array}$ & $\begin{array}{l}\text { Mortalidade } \\
\text { por Câncer } \\
\text { em geral }\end{array}$ & $\begin{array}{l}\text { Município e } \\
\text { conjunto de } \\
\text { municípios }\end{array}$ & $\begin{array}{l}8.546 \text { casos; } \\
\text { (idade de } 10 \\
\text { anos ou mais) }\end{array}$ & $\begin{array}{l}\text { Sistema de } \\
\text { Informação } \\
\text { de } \\
\text { Mortalidade }\end{array}$ & $\begin{array}{l}\text { Razão de taxas } \\
\text { de mortalidade } \\
\text { padronizadas } \\
\text { por idade com } \\
\text { IC95\% }\end{array}$ & $\begin{array}{l}\text { Áreas } \\
\text { industrializadas x } \\
\text { áreas não } \\
\text { industrializadas }\end{array}$ & $\begin{array}{l}\text { Ajuste para } \\
\text { idade. Análise } \\
\text { restrita ao gênero } \\
\text { masculino }\end{array}$ \\
\hline $\begin{array}{l}\text { Drummond } \\
\text { Jr e Barros, } \\
1999\end{array}$ & 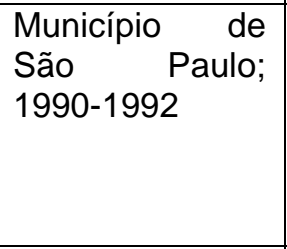 & \begin{tabular}{l}
\multicolumn{2}{l}{ Mortalidade } \\
por diversos \\
tipos de \\
Câncer
\end{tabular} & $\begin{array}{l}\text { Distrito } \\
\text { municipal }\end{array}$ & $\begin{array}{l}\text { Não disponível } \\
\text { (idade de } 15 \text { a } \\
64 \text { anos) }\end{array}$ & $\begin{array}{l}\text { Fundação } \\
\text { SEADE }\end{array}$ & $\begin{array}{l}\text { Razão de taxas } \\
\text { de mortalidade } \\
\text { padronizadas } \\
\text { por idade e } \\
\text { teste de } \\
\text { significância } \\
\end{array}$ & $\begin{array}{l}\text { Índice de status } \\
\text { sócio-econômico }\end{array}$ & $\begin{array}{l}\text { Ajuste } \\
\text { idade. } \\
\text { estratificada para } \\
\text { gnase } \\
\text { gênero. Não se } \\
\text { calcularam os IC } \\
95 \%\end{array}$ \\
\hline $\begin{array}{l}\text { Faria et al., } \\
2000\end{array}$ & $\begin{array}{l}\text { Baixada } \\
\text { Santista; 1980- } \\
1993\end{array}$ & $\begin{array}{l}\text { Mortalidade } \\
\text { por Câncer } \\
\text { do SNC }\end{array}$ & $\begin{array}{l}\text { Município e } \\
\text { conjuntos de } \\
\text { municípios }\end{array}$ & $\begin{array}{l}103 \text { casos; } \\
\text { (idade de } 10 \\
\text { anos ou mais) }\end{array}$ & $\begin{array}{l}\text { Sistema de } \\
\text { Informação } \\
\text { de } \\
\text { Mortalidade }\end{array}$ & $\begin{array}{l}\text { Razão de taxas } \\
\text { de mortalidade } \\
\text { padronizadas } \\
\text { por idade com } \\
\text { IC95\% }\end{array}$ & $\begin{array}{l}\text { Áreas } \\
\text { industrializadas x } \\
\text { áreas não } \\
\text { industrializadas }\end{array}$ & $\begin{array}{l}\text { Ajuste para } \\
\text { idade. Análise } \\
\text { restrita ao gênero } \\
\text { masculino }\end{array}$ \\
\hline $\begin{array}{l}\text { Ishitani e } \\
\text { França, } \\
2000\end{array}$ & $\begin{array}{lr}\text { Região } & \text { centro- } \\
\text { sul do município } \\
\text { de } & \text { Belo } \\
\text { Horizonte; } & 1996\end{array}$ & $\begin{array}{l}\text { Mortalidade } \\
\text { por Câncer } \\
\text { em geral e } \\
\text { alguns tipos }\end{array}$ & $\begin{array}{l}\text { Conjunto de } \\
\text { bairros e de } \\
\text { favelas }\end{array}$ & $\begin{array}{l}722 \text { casos; } \\
\text { (idade de } 20 \text { a } \\
69 \text { anos) }\end{array}$ & $\begin{array}{l}\text { Sistema de } \\
\text { Informação } \\
\text { de } \\
\text { Mortalidade }\end{array}$ & $\begin{array}{l}\text { Razão de taxas } \\
\text { de mortalidade } \\
\text { padronizadas } \\
\text { por idade }\end{array}$ & $\begin{array}{l}\text { Área de bairros } x \\
\text { áreas de favelas }\end{array}$ & $\begin{array}{l}\text { Ajuste para } \\
\text { idade. Não se } \\
\text { calcularam os IC } \\
95 \%\end{array}$ \\
\hline $\begin{array}{l}\text { Faria et al.. } \\
2001\end{array}$ & $\begin{array}{l}\text { Baixada } \\
\text { Santista; 1980- } \\
1993\end{array}$ & $\begin{array}{l}\text { Mortalidade } \\
\text { por Câncer } \\
\text { de Estômago } \\
\text { e Colorretal }\end{array}$ & $\begin{array}{l}\text { Município e } \\
\text { conjuntos de } \\
\text { municípios }\end{array}$ & $\begin{array}{l}1.105 \text { casos } \\
\text { (estômago) e } \\
690 \text { (colorretal); } \\
\text { (idade de } 10 \\
\text { anos ou mais) }\end{array}$ & $\begin{array}{l}\text { Sistema de } \\
\text { Informação } \\
\text { de } \\
\text { Mortalidade }\end{array}$ & $\begin{array}{l}\text { Razão de taxas } \\
\text { de mortalidade } \\
\text { padronizadas } \\
\text { por idade com } \\
\text { IC95\% }\end{array}$ & $\begin{array}{l}\text { Áreas } \\
\text { industrializadas x } \\
\text { áreas não } \\
\text { industrializadas }\end{array}$ & $\begin{array}{l}\text { Ajuste para } \\
\text { idade. Análise } \\
\text { restrita ao gênero } \\
\text { masculino }\end{array}$ \\
\hline
\end{tabular}




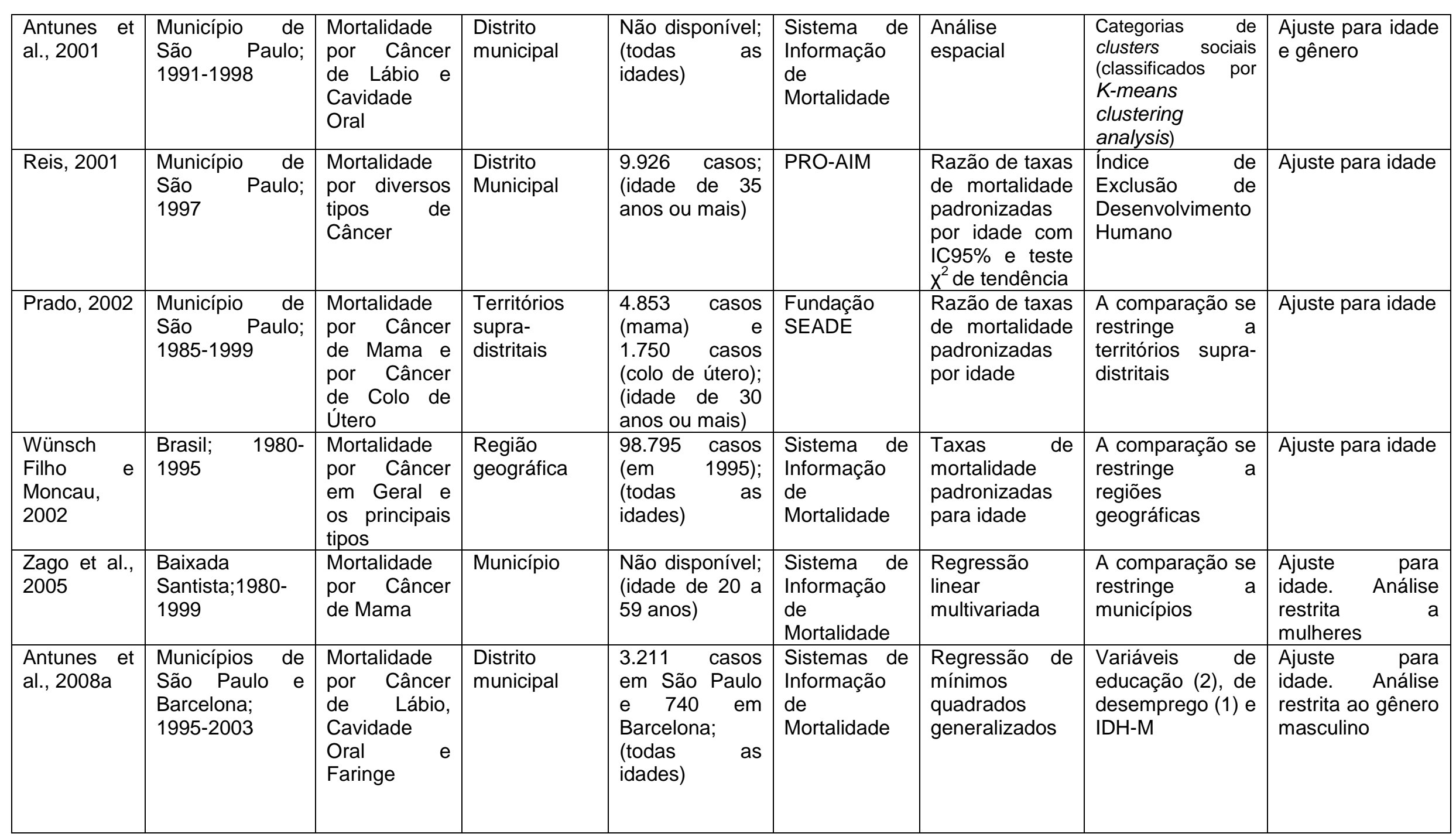




\begin{tabular}{|c|c|c|c|c|c|c|c|c|}
\hline $\begin{array}{l}\text { Antunes et } \\
\text { al., 2008b }\end{array}$ & $\begin{array}{ll}\text { Municípios } & \text { de } \\
\text { São Paulo e } \\
\text { Barcelona; } \\
\text { 1995-2003 }\end{array}$ & $\begin{array}{l}\text { Mortalidade } \\
\text { por Câncer } \\
\text { de Pulmão, } \\
\text { Traquéia e } \\
\text { Brônquios }\end{array}$ & $\begin{array}{l}\text { Distrito } \\
\text { municipal }\end{array}$ & $\begin{array}{l}12.444 \text { casos } \\
\text { em São Paulo } \\
\text { e } 7.836 \text { em } \\
\text { Barcelona; } \\
\text { (idade de } 35 \\
\text { anos ou mais) }\end{array}$ & $\begin{array}{l}\text { Sistemas de } \\
\text { Informação } \\
\text { de } \\
\text { Mortalidade }\end{array}$ & $\begin{array}{l}\text { Regressão de } \\
\text { Poisson }\end{array}$ & IDH-M & $\begin{array}{lr}\text { Ajuste r para } \\
\text { idade. Análise } \\
\text { estratificada por } \\
\text { gênero }\end{array}$ \\
\hline $\begin{array}{l}\text { Cavalini e } \\
\text { De Leon, } \\
2008\end{array}$ & Brasil; 2001 & $\begin{array}{l}\text { Mortalidade } \\
\text { por Câncer } \\
\text { em geral }\end{array}$ & Município & $\begin{array}{l}\text { Não disponível; } \\
\text { (todas as } \\
\text { idades) }\end{array}$ & $\begin{array}{l}\text { Sistema de } \\
\text { Informação } \\
\text { de } \\
\text { Mortalidade }\end{array}$ & $\begin{array}{lr}\text { Regressão } & \text { de } \\
\text { Poisson } & \text { de } \\
\text { múltiplos níveis }\end{array}$ & \begin{tabular}{lr}
\multicolumn{2}{l}{ Renda per capita, } \\
índice de & Theil, \\
razão & de \\
dependência & de \\
idosos, & \\
proporção & de \\
crianças & na \\
escola & \\
\end{tabular} & Não houve ajuste \\
\hline $\begin{array}{l}\text { Borges et } \\
\text { al., } 2009\end{array}$ & $\begin{array}{lr}\text { Capitais } & \text { do } \\
\text { Brasil; } & 1998- \\
2002 & \end{array}$ & $\begin{array}{l}\text { Mortalidade } \\
\text { por Câncer } \\
\text { de Cavidade } \\
\text { Oral }\end{array}$ & $\begin{array}{l}\text { Região } \\
\text { geográfica }\end{array}$ & \begin{tabular}{lr}
\multicolumn{2}{|l|}{ Não disponível; } \\
(todas & as \\
idades) &
\end{tabular} & $\begin{array}{l}\text { Sistema de } \\
\text { Informação } \\
\text { de } \\
\text { Mortalidade }\end{array}$ & $\begin{array}{l}\text { Regressão } \\
\text { linear } \\
\text { (correlação de } \\
\text { Pearson) }\end{array}$ & $\begin{array}{l}\text { IDH-M, renda per } \\
\text { capita, taxa de } \\
\text { mortalidade } \\
\text { infantil, índice de } \\
\text { Gini }\end{array}$ & Não houve ajuste \\
\hline
\end{tabular}

IC 95\%: Intervalo de Confiança de 95\%; IDH-M: Índice de Desenvolvimento Humano Municipal; PRO-AIM: Programa de Aprimoramento das Informações de Mortalidade da Secretaria Municipal de Saúde de São Paulo; SEADE: Fundação Sistema Estadual de Análise de Dados; SNC: Sistema Nervoso Central; Teste $X^{2}$ : teste Qui-Quadrado 
FARIA et al. (1999), visando investigar a relação entre câncer e industrialização, observaram excesso de mortalidade total por câncer na população masculina da Baixada Santista em relação à capital do Estado, ao Estado de São Paulo e ao Brasil, no período de 1980 a 1993. Verificou-se que esse excesso decorria da maior taxa de mortalidade de câncer em geral, padronizada por idade, na população masculina do complexo industrialportuário (Santos, São Vicente, Cubatão, Guarujá) em relação à região não industrializada (Praia Grande, Mongaguá, Itanhaém, Peruíbe) da Baixada Santista, diferença estatisticamente significante. Os autores consideraram a exposição ocupacional e a poluição ambiental por agentes carcinógenos, geradas pelo processo de industrialização ocorrido nas últimas 4 décadas no complexo industrial-portuário, como importantes fatores que poderiam explicar a diferença constatada.

Em dois outros estudos, com a mesma metodologia, na mesma região e durante o mesmo período, FARIA et al. $(2000,2001)$ observaram maiores taxas significantes de mortalidade de câncer colorretal e do sistema nervoso central (SNC), padronizadas pela idade, na população masculina do complexo industrial-portuário em relação àquela da região não industrializada, mas o câncer gástrico não mostrou diferença significante entre as duas regiões. Essas diferenças foram interpretadas da mesma forma que a ocorrida no primeiro estudo. Notou-se redução significante na mortalidade por câncer gástrico e ausência de alteração significante na mortalidade por cânceres colorretal e do SNC no período estudado de 1980 a 1993.

Estudo empreendido no município de São Paulo, entre 1990 e 1992, investigou as desigualdades sociais na mortalidade no adulto por diversas causas, por meio da divisão dos seus distritos constituintes em 4 estratos sócio-econômicos, de acordo com índice distrital composto por diversas variáveis sócio-econômicas. Os homens residentes dos estratos mais pobres apresentaram maior risco de morte por câncer de esôfago, estômago e laringe, e as mulheres aí residentes por câncer de esôfago, estômago, fígado, laringe e colo uterino. Nos estratos mais ricos, mortalidade 
aumentada foi verificada, nos homens, para câncer de pulmão, cólon e fígado, e nas mulheres, para câncer de pulmão, cólon e mama. As associações não foram estatisticamente significantes, sendo que gradiente dose-resposta linear entre os diversos estratos considerados ocorreu em poucos casos (DRUMMOND JR E BARROS, 1999).

ISHITANI e FRANÇA (2000) compararam a mortalidade por diversas causas, segundo a residência em área de favelas ou de bairros, dos adultos moradores da região centro-sul do município de Belo Horizonte no ano de 1996. Verificou-se que as taxas de mortalidade de câncer em geral padronizadas por idade eram maiores na área das favelas que na dos bairros. Os cânceres de traquéia, brônquio e pulmões e o de estômago também apresentaram maior risco de morte na área de favelas, enquanto o colorretal na área dos bairros. Não foram apresentados os intervalos de confiança.

Em estudo enfocando a mortalidade por câncer de lábio e cavidade oral no município de São Paulo, ANTUNES et al. (2001) realizaram análise espacial, em nível distrital, no período de 1991 a 1998, observando que os distritos com pior perfil de mortalidade por tal câncer foram aqueles que apresentaram maior desigualdade na distribuição de renda (expressa pelo coeficiente de Gini), maiores taxas de analfabetismo e de desemprego, maior número médio de pessoas por cômodo em domicílio e menores níveis de renda média domiciliar e de grau acadêmico e vice-versa, com tendência temporal à polarização da doença nas áreas mais carentes. As taxas municipais de mortalidade e incidência ajustadas pela idade por esses tipos de cânceres permaneceram estacionárias no período de 1980 a 1998.

Por sua vez, REIS (2001) analisou a mortalidade pelos tipos mais comuns de câncer em relação ao índice de exclusão de desenvolvimento humano de distrito do município de São Paulo, no ano de 1997. Observaram risco aumentado de morte por câncer de pulmão e cólon, nos homens residentes dos distritos mais afluentes, e de mama e cólon, nas mulheres aí residentes. Por outro lado, ocorreu aumento de risco nos residentes dos distritos mais pobres do sexo masculino para os cânceres de estômago, 
esôfago e laringe, e do sexo feminino, para os de estômago, esôfago e de colo uterino. Embora não se tenha verificado gradiente dose-resposta linear para a maioria desses desfechos, o teste de tendência qui-quadrado se mostrou significante para todos eles.

PRADO (2002) escolheu territórios no interior do município de São Paulo e classificou-os, segundo critérios histórico-sociais, em 4 categorias, a saber, os das elites, operários 1, operários 2 e os periféricos, analisando a mortalidade por neoplasias femininas e a sua evolução ao longo do período de 1985 a 1999. Em 1985, a mortalidade por câncer de mama padronizada por idade era mais alta nos territórios das elites e bem menor nos periféricos, enquanto no tocante à mortalidade padronizada por câncer de colo uterino o contrário se verificava, com valores intermediários nos territórios operários. Observou-se, ao longo do período estudado, que nos territórios ocupados pelas elites, a mortalidade por câncer de mama padronizada por idade manteve-se estável nesse período, ao passo que nos demais territórios ela aumentou sistematicamente, com crescimento mais acelerado nas áreas periféricas. Por outro lado, a mortalidade por câncer de colo de útero padronizada por idade decresceu de forma distinta nos territórios, com exceção dos operários 1 , onde aumentou. A diminuição foi mais expressiva nos territórios das elites. De tal forma, que se observou uma diminuição das disparidades em saúde em relação à mortalidade por câncer de mama em favor das populações femininas dos territórios mais afluentes, e um aumento dessas quanto à mortalidade por câncer de colo uterino em prejuízo das populações dos territórios mais pobres.

Visando descrever a distribuição da mortalidade por câncer nas populações das cinco regiões geográficas brasileiras e avaliar a tendência temporal da doença no período compreendido entre 1980 e 1995, WÜNSCH FILHO e MONCAU (2002) verificaram que as taxas de mortalidade, padronizadas por idade, por câncer em geral e por todos os tipos específicos de câncer (com exceção do de colo de útero) foram mais altas nas regiões Sul e Sudeste e expressivamente mais baixas na região Nordeste, em relação às demais regiões. Porém, as taxas de mortalidade por câncer em 
geral, no período examinado, apresentaram tendência declinante nas regiões Sul e Sudeste, com melhores indicadores sócio-econômicos, e ascendente nas regiões Norte, Nordeste e Centro-Oeste, as menos desenvolvidas. Entre os determinantes das tendências e padrões de mortalidade observados, os autores apontaram as diferenças inter-regionais na prevalência de fatores de risco e exposições específicas, no acesso ao diagnóstico e tratamento de câncer, na qualidade dos registros de morte, além de fatores temporais, geográficos, socioeconômicos e políticos. No Brasil como um todo, ao longo do período de estudo, notou-se discreta queda da mortalidade por câncer.

ZAGO et al. (2005), em estudo com metodologia semelhante aos de FARIA et. al (1999, 2000, 2001), na Baixada Santista, entre 1980 a 1999, verificaram que Santos apresentava taxas de mortalidade por câncer de mama significantemente superiores às encontradas nas demais cidades da região, na capital paulista, no Estado de São Paulo e no Brasil, durante todo o período do estudo. São Vicente, Cubatão, Itanhaém e Peruíbe também apresentavam taxas superiores às do Estado de São Paulo e Brasil, em 1999, de forma significativa. Notou-se padrão consistente de aumento nas taxas de mortalidade por câncer de mama em todos os municípios estudados da região ao longo do período de estudo. Tais observações foram atribuídas a diversos fatores tradicionalmente associados a esse tipo de câncer, mas também à exposição aumentada a poluentes ambientais carcinogênicos em algumas cidades da Baixada Santista.

Com o objetivo de comparar as desigualdades sócio-econômicas na mortalidade masculina por câncer de lábio, cavidade oral e faringe, em Barcelona (Espanha) e em São Paulo, no período de 1995 a 2003, ANTUNES et al. (2008a) realizaram correlações, em nível distrital, entre as taxas anuais de mortalidade ajustadas por idade por essas neoplasias malignas na população masculina e variáveis sócio-econômicas, a saber taxa de desemprego, instrução insuficiente, IDH-M e grau acadêmico. Em geral, as duas primeiras variáveis se correlacionaram positivamente e as duas últimas negativamente com a mortalidade. Encontraram distribuição 
desigual e iníqua da doença, nas duas cidades, com áreas mais pobres tendendo a apresentar maior mortalidade. Apesar de ambas as cidades apresentarem elevada mortalidade por câncer oral e de faringe, Barcelona apresentou menor magnitude de mortes, tendência a diminuição, com uma maior polarização das neoplasias em áreas mais pobres, do que São Paulo, que apresentou tendência estacionária.

ANTUNES et al. (2008b) analisaram a mortalidade por câncer de pulmão em Barcelona e em São Paulo, entre 1995 e 2003, por meio da divisão dos seus distritos constituintes em 3 estratos sócio-econômicos a partir do Índice de Desenvolvimento Humano (IDH-M) distrital. Observaram, em Barcelona, risco aumentado de morte por esse câncer nos homens residentes no estrato mais pobre, com gradiente dose-resposta, e em mulheres tanto do estrato mais rico quanto do mais pobre. Em São Paulo, por sua vez, a elevação do risco de morte se verificou nos homens residentes no estrato mais rico, com gradiente dose-resposta, e nas mulheres desse mesmo estrato, sem tal gradiente. Barcelona apresentou maior magnitude de mortalidade por câncer de pulmão nos homens que São Paulo, com tendência declinante no primeiro município e estacionária no segundo. Já para as mulheres, a mortalidade foi semelhante nos dois municípios, com tendência ascendente no primeiro e estacionária no segundo.

Empreendeu-se estudo, com o objetivo de avaliar a associação de indicadores sócio-econômicos e de cuidados em saúde com indicadores de morbidade e mortalidade de vários desfechos em saúde, em 5505 municípios brasileiros, em 2001, observando-se uma associação positiva entre as taxas de mortalidade por neoplasias, com efeito dose-resposta, e a razão de dependência para 65 anos ou mais, a renda per capita, a desigualdade na distribuição de renda (avaliada pelo índice de Theil) e a proporção de crianças entre 7 e 14 anos que freqüentavam a escola (CAVALINI e DE LEON, 2008).

Já BORGES et. al. (2009), ao correlacionar os índices de mortalidade proporcional, nas capitais do Brasil, agrupadas por regiões geográficas, no 
período de 1998 a 2002, com indicadores sócio-econômicos, verificaram que a mortalidade por câncer de cavidade oral apresentava correlação positiva e significativa com o Índice de Desenvolvimento Humano Municipal, com os seus três subíndices constituintes referentes à renda, educação e longevidade e com a renda per capita e correlação negativa e significativa com a mortalidade infantil. Não se observou correlação com o índice de Gini. As regiões com melhores índices sócio-econômicos, Sul e Sudeste, apresentaram maiores índices de mortalidade por câncer oral, o que foi interpretado como devido à maior expectativa de vida e à melhor notificação dos registros nas capitais dessas regiões. 


\section{Anexo 2}

Quadro 6 - Relação de estudos ecológicos internacionais de desigualdades sócio-econômicas em câncer. 1998-2008.

\begin{tabular}{|c|c|c|c|c|c|c|c|c|}
\hline $\begin{array}{c}\text { Autores e } \\
\text { ano de } \\
\text { publicação }\end{array}$ & $\begin{array}{l}\text { Local e } \\
\text { período }\end{array}$ & $\begin{array}{l}\text { Desfecho(s) } \\
\text { Estudado(s) }\end{array}$ & $\begin{array}{c}\text { Nível de } \\
\text { agregação }\end{array}$ & $\begin{array}{c}\text { Número, } \\
\text { atributo(s) e } \\
\text { idade de casos }\end{array}$ & $\begin{array}{c}\text { Fonte de } \\
\text { dados dos } \\
\text { casos }\end{array}$ & $\begin{array}{c}\text { Análise } \\
\text { estatística }\end{array}$ & $\begin{array}{l}\text { Variáveis sócio- } \\
\text { econômicas }\end{array}$ & Comentários \\
\hline $\begin{array}{l}\text { Harrison et } \\
\text { al., } 1998\end{array}$ & $\begin{array}{l}\text { EUA; } \\
1993\end{array}$ & $\begin{array}{l}\text { Incidência de } \\
\text { Melanoma } \\
\text { Maligno }\end{array}$ & Condado & $\begin{array}{ll}54.979 & \text { casos; } \\
\text { raça } & \text { branca; } \\
\text { (idade de } 15 \\
\text { anos ou mais) }\end{array}$ & $\begin{array}{l}\text { Registro do } \\
\text { SEER } \\
\text { (Surveillance, } \\
\text { Epidemiology } \\
\text { and End } \\
\text { Results) }\end{array}$ & $\begin{array}{l}\text { Regressão } \\
\text { de Poisson } \\
\text { de múltiplos } \\
\text { níveis }\end{array}$ & $\begin{array}{lr}\begin{array}{l}\text { Variáveis } \\
\text { educação }\end{array} & \text { de } \\
\text { renda } & (1), \\
\text { pobreza (1) } & \text { para } \\
1950,1960,1970 \\
\text { e } 1980\end{array}$ & $\begin{array}{l}\text { Ajuste para etnia, } \\
\text { latitude, gênero, } \\
\text { idade e período } \\
\text { de diagnóstico }\end{array}$ \\
\hline $\begin{array}{l}\operatorname{Liu}_{1998} \text { et al., } \\
\end{array}$ & $\begin{array}{lr}\text { Los } & \text { Angeles, } \\
\text { EUA; } & 1972- \\
1992 & \end{array}$ & $\begin{array}{l}\text { Incidência de } \\
\text { Câncer de } \\
\text { Mama, } \\
\text { Ovário, Corpo } \\
\text { e Colo de } \\
\text { Útero }\end{array}$ & $\begin{array}{l}\text { Census tract } \\
\text { (com } \\
\text { população } \\
\text { média de } \\
4000 \\
\text { residentes) }\end{array}$ & $\begin{array}{l}82.453 \text { (mama); } \\
13.002 \text { (ovário); } \\
21.667 \text { (corpo do } \\
\text { útero); 10.697 } \\
\text { (colo de útero); } \\
\text { (idade de } 15 \\
\text { anos ou mais) }\end{array}$ & $\begin{array}{lr}\text { Programa } & \text { de } \\
\text { Vigilância } & \text { de } \\
\text { Câncer } & \text { do } \\
\text { Condado de } \\
\text { Los Angeles } \\
\text { (registro de } \\
\text { base } \\
\text { populacional) }\end{array}$ & $\begin{array}{l}\text { Regressão } \\
\text { de Poisson }\end{array}$ & $\begin{array}{l}\text { Índice de status } \\
\text { sócio-econômico } \\
\text { (método } \\
\text { desenvolvido } \\
\text { pelos } \\
\text { pesquisadores) }\end{array}$ & $\begin{array}{l}\text { Ajuste para idade } \\
\text { e raça / etnia. } \\
\text { Análise adicional } \\
\text { estratificada por } \\
\text { raça / etnia }\end{array}$ \\
\hline $\begin{array}{l}\text { Prehn e } \\
\text { West, } 1998\end{array}$ & $\begin{array}{l}\text { Baía de } \\
\text { Francisco } \\
\text { arredores, } \\
\text { EUA; } \\
1992\end{array}$ & $\begin{array}{ll}\text { Incidência } & \text { de } \\
\text { Câncer } & \text { de } \\
\text { Mama } & \end{array}$ & $\begin{array}{l}\text { Census block } \\
\text { group (com } \\
\text { população } \\
\text { média de } \\
1000 \\
\text { residentes) }\end{array}$ & $\begin{array}{lr}22.757 & \text { casos; } \\
\text { raça } & \text { branca, } \\
\text { etnia } & \text { não- } \\
\text { hispânica; } & \text { (todas } \\
\text { as idades) } & \end{array}$ & $\begin{array}{l}\text { Registro de } \\
\text { Câncer da Área } \\
\text { da Grande } \\
\text { Baía (de base } \\
\text { populacional) }\end{array}$ & $\begin{array}{l}\text { Razão de } \\
\text { taxas de } \\
\text { incidência } \\
\text { padronizadas } \\
\text { por idade } \\
\text { com IC95\% }\end{array}$ & 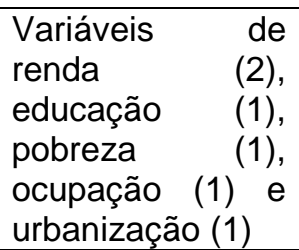 & dade \\
\hline $\operatorname{Liu}_{2001}$ et al., & $\begin{array}{lr}\text { Los } & \text { Angeles, } \\
\text { EUA; } & 1972- \\
1997 & \end{array}$ & $\begin{array}{ll}\text { Incidência } & \text { de } \\
\text { Câncer } & \text { de } \\
\text { Próstata } & \end{array}$ & $\begin{array}{l}\text { Census tract } \\
\text { (com } \\
\text { população } \\
\text { média de } \\
4000 \\
\text { residentes) }\end{array}$ & $\begin{array}{l}80.704 \text { casos } \\
\text { (todas as idades) }\end{array}$ & $\begin{array}{ll}\text { Programa } & \text { de } \\
\text { Vigilância } & \text { de } \\
\text { Câncer } & \text { do } \\
\text { Condado de } \\
\text { Los Angeles } \\
\text { (de base } \\
\text { populacional) }\end{array}$ & $\begin{array}{l}\text { Taxas de } \\
\text { incidência } \\
\text { padronizadas } \\
\text { por idade e } \\
\text { raça / etnia e } \\
\text { teste de } \\
\text { tendência }\end{array}$ & $\begin{array}{l}\text { Índice de status } \\
\text { sócio-econômico } \\
\text { (desenvolvido } \\
\text { pelos próprios } \\
\text { pesquisadores) }\end{array}$ & $\begin{array}{l}\text { Ajuste para idade } \\
\text { e raça / etnia. } \\
\text { Análise adicional } \\
\text { estratificada por } \\
\text { raça / etnia }\end{array}$ \\
\hline
\end{tabular}




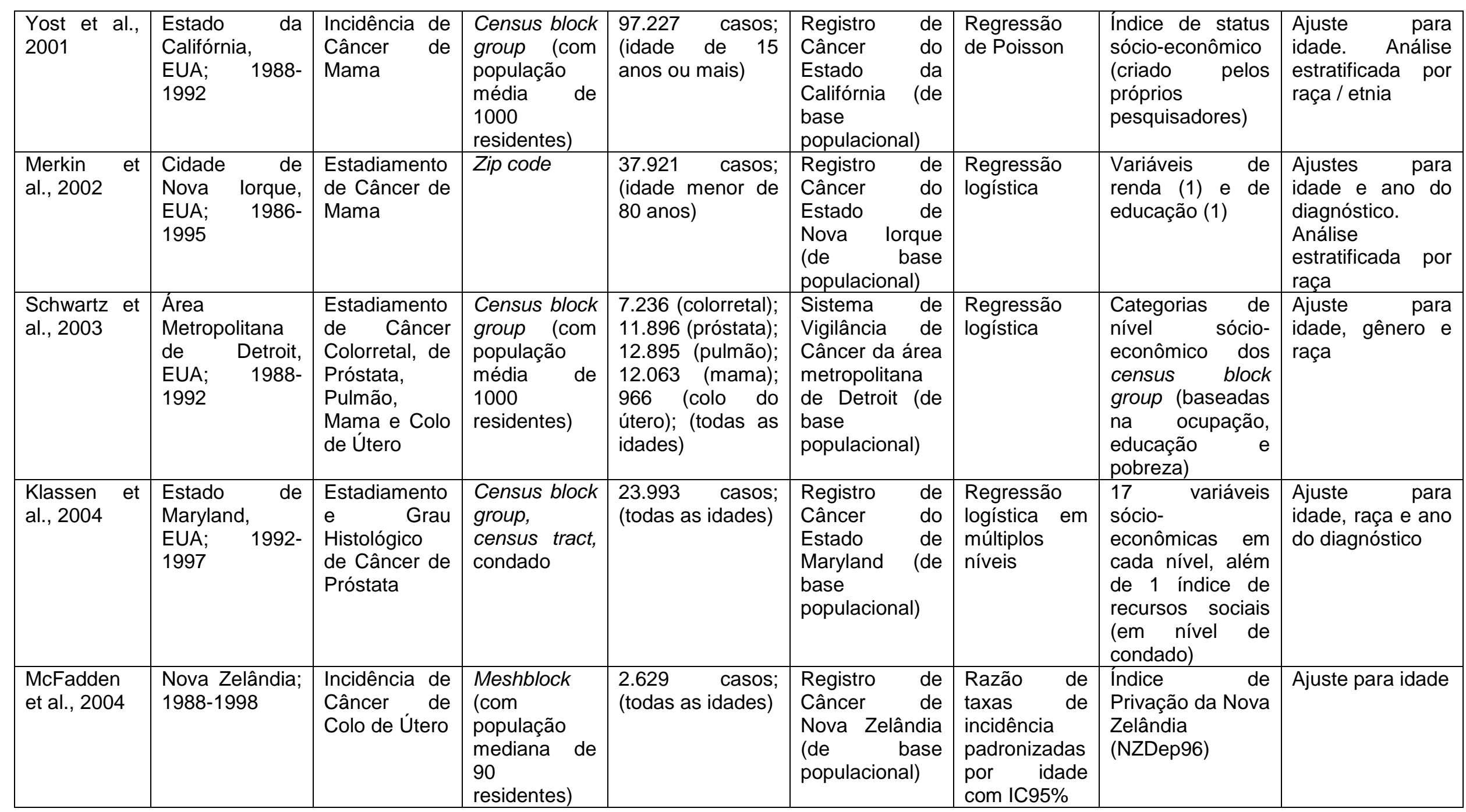




\begin{tabular}{|c|c|c|c|c|c|c|c|c|}
\hline $\begin{array}{l}\mathrm{Ng} \text { et al., } \\
2004\end{array}$ & $\begin{array}{l}\text { Canadá, 1971, } \\
\text { 1986, } 1991 \text { e } \\
1996\end{array}$ & $\begin{array}{l}\text { Mortalidade } \\
\text { por Câncer } \\
\text { de Colo de } \\
\text { Útero }\end{array}$ & $\begin{array}{l}\text { Census tract } \\
\text { (com } \\
\text { população } \\
\text { média de } \\
4000 \\
\text { residentes) }\end{array}$ & $\begin{array}{l}1.064 \text { casos; } \\
\text { (todas as idades) }\end{array}$ & $\begin{array}{l}\text { Declarações de } \\
\text { óbito }\end{array}$ & $\begin{array}{l}\text { Razão de } \\
\text { taxas de } \\
\text { mortalidade } \\
\text { padronizadas } \\
\text { por idade } \\
\text { com IC95\% }\end{array}$ & $\begin{array}{l}\text { Proporção da } \\
\text { população abaixo } \\
\text { da linha de renda } \\
\text { mínima }\end{array}$ & Ajuste para idade \\
\hline $\begin{array}{l}\text { Ocaña-Riola } \\
\text { et al., } 2004\end{array}$ & $\begin{array}{l}168 \text { municípios } \\
\text { da Província de } \\
\text { Granada, } \\
\text { Espanha; } \\
\text { 1985-1996 }\end{array}$ & $\begin{array}{l}\text { Incidência de } \\
24 \text { tipos de } \\
\text { Câncer }\end{array}$ & Município & $\begin{array}{l}26.380 \text { casos } \\
\text { totais de câncer; } \\
\text { (todas as idades) }\end{array}$ & $\begin{array}{lr}\text { Registro } & \text { de } \\
\text { Câncer } & \text { da } \\
\text { Província } & \text { de } \\
\text { Granada } & \text { (de } \\
\text { base } & \\
\text { populacional) }\end{array}$ & $\begin{array}{l}\text { Regressão } \\
\text { de Poisson }\end{array}$ & $\begin{array}{l}\text { Fatores de } \\
\text { urbanização, de } \\
\text { analfabetismo e } \\
\text { de desemprego } \\
\text { (obtidos por } \\
\text { análise fatorial) }\end{array}$ & $\begin{array}{l}\text { Ajuste para idade } \\
\text { e gênero }\end{array}$ \\
\hline $\begin{array}{l}\text { Suarez- } \\
\text { Varela et al., } \\
2004\end{array}$ & $\begin{array}{l}50 \text { províncias } \\
\text { da } \\
\text { Espanha; } \\
1989-1997\end{array}$ & $\begin{array}{l}\text { Mortalidade } \\
\text { por Câncer } \\
\text { de Colo de } \\
\text { Útero }\end{array}$ & Província & $\begin{array}{l}\text { Não disponível; } \\
\text { (todas as idades) }\end{array}$ & $\begin{array}{l}\text { Instituto } \\
\text { Nacional de } \\
\text { Estatística }\end{array}$ & $\begin{array}{l}\text { Razão de } \\
\text { taxas de } \\
\text { mortalidade } \\
\text { padronizadas } \\
\text { por idade } \\
\text { com IC95\% }\end{array}$ & $\begin{array}{lr}\text { Produto } & \text { Interno } \\
\text { Bruto } & \text { da } \\
\text { província } & \end{array}$ & Ajuste para idade \\
\hline $\begin{array}{l}\text { Clarke et al., } \\
2005\end{array}$ & $\begin{array}{l}\text { Estado da } \\
\text { Califórnia, } \\
\text { EUA; 1988- } \\
1992\end{array}$ & $\begin{array}{ll}\text { Incidência de } \\
\text { Linfoma de } \\
\text { Hodgkin }\end{array}$ & $\begin{array}{l}\text { Census block } \\
\text { group (com } \\
\text { população } \\
\text { média de } \\
1000 \\
\text { residentes) }\end{array}$ & $\begin{array}{l}3.794 \text { casos; } \\
\text { (todas as idades) }\end{array}$ & $\begin{array}{lr}\text { Registro } & \text { de } \\
\text { Câncer } & \text { do } \\
\text { Estado } & \text { da } \\
\text { Califórnia } & \text { (de } \\
\text { base } & \\
\text { populacional) }\end{array}$ & $\begin{array}{l}\text { Regressão } \\
\text { de Poisson }\end{array}$ & $\begin{array}{l}\text { Índice de status } \\
\text { sócio-econômico } \\
\text { (método de Yost) }\end{array}$ & $\begin{array}{l}\text { Ajuste para idade } \\
\text { e raça / etnia. } \\
\text { Análise } \\
\text { estratificada por } \\
\text { gênero e raça / } \\
\text { etnia }\end{array}$ \\
\hline $\begin{array}{l}\text { Fukuda et } \\
\text { al., } 2005\end{array}$ & $\begin{array}{l}\text { Japão; 1993- } \\
1998\end{array}$ & $\begin{array}{l}\text { Mortalidade } \\
\text { por Câncer } \\
\text { de Pulmão e } \\
\text { Cólon (em } \\
\text { homens) e de } \\
\text { mama (em } \\
\text { mulheres) }\end{array}$ & Município & $\begin{array}{l}\text { Não disponível; } \\
\text { (todas as idades) }\end{array}$ & $\begin{array}{l}\text { Sistema de } \\
\text { Estatísticas } \\
\text { Sociais e } \\
\text { Demográficas }\end{array}$ & $\begin{array}{l}\text { Análise } \\
\text { espacial } \\
\text { (spatial scan } \\
\text { statistics) }\end{array}$ & $\begin{array}{l}\text { Categorias de } \\
\text { clusters sociais } \\
\text { (obtidas por } \\
\text { análise de cluster } \\
\text { de variáveis } \\
\text { sócio- } \\
\text { demográficas) }\end{array}$ & $\begin{array}{lr}\text { Ajuste } & \text { para } \\
\text { idade. Análise } \\
\text { estratificada por } \\
\text { gênero }\end{array}$ \\
\hline
\end{tabular}




\begin{tabular}{|c|c|c|c|c|c|c|c|c|}
\hline $\begin{array}{l}\text { Shipp et al., } \\
2005\end{array}$ & $\begin{array}{l}\text { Estado de } \\
\text { Alabama, EUA; } \\
\text { 1996-1999 }\end{array}$ & $\begin{array}{ll}\text { Incidência } & \text { de } \\
\text { Câncer } & \text { de } \\
\text { Cólon } & \\
\text { Intestinal } & \end{array}$ & Condado & $\begin{array}{ll}5.788 & \text { casos; } \\
\text { (idade de } & 15 \\
\text { anos ou mais) }\end{array}$ & $\begin{array}{|lr|}\text { Registro } & \text { de } \\
\text { Câncer } & \text { do } \\
\text { Estado } & \text { de } \\
\text { Alabama } & \text { (de } \\
\text { base } & \\
\text { populacional) }\end{array}$ & $\begin{array}{l}\text { Regressão } \\
\text { de Poisson } \\
\text { de múltiplos } \\
\text { níveis }\end{array}$ & 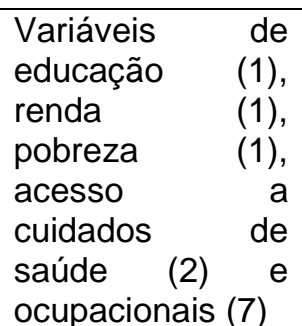 & 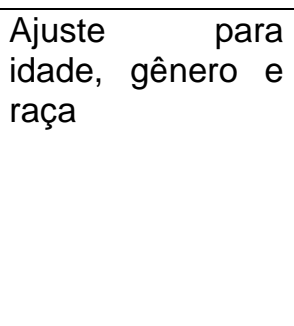 \\
\hline $\begin{array}{l}\text { Ueda et al., } \\
2005\end{array}$ & $\begin{array}{ll}\text { Área } & \\
\text { metropolitana } \\
\text { de } \quad \text { Osaka, } \\
\text { Japão; } 1995- \\
\text { 1999 }\end{array}$ & $\begin{array}{l}\text { Incidência, } \\
\text { Mortalidade e } \\
\text { Sobrevida de } \\
\text { Câncer em } \\
\text { geral }\end{array}$ & Município & $\begin{array}{l}\text { Não disponível; } \\
\text { (todas as idades) }\end{array}$ & \begin{tabular}{|lr} 
Registro & de \\
Câncer & de \\
Osaka & (de \\
base & \\
populacional)
\end{tabular} & $\begin{array}{l}\text { Regressão } \\
\text { linear }\end{array}$ & $\begin{array}{l}\text { Variáveis de } \\
\text { desemprego (1), } \\
\text { residência (3) e } \\
\text { educação (1) }\end{array}$ & $\begin{array}{l}\text { Ajuste para idade } \\
\text { e estratificação } \\
\text { por gênero }\end{array}$ \\
\hline $\begin{array}{l}\text { Lancaster et } \\
\text { al., } 2006\end{array}$ & $\begin{array}{ll}\text { Norte } & \text { da } \\
\text { Inglaterra; } & \\
\text { 1993-1996 } & \end{array}$ & $\begin{array}{ll}\text { Incidência } & \text { de } \\
\text { Câncer } & \text { de } \\
\text { Pulmão } & \end{array}$ & $\begin{array}{l}\text { Distrito de } \\
\text { Autoridade } \\
\text { Local }\end{array}$ & $\begin{array}{l}\text { Não disponível; } \\
\text { (idade de } 45 \text { a } 74 \\
\text { anos) }\end{array}$ & $\begin{array}{l}3 \text { registros de } \\
\text { câncer do norte } \\
\text { da } \\
\text { (de Inglaterra } \\
\text { populacional) }\end{array}$ & $\begin{array}{l}\text { Regressão } \\
\text { de Poisson }\end{array}$ & $\begin{array}{lr}\text { Variáveis } & \text { de } \\
\text { renda } & (1) \text {, } \\
\text { ocupacionais } & (3) \text {, } \\
\text { e de residência } \\
\text { (1) }\end{array}$ & $\begin{array}{l}\text { Ajuste para idade } \\
\text { e gênero }\end{array}$ \\
\hline $\begin{array}{l}\text { Oliver et al., } \\
2006\end{array}$ & $\begin{array}{l}\text { Estado da } \\
\text { Virgínia, EUA; } \\
\text { 1990-1999 }\end{array}$ & $\begin{array}{ll}\text { Incidência de } \\
\text { Câncer de } \\
\text { Próstata }\end{array}$ & $\begin{array}{l}\text { Census tract } \\
\text { (com } \\
\text { população } \\
\text { média de } \\
4000 \\
\text { residentes) e } \\
\text { condado }\end{array}$ & $\begin{array}{l}35.666 \text { casos } \\
\text { (todas as idades) }\end{array}$ & \begin{tabular}{|lr} 
Registro & de \\
Câncer & do \\
Estado & da \\
Virgínia & (de \\
base & \\
populacional)
\end{tabular} & $\begin{array}{l}\text { Regressão } \\
\text { de Poisson } \\
\text { hierárquica }\end{array}$ & $\begin{array}{lr}\begin{array}{l}\text { Variáveis } \\
\text { renda }\end{array} & \text { de } \\
\text { educação } & (2), \\
\text { pobreza } & (2), \\
\text { residência } & (1), \\
\text { acesso } & \text { a } \\
\text { cuidados } & \text { de } \\
\text { saúde (1) } & \text { e } \\
\text { urbanização (1) }\end{array}$ & $\begin{array}{lr}\text { Ajuste } & \text { para } \\
\text { idade. Análise } \\
\text { estratificada por } \\
\text { raça }\end{array}$ \\
\hline $\begin{array}{l}\text { Pollack } \\
\text { al., } 2006\end{array}$ & $\begin{array}{l}\text { Estado da } \\
\text { Califórnia, } \\
\text { EUA; 1996- } \\
2000\end{array}$ & $\begin{array}{l}\text { Estadiamento } \\
\text { de Câncer } \\
\text { Colorretal }\end{array}$ & $\begin{array}{l}\begin{array}{l}\text { Census block } \\
\text { group (com } \\
\text { população } \\
\text { media de } \\
1000 \\
\text { residentes) }\end{array}\end{array}$ & $\begin{array}{l}59.076 \text { casos } \\
\text { (idade de } 50 \\
\text { anos ou mais) }\end{array}$ & $\begin{array}{|lr|}\text { Registro } & \text { de } \\
\text { Câncer } & \text { do } \\
\text { estado } & \text { da } \\
\text { Califórnia } & \text { (de } \\
\text { base } & \\
\text { populacional) }\end{array}$ & $\begin{array}{l}\text { Análise } \\
\text { espacial } \\
\text { (spatial scan } \\
\text { statistics) e } \\
\text { regressão } \\
\text { logística }\end{array}$ & $\begin{array}{l}\text { İndice de status } \\
\text { sócio-econômico } \\
\text { (método de Yost) }\end{array}$ & $\begin{array}{l}\text { Ajuste para } \\
\text { idade, gênero e } \\
\text { raça /etnia }\end{array}$ \\
\hline
\end{tabular}




\begin{tabular}{|c|c|c|c|c|c|c|c|c|}
\hline $\begin{array}{l}\text { Alazraqui et } \\
\text { al., } 2007\end{array}$ & \begin{tabular}{ll|} 
Município de \\
Lanús, \\
Argentina; \\
1995-2001
\end{tabular} & $\begin{array}{l}\text { Mortalidade } \\
\text { por Câncer } \\
\text { de Mama }\end{array}$ & $\begin{array}{l}\text { Radios } \\
\text { censales } \\
\text { (com 200 a } \\
400 \\
\text { domicílios } \\
\text { urbanos) }\end{array}$ & $\begin{array}{l}304 \text { casos (idade } \\
\text { de } 40 \text { anos ou } \\
\text { mais) }\end{array}$ & $\begin{array}{l}\text { Declarações de } \\
\text { óbito }\end{array}$ & $\begin{array}{l}\text { Taxas de } \\
\text { mortalidade e } \\
\text { Teste } x^{2} \text { de } \\
\text { tendência }\end{array}$ & 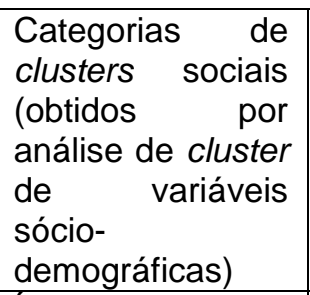 & $\begin{array}{lr}\text { Não } r \text { houve } \\
\text { ajuste. As taxas } \\
\text { de mortalidade } \\
\text { não foram } \\
\text { padronizadas } \\
\text { para idade }\end{array}$ \\
\hline $\begin{array}{l}\text { Brown et al., } \\
2007\end{array}$ & $\begin{array}{l}\text { Escócia; 1991- } \\
2000\end{array}$ & $\begin{array}{ll}\text { Incidência } & \text { de } \\
\text { Câncer } & \text { de } \\
\text { Mama } & \end{array}$ & Postcode & $\begin{array}{l}\text { Não disponível } \\
\text { (todas as idades) }\end{array}$ & $\begin{array}{lr}\text { Divisão } & \text { de } \\
\text { Informação } & \text { e } \\
\text { Estatística } & \text { da } \\
\text { Executiva } & \\
\text { Escocesa } & \end{array}$ & $\begin{array}{l}\text { Taxas de } \\
\text { incidência } \\
\text { padronizadas } \\
\text { por idade }\end{array}$ & $\begin{array}{lr}\text { Índice } & \text { de } \\
\text { Carstairs e Morris }\end{array}$ & Ajuste para idade \\
\hline $\begin{array}{l}\text { Dechello e } \\
\text { Sheehan, } \\
2007\end{array}$ & \begin{tabular}{lr|} 
Estado rass re de \\
Massachusetts, \\
EUA; 1995- \\
1998
\end{tabular} & $\begin{array}{l}\text { Incidência de } \\
\text { Câncer } \\
\text { Colorretal }\end{array}$ & $\begin{array}{l}\text { Census tract } \\
\text { (com } \\
\text { população } \\
\text { média de } \\
4000 \\
\text { residentes) }\end{array}$ & $\begin{array}{l}12.988 \text { casos } \\
\text { (todas as idades) }\end{array}$ & $\begin{array}{ll}\text { Registro de } & \text { de } \\
\text { Câncer do } \\
\text { estado de } \\
\text { Massachusetts } \\
\text { (de base } \\
\text { populacional) }\end{array}$ & $\begin{array}{l}\text { Análise } \\
\text { espacial } \\
\text { têmporo- } \\
\text { espacial }\end{array}$ & $\begin{array}{l}\text { Índice de status } \\
\text { sócio-econômico } \\
\text { (método de Yost) } \\
\text { e variável de } \\
\text { urbanização (1) }\end{array}$ & $\begin{array}{lr}\text { Ajuste r para } \\
\text { idade. Análise } \\
\text { estratificada por } \\
\text { gênero }\end{array}$ \\
\hline $\begin{array}{l}\text { Xiao et al., } \\
2007\end{array}$ & $\begin{array}{lr}\text { Estado } & \text { da } \\
\text { Flórida, } & \text { EUA; } \\
1990-2001 & \end{array}$ & $\begin{array}{l}\text { Estadiamento } \\
\text { e Grau } \\
\text { Histológico } \\
\text { de Câncer de } \\
\text { Próstata }\end{array}$ & $\begin{array}{l}\text { Census tract } \\
\text { (com } \\
\text { população } \\
\text { média de } \\
4000 \\
\text { residentes) }\end{array}$ & $\begin{array}{ll}167.386 & \text { casos } \\
\text { (idade de } 40 & \\
\text { anos ou mais) }\end{array}$ & $\begin{array}{lr}\text { Sistema } & \text { de } \\
\text { Dados } & \text { de } \\
\text { Câncer } & \text { do } \\
\text { Estado } & \text { da } \\
\text { Flórida } & \text { (de } \\
\text { base } & \\
\text { populacional) }\end{array}$ & $\begin{array}{l}\text { Regressão } \\
\text { logística de } \\
\text { múltiplos } \\
\text { níveis }\end{array}$ & \begin{tabular}{lll}
\multicolumn{2}{l}{ Variáveis } & de \\
renda (1) e & de \\
educação (1) &
\end{tabular} & $\begin{array}{ll}\text { Ajuste para } \\
\text { idade, raça, } \\
\text { estado civil, uso } \\
\text { atual ou prévio } \\
\text { de tabaco, ano } \\
\text { de diagnóstico e } \\
\text { variáveis } \\
\text { ambientais de } \\
\text { condado }\end{array}$ \\
\hline $\begin{array}{l}\text { Rowan, } \\
2007\end{array}$ & $\begin{array}{l}\text { Inglaterra e e } \\
\text { País de Gales; } \\
\text { 1990-2002 }\end{array}$ & $\begin{array}{ll}\text { Incidência } & \text { de } \\
\text { Câncer } & \text { de } \\
\text { Pulmão, } & \\
\text { Mama } & \text { e } \\
\text { Próstata } & \end{array}$ & Census ward & $\begin{array}{l}\text { Não disponível; } \\
\text { (todas as idades) }\end{array}$ & $\begin{array}{l}\text { Registro } \\
\text { Câncer } \\
\begin{array}{l}\text { Nacional } \\
\text { base }\end{array} \\
\text { populacional) }\end{array}$ & $\begin{array}{l}\text { Razão de } \\
\text { taxas de } \\
\text { incidência } \\
\text { padronizadas } \\
\text { por idade } \\
\text { com IC95\% }\end{array}$ & $\begin{array}{l}\text { Índice } \\
\text { Carstairs }\end{array}$ & $\begin{array}{lr}\text { Ajuste r para } \\
\text { idade. Análise } \\
\text { estratificada por } \\
\text { gênero }\end{array}$ \\
\hline
\end{tabular}




\begin{tabular}{|c|c|c|c|c|c|c|c|c|}
\hline $\begin{array}{l}\text { Downing et } \\
\text { al., } 2008\end{array}$ & $\begin{array}{ll}\text { Região } & \text { de } \\
\text { Yorkshire, } & \\
\text { Inglaterra; } & \\
1983-2003 & \end{array}$ & $\begin{array}{l}\text { Incidência de } \\
\text { Câncer de } \\
\text { Pulmão, } \\
\text { Estômago, } \\
\text { Esôfago, } \\
\text { Pâncreas, } \\
\text { Bexiga e Rim }\end{array}$ & $\begin{array}{l}\text { Electoral } \\
\text { ward (com } \\
\text { população } \\
\text { média de } \\
5000 \\
\text { residentes) }\end{array}$ & $\begin{array}{l}54.520 \text { (pulmão); } \\
15.045 \\
\text { (estômago); } \\
7.444 \text { (esôfago); } \\
8.522 \text { (pâncreas); } \\
15.072 \text { (bexiga); } \\
5.918 \text { (rim); } \\
\text { (todas as idades) }\end{array}$ & $\begin{array}{lr}\text { Registro } & \text { de } \\
\text { Câncer } & \text { das } \\
\text { Regiões } & \text { do } \\
\text { Norte e de } & \text { de } \\
\text { Yorkshire } & \text { (de } \\
\text { base } & \\
\text { populacional) }\end{array}$ & $\begin{array}{l}\text { Análise } \\
\text { espacial } \\
\text { (Bayesian } \\
\text { shared- } \\
\text { component } \\
\text { model) }\end{array}$ & $\begin{array}{l}\text { Índice } \\
\text { Townsend }\end{array}$ & Ajuste para idade \\
\hline $\begin{array}{l}\text { Shack et al., } \\
2008\end{array}$ & $\begin{array}{l}\text { Inglaterra; } \\
\text { 1998-2003 }\end{array}$ & $\begin{array}{l}\text { Incidência de } \\
\text { Câncer de } \\
\text { Pulmão, } \\
\text { Mama, Colo } \\
\text { de Útero e } \\
\text { Melanoma } \\
\text { Maligno }\end{array}$ & $\begin{array}{l}\text { Lower super } \\
\text { output area } \\
\text { (com } \\
\text { população } \\
\text { média de } \\
1500 \\
\text { residentes) }\end{array}$ & $\begin{array}{l}187.148 \\
\text { (pulmão); } \\
210.020 \text { (mama); } \\
14.880 \text { (colo de } \\
\text { útero): } 36.142 \\
\text { (melanoma); } \\
\text { (todas as idades) }\end{array}$ & $\begin{array}{l}\text { Todos os } 8 \\
\text { registros } \\
\text { ingleses de } \\
\text { câncer de base } \\
\text { populacional }\end{array}$ & $\begin{array}{l}\text { Razão de } \\
\text { taxas de } \\
\text { incidência } \\
\text { padronizadas } \\
\text { por idade } \\
\text { com IC95\% }\end{array}$ & $\begin{array}{l}\text { İndice de } \\
\text { Privação Múltipla } \\
\text { (Index of Multiple } \\
\text { Deprivation) }\end{array}$ & $\begin{array}{lr}\text { Ajuste } & \text { para } \\
\text { idade. Análise } \\
\text { estratificada por } \\
\text { gênero }\end{array}$ \\
\hline
\end{tabular}

EUA: Estados Unidos da América; IC 95\%: Intervalo de Confiança de 95\%; Teste $x^{2}$ : teste Qui-Quadrado 
Em estudo que visou investigar os efeitos relativos da educação, renda e pobreza, medidas em nível de condado, sobre as taxas de incidência de melanoma maligno entre brancos de 199 condados dos Estados Unidos da América, entre 1973 e 1993, observou-se que a porcentagem de indivíduos com 12 ou mais anos de estudo esteve significante e positivamente associada com a incidência de melanoma, assim como a porcentagem de famílias abaixo da linha de pobreza esteve significante e negativamente associada com a sua incidência, após controle para renda, etnia, latitude, gênero, idade, período de diagnóstico. A associação foi verificada em todos os tempos de latência considerados (10 a 40 anos), sendo que a educação explicou a maior parte da variação entre condados. A renda mediana domiciliar não esteve associada com a incidência da doença (HARRISON et al., 1998).

Já LIU et al. (1998) investigou a incidência de vários tipos de câncer feminino em relação a um índice de status sócio-econômico, desenvolvido pelos próprios pesquisadores, do census tract de residência dos pacientes no momento do diagnóstico, entre 1972 e 1992, em Los Angeles, Estados Unidos. Este estudo observou que mulheres vivendo em áreas mais ricas apresentaram maior risco de câncer de mama, de ovário e de corpo de útero e menor risco de câncer de colo de útero em relação às mulheres moradores de áreas mais pobres, com formação de gradiente ao longo dos vários estratos socioeconômicos apreciados. Estimativas de risco permaneceram significantes após controle para idade e raça / etnia.

Visando investigar se a variação geográfica nas taxas de incidência de câncer de mama dos condados da região da baía de São Francisco, Estados Unidos, no período de 1988 a 1992, estaria relacionada à distribuição desigual de fatores de risco conhecidos, PREHN e WEST (1998) analisaram a relação entre variáveis sócio-econômicas e tais taxas padronizadas por idade em nível de census block group. Encontrou-se risco aumentado de desenvolvimento de câncer de mama nas áreas com maiores renda residencial mediana, renda per capita mediana, proporção de pessoas com educação secundária completa e moradoras em áreas urbanas, e com 
menores proporções de residências abaixo da linha de pobreza e de pessoas em ocupações das classes trabalhadoras.

Por sua vez, LIU et al. (2001) investigou a relação entre a incidência e o estadiamento de câncer de próstata e o índice sócio-econômico que desenvolveram previamente (LIU et al., 1998) do census tract de residência dos pacientes no momento do diagnóstico, em diversos períodos-calendário entre 1972 e 1997, no contexto de Los Angeles, Estados Unidos. Risco aumentado de desenvolvimento do câncer foi encontrado nos estratos mais abastados a partir de 1987, com gradiente dose-resposta pelos vários estratos intermediários. Por outro lado, também a partir de 1987, estágios localizados do câncer se associaram positivamente com o nível sócioeconômico dos estratos e estágios mais avançados negativamente, com formação de gradiente dose-resposta. Nos anos anteriores a 1987, não foi observada associação entre o nível sócio-econômico e os desfechos. Os autores atribuíram a associação encontrada ao uso diferenciado e disseminado do exame de PSA (Prostate-Specific Antigen) a partir do final da década de 1980.

A relação entre a incidência de câncer de mama e índice de status socioeconômico, criado a partir de análise de componente principal, do census block group em que residia o paciente na época do diagnóstico foi analisada no estudo de YOST et al. (2001) no Estado de Califórnia, entre 1988 e 1992. Encontrou-se risco aumentado de desenvolvimento de câncer de mama nas mulheres residentes nas áreas mais ricas, com gradiente dose-resposta nos 4 grupos raciais / étnicos analisados (brancos, negros, hispânicos e asiáticos e outros), após ajuste para idade.

Analisando a relação entre medidas de status sócio-econômico da área zip code de residência do indivíduo na época do diagnóstico e o estadiamento do câncer de mama em mulheres das raças branca e negra da cidade de Nova Iorque, Estados Unidos, no período de 1986 a 1995, MERKIN et al. (2002) verificou que mulheres residentes nas áreas com menor proporção de indivíduos com educação secundária concluída apresentavam maior risco de serem diagnosticadas em estádios mais 
avançados do câncer que as residentes em áreas com maior proporção desses indivíduos, com gradiente dose-resposta pelas diversas categorias intermediárias. A associação ocorreu nas duas raças, com maior magnitude na raça branca. Ajustes foram feitos para idade e ano do diagnóstico.

Estudo na área metropolitana de Detroit, Estados Unidos, entre 1988 e 1992, analisou a relação entre o estadiamento de alguns tipos de câncer e o nível sócio-econômico do census block group (baseado na ocupação, educação e estado de pobreza dos moradores) de residência dos casos na época do diagnóstico. Risco maior de estádios mais avançados de câncer de pulmão, próstata, colorretal, mama e colo de útero foi observado nos moradores das áreas menos favorecidas socioeconomicamente em relação aos das mais favorecidas, após ajuste para idade, sexo e raça, com gradiente dose-resposta para alguns dos cânceres estudados (SCHWARTZ et al., 2003).

Por sua vez, KLASSEN et al. (2004), por meio de estudo com múltiplos níveis, relacionou o estadiamento e o grau histológico de câncer de próstata com 17 variáveis sócio-econômicas em nível de census block group, census tract e condado de residência dos casos diagnosticados entre 1992 e 1997, no estado de Maryland, Estados Unidos. Maior proporção de trabalhadores do colarinho branco na população trabalhadora total do census block group e maiores recursos sócio-econômicos do condado apresentaram efeito protetor significante em relação aos estádios avançados do câncer no diagnóstico, assim como elevada renda residencial mediana do census block group em relação a pior grau histológico. Entretanto, recursos sócio-econômicos do condado elevados aumentaram significantemente o risco de pior grau histológico do câncer no diagnóstico. Não se observaram associações significantes em nível de census tract. Ajustes foram feitos para idade, raça e ano do diagnóstico.

Na Nova Zelândia, no período de 1988 a 1998, utilizando-se dados individuais para cálculo da incidência de câncer de colo de útero invasivo e o Índice de Privação do país (NZDep96) da área de residência meshblock (com uma população mediana de 90 pessoas) de cada caso no momento do 
diagnóstico, MCFADDEN et al. (2004) verificaram que mulheres vivendo em áreas com maior privação social e material apresentaram maior risco de desenvolver câncer cervical que as mulheres vivendo nas áreas mais vantajosas material e socialmente, com gradiente através dos diversos estratos intermediários considerados. Observou-se declínio significativo da incidência padronizada por idade desse câncer durante o período de estudo.

Nas áreas metropolitanas do Canadá, nos anos de 1971, 1986, 1991 e 1996, estudou-se a associação entre a mortalidade por câncer de colo de útero e medida sócio-econômica, baseada na proporção de população abaixo da linha de renda mínima, dos census tracts de residência dos casos, tendo sido observado que mulheres residentes em áreas mais pobres apresentaram maior risco de mortalidade por tal câncer que as vivendo nas áreas mais ricas, durante todo o período do estudo, com gradiente através dos diversos estratos sociais intermediários considerados. Nesse período, ocorreu declínio importante da mortalidade padronizada por idade desse câncer em todos os estratos, mas com diminuições muito maiores nos estratos socialmente mais desfavorecidos, resultando em estreitamento das desigualdades sócio-econômicas quanto ao desfecho estudado (NG et al., 2004).

Estudo na Província de Granada, Espanha, examinou a relação entre a incidência de diversos tipos de câncer ocorridos entre 1985 e 1996 e alguns indicadores sócio-econômicos, obtidos por análise fatorial de inúmeras variáveis originais, utilizando o município como unidade de investigação. Associação significante e positiva foi encontrada entre o indicador de urbanização e quase todos os tipos de câncer. Já o indicador de desemprego se associou significante e positivamente com os cânceres de cavidade oral, esôfago e estômago, e negativamente com o melanoma. Por sua vez, o indicador de analfabetismo se associou significante e negativamente com os cânceres de vesícula biliar, mama, próstata e leucemia (OCAÑA-RIOLA et al., 2004).

SUAREZ-VARELA et al. (2004) empreenderam estudo a fim de relacionar a taxas de mortalidade por câncer de colo de útero padronizadas 
por idade com o PIB (Produto Interno Bruto) das províncias constituintes da Espanha, no período de 1989 a 1997, observando risco aumentado do desfecho nas províncias com menor PIB. Ocorreu também tendência levemente crescente da mortalidade por esse câncer ao longo do período do estudo no país como um todo.

CLARKE et al. (2005), estudando a população do estado da Califórnia, Estados Unidos da América, no período de 1988 a 1992, observou gradiente positivo e significante do nível sócio-econômico da área census block group de moradia do caso (com uma média de 1000 residentes) no momento do diagnóstico com as taxas de incidência padronizadas pela idade de linfoma de Hodgkin, somente na faixa etária de 15 a 44 anos. Verificou-se que tal achado era devido à ocorrência de gradiente sócio-econômico com o subtipo histológico de esclerose nodular. Já na faixa etária de 45 anos ou mais e somente no sexo masculino, o subtipo histológico de celularidade mista mostrou padrão semelhante. Digno de nota foi o efeito modificador observado do gênero e da raça sobre a associação entre a variável sócio-econômica utilizada e as taxas de incidência ajustadas pela idade do linfoma de Hodgkin e seus subtipos.

Estudo no Japão, entre 1993 e 1998, em nível de município, identificou clusters espaciais de altas razões de mortalidade padronizada de câncer de pulmão e cólon, em homens, e de mama, em mulheres, correlacionando-os, em seguida, com clusters sociais, obtidos por análise de componente principal e análise de cluster de variáveis sócio-econômicas e demográficas. Evidenciou-se que a maioria dos clusters com alta mortalidade por câncer de cólon masculino e mama feminina se localizava em áreas municipais caracterizadas por alta densidade populacional e elevados níveis de renda e de educação. Já para o câncer de pulmão, os clusters com alta mortalidade pertenciam a áreas com características sóciodemográficas as mais variadas (FUKUDA et al., 2005).

Analisando a incidência de câncer de cólon intestinal em relação a raça e variáveis sócio-econômicas, ocupacionais e de cuidado em saúde, nos condados do estado de Alabama, Estados Unidos, no período de 1996 
1999, e utilizando dados individuais e agregados, SHIPP et al. (2005) encontraram uma associação positiva da incidência dessa neoplasia com o número de médicos por 1000 habitantes e com a porcentagem de indivíduos com 12 anos ou mais de estudo do condado, não mediada por idade, sexo, renda e raça, indicando uma associação positiva de indicadores sócioeconômicos favoráveis dos condados e o desfecho medido. Porém, não foi encontrada associação entre renda residencial média e tal desfecho. $O$ número de médicos por 1000 habitantes explicou a maior parte da variação nas taxas de incidência entre os condados. Além disso, a proporção de indivíduos no condado com 16 anos ou mais empregada nos setores de comércio, administração pública e serviços de saúde se associou positivamente com a incidência do câncer, enquanto a de empregados nos setores de agricultura, pesca e indústria se associou inversamente, revelando também diferenciais sócio-econômicos no desfecho.

Em estudo realizado em 67 municípios da área metropolitana de Osaka, Japão, visando analisar as diferenças na incidência, mortalidade e sobrevivência por câncer, entre 1995 a 1999, UEDA et. al. (2005) observou correlações positivas da taxa municipal de desemprego, das porcentagens municipais de residências recebendo assistência governamental e de residências abaixo do nível de subsistência com a mortalidade e a incidência de câncer e negativas dessas variáveis com a sobrevivência relativa em 5 anos e a proporção de câncer em estágio inicial. Correlações negativas da porcentagem municipal de residências próprias e de grau acadêmico com a incidência e a mortalidade por câncer e positivas dessas com a sobrevivência e a proporção de câncer em estágio inicial também foram encontradas. Levando em conta as diferenças entre as variáveis estudadas, os achados deste estudo diferem dos estudos brasileiros anteriores com nível de agregação municipal, o que talvez se explique pela cobertura uniforme do registro de câncer de base populacional da região metropolitana de Osaka e pelos riscos competitivos de morte, expectativas de vida e acesso a cuidados de saúde semelhantes ao longo dos seus municípios constituintes. 
Comparando o desenho ecológico estratificado com o tradicional, LANCASTER et al. (2006) analisou a incidência de câncer de pulmão em relação a diversas variáveis sócio-econômicas ecológicas, em nível de distritos de autoridade local do norte da Inglaterra, entre 1993 e 1996. Por meio da primeira abordagem, que utiliza dados individuais de inquérito populacional e que seria menos sujeita a vieses, encontrou-se risco aumentado de câncer de pulmão associado a características socioeconômicas desfavoráveis do distrito, a saber, maior proporção de desempregados, de não proprietários de automóveis, de moradores de residências alugadas da autoridade local, e de indivíduos de classes sociais mais baixas.

OLIVER et al. (2006) investigou a relação entre diversas variáveis sócio-econômicas e a incidência de câncer de próstata no estado da Virgínia, Estados Unidos, entre 1990 e 1999, através de análise ecológica, em dois níveis de agregação, estratificada pelas raças branca e negra. Em nível de census tract e somente em brancos, a proporção da população abaixo da linha de pobreza e a que não atingiu o nível secundário da educação se associaram negativamente com o desfecho, enquanto a proporção de médicos na população e a de mulheres chefes de família se associaram positivamente com o mesmo. A renda residencial mediana e 0 grau de urbanização se associaram positivamente com o desenvolvimento do câncer de próstata em brancos e negros. Associações significantes não foram observadas em nível de condado. Entretanto, enquanto nesse nível a geocodificação atingiu $100 \%$ dos casos, no de census tract alcançou apenas $74 \%$.

Já POLLACK et al. (2006) analisou a relação entre o estadiamento do câncer colorretal e o índice de status sócio-econômico, desenvolvido por YOST et al. (2001), do census block group de residência do paciente à época do diagnóstico, no Estado da Califórnia, Estados Unidos, entre 1996 e 2000, por meio de duas abordagens estatísticas diferentes. Por meio de regressão logística, observou-se que morar em áreas mais pobres estava associado a maior risco de se diagnosticar câncer colorretal em estádios 
mais avançados, com gradiente dose-resposta pelas categorias sócioeconômicas consideradas, após ajuste para gênero, idade e raça / etnia. Por sua vez, a análise espacial de cluster identificou áreas geográficas circunscritas com maior risco de estadiamento avançado do câncer ao diagnóstico e que estas áreas apresentavam características sócioeconômicas desfavoráveis, em relação ao restante do estado.

Investigou-se no município de Lanús, Argentina, entre 1995 e 2001, a relação entre mortalidade por câncer de mama e o nível sócio-econômico dos radios censales (com cerca de 200 a 400 habitações) de residência dos casos à época do diagnóstico. Encontrou-se risco aumentado do câncer nos residentes das áreas mais ricas, com gradiente dose-resposta pelos vários estratos de área apreciados. Entretanto, somente se conseguiu georreferenciar $84 \%$ dos 360 casos registrados no período e não houve padronização das taxas de mortalidade para idade por falta de dados (ALAZRAQUI et al., 2007).

Estudo na Escócia, entre 1990 e 2001, correlacionou a incidência de câncer de mama com o Índice de Carstairs e Morris do postcode de residência do paciente no momento do diagnóstico e evidenciou que as taxas de incidência padronizadas por idade desse desfecho eram mais altas nos residentes das áreas mais ricas, com gradiente ao longo dos vários estratos sócio-econômicos apreciados. Além disso, observou-se tendência estacionária em relação às diferenças sócio-ecônomicas na incidência desse câncer durante o período do estudo (BROWN et al., 2007)

DECHELLO e SHEEHAN (2007), em análise espacial e têmporoespacial realizada no estado de Massachusetts, Estados Unidos, no período de 1995 a 1998, observaram que as diferenças encontradas na incidência de câncer colorretal entre as áreas census tracts desse estado poderiam ser explicadas, em grande parte, por fatores sócio-econômicos e pela porcentagem da população urbana de cada área, sem poder, entretanto, inferir a direção dessa associação.

ROWAN (2007), a partir de dados individuais de registros de câncer, na Inglaterra e País de Gales, entre 1990 e 2002, correlacionou a incidência 
de câncer de mama, pulmão e próstata com o índice de privação de Carstairs da área census ward de residência do paciente no momento do diagnóstico, observando taxas de incidência padronizadas por idade mais altas para os cânceres de mama e próstata nos residentes de census wards mais ricos, e nos residentes dos mais pobres, taxas mais altas para câncer de pulmão, com formação de gradiente pelos vários estratos sócioeconômicos medidos. As maiores diferenças sócio-econômicas foram verificadas, em ordem decrescente, para câncer de pulmão, de mama e próstata. Tendências de ampliação das desigualdades, ao longo do período em questão, foram encontradas para o câncer de pulmão e próstata. Já para o câncer de mama, observou-se tendência estacionária. Achados, em geral, semelhantes foram encontrados para o País de Gales e cada Região Governamental da Inglaterra.

Em estudo com múltiplos níveis, no estado norte-americano da Flórida, entre os anos de 1990 e 2001, observou-se que homens que residiam em census tract com maior porcentagem de graduados em curso superior apresentaram menor risco de serem diagnosticados com câncer de próstata em estágios avançados e com graus histológicos de pior prognóstico e que também homens residentes em regiões de renda domiciliar mediana mais alta apresentavam menor risco de estágios avançados desse câncer ao diagnóstico (XIAO et al., 2007).

DOWNING et al. (2008) analisaram espacialmente e de forma conjunta as razões de incidência padronizada de 6 tipos de câncer (pulmão, estômago, esôfago, pâncreas, bexiga e rim), em nível de electoral ward, na região de Yorkshire, Inglaterra, entre 1983 e 2003. Ao avaliar a relação entre tal medida de incidência e o índice de privação de Townsend da área de moradia dos participantes à época do diagnóstico, observaram que viver em áreas com maior nível de privação estava associado significantemente a risco aumentado de desenvolver os cânceres de pulmão e estômago, com evidente gradiente dose-resposta. Para as demais neoplasias, evidenciaramse associações não significantes e sem gradiente dose-resposta. 
Em estudo realizado na Inglaterra, no período de 1998 a 2003, utilizando dados individuais para cálculo da incidência de câncer e correlacionando-a com o domínio renda do Índice de Privação Múltipla nacional da lower super output area (com uma população média de 1500 residentes) de residência de cada caso no momento do diagnóstico, observou-se que as taxas de incidência padronizadas por idade de câncer de pulmão e de colo de útero eram maiores nos residentes das regiões mais pobres, enquanto tais taxas, para câncer de mama e melanoma maligno, eram maiores nos residentes das regiões mais ricas, com formação de gradiente pelos vários estratos sócio-econômicos medidos. As maiores diferenças sócio-econômicas na incidência foram verificadas para o câncer de pulmão nos homens e nas mulheres e a menor para o câncer de mama. Tais diferenças permaneceram, algumas vezes com magnitudes diferentes, quando medidas no interior das Regiões Governamentais da Inglaterra (SHACK et al., 2008). 


\section{Anexo 3}

Quadro 7 - Relação de estudos sobre os efeitos da poluição do ar sobre o risco de câncer em adultos. 1998-2008.

\begin{tabular}{|c|c|c|c|c|c|c|c|c|}
\hline $\begin{array}{l}\text { Autores e } \\
\text { ano de } \\
\text { publicação }\end{array}$ & $\begin{array}{l}\text { Local e } \\
\text { período }\end{array}$ & Desenho & $\begin{array}{l}\text { Desfecho(s) } \\
\text { estudado(s) }\end{array}$ & $\begin{array}{l}\text { Número e } \\
\text { idade de } \\
\text { casos e } \\
\text { controles }\end{array}$ & Métodos de exposição & $\begin{array}{c}\text { Medidas de exposição } \\
\text { utilizadas }\end{array}$ & Resultados & Comentários \\
\hline $\begin{array}{l}\text { Beeson et al., } \\
1998\end{array}$ & $\begin{array}{l}\text { Estado da } \\
\text { Califórnia, } \\
\text { EUA; 1977- } \\
1992\end{array}$ & 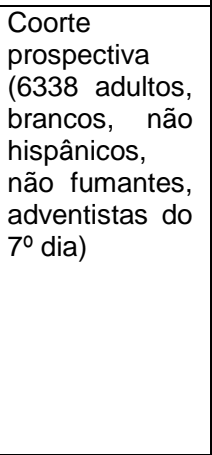 & $\begin{array}{ll}\text { Incidência } & \text { de } \\
\text { Câncer } & \text { de } \\
\text { Pulmão } & \end{array}$ & $\begin{array}{l}36 \text { casos } \\
\text { (adultos de } \\
27-95 \text { anos) }\end{array}$ & $\begin{array}{l}\text { Concentrações médias } \\
\text { anuais e freqüências } \\
\text { médias anuais de horas } \\
\text { de ultrapassagem acima } \\
\text { de valores pré- } \\
\text { determinados } r \text { de } \\
\text { concentração } \\
\text { poluentes, baseadas } \\
\text { nos zip codes de } \\
\text { residência e de trabalho } \\
\text { de cada participante } \\
\text { entre } 1966 \text { e } 1992 \text {, e } \\
\text { estimadas } \\
\text { interpolação estatística }\end{array}$ & $\begin{array}{l}\text { Concentrações médias } \\
\text { de } \mathrm{MP}_{10} \\
\left(\text { aumento de } 24 \mu \mathrm{g} / \mathrm{m}^{3}\right) \\
\text { Concentrações médias } \\
\text { de } \mathrm{SO}_{2} \text { (aumento de } 3,7 \\
\mathrm{ppb}) \\
\\
\text { Freqüências médias de } \\
\text { ultrapassagem horária } \\
\text { da concentração de } \\
100 \text { ppb de } \mathrm{O}_{3} \text { (aumento } \\
\text { de } 556 \text { horas/ano) }\end{array}$ & $\begin{array}{l}\text { Homens: } \quad R R=5,21 ; \\
\text { IC95\% }(1,94-13,99) \\
\text { Homens: RR=2,68; IC } \\
\text { 95\% (1,62-4,39) } \\
\text { Mulheres: RR=2,14; } \\
\text { IC95\% }(1,36-3,37) \\
\text { Homens: RR=3,56; } \\
\text { IC95\% }(1,55-9,09) \\
\text { Mulheres: RR=0,94; IC } \\
\text { 95\% }(0,41-2,16)\end{array}$ & $\begin{array}{l}\text { Ajustes foram feitos } \\
\text { para idade, história } \\
\text { pregressa de tabagismo, } \\
\text { nível educacional e uso } \\
\text { de álcool. Várias } \\
\text { variáveis de confusão } \\
\text { potenciais foram } \\
\text { testadas antes da } \\
\text { inclusãono modelo final, } \\
\text { mas não alteraram } \\
\text { significantemente as } \\
\text { estimativas de risco }\end{array}$ \\
\hline $\begin{array}{l}\text { Abbey et al., } \\
1999\end{array}$ & $\begin{array}{l}\text { Estado da } \\
\text { Califórnia, } \\
\text { EUA; 1977- } \\
1992\end{array}$ & $\begin{array}{l}\text { Coorte } \\
\text { prospectiva } \\
\text { (6338 adultos, } \\
\text { brancos, não } \\
\text { hispânicos, } \\
\text { não fumantes, } \\
\text { adventistas do } \\
7^{\circ} \text { dia) }\end{array}$ & $\begin{array}{l}\text { Mortalidade } \\
\text { por Câncer de } \\
\text { Pulmão }\end{array}$ & $\begin{array}{l}30 \text { casos } \\
\text { (adultos de } \\
27-95 \text { anos) }\end{array}$ & $\begin{array}{l}\text { Concentrações médias } \\
\text { anuais e freqüências } \\
\text { médias anuais de horas } \\
\text { de ultrapassagem acima } \\
\text { de valores pré- } \\
\text { determinados } r \text { de } \\
\text { concentração dos } \\
\text { poluentes, baseadas } \\
\text { nos zip codes de } \\
\text { residência e de trabalho } \\
\text { de cada participante } \\
\text { entre } 1966 \text { e 1992, e } \\
\text { estimadas pactic por } \\
\text { interpolação estatística }\end{array}$ & 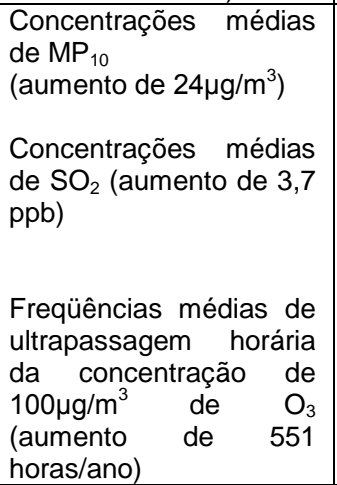 & 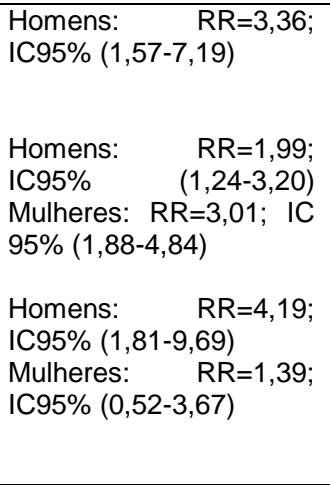 & $\begin{array}{l}\text { Ajustes foram feitos } \\
\text { para idade, história } \\
\text { pregressa de tabagismo, } \\
\text { nível educacional e uso } \\
\text { de álcool. Várias } \\
\text { variáveis de confusão } \\
\text { potenciais foram } \\
\text { testadas antes da } \\
\text { inclusãono modelo final, } \\
\text { mas não alteraram } \\
\text { significantemente as } \\
\text { estimativas de risco }\end{array}$ \\
\hline $\begin{array}{l}\text { Cangerana- } \\
\text { Pereira, } 2000\end{array}$ & $\begin{array}{l}12 \text { Distritos do } \\
\text { Município de } \\
\text { São Paulo, } \\
\text { Brasil; } 1997\end{array}$ & Ecológico & $\begin{array}{ll}\text { Incidência } & \text { de } \\
\text { Câncer } & \text { em } \\
\text { geral e } & \text { de } \\
\text { Estômago, } \\
\text { Laringe, }\end{array}$ & $\begin{array}{l}4631 \text { casos de } \\
\text { câncer; } 266 \text { de } \\
\text { estômago, } 70 \\
\text { de laringe; } 364 \\
\text { de pulmão; }\end{array}$ & \begin{tabular}{lr} 
Freqüências & \multicolumn{2}{r}{ médias } \\
anuais de dias de \\
ultrapassagem acima de \\
valores & pré- \\
determinados & de
\end{tabular} & $\begin{array}{l}\text { Freqüências médias de } \\
\text { ultrapassagem diária da } \\
\text { concentração } \\
160 \mu \mathrm{g} / \mathrm{m}^{3} \mathrm{de} \mathrm{O}_{3}\end{array}$ & $\begin{array}{l}\text { Câncer de laringe: } \\
r=0,9929 ; p=0,007 \\
\text { Câncer de pele: } \\
r=0,9851 ; p=0,015\end{array}$ & $\begin{array}{lcc}\text { Não houve ajuste para } \\
\text { potenciais } & \text { variáveis de } \\
\text { confusão. } & \text { Não se se } \\
\text { observou } & \text { associação } \\
\text { significante } & \text { para os }\end{array}$ \\
\hline
\end{tabular}




\begin{tabular}{|c|c|c|c|c|c|c|c|c|}
\hline & & & $\begin{array}{lr}\text { Pulmão, } & \text { Pele, } \\
\text { Mama } & \text { exiga }\end{array}$ & $\begin{array}{l}507 \text { de pele; } \\
725 \text { de mama; } \\
138 \text { de bexiga } \\
\text { (todas as as } \\
\text { idades) }\end{array}$ & $\begin{array}{l}\text { concentração dos } \\
\text { poluentes, mensurados } \\
\text { nas estações de } \\
\text { monitoramento do ar } \\
\text { dentro de cada distrito } \\
\text { (uma estação por } \\
\text { distrito) }\end{array}$ & & & \begin{tabular}{|ll} 
demais & poluentes \\
testados & \\
\end{tabular} \\
\hline $\begin{array}{l}\text { Mcdonnell et } \\
\text { al., } 2000\end{array}$ & $\begin{array}{l}\text { Estado da da } \\
\text { Califórnia, } \\
\text { EUA; 1977- } \\
1992\end{array}$ & $\begin{array}{l}\text { Coorte } \\
\text { prospectiva } \\
\text { (3769 adultos, } \\
\text { brancos, não } \\
\text { hispânicos, } \\
\text { não fumantes, } \\
\text { adventistas do } \\
7^{0} \text { dia) }\end{array}$ & $\begin{array}{l}\text { Mortalidade } \\
\text { por Câncer de } \\
\text { Pulmão }\end{array}$ & $\begin{array}{l}24 \quad \text { casos } \\
\text { (adultos de } \\
27-95 \text { anos) }\end{array}$ & 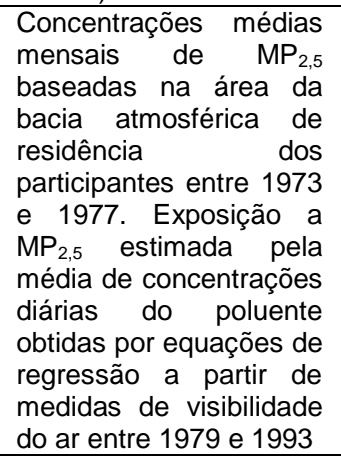 & $\begin{array}{l}\text { Concentrações médias } \\
\text { de } \mathrm{MP}_{2,5} \text { (aumento de } \\
24,3 \mu \mathrm{g} / \mathrm{m}^{3} \text { ) } \\
\text { Concentrações médias } \\
\text { de } \mathrm{MP}_{10} \\
\text { (aumento de } 29,5 \mu \mathrm{g} / \mathrm{m}^{3} \text { ) }\end{array}$ & $\begin{array}{l}\text { Homens: } \quad \text { RR=2,23; } \\
\text { IC95\% }(0,56-8,94) \\
\\
\text { Homens: RR=1,84; } \\
\text { IC95\% }(0,59-5,67)\end{array}$ & \begin{tabular}{|l|} 
Ajustes foram feitos \\
para nível educacional, \\
história pregressa de \\
tabagismo e uso de \\
álcool. Várias variáveis \\
de confusão potenciais \\
foram testadas antes da \\
inclusão no modelo final, \\
mas não alteraram \\
significantemente as \\
estimativas de risco. \\
Concentraçôes de MP 10 \\
estimadas por \\
interpolaçãa estatística
\end{tabular} \\
\hline $\begin{array}{l}\text { Nyberg et al., } \\
2000\end{array}$ & $\begin{array}{l}\text { Estocolmo, } \\
\text { Suécia; 1985- } \\
1990\end{array}$ & $\begin{array}{l}\text { Caso-controle } \\
\text { de base } \\
\text { populacional }\end{array}$ & $\begin{array}{ll}\text { Incidência } & \text { de } \\
\text { Câncer } & \text { de } \\
\text { Pulmão } & \end{array}$ & $\begin{array}{l}1042 \text { casos e } \\
2364 \text { controles } \\
\text { (homens de } \\
40-75 \text { anos) }\end{array}$ & $\begin{array}{l}\text { Concentrações médias } \\
\text { anuais modeladas de } \\
\text { poluentes baseadas nos } \\
\text { endereços históricos de } \\
\text { residência de cada } \\
\text { participante entre } 1950 \\
\text { e } 1990 \text { para diversas } \\
\text { janelas de tempo. } \\
\text { Modelo de exposição } \\
\text { validado para } \mathrm{NO}_{2}\end{array}$ & $\begin{array}{l}\text { Concentrações médias } \\
\text { de } \mathrm{NO}_{2} \text { oriundo de } \\
\text { tráfego (aumento de } \\
10 \mu \mathrm{mg} / \mathrm{m}^{3} \text { ) } \\
\text { Concentrações médias } \\
\text { de } \mathrm{NO}_{2} \text { oriundo de } \\
\text { tráfego }(>\mathrm{p} 90 \text { vs }<\mathrm{p} 25 \\
\text { ou }>29 \quad \mu \mathrm{g} / \mathrm{m}^{3} \text { vs }<13 \\
\left.\mu \mathrm{g} / \mathrm{m}^{3}\right)\end{array}$ & $\begin{array}{l}\mathrm{RR}=1,10 ; \text { IC95\% }(0,97- \\
1,23) \\
\\
\mathrm{RR}=1,44 ; \text { OR95\% }(1,05- \\
1,99)\end{array}$ & $\begin{array}{l}\text { Ajuste para idade, ano } \\
\text { de seleção, tabagismo, } \\
\text { grupos } \text { sócio- } \\
\text { econômicos, exposição } \\
\text { residencial ao radônio e } \\
\text { diversas exposições } \\
\text { ocupacionais. Exposição } \\
\text { avaliada por modelo } \\
\text { AlRVIRO de dispersão } \\
\text { com uso de dados de } \\
\text { emissão ed de } \\
\text { configuração das das } \\
\text { edificações das ruas }\end{array}$ \\
\hline
\end{tabular}




\begin{tabular}{|c|c|c|c|c|c|c|c|c|}
\hline $\begin{array}{lll}\text { Pope } & \text { et } & \text { al., } \\
2002 & & \end{array}$ & $\begin{array}{l}\text { Áreas } \\
\text { metropolitanas } \\
\text { dos EUA: } \\
1982-1998\end{array}$ & $\begin{array}{l}\text { Coorte } \\
\text { prospectiva } \\
\text { (500,000 } \\
\text { participantes; } \\
\text { amigos, } \\
\text { vizinhos ou } \\
\text { conhecidos de } \\
\text { voluntários da } \\
\text { American } \\
\text { Cancer } \\
\text { Society) }\end{array}$ & $\begin{array}{l}\text { Mortalidade } \\
\text { por Câncer de } \\
\text { Pulmão }\end{array}$ & $\begin{array}{l}\text { Não disponível } \\
\text { (idade de } 30 \\
\text { anos ou mais) }\end{array}$ & 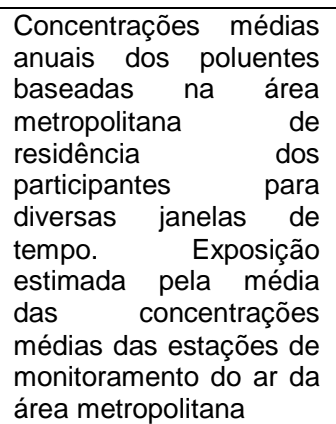 & 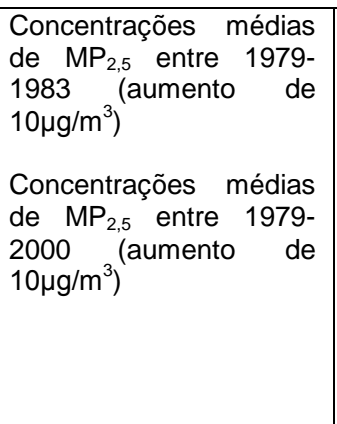 & $\begin{array}{l}\mathrm{RR}=1,08 ; \mathrm{IC} 95 \%(1,01- \\
1,16)\end{array}$ & 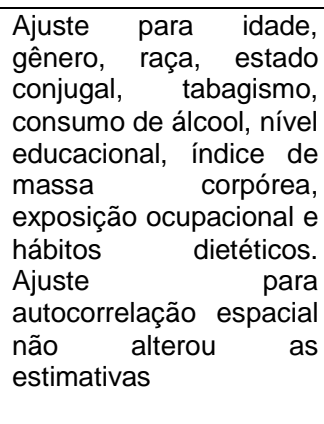 \\
\hline $\begin{array}{l}\text { Nafstad et al., } \\
2003\end{array}$ & $\begin{array}{l}\text { Oslo, } \\
\text { Noruega; } \\
\text { 1972-1998 }\end{array}$ & $\begin{array}{l}\text { Coorte } \\
\text { prospectiva } \\
(16.209 \\
\text { homens) }\end{array}$ & $\begin{array}{ll}\text { Incidência } & \text { de } \\
\text { Câncer } & \text { de } \\
\text { Pulmão } & \end{array}$ & $\begin{array}{l}418 \text { casos } \\
\text { (homens de } \\
40-49 \text { anos) }\end{array}$ & $\begin{array}{l}\text { Concentrações médias } \\
\text { anuais de poluentes } \\
\text { modeladas e baseadas } \\
\text { nos endereços } \\
\text { históricos de residência } \\
\text { de cada participante } \\
\text { entre } 1974 \text { e } 1998 \text { para } \\
\text { diversas janelas de } \\
\text { tempo }\end{array}$ & $\begin{array}{l}\text { Concentrações médias } \\
\text { de } \mathrm{NOx} \text { (aumento de } \\
\left.10 \mu \mathrm{g} / \mathrm{m}^{3}\right) \\
\text { Concentrações médias } \\
\text { de } \mathrm{NOx}\left(30 \mu \mathrm{m} / \mathrm{m}^{3} \text { vs }\right. \\
\left.10 \mu \mathrm{g} / \mathrm{m}^{3}\right)\end{array}$ & $\begin{array}{l}\text { RR=1,08; IC95\%(1,02- } \\
1,15) \\
\\
R R=1,36 ; \quad I C 95 \%(1,01- \\
1,83)\end{array}$ & $\begin{array}{l}\text { Ajuste para idade, nível } \\
\text { educacional } \\
\text { tabagismo. Não houve a } \\
\text { necessidade de ajuste } \\
\text { para ocupação e outras } \\
\text { variáveis no modelo } \\
\text { estatístico final, por não } \\
\text { aumentarem a sua } \\
\text { precisão. Exposição } \\
\text { avaliada por modelo de } \\
\text { dispersão com uso de } \\
\text { dados de emissão, } \\
\text { topográficos } \\
\text { meteorológicos }\end{array}$ \\
\hline $\begin{array}{l}\text { Nafstad et al., } \\
2004\end{array}$ & $\begin{array}{l}\text { Oslo, } \\
\text { Noruega; } \\
\text { 1972-1998 }\end{array}$ & $\begin{array}{l}\text { Coorte } \\
\text { prospectiva } \\
\text { (16.209 } \\
\text { homens) }\end{array}$ & $\begin{array}{l}\text { Mortalidade } \\
\text { por Câncer de } \\
\text { Pulmão }\end{array}$ & $\begin{array}{l}382 \text { casos } \\
\text { (homens de } \\
40-49 \text { anos) }\end{array}$ & $\begin{array}{l}\text { Concentrações médias } \\
\text { anuais de poluentes } \\
\text { modeladas e baseadas } \\
\text { nos endereços } \\
\text { históricos de residência } \\
\text { de cada participante } \\
\text { entre } 1974 \text { e } 1998 \text { para } \\
\text { diversas janelas de } \\
\text { tempo }\end{array}$ & $\begin{array}{l}\text { Concentrações médias } \\
\text { de } \mathrm{NOx} \text { (aumento de } \\
\left.10 \mu \mathrm{g} / \mathrm{m}^{3}\right) \\
\text { Concentrações médias } \\
\text { de } \mathrm{NOx}\left(30 \mu \mathrm{m} / \mathrm{m}^{3} \text { vs }\right. \\
\left.10 \mu \mathrm{g} / \mathrm{m}^{3}\right)\end{array}$ & $\begin{array}{l}R R=1,11 ; \quad I C 95 \%(1,03- \\
1,19) \\
\\
R R=1,30 ; \quad I C 95 \%(0,94- \\
1,78)\end{array}$ & $\begin{array}{l}\text { Ajuste para idade, nível } \\
\text { educacional, tabagismo, } \\
\text { atividade física no } \\
\text { tempo livre, ocupação e } \\
\text { grupos de risco } \\
\text { cardiovascular. } \\
\text { Observou-se gradiente } \\
\text { dose-resposta entre as } \\
\text { categorias de exposição }\end{array}$ \\
\hline $\begin{array}{l}\text { Visser et al., } \\
2004\end{array}$ & $\begin{array}{l}\text { Amsterdã, } \\
\text { Holanda; } \\
\text { 1989-1997 }\end{array}$ & Ecológico & $\begin{array}{l}\text { Incidência de } \\
\text { Câncer em } \\
\text { geral e dos } \\
\text { seus principais } \\
\text { grupos }\end{array}$ & $\begin{array}{l}27.157 \text { casos } \\
\text { de Câncer em } \\
\text { geral, } 378 \text { do } \\
\text { trato } \\
\text { gastrintestinal } \\
\text { em homens, } \\
176 \text { do } \\
\text { sistema }\end{array}$ & $\begin{array}{l}\text { Razão da taxa de } \\
\text { incidência padronizada } \\
\text { observada sobre a } \\
\text { esperada da população } \\
\text { residente dentro de um } \\
\text { raio de } 50 \text { metros do } \\
\text { eixo de vias com alto } \\
\text { Escore de Intensidade }\end{array}$ & $\begin{array}{llr}\text { Razão da } & \text { taxa } & \text { de } \\
\text { incidência } & \text { padronizada } \\
\text { observada } & \text { sobre } & \text { a } \\
\text { esperada } & & \end{array}$ & $\begin{array}{lr}\text { Câncer do } & \text { trato } \\
\text { gastrintestinal } & \text { em } \\
\text { homens: SIR=1,16; } \\
\text { IC95\% (1,04-1,28); } \\
\text { Câncer do sistema } \\
\text { respiratório r em } \\
\text { mulheres: } \\
\text { SIR=1,13; IC95\% } & (0,97-\end{array}$ & 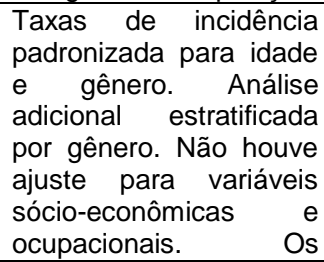 \\
\hline
\end{tabular}




\begin{tabular}{|c|c|c|c|c|c|c|c|c|}
\hline & & & & $\begin{array}{l}\text { respiratório e } \\
148 \\
\text { neoplasias } \\
\text { hematológicas } \\
\text { em mulheres } \\
\text { (todas as } \\
\text { faixas etárias) }\end{array}$ & de Tráfego $(\geq 10.000)$ & & $\begin{array}{l}1,31) \text {; } \\
\text { Neoplasias } \\
\text { hematológicas em } \\
\text { mulheres com } 15 \text { anos } \\
\text { ou mais: } \\
\text { SIR=1,23; IC95\% (1,04- } \\
1,44)\end{array}$ & $\begin{array}{l}\text { hábitos de tabagismo } \\
\text { foram semelhantes } \\
\text { entre os residentes das } \\
\text { duas áreas comparadas. } \\
\text { Não houve gradiente } \\
\text { dose-resposta }\end{array}$ \\
\hline $\begin{array}{l}\text { Bonner et al., } \\
2005\end{array}$ & $\begin{array}{l}\text { Condados de } \\
\text { Erie e de } \\
\text { Niagara; oeste } \\
\text { do Estado de } \\
\text { Nova lorque, } \\
\text { EUA; 1996- } \\
2001\end{array}$ & $\begin{array}{l}\text { Caso-controle } \\
\text { de base } \\
\text { populacional }\end{array}$ & $\begin{array}{ll}\text { Incidência } & \text { de } \\
\text { Câncer } & \text { de } \\
\text { Mama } & \end{array}$ & $\begin{array}{l}1166 \text { casos e } \\
2105 \text { controles } \\
\text { (mulheres de } \\
35-79 \text { anos) }\end{array}$ & $\begin{array}{l}\text { Concentrações } \\
\text { anuais dédias } \\
\text { modeladas e baseadas } \\
\text { no endereço de } \\
\text { residência de cada } \\
\text { participante } \\
\text { diversos períodos da } \\
\text { vida da mulher entre } \\
1960 \text { e } 1997 \text { e diversas } \\
\text { janelas de tempo, } \\
\text { através de interpolação } \\
\text { estatística }\end{array}$ & $\begin{array}{l}\text { Concentrações r médias } \\
\text { de PTS (>p75 vs <p25 } \\
\text { em } 1960 \text { ou }>140 \mu \mathrm{g} / \mathrm{m}^{3} \\
\left.\text { e }<84 \mu \mathrm{m}^{3}\right)\end{array}$ & $\begin{array}{l}\text { Câncer de mama: } \\
\text { Na pós-menopausa: } \\
\text { OR=2,42; IC95\% (0,97- } \\
6,09) \text {, exposição no } \\
\text { nascimento; } \\
\text { OR=1,45; IC95\% (0,74- } \\
2,87) \text {, exposição na } \\
\text { menarca; } \\
\text { Na pré-menopausa: } \\
\text { OR=1,78; IC95\% (0,69- } \\
5,10) \text {, exposição no } \\
\text { nascimento }\end{array}$ & 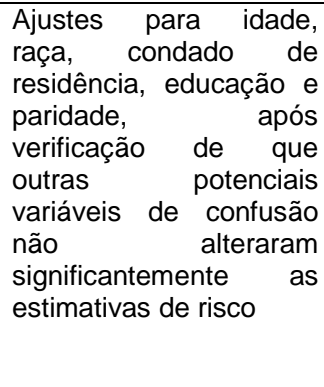 \\
\hline $\begin{array}{l}\text { Filleul et al., } \\
2005\end{array}$ & $\begin{array}{l}24 \text { áreas de } 7 \\
\text { cidades da } \\
\text { França; 1974- } \\
1998\end{array}$ & $\begin{array}{l}\text { Coorte } \\
\text { prospectiva } \\
(17.805 \\
\text { participantes, } \\
\text { residentes há } \\
3 \text { anos ou } \\
\text { mais em uma } \\
\text { das áreas ao } \\
\text { tempo do } \\
\text { recrutamento) }\end{array}$ & $\begin{array}{l}\text { Mortalidade } \\
\text { por Câncer de } \\
\text { Pulmão }\end{array}$ & $\begin{array}{l}178 \text { casos } \\
\text { (idade de 25- } \\
59 \text { anos) }\end{array}$ & $\begin{array}{l}\text { Concentrações médias } \\
\text { anuais de poluentes } \\
\text { baseadas na área de } \\
\text { residência de cada } \\
\text { participante. Exposição } \\
\text { estimada pela média } \\
\text { das concentrações } \\
\text { mensuradas por estação } \\
\text { de monitoramento do ar } \\
\text { localizada no centro de } \\
\text { cada área entre } 1974 \text { a } \\
1976\end{array}$ & $\begin{array}{l}\text { Concentrações médias } \\
\text { de } \mathrm{NO}_{2} \text { (aumento de } \\
10 \mu \mathrm{g} / \mathrm{m}^{3} \text { ) }\end{array}$ & $\begin{array}{l}\mathrm{RR}=1,48 ; \mathrm{IC} 95 \% \quad(1,05- \\
2,06)\end{array}$ & 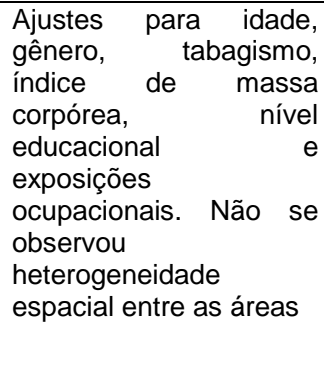 \\
\hline $\begin{array}{l}\text { Iwai et al., } \\
2005\end{array}$ & Japão, 2000 & Ecológico & \begin{tabular}{ll}
\multicolumn{2}{l}{ Mortalidade } \\
por diversos \\
tipos de \\
Câncer
\end{tabular} & 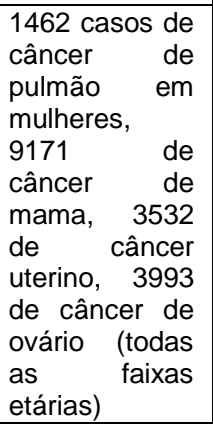 & 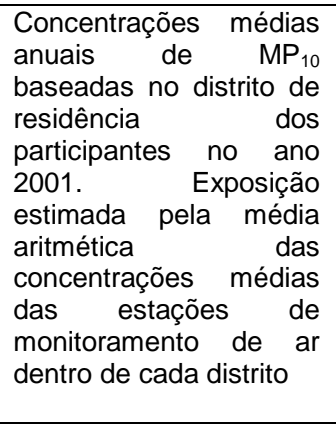 & $\begin{array}{lcr}\text { Coeficientes } & & \text { de } \\
\text { correlação } & \text { entre } & \text { a } \\
\text { exposição } & \text { e } & \text { os } \\
\text { desfechos } & & \end{array}$ & $\begin{array}{l}\text { Câncer de pulmão em } \\
\text { mulheres: } \quad r=0,306 ; \\
\text { p<0.05 } \\
\text { Câncer de mama: } \\
r=0.373 ; p<0,01 \\
\text { Câncer de ovário: } \\
r=0,428 ; p<0,05 \\
\text { Câncer de endométrio: } \\
r=0,29 ; p<0,05\end{array}$ & $\begin{array}{l}\text { Ajuste para idade, } \\
\text { prevalência distrital de } \\
\text { tabagismo, idade da } \\
\text { mulher no primeiro parto } \\
\text { e paridade. Grande } \\
\text { número de testes } \\
\text { estatísticos pode ter } \\
\text { resultado em } \\
\begin{array}{l}\text { associações espúrias } \\
\text { devidas ao acaso }\end{array}\end{array}$ \\
\hline
\end{tabular}




\begin{tabular}{|c|c|c|c|c|c|c|c|c|}
\hline $\begin{array}{l}\text { Jerret et al., } \\
2005 a\end{array}$ & $\begin{array}{l}\text { Hamilton, } \\
\text { Canadá; 1985- } \\
1994\end{array}$ & Ecológico & $\begin{array}{l}\text { Mortalidade } \\
\text { por Câncer em } \\
\text { geral }\end{array}$ & $\begin{array}{lr}29040 \quad \text { casos } \\
\text { (todas as } \\
\text { faixas etárias) }\end{array}$ & $\begin{array}{l}\text { Concentrações médias } \\
\text { anuais de poluente } \\
\text { modeladas e baseadas } \\
\text { no census tract de } \\
\text { residência dos } \\
\text { participantes, estimadas } \\
\text { por interpolação } \\
\text { estatística }\end{array}$ & $\begin{array}{l}\text { Concentrações médias } \\
\text { de PTS (aumento de } \\
13 \mu \mathrm{g} / \mathrm{m}^{3} \text { ) em homens } \\
\text { Concentrações médias } \\
\text { de PTS (aumento de } \\
46 \mu \mathrm{g} / \mathrm{m}^{3} \text { ) em homens }\end{array}$ & $\begin{array}{l}\mathrm{RR}=1,11 ; \mathrm{IC} 95 \%(1,04- \\
1,18) \\
\mathrm{RR}=1,43 ; \mathrm{IC} 95 \%(1,13- \\
1,81)\end{array}$ & $\begin{array}{l}\text { Ajuste para idade, } \\
\text { variáveis ecológicas } \\
\text { sócio-econômicas, } \\
\text { demográficas, de estilos } \\
\text { de vida e de tabagismo } \\
\text { e para autocorrelação } \\
\text { espacial. Análise } \\
\text { estratificada por gênero }\end{array}$ \\
\hline $\begin{array}{l}\text { Jerret et al., } \\
2005 b\end{array}$ & 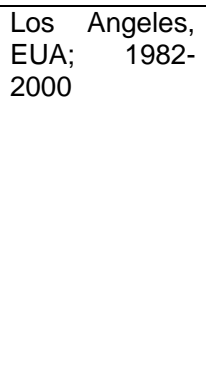 & $\begin{array}{l}\text { Coorte } \\
\text { prospectiva } \\
\text { (22.905 } \\
\text { participantes; } \\
\text { amigos, } \\
\text { vizinhos ou } \\
\text { conhecidos de } \\
\text { voluntários da } \\
\text { American } \\
\text { Cancer } \\
\text { Society) }\end{array}$ & $\begin{array}{l}\text { Mortalidade } \\
\text { por Câncer de } \\
\text { Pulmão e } \\
\text { Digestivo }\end{array}$ & $\begin{array}{l}434 \text { casos de } \\
\text { pulmão e } 429 \\
\text { de digestivo } \\
\text { (idade de } 30 \\
\text { anos ou mais) }\end{array}$ & $\begin{array}{l}\text { Concentrações médias } \\
\text { anuais de poluentes } \\
\text { modeladas e baseadas } \\
\text { na área zip code de } \\
\text { residência } \\
\text { participantes na época } \\
\text { do recrutamento, } \\
\text { estimadas por } \\
\text { interpolação estatística. } \\
\text { Distâncias de vias de } \\
\text { alto tráfego ao centróide } \\
\text { do zip code }\end{array}$ & $\begin{array}{l}\text { Concentrações de } \mathrm{MP}_{2,5} \\
\text { (aumento de } 10 \mu \mathrm{g} / \mathrm{m}^{3} \text { ) } \\
\text { Distâncias até } 500 \\
\text { metros de vias de alto } \\
\text { tráfego ao centróide do } \\
\text { zip code }\end{array}$ & 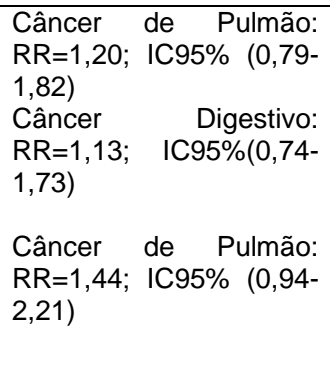 & $\begin{array}{l}\text { Ajuste para } 44 \text { variáveis } \\
\text { individuais e } 8 \text { variáveis } \\
\text { contextuais. Não se } \\
\text { observou autocorrelação } \\
\text { espacial, após ajuste } \\
\text { para todas as variáveis }\end{array}$ \\
\hline $\begin{array}{l}\text { Laden et al., } \\
2006\end{array}$ & $\begin{array}{l}\text { Cidades de } \\
\text { Watertown, } \\
\text { Harriman, } \\
\text { Saint Louis, } \\
\text { Steubenville, } \\
\text { Portage e } \\
\text { Topeka; } \\
\text { nordeste dos } \\
\text { EUA; 1974- } \\
1998\end{array}$ & $\begin{array}{l}\text { Coorte } \\
\text { prospectiva } \\
\text { (8.096 adultos, } \\
\text { brancos) }\end{array}$ & $\begin{array}{l}\text { Mortalidade } \\
\text { por Câncer de } \\
\text { Pulmão }\end{array}$ & $\begin{array}{l}226 \text { casos } \\
\text { (idade de 25- } \\
74 \text { anos) }\end{array}$ & $\begin{array}{l}\text { Concentrações } \\
\text { anuais dédias } \\
\text { baseadas na cidade de } \\
\text { residência } \mathrm{MP}_{2,5} \\
\text { participantes na época } \\
\text { do recrutamento. } \\
\text { Exposição estimada } \\
\text { pela média aritmética } \\
\text { das concentrações } \\
\text { quadrimestrais médias } \\
\text { do poluente estimadas } \\
\text { para cada cidade }\end{array}$ & $\begin{array}{l}\text { Concentrações de } \mathrm{MP}_{2,5} \\
\text { (aumento de } 10 \mu \mathrm{\mu g} / \mathrm{m}^{3} \text { )- } \\
\text { acompanhamento entre } \\
1974 \text { e } 1998 \\
\text { Concentrações de } \mathrm{MP}_{2,5} \\
\text { (aumento de } 10 \mu \mathrm{g} / \mathrm{m}^{3} \text { ) - } \\
\text { acompanhamento entre } \\
1974 \text { e } 1989\end{array}$ & $\begin{array}{l}\text { RR=1,27; IC95\% }(0,96- \\
1,69) \\
\\
R R=1,20 ; \quad I C 95 \% \quad(0,91- \\
1,58)\end{array}$ & $\begin{array}{l}\text { Ajuste para idade, } \\
\text { gênero, tabagismo } \\
\text { pregresso e à época do } \\
\text { recrutamento, nível } \\
\text { educacional e índice de } \\
\text { massa corpórea. } \\
\text { Equações de regressão } \\
\text { a partir de medidas de } \\
\text { visibilidade do ar e de } \\
\mathrm{MP}_{10} \text { foram utilizadas } \\
\text { para estimar } \mathrm{MP}_{2,5} \text { entre } \\
1985 \text { e } 1998\end{array}$ \\
\hline $\begin{array}{l}\text { Vineis et al., } \\
2006\end{array}$ & $\begin{array}{lr}\text { Europa } & (10 \\
\text { países); } 1993- \\
1998\end{array}$ & $\begin{array}{l}\text { Caso-controle } \\
\text { aninhado de } \\
\text { base } \\
\text { populacional } \\
\text { (participantes } \\
\text { não fumantes } \\
\text { ou } \quad \text { ex- } \\
\text { fumantes há } \\
\text { mais de } 10 \\
\text { anos) }\end{array}$ & $\begin{array}{ll}\text { Incidência } & \text { de } \\
\text { Câncer } & \text { de } \\
\text { Pulmão } & \end{array}$ & $\begin{array}{l}197 \text { casos e } \\
556 \text { controles } \\
\text { (idade de 35- } \\
74 \text { anos) }\end{array}$ & $\begin{array}{l}\text { Concentrações médias } \\
\text { anuais de poluentes } \\
\text { baseadas na residência } \\
\text { dos participantes no } \\
\text { início do estudo. } \\
\text { Exposição avaliada } \\
\text { pelas concentrações } \\
\text { médias das estações de } \\
\text { monitoramento do ar } \\
\text { mais próximas da } \\
\text { residência. Residência } \\
\text { em vias de alto tráfego }\end{array}$ & $\begin{array}{l}\text { Concentrações médias } \\
\text { de } \mathrm{NO}_{2}(\geq \mathrm{p} 66 \text { vs }<\mathrm{p} 66 \text { ou } \\
\left.\geq 30 \mu \mathrm{g} / \mathrm{m}^{3} \text { vs }<30 \mu \mathrm{g} / \mathrm{m}^{3}\right) \\
\text { Concentrações médias } \\
\text { de } \mathrm{SO}_{2}(\geq \mathrm{p} 66 \text { vs }<\mathrm{p} 66 \\
\left.\text { ou } \geq 11 \mu / \mathrm{m}^{3} \text { vs }<11 \mu / \mathrm{m}^{3}\right) \\
\text { Residência em vias de } \\
\text { alto tráfego } \\
\begin{array}{l}\text { ( } \geq 10.000 \mathrm{VPD} \text { vs } \\
<10.000 \mathrm{VPD})\end{array}\end{array}$ & $\begin{array}{l}\text { RR=1,56; IC 95\% }(1,13- \\
2,16) \\
\text { RR=1,15; IC95\% }(0,92- \\
1,43) \\
\text { RR=1,46; IC } \\
2,40)\end{array}$ & 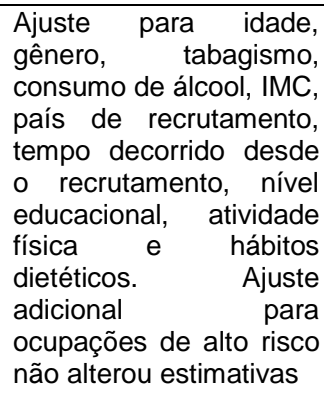 \\
\hline
\end{tabular}




\begin{tabular}{|c|c|c|c|c|c|c|c|c|}
\hline $\begin{array}{l}\text { Naess et al., } \\
2007\end{array}$ & $\begin{array}{l}\text { Oslo, } \\
\text { Noruega; } \\
\text { 1992-1998 }\end{array}$ & $\begin{array}{l}\text { Coorte } \\
\text { prospectiva } \\
\text { (143.842 } \\
\text { participantes) }\end{array}$ & $\begin{array}{l}\text { Mortalidade } \\
\text { por Câncer de } \\
\text { Pulmão }\end{array}$ & $\begin{array}{l}1453 \text { casos } \\
\text { (idade de 51- } \\
90 \text { anos) }\end{array}$ & $\begin{array}{l}\text { Concentrações médias } \\
\text { diárias de poluentes } \\
\text { baseadas na residência } \\
\text { dos participantes no } \\
\text { período de } 1992 \text { a } 1995 .\end{array}$ & $\begin{array}{l}\text { Concentrações de } \mathrm{MP}_{2,5} \\
\text { (aumento de } 7 \mu \mathrm{g} / \mathrm{m}^{3} \text { ) }\end{array}$ & $\begin{array}{l}\text { Mulheres (51-70 anos): } \\
\text { RR=1,27; IC95\% (1,13- } \\
1,43) \\
\text { Mulheres ( } 71-90 \text { anos): } \\
\text { RR=1,16; IC95\% (1,02- } \\
1,16) \\
\text { Homens ( } 51-70 \text { anos): } \\
\text { RR=1,07; IC95\% (0,97- } \\
1,18)\end{array}$ & $\begin{array}{l}\text { Ajuste para } \text { nível } \\
\text { educacional e classe } \\
\text { ocupacional. } \\
\text { Estratificação por idade } \\
\text { e gênero. Exposição } \\
\text { avaliada por modelo } \\
\text { validado AirQUIS de } \\
\text { dispersão com uso de } \\
\text { dados de emissão, } \\
\text { topográficos } \\
\text { meteorológicos }\end{array}$ \\
\hline $\begin{array}{l}\text { Nie et al., } \\
2007\end{array}$ & $\begin{array}{l}\text { Condados de } \\
\text { Erie e de } \\
\text { Niagara; oeste } \\
\text { do Estado de } \\
\text { Nova lorque, } \\
\text { EUA; 1996- } \\
2001\end{array}$ & $\begin{array}{l}\text { Caso-controle } \\
\text { de base } \\
\text { populacional }\end{array}$ & $\begin{array}{ll}\text { Incidência } & \text { de } \\
\text { Câncer } & \text { de } \\
\text { Mama } & \end{array}$ & $\begin{array}{l}1068 \text { casos e } \\
1944 \text { controles } \\
\text { (mulheres de } \\
35-79 \text { anos) }\end{array}$ & $\begin{array}{l}\text { Concentrações } \\
\text { anuais dédias } \\
\text { modeladas e baseadas } \\
\text { no endereço de } \\
\text { residência de cada } \\
\text { participante } \\
\text { diversos períodos de } \\
\text { sua vida entre } 1960 \text { e } \\
2001 \text { e diversas janelas } \\
\text { de tempo. Exposição } \\
\text { avaliada por modelo } \\
\text { validado de dispersão } \\
\text { com uso de dados } \\
\text { meteorológicos, de } \\
\text { volume e emissão do } \\
\text { tráfego }\end{array}$ & 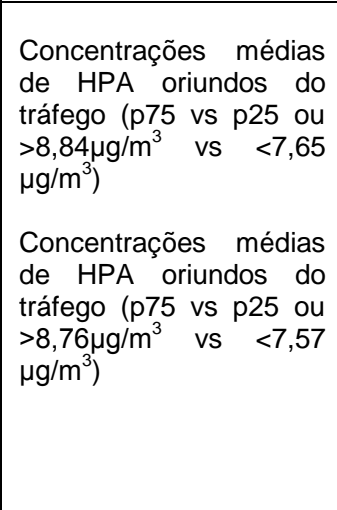 & $\begin{array}{l}\text { Câncer de mama: } \\
\mathrm{Na} \text { pré-menopausa: } \\
\mathrm{RR}=2,07 \text {; IC95\% (0,91- } \\
4,72) \text {, exposição na } \\
\text { menarca; } \\
\text { Na pós-menopausa: } \\
\mathrm{RR}=2,58 ; \text { IC95\% (1,15- } \\
5,83) \text {, exposição no } \\
\text { primeiro parto }\end{array}$ & $\begin{array}{l}\text { Ajustes para idade, } \\
\text { raça, educação, índice } \\
\text { de massa corpórea, } \\
\text { doença benigna de } \\
\text { mama prévia, história } \\
\text { familiar de câncer de } \\
\text { mama, ano de } \\
\text { entrevista, número de } \\
\text { filhos e idade na } \\
\text { menarca, no nascimento } \\
\text { do primeiro filho e na } \\
\text { menopausa }\end{array}$ \\
\hline $\begin{array}{l}\text { Bellen et al., } \\
2008 a\end{array}$ & $\begin{array}{l}\text { Holanda; } \\
\text { 1986-1996 }\end{array}$ & $\begin{array}{l}\text { Coorte } \\
\text { prospectiva } \\
\text { (120.852 } \\
\text { participantes) } \\
\text { e caso-coorte } \\
\text { (5.000 } \\
\text { participantes) }\end{array}$ & $\begin{array}{l}\text { Mortalidade } \\
\text { por Câncer de } \\
\text { Pulmão }\end{array}$ & $\begin{array}{lr}1888 & \text { (coorte) } \\
\text { e 1059 } & \text { (caso- } \\
\text { coorte) } & \text { (idade } \\
\text { de } & 55-69 \\
\text { anos) } & \end{array}$ & $\begin{array}{l}\text { Concentrações médias } \\
\text { anuais de poluentes } \\
\text { baseadas no endereço } \\
\text { de residência de cada } \\
\text { participante no início do } \\
\text { estudo. Diversas } \\
\text { variáveis de intensidade } \\
\text { e proximidade de vias } \\
\text { de alto tráfego. } \\
\text { Exposição avaliada pela } \\
\text { soma das contribuições } \\
\text { regional, urbana e de } \\
\text { tráfego local à poluição } \\
\text { do ar no endereço de } \\
\text { residência }\end{array}$ & $\begin{array}{l}\text { Concentrações médias } \\
\text { de } \mathrm{MP}{ }^{2,5} \text { (aumento de } \\
10 \mu \mathrm{g} / \mathrm{m}^{3} \text { ) } \\
\text { Concentrações de } \\
\text { carbono elementar } \\
\text { aumento de } 10 \mu \mathrm{g} / \mathrm{m}^{3} \text { ) } \\
\text { Concentrações médias } \\
\text { de } \mathrm{NO}_{2} \text { (aumento de } \\
30 \mu \mathrm{g} / \mathrm{m}^{3} \text { ) } \\
\text { Residir próximo a vias } \\
\text { de alto fluxo veicular } \\
\text { (sim vs não) }\end{array}$ & $\begin{array}{l}\begin{array}{l}R R=1,06 ; \quad I C 95 \%(0,82- \\
1,38)\end{array} \\
\begin{array}{l}R R=1,03 ; \quad I C 95 \%(0,88- \\
1,20)\end{array} \\
\begin{array}{l}\text { RR=0,91; IC } 95 \% \quad(0,72- \\
1,15)\end{array} \\
R R=1,20 ; \quad I C 95 \% \quad(0,98- \\
1,47)\end{array}$ & $\begin{array}{l}\text { Ajuste para idade, } \\
\text { gênero, tabagismo e } \\
\text { variáveis } \quad \text { sócio- } \\
\text { econômicas de área (na } \\
\text { coorte). Não houve } \\
\text { ajuste para exposições } \\
\text { ocupacionais. Uso de } \\
\text { interpolação estatística, } \\
\text { dados de ocupação do } \\
\text { solo e de intensidade de } \\
\text { tráfego no modelo de } \\
\text { exposição (modelo } \\
\text { híbrido). }\end{array}$ \\
\hline
\end{tabular}




\begin{tabular}{|c|c|c|c|c|c|c|c|c|}
\hline $\begin{array}{l}\text { Bellen et al., } \\
2008 b\end{array}$ & $\begin{array}{l}\text { Holanda; } \\
\text { 1986-1997 }\end{array}$ & $\begin{array}{l}\text { Coorte } \\
\text { prospectiva } \\
\text { (114.378 } \\
\text { participantes) } \\
\text { e caso-coorte } \\
\text { (5.000 } \\
\text { participantes) }\end{array}$ & $\begin{array}{ll}\text { Incidência } & \text { de } \\
\text { Câncer } & \text { de } \\
\text { Pulmão } & \end{array}$ & $\begin{array}{lr}2183 & \text { (coorte) } \\
\text { e 1295 } & \text { (caso- } \\
\text { coorte) } & \text { (idade } \\
\text { de } & 55-69 \\
\text { anos) } & \\
\end{array}$ & $\begin{array}{l}\text { Concentrações médias } \\
\text { anuais de poluentes } \\
\text { baseadas no endereço } \\
\text { de residência de cada } \\
\text { participante no início do } \\
\text { estudo. Exposição } \\
\text { avaliada pela soma das } \\
\text { contribuições regional, } \\
\text { urbana e de tráfego } \\
\text { local à poluição do ar no } \\
\text { endereço de residência }\end{array}$ & $\begin{array}{l}\text { Concentrações médias } \\
\text { de } \mathrm{MP}_{2,5} \text { (aumento de } \\
10 \mu \mathrm{g} / \mathrm{m}^{3} \text { ) } \\
\text { Concentrações médias } \\
\text { de } \mathrm{NO}_{2} \text { (aumento de } \\
30 \mu \mathrm{g} / \mathrm{m}^{3} \text { ) } \\
\text { Residir próximo a vias } \\
\text { de alto fluxo veicular } \\
\text { (sim vs não) }\end{array}$ & $\begin{array}{l}\text { RR=0,81; IC95\% }(0,63- \\
1,04) \\
\text { RR=0,86; IC95\% }(0,70- \\
1,07) \\
\text { RR=1,11; IC95\% }(0,91- \\
1,34)\end{array}$ & $\begin{array}{l}\text { Ajuste para gênero, } \\
\text { idade, tabagismo e } \\
\text { variáveis } \quad \text { sócio- } \\
\text { econômicas de área (na } \\
\text { coorte). Não houve } \\
\text { ajuste para exposições } \\
\text { ocupacionais }\end{array}$ \\
\hline Yanagi, 2010 & $\begin{array}{l}11 \text { Distritos do } \\
\text { município de } \\
\text { São Paulo, } \\
\text { Brasil; 1997- } \\
2005\end{array}$ & $\begin{array}{l}\text { Estudo } \\
\text { ecológico }\end{array}$ & $\begin{array}{ll}\text { Incidência } & \text { e } \\
\text { Mortalidade } & \\
\text { por diversos } \\
\text { tipos de } \\
\text { Câncer }\end{array}$ & $\begin{array}{lr}36.534 & \text { casos } \\
\text { de } & \text { Câncer; } \\
12.934 & \text { mortes } \\
\text { por } & \text { Câncer } \\
\text { (todas } & \text { as } \\
\text { idades) } & \end{array}$ & $\begin{array}{lr}\text { Concentrações } & \text { médias } \\
\text { anuais de } & \mathrm{MP}_{10} \\
\text { mensuradas } & \text { nas } \\
\text { estações } & \text { de } \\
\text { monitoramento do ar } \\
\text { dentro de cada } & \text { distrito } \\
\text { (uma estação r por } \\
\text { distrito) } & \end{array}$ & $\begin{array}{l}\text { Concentrações médias } \\
\text { de } \mathrm{MP}_{10} \text { de cada distrito }\end{array}$ & $\begin{array}{l}\text { Correlação significante, } \\
\text { positiva e > } 0,6 \text { entre os } \\
\text { níveis do poluente } \\
\text { estudado e a incidência } \\
\text { de câncer de pele e de } \\
\text { pulmão e a mortalidade } \\
\text { por câncer de pulmão, } \\
\text { para diversos intervalos } \\
\text { de tempo entre a } \\
\text { exposição e o desfecho }\end{array}$ & $\begin{array}{l}\text { Não houve ajuste para } \\
\text { idade, gênero e outras } \\
\text { potenciais variáveis de } \\
\text { confusão. arande } \\
\text { número de testes } \\
\text { estatísticos pode ter } \\
\text { resultado rom } \\
\text { associações espúrias } \\
\text { devidas ao acaso }\end{array}$ \\
\hline
\end{tabular}

EUA: Estados Unidos da América; HPA: Hidrocarbonetos Policíclicos Aromáticos; IC95\%: Intervalo de Confiança de 95\%; IMC: Índice de Massa Corpórea; PTS: Partículas Totais em Suspensão; $\mathrm{MP}_{2,5}$ : Material Particulado inalável com diâmetro aerodinâmico menor que 2,5 $\mu \mathrm{m} ; \mathrm{MP}_{10}$ : Material Particulado inalável com diâmetro aerodinâmico menor que $10 \mu \mathrm{m} ; \mathrm{NO}_{2}$ : Dióxido de Nitrogênio; NOx: Óxidos de Nitrogênio; $\mathrm{O}_{3}$ : Ozônio; ppb: partes por bilhão; r: coeficiente de correlação; RR: Risco Relativo; SO ${ }_{2}$ : Dióxido de Enxofre;VPD: Veículos por dia; $\mu$ g/m³; microgramas por metro cúbico 
Coorte prospectiva foi conduzida no Estado da Califórnia, Estados Unidos, no período de 1977 a 1992, entre 6338 adultos brancos, nãohispânicos, não fumantes e adventistas do sétimo dia, visando investigar a relação entre exposição crônica a diversos poluentes do ar e o desenvolvimento de câncer de pulmão. Utilizaram-se várias medidas de exposição baseadas nos endereços históricos de residência e de trabalho dos participantes entre 1966 e 1992. Para os homens, observaram-se riscos aumentados de câncer de pulmão associados a aumento das concentrações médias anuais de $\mathrm{MP}_{10}$ [RR=5,21; IC95\% (1,94-13,99)], SO 2 [RR=2,68; IC $95 \%(1,62-4,39)], O_{3}[R R=1,65 ; \mathrm{IC} 95 \%(0,72-3,80)]$ e NO 2 [RR=1,45; IC95\% $(0,67-3,14)]$ referentes à variação entre os quartis extremos de exposição, assim como a aumento da freqüência de ultrapassagem horária e diária de diversos valores pré-determinados da concentração, respectivamente, de $\mathrm{O}_{3}$ e $\mathrm{MP}_{10}$. Em mulheres, somente a concentração média de $\mathrm{SO}_{2}[\mathrm{RR}=2,14$; IC95\% (1,36-3,37)] esteve significantemente associada ao desfecho, com estimativas de risco pouco acima da unidade e não significantes para a mesma medida de $\mathrm{NO}_{2}$ e $\mathrm{MP}_{10}$. Ajustes foram feitos para idade, história pregressa de tabagismo, nível educacional e uso de álcool. Em análise com múltiplos poluentes, os efeitos de $\mathrm{MP}_{10} \mathrm{e} \mathrm{SO}_{2}$ sobre o desfecho revelaram-se mais fortes e estáveis que os dos demais poluentes (BEESON et al., 1998).

A mesma coorte, acompanhada durante o mesmo período, foi utilizada para investigar a mortalidade por câncer de pulmão relacionada com a exposição crônica à poluição do ar, por meio das mesmas medidas e métodos de avaliação da exposição. Nos homens, riscos aumentados desse desfecho se associaram ao aumento das concentrações médias de $\mathrm{MP}_{10}$ [RR=3,36; IC95\% (1,57-7,19)], SO $\mathrm{SO}_{2}$ [RR=1,99; IC95\% $\left.(1,24-3,20)\right], \quad \mathrm{O}_{3}$ [RR=2,10; IC95\% (0,99-4,44)] e $\mathrm{NO}_{2} \quad$ [RR=1,82; IC $\left.95 \% \quad(0,93-3,57)\right]$ referentes à variação entre os quartis extremos de exposição, assim como a aumento da freqüência de ultrapassagem horária e diária de diversos valores pré-determinados da concentração, respectivamente, de $\mathrm{O}_{3}$ e $\mathrm{PM}_{10}$. Já nas mulheres, concentrações médias de $\mathrm{SO}_{2}$ [RR=3,01; IC 95\% (1,884,84)] e de $\mathrm{NO}_{2} \quad[\mathrm{RR}=2,80 ;$ IC95\% $(1,15-6,89)]$ se mostraram 
significantemente associadas ao desfecho, enquanto as de $\mathrm{O}_{3}$ e $\mathrm{MP}_{10}$ não, com estimativas abaixo ou pouco acima da unidade. Ajustes foram feitos para as mesmas variáveis do estudo anterior. Os efeitos de $\mathrm{MP}_{10}, \mathrm{O}_{3}$ e $\mathrm{SO}_{2}$ permaneceram robustos na análise com múltiplos poluentes, não tendo sido possível separar os efeitos dos 2 primeiros poluentes por estarem altamente correlacionados (ABBEY et al., 1999).

MACDONNELL et al. (2000) conduziu estudo com uma parcela dessa mesma coorte acompanhada pelo mesmo período (1977 a 1992), visando identificar qual a fração de material particulado - $\mathrm{MP}_{2,5}$ ou $\mathrm{MP}_{2,5-10}$ - seria responsável pelos efeitos sobre vários desfechos de mortalidade anteriormente identificados para a exposição crônica a $\mathrm{MP}_{10}(\mathrm{ABBEY}$ et al., 1999). Utilizando como medida de exposição a concentração dos poluentes na bacia atmosférica (airshed) de residência dos participantes entre 1973 e 1977, observaram risco aumentado de câncer de pulmão nos homens para o aumento nas concentrações de $\mathrm{MP}_{10}[\mathrm{RR}=1,84$; IC95\% $(0,59-5,67)], \mathrm{MP}_{2,5}$ [RR=2,23; IC95\% (0,56-8,94)] e $M_{2,5-10}$ [RR=1,25; IC95\% (0,63-2,49)] referentes à variação entre os quartis extremos de exposição. Para as mulheres, as estimativas de risco foram pouco acima ou abaixo da unidade. Ajustes foram feitos para o nível educacional, história pregressa de tabagismo e uso de álcool. Portanto, a maior parte do efeito provocado por $\mathrm{MP}_{10}$ sobre a mortalidade por câncer de pulmão pôde ser atribuída à exposição crônica a $\mathrm{MP}_{2,5}$.

Em um dos primeiros estudos nacionais a avaliar os efeitos da exposição crônica da poluição do ar sobre a determinação do câncer, CANGERANA-PEREIRA (2000) correlacionou, em nível distrital, medidas de diversos poluentes do ar entre 1981 e 1990 com a incidência de variados tipos de câncer em 1997, em 12 distritos do município de São Paulo. Observou associação significante e positiva entre a frequência média anual de ultrapassagem diária da concentração de $160 \mu \mathrm{m} / \mathrm{m}^{3}$ de $\mathrm{O}_{3}$ e a incidência dos cânceres de laringe $[r=0,993 ; p=0,007]$ e pele $[r=0,985 ; p=0,015]$. Verificou-se associação não significante com coeficiente de correlação maior que 0,6 entre essa medida de $\mathrm{O}_{3}$ e a incidência de câncer total $[\mathrm{r}=0,76$; 
$p=0,241]$, de pulmão $[r=0,723 ; p=0,277]$ e de bexiga $[r=0,628 ; p=0,372]$, assim como entre a concentração média de $\mathrm{CO}$ e o câncer de estômago $[r=0,707 ; p=0,293]$. Não se procedeu à ajuste para potenciais variáveis de confusão. A principal fonte de poluentes formadores de $\mathrm{O}_{3}$ no período de exposição do estudo era a emissão dos veículos.

NYBERG et al. (2000), através de estudo caso-controle de base populacional, em Estocolmo, Suécia, com 1042 casos de câncer de pulmão, diagnosticados entre 1985 e 1990, analisou o papel da poluição urbana do ar sobre a determinação de câncer de pulmão. Utilizaram como medidas de exposição as concentrações modeladas de $\mathrm{NO}_{2}$ e $\mathrm{SO}_{2}$ oriundas, respectiva e especificamente, das emissões do tráfego e do aquecimento residencial, para cada indivíduo nos locais em que residiu por um período de 30 anos. Com um período de latência de 20 anos entre exposição e desfecho, observou-se aumento de risco desse câncer de 10\% [RR=1,10; IC95\% $(0,97-1,23)]$ com incremento de $10 \mu \mathrm{m} / \mathrm{m}^{3}$ na concentração de $\mathrm{NO}_{2}$, e de $44 \%$ [RR=1,44; OR95\% (1,05-1,99)] na comparação dos indivíduos mais expostos (acima do percentil 90) com os menos expostos (abaixo do percentil 25), após ajuste para idade, ano de seleção, tabagismo, grupos sócio-econômicos, exposição residencial ao radônio e diversas exposições ocupacionais relevantes. Não se observou aumento de risco associado com as concentrações de $\mathrm{SO}_{2}$. Os achados apontaram para o importante papel das emissões veiculares sobre o câncer de pulmão na capital sueca, em que o risco atribuível a essa exposição sobre tal desfecho poderia chegar até $10 \%$.

A partir da coorte da American Cancer Society, nos Estados Unidos, acompanhada entre 1982 e 1998, POPE et al. (2002) investigaram a associação de diversos desfechos de mortalidade com medidas ecológicas de exposição de longo prazo a poluentes ambientais do ar baseadas na área metropolitana de residência do indivíduo no início do estudo. Para exposições estimadas entre 1979 e 1983, demonstrou-se aumento do risco de morte por câncer de pulmão [RR=1,08; IC95\% $(1,01-1,16)]$ com aumento de $10 \mu / \mathrm{m}^{3}$ na concentração de $\mathrm{MP}_{2,5}$, após ajuste para idade, gênero, raça, 
estado conjugal, tabagismo, consumo de álcool, nível educacional, índice de massa corpórea, exposições ocupacionais e hábitos dietéticos. Para exposições médias entre 1979 e 2000, o risco se elevou ainda mais [RR=1,14 IC95\% (1,04-1,23)]. A associação permaneceu robusta mesmo após controle para diferenças regionais e outras diferenças espaciais. Elevação significativa do risco de morte por esse câncer foi também observada com aumento na concentração de partículas de sulfato no ar.

NAFSTAD et al. (2003) investigaram a associação entre incidência de câncer de pulmão e medidas individuais de exposição crônica à poluição do ar nos endereços históricos de residência, em coorte de 16209 homens de Oslo, Noruega, acompanhada entre 1974 a 1998. Para exposições ocorridas entre 1974 e 1978, observou-se aumento do risco de desenvolver câncer de pulmão [RR=1,08; IC95\%(1,02-1,15)] com incremento de $10 \mu \mathrm{m} / \mathrm{m}^{3}$ na concentração de óxidos de nitrogênio $\left(\mathrm{NO}_{\mathrm{x}}\right)$, após ajuste para idade, nível educacional e tabagismo. Não houve a necessidade de ajuste para ocupação e outras potenciais variáveis de confusão no modelo estatístico final, por não aumentarem a precisão do modelo. Exposições acima de $30 \mu \mathrm{m} / \mathrm{m}^{3}$ apresentaram estimativas de risco ainda maiores [RR $=1,36 ; \operatorname{IC} 95 \%(1,01-1,83)]$ quando comparadas com as abaixo de $10 \mu \mathrm{m} / \mathrm{m}^{3}$. As concentrações de $\mathrm{SO}_{2}$ não se associaram com o risco do desfecho. Dado que a principal fonte de $\mathrm{NO}_{\mathrm{x}}$ atmosférico em Oslo são as emissões veiculares, o estudo apontou para a associação entre a poluição do ar relacionada ao tráfego e o câncer de pulmão.

Na mesma coorte e período, NAFSTAD et al. (2004) observaram que, para exposições ocorridas entre 1974 e 1978, houve aumento do risco de mortalidade por câncer de pulmão [RR=1,11; IC95\%(1,03-1,19)] com incremento de $10 \mu \mathrm{m} / \mathrm{m}^{3}$ na concentração de óxidos de nitrogênio $\left(\mathrm{NO}_{\mathrm{x}}\right)$, após ajuste para idade, nível educacional, tabagismo, atividade física no tempo livre, ocupação e grupos de risco de doenças cardiovasculares. Exposições acima de $30 \mu \mathrm{m} / \mathrm{m}^{3}$ apresentaram estimativas aumentadas [RR $=1,30 ; \operatorname{IC} 95 \%(0,94-1,78)]$ quando comparadas com as abaixo de $10 \mu \mathrm{m} / \mathrm{m}^{3}$. Observou-se também gradiente dose-resposta entre as categorias 
de exposição consideradas, revelando risco crescente de morte por esse câncer com aumento dos níveis de exposição a $\mathrm{NO}_{x}$. Exposições em períodos mais recentes resultaram apenas em leve diminuição das estimativas de risco. Não foi possível, porém, explorar o tempo de latência entre exposição e desfechos, devido à alta correlação existente entre níveis de exposição de diferentes anos.

Estudo ecológico comparou as taxas de incidência, padronizadas para a idade e gênero, de câncer em geral e de vários sistemas corporais, diagnosticados entre 1989 e 1997, em residentes a até 50 metros de vias de alto tráfego em relação a residentes a distâncias maiores, em Amsterdã, Holanda. Verificaram-se razões de incidência padronizada (Standardized Incidence Ratio - SIR) aumentadas para câncer do trato gastrintestinal em homens [SIR=1,16; IC95\% $(1,04-1,28)]$, para câncer do trato respiratório em mulheres [SIR=1,13; IC95\% (0,97-1,31)] e para neoplasias hematológicas em mulheres adultas [SIR=1,23; IC95\% $(1,04-1,44)]$, sem observação de gradiente dose-resposta. Inquérito sobre os hábitos de tabagismo não demonstrou diferenças entre os residentes das duas áreas comparadas. Não se procedeu a ajuste para o nível sócio-econômico e variáveis ocupacionais, e muitos dos achados podem ser devidos ao acaso, devido a múltiplas comparações realizadas (VISSER et al., 2004).

BONNER et al. (2005) investigou a associação entre o câncer de mama e a exposição a partículas totais em suspensão (PTS) em diferentes momentos históricos da vida da mulher, no oeste do estado de Nova lorque, Estados Unidos, por meio de estudo caso-controle de base populacional com 1066 casos incidentes da doença, diagnosticados entre 1996 e 2001. Elevação de risco de câncer de mama na pós-menopausa foi observado para exposições aumentadas na época do nascimento [OR=2,42; IC95\% $(0,97-6,09)]$, na época da menopausa [OR=1,45; IC95\% $(0,74-2,87)]$ e do parto do primeiro filho $[\mathrm{OR}=1,33$; IC $\mathrm{I} 95 \%(0,87-2,06)]$, assim como para a exposição acumulada entre o nascimento e o diagnóstico [OR=3,5; IC95\% (1,4-8,9)], na comparação entre os quartis extremos de exposição. Evidência de aumento de risco de câncer mamário na pré-menopausa só ocorreu para 
exposições aumentadas na época do nascimento [OR=1,71; IC $95 \%(0,60$ $4,87)$ ], entre os quartis extremos de exposição. Ajustes foram feitos para idade, raça, condado de residência, educação e paridade, após verificação de que outras variáveis (índice de massa corpórea, história familiar, idade na menarca e na menopausa, entre outros fatores de risco pré-estabelecidos) não alteraram significantemente as estimativas de risco.

Dados do inquérito populacional PAARC (Pollution Atmosphérique et Affections Respiratoires Chroniques - Poluição do $\mathrm{Ar}$ e Doenças Respiratórias Crônicas) conduzido em 24 áreas de 7 cidades francesas, entre 1974 e 1976, foram utilizados na investigação da associação de vários poluentes atmosféricos medidos no mesmo período com diversos desfechos de mortalidade ocorridos 25 anos depois. As exposições foram determinadas por estações de monitoramento do ar instaladas no centro de cada área e localizadas entre 0,5 e 2,3 quilômetros da residência dos participantes no início do estudo. Após exclusão de seis áreas com estações de monitoramento altamente influenciadas pelo tráfego local (razão $\mathrm{NO} / \mathrm{NO}_{2}$ $>3$ ), observou-se risco aumentado de morte por câncer de pulmão [RR=1,48; IC95\% $(1,05-2,06)]$ com aumento de $10 \mu / \mathrm{m}^{3}$ na concentração de $\mathrm{NO}_{2}$, ajustando-se para idade, gênero, tabagismo, índice de massa corpórea, nível educacional e exposições ocupacionais. Tal exclusão se justificou pela superestimação das medidas de exposição pelo tráfego intenso próximo às estações, resultando em medidas não representativas da exposição média da população em toda a área (FILLEUL et al., 2005).

IWAI et al. (2005) empreenderam estudo ecológico nos 60 distritos que formam o Japão utilizando dados de mortalidade do ano $2000 \mathrm{e}$ medições de $\mathrm{MP}_{10}$ do ano 2001 provenientes de 1881 estações de monitoramento do ar distribuídas por todo o território do país, para analisar a correlação entre essa medida de poluição de ar e as taxas de mortalidade por diversas causas padronizadas pela idade. Encontrou-se correlação positiva para o câncer de pulmão em mulheres $(r=0,306 ; p<0.05)$, significante após ajuste para prevalência distrital de tabagismo, assim como para o câncer de mama $(r=0.373 ; p<0,01)$, de ovário $(r=0,428 ; p<0,05)$ e de 
endométrio $(r=0,29 ; p<0,05)$, significantes após ajustes para variáveis ecológicas distritais de tabagismo, de idade no nascimento do primeiro filho e de paridade. Não se ajustou para porcentagem de mulheres solteiras e índice de massa corpórea média, por não se mostrarem associados à medida de poluição do ar. Devido à ausência de dados e à própria natureza ecológica do estudo, não foi possível o ajuste para outras potenciais variáveis de confusão, como, por exemplo, as ocupacionais.

Em estudo ecológico, que analisava as razões de mortalidade ajustadas para idade por diferentes causas, nos 88 census tracts (com população média de 3500 pessoas) da cidade industrial de Hamilton, Canadá, no período de 1985 a 1994, JERRETT et al. (2005b) observaram associação positiva entre a exposição a partículas totais em suspensão (PTS) e a mortalidade por câncer em geral, significante na maioria dos modelos estatísticos de controle para variáveis ecológicas sócioeconômicas, demográficas, de estilos de vida e de tabagismo, assim como para a autocorrelação espacial. A magnitude de efeito, no sexo masculino, variou entre 7 a $18 \%$ na comparação entre os quartis extremos de exposição. Apesar do controle para diversas variáveis de confusão em potencial, a possibilidade de confundimento residual não pôde ser descartada, limitação inerente aos estudos ecológicos.

Em estudo com a utilização da coorte da American Cancer Society, em Los Angeles, no período de 1982 a 2000, que visava a analisar o efeito crônico de poluentes do ar sobre a mortalidade por diferentes causas, com exposição avaliada em nível de área zip code de residência do indivíduo no recrutamento (com população média de 35.000 habitantes), JERRET et al. (2005c) observou aumento de risco de câncer de pulmão com um incremento de $10 \mu \mathrm{m} / \mathrm{m}^{3}$ na concentração de $\mathrm{MP}_{2,5}$ da ordem de $60 \%$ [RR=1,60; OR95\% (1,09-2,33)], sem nenhum controle de confundimento, de $44 \%$ [RR=1,44; OR95\% $(0,98-2,11)]$, após controle para 44 variáveis de nível individual, e de 20\% [RR=1,20; OR95\% (0,79-1,82)], após controle para essas variáveis individuais e 8 variáveis ecológicas contextuais. Tais estimativas permaneceram robustas após ajustes adicionais para 
concentração de $\mathrm{O}_{3}$ e proximidade a vias de alto tráfego. Além disso, risco elevado de 44\% [RR=1,44; OR95\% $(0,94-2,21)]$ para esse câncer foi encontrado para distâncias de até 500 metros das vias de alto tráfego ao centróide da área zip code. Outro achado, embora com estimativas de menor efeito, foi o aumento do risco de câncer digestivo da ordem de $29 \%$ [RR:1,29; IC95\% (0,87-1,90)], sem ajuste para confundimento, de $18 \%$ [RR=1,18; IC95\% (0,79-1,75)], com ajuste para variáveis individuais, e de $13 \%$ [RR=1,13; IC95\%(0,74-1,73)], com ajuste para variáveis individuais e ecológicas, para o mesmo incremento de $\mathrm{MP}_{2,5}$ acima. $\mathrm{O}$ controle da autocorrelação espacial pouco influiu nessas estimativas. Não se observou aumento de risco desses cânceres com o aumento da concentração de $\mathrm{O}_{3}$ nem com a proximidade de até 1000 metros da via de alto tráfego ao centróide da área.

LADEN et al. (2006) acompanharam a coorte prospectiva Harvard Six Cities Study entre 1974 e 1998, visando investigar a relação entre a exposição a $\mathrm{MP}_{2,5}$ e diversos desfechos de mortalidade. Atribuíram a cada participante a concentração média do poluente da cidade de residência na época do recrutamento, observando risco aumentado de morte por câncer de pulmão com aumento de $10 \mu \mathrm{m} / \mathrm{m}^{3}$ na concentração de $\mathrm{MP}_{2,5}$ para exposições ocorridas nos períodos de 1974 a 1998 [RR=1,27; IC95\% (0,96$1,69)]$ e de 1974 a 1989 [RR=1,20; IC95\% $(0,91-1,58)]$. Ajustes foram feitos para idade, gênero, tabagismo pregresso e à época do recrutamento, nível educacional, e índice de massa corpórea. Não se verificou diminuição do risco do câncer de pulmão com a diminuição da concentração do poluente no ar entre as décadas de 1980 e 1990, provavelmente devido a seu longo período de latência.

Estudo multicêntrico europeu caso-controle aninhado à coorte EPIC (European Prospective Investigation into Cancer and Nutrition), com tempo de seguimento médio de 7 anos de casos e controles, utilizou medidas individuais de exposições de alguns poluentes do ar estimadas por meio de estações de monitoramento representativas da exposição à população e localizadas próximas da residência dos participantes no início do estudo. 
Observou risco aumentado de câncer de pulmão [RR=1,46; IC95\% (0,892,40 )] relacionado à residência em vias de tráfego intenso (com fluxo maior que 10.000 carros por dia), assim como a exposições a $\mathrm{NO}_{2}$ maiores que $30 \mu / \mathrm{m}^{3}$ [RR=1,56; IC 95\% $\left.(1,13-2,16)\right]$ comparadas a níveis menores, e ao aumento de $10 \mu / \mathrm{m}^{3}$ em sua concentração [RR=1,14; IC95\% $(0,78-1,67)$ ] após ajuste para idade, gênero, tabagismo, consumo de álcool, índice de massa corpórea, país de recrutamento, tempo decorrido desde o recrutamento, nível educacional, atividade física e hábitos dietéticos. As estimativas não se alteraram após ajuste adicional para ocupações de alto risco. Encontrou-se também associação mais fraca entre câncer de pulmão e concentrações de $\mathrm{SO}_{2}$ acima de $11 \mu / \mathrm{m}^{3}$ em relação a níveis menores [RR=1,15; IC95\% (0,92-1,43)] (VINEIS et al., 2006).

Coorte prospectiva acompanhou, entre 1992 e 1998, todos os indivíduos moradores de Oslo, Noruega, com idade de 51 a 90 anos, e investigou a relação entre a exposição por 4 anos (1992 a 1995) a diversos poluentes e desfechos de mortalidade. A medida de exposição se baseou na área neighborhood (vizinhança) de residência dos participantes na época do recrutamento e se estratificou a análise por gênero e idade. Risco aumentado de morte por câncer de pulmão foi encontrado para aumentos na concentração de $\mathrm{NO}_{2}, \mathrm{MP}_{2,5}$ e $\mathrm{MP}_{10}$ nos dois sexos e nas duas faixas etárias consideradas (51 a 70 e 71 a 90 anos) com maiores estimativas de efeito em mulheres na primeira faixa etária $\left(\mathrm{MP}_{2,5}\right.$ e $M P_{10}$ : $[R R=1,27$; IC $95 \%(1,13-$ $1,43)$ ] e $\mathrm{NO}_{2}$ : [RR=1,23; IC95\% $\left.(1,10-1,38)\right]$, correspondentes à variação interquartil da exposição). Procedeu-se ajuste somente para nível educacional e classe ocupacional, não se podendo descartar a possibilidade de confundimento por tabagismo e outros fatores de estilo de vida (NAESS et al., 2007).

Já NIE et al. (2007) investigou a associação entre câncer de mama e exposição a hidrocarbonetos policíclicos aromáticos, como marcador de exposição a emissões de tráfego, em diferentes momentos históricos da vida da mulher, através de estudo caso-controle de base populacional com 1068 casos incidentes da doença, diagnosticados entre 1996 e 2001, no 
oeste do estado de Nova lorque, Estados Unidos. Demonstraram risco aumentado de câncer de mama na pré-menopausa associado a exposição a emissões de tráfego ocorridas na época da menarca $[R R=2,07$; IC95\% (0,91-4,72)] e risco aumentado desse câncer na pós-menopausa associado a tal exposição na época de nascimento do primeiro filho [RR=2,58; IC95\% $(1,15-5,83)]$, na comparação entre os quartis extremos de exposição, com ajustes para idade, raça, ano de entrevista, índice de massa corpórea, doença benigna de mama prévia, história familiar de câncer de mama, número de filhos e idade na menarca, no nascimento do primeiro filho e na menopausa. A partir da análise estratificada, observou-se que os aumentos de risco observados se restringiram às mulheres não fumantes.

Visando estudar a associação entre exposição à poluição de ar de longa duração relacionada ao tráfego no local de residência do indivíduo e várias causas de mortalidade, na Netherlands Cohort on Diet and Cancer (coorte em dieta e câncer da Holanda), com cerca de 120.000 participantes, entre 1987 e 1996, BEELEN et al. (2008a) observaram estimativas pouco acima da unidade entre a mortalidade por câncer de pulmão e o aumento de $10 \mu \mathrm{m} / \mathrm{m}^{3}$ nas concentrações modeladas de Carbono elementar $[R R=1,03$; IC95\% $(0,88-1,20)$ e $\mathrm{MP}_{2,5}$ [RR=1,06; IC95\% (0,82-1,38). Estimativas abaixo da unidade foram encontradas para $\mathrm{NO}_{2}$ e $\mathrm{SO}_{2}$. Porém, diversas medidas de intensidade de tráfego se mostraram associadas com esse desfecho, com aumento de risco de 7 a 20\%, embora com significância marginal, após ajuste para sexo, idade, tabagismo e variáveis sócio-econômicas de área. $\mathrm{O}$ maior risco se associou a morar próximo a vias de alto tráfego $[R R=1,20$; IC95\% $(0,98-1,47)]$. Entretanto, em análise caso-coorte, com uma amostra da coorte e um controle mais completo das variáveis de confusão, tais estimativas para as medidas de tráfego diminuíram para 3 a 10\%. Entre os não fumantes da coorte, na análise de subgrupo, estimativas marginalmente significantes foram observadas para aumento de $10 \mu \mathrm{m} / \mathrm{m}^{3}$ na concentração de carbono elementar [RR: 1,48; IC95\% $(0,97-2,25)$ ] e para a soma da intensidade de tráfego dentro de um raio de 100 metros da residência [RR: 1,36: IC95\% (0,96-1,93)], comparando-se os $5 \%$ mais e os $5 \%$ menos 
expostos. Entretanto, não foi feito ajuste para exposições ocupacionais relevantes e o tempo de seguimento de 9 anos pode não ter sido suficiente para se revelar uma associação positiva entre poluição do ar pelo tráfego e câncer de pulmão.

Utilizando a mesma coorte, BEELEN et al. (2008b) avaliaram a exposição de longa duração à poluição pelo tráfego na residência do indivíduo e a incidência de câncer de pulmão, encontrando estimativas de efeito menor que um entre concentrações dos diversos poluentes e 0 desfecho estudado, e levemente aumentadas (de 5 a $11 \%$ ) entre as medidas de intensidade de tráfego e o mesmo desfecho, porém sem significância estatística. A maior estimativa de risco se associou a morar próximo a vias de alto tráfego $[R R=1.11 ; \mathrm{IC} 95 \%(0,91-1,34)]$. Os resultados da análise casocoorte foram semelhantes. Além disso, entre os que nunca fumaram, associação significante foi encontrada entre o aumento de $10 \mu \mathrm{m} / \mathrm{m}^{3}$ na concentração de carbono elementar e a incidência de câncer de pulmão [RR: 1,47; IC95\% (1,01-2,16)], e entre as medidas de tráfego e o desfecho, com aumento de risco de 11 a 55\%, marginalmente significante, na comparação entre os $5 \%$ mais e menos expostos. Como se procedeu a ajuste somente para sexo, idade, tabagismo e variáveis sócio-econômicas de área, permanecem dúvidas sobre a presença de confundimento nessas estimativas, devido à ausência de dados sobre exposição ocupacional a carcinógenos na coorte. Além disso, o tempo de seguimento pode ter sido relativamente curto para se observar uma associação significante e positiva entre os poluentes e o desfecho.

Estudo ecológico, em 11 distritos do município de São Paulo que continham em seu interior estações de monitoramento do $\mathrm{MP}_{10}$ no ar ambiente, relacionou a incidência e a mortalidade anual por diversos tipos de câncer, entre 1997 a 2005, e as médias anuais de MP ${ }_{10}$, entre 1988 e 1997, em nível distrital, através de correlações ano a ano. Observaram-se correlações significantes, positivas e de magnitude considerável entre os níveis do poluente estudado e a incidência de câncer de pele e de pulmão e a mortalidade por câncer de pulmão, para diversos intervalos de tempo entre 
a exposição e o desfecho, frequentemente maiores que 10 anos. Resultados similares em menor número de intervalos de tempo foram encontrados para as incidências de câncer de laringe, tireóide e bexiga. Entretanto, as taxas de mortalidade e de incidência não foram ajustadas para idade e gênero, nem houve ajuste para outras potenciais variáveis de confusão, devido à falta de dados disponíveis. Ademais se procedeu a grande número de testes estatísticos, o que pode resultar em associações significantes somente devidas ao acaso (YANAGI, 2010). 


\section{Anexo 4}

Quadro 8 - Relação de estudos sobre os efeitos da poluição do ar sobre o risco de câncer em crianças e adolescentes. $1998-2008$.

\begin{tabular}{|c|c|c|c|c|c|c|c|c|}
\hline $\begin{array}{l}\text { Autores e } \\
\text { ano de } \\
\text { publicação }\end{array}$ & $\begin{array}{l}\text { Local e } \\
\text { período }\end{array}$ & Desenho & $\begin{array}{l}\text { Desfecho(s) } \\
\text { estudado(s) }\end{array}$ & $\begin{array}{c}\text { Número e idade } \\
\text { de casos e } \\
\text { controles }\end{array}$ & Métodos de exposição & $\begin{array}{c}\text { Medidas de } \\
\text { exposição utilizadas }\end{array}$ & Resultados & Comentários \\
\hline $\begin{array}{l}\text { Harrison et } \\
\text { al.; } 1999\end{array}$ & $\begin{array}{l}\text { Região de } \\
\text { West } \\
\text { Midlands, } \\
\text { Reino Unido; } \\
\text { 1990-1994 }\end{array}$ & $\begin{array}{l}\text { Caso-controle } \\
\text { de base } \\
\text { populacional e } \\
\text { ecológico }\end{array}$ & $\begin{array}{l}\text { Incidência de } \\
\text { Leucemia }\end{array}$ & $\begin{array}{l}130 \text { casos e } 251 \\
\text { controles; (idade } \\
\text { de } 0 \text { a } 15 \text { anos) }\end{array}$ & $\begin{array}{l}\text { Presença de vias de alto } \\
\text { tráfego dentro de um } \\
\text { raio de } 100 \text { metros da } \\
\text { residência dos } \\
\text { participantes na época } \\
\text { do diagnóstico; razão da } \\
\text { incidência observada } \\
\text { sobre a esperada da } \\
\text { população dentro de um } \\
\text { raio de } 100 \text { metros de } \\
\text { vias de alto tráfego }\end{array}$ & $\begin{array}{l}\text { Presença de vias de } \\
\text { alto tráfego dentro de } \\
\text { um raio de } 100 \text { metros } \\
\text { da residência (sim vs } \\
\text { não) } \\
\text { Razão da incidência } \\
\text { observada sobre a } \\
\text { esperada }\end{array}$ & $\begin{array}{l}\text { OR=1,61; IC95\% }(0,90- \\
2,87)\end{array}$ & $\begin{array}{l}\text { Ajustes não foram feitos } \\
\text { para potenciais variáveis } \\
\text { de confusão, devido à } \\
\text { falta de dados } \\
\text { disponíveis. Os controles } \\
\text { foram pacientes com } \\
\text { neoplasias sólidas. Há } \\
\text { incerteza sobre o } \\
\text { número da população } \\
\text { exposta e de referência } \\
\text { (estudo ecológico) }\end{array}$ \\
\hline $\begin{array}{l}\text { Pearson et } \\
\text { al., } 2000\end{array}$ & $\begin{array}{l}\text { Área } \\
\text { metropolitana } \\
\text { de Denver, } \\
\text { EUA; 1976- } \\
1983\end{array}$ & $\begin{array}{l}\text { Caso-controle } \\
\text { de base } \\
\text { populacional }\end{array}$ & $\begin{array}{ll}\text { Incidência } & \text { de } \\
\text { Câncer } & \text { em } \\
\text { geral e } & \text { de } \\
\text { Leucemia } & \end{array}$ & $\begin{array}{lr}320 \text { casos } & \text { de } \\
\text { Câncer } & (97 \\
\text { casos } & \text { de } \\
\text { Leucemia) e } 259 \\
\text { controles; (idade } \\
\text { de } 0 \text { a } 14 \text { anos) }\end{array}$ & $\begin{array}{l}\text { Densidade de tráfego da } \\
\text { via de maior tráfego } \\
\text { dentro de um raio de } \\
453 \text { metros da residência } \\
\text { dos participantes na } \\
\text { época do diagnóstico, } \\
\text { calculada pela sua } \\
\text { contagem veicular } \\
\text { ponderada pela sua } \\
\text { distância à residência }\end{array}$ & $\begin{array}{l}\text { Densidade de tráfego } \\
(\geq 20.000 \text { VPD vs }<500 \\
\text { VPD) }\end{array}$ & $\begin{array}{l}\text { Câncer em } \quad \text { geral: } \\
\text { OR=5,90; IC95\% } \\
\text { 20,56) } \\
\\
\text { Leucemia: } \quad \text { OR=8,28; } \\
\text { IC95\% }(2,09-32,80)\end{array}$ & $\begin{array}{l}\text { Ajustes somente } \\
\text { idade e para } \\
\text { Utilização de } \\
\text { Gaunssianas } \\
\text { pondero. } \\
\text { ponderar a contagem de } \\
\text { tráfego pela distância }\end{array}$ \\
\hline $\begin{array}{l}\text { Raaschou- } \\
\text { Nielsen et al., } \\
2001\end{array}$ & $\begin{array}{l}\text { Dinamarca; } \\
\text { 1968-1991 }\end{array}$ & $\begin{array}{l}\text { Caso-controle } \\
\text { aninhado de } \\
\text { base } \\
\text { populacional }\end{array}$ & $\begin{array}{l}\text { Incidência de } \\
\text { Câncer em } \\
\text { geral, } \\
\text { Leucemia, } \\
\text { Neoplasias do } \\
\text { SNC } \\
\text { Linfoma }\end{array}$ & $\begin{array}{l}1989 \text { casos de } \\
\text { Câncer (986 de } \\
\text { Leucemia, } 740 \\
\text { de Neoplasias } \\
\text { do SNC e 263 } \\
\text { de Linfoma) e } \\
5506 \text { controles; } \\
\text { (idade de } 0 \text { a } 14 \\
\text { anos) }\end{array}$ & 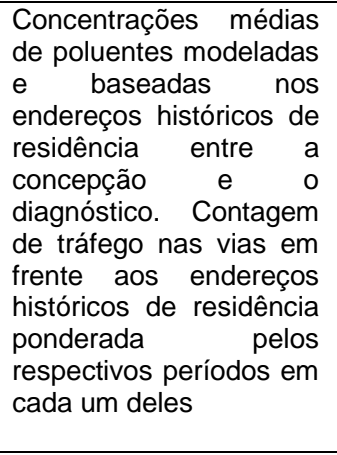 & $\begin{array}{l}\text { Concentrações } \\
\text { muladas de } \mathrm{NO}_{2} \\
\text { durante a gestação } \\
\text { (ao se dobrá-las) } \\
\text { Concentrações acu- } \\
\text { muladas de benzeno } \\
\text { durante a gestação } \\
\text { (ao se dobrá-las) } \\
\text { Contagem de tráfego } \\
\text { durante a gestação } \\
\text { ( } \geq 10.000 \text { VPD vs }<500 \\
\text { VPD) }\end{array}$ & $\begin{array}{l}\text { Linfoma: } \quad \mathrm{RR}=1,25 \text {; } \\
\text { IC95\%(0,99-1,58) } \\
\\
\text { Linfoma: } \quad \mathrm{RR}=1,51 \text {; } \\
\text { IC95\% }(0,99-2,30)\end{array}$ & $\begin{array}{l}\text { Ajustes foram feitos para } \\
\text { sexo, idade, período- } \\
\text { calendário, grau de } \\
\text { desenvolvimento urbano, } \\
\text { região geográfica, tipo de } \\
\text { residência, exposição a } \\
\text { campos } \\
\text { eletromagnéticos, idade } \\
\text { materna e ordem de } \\
\text { nascimento. Exposição } \\
\text { avaliada por modelo de } \\
\text { dispersão validado }\end{array}$ \\
\hline
\end{tabular}




\begin{tabular}{|c|c|c|c|c|c|c|c|c|}
\hline $\begin{array}{l}\text { Langholz et } \\
\text { al., 2002 }\end{array}$ & $\begin{array}{lr}\text { Los } & \text { Angeles, } \\
\text { EUA; } & 1978- \\
1984 & \end{array}$ & $\begin{array}{l}\text { Caso-controle } \\
\text { de base } \\
\text { populacional }\end{array}$ & $\begin{array}{l}\text { Incidência de } \\
\text { Leucemia }\end{array}$ & $\begin{array}{l}212 \text { casos e } 202 \\
\text { controles; (idade } \\
\text { de } 0 \text { a } 10 \text { anos) }\end{array}$ & $\begin{array}{l}\text { Densidade de tráfego } \\
\text { calculada pela soma das } \\
\text { contagens de tráfego } \\
\text { ponderadas pela } \\
\text { distância de todas as } \\
\text { ruas dentro de um raio } \\
\text { de } 453 \text { metros do } \\
\text { endereço de residência } \\
\text { mais longa dos } \\
\text { participantes }\end{array}$ & $\begin{array}{l}\text { Densidade de tráfego } \\
(\geq \mathrm{p} 80 \text { vs }<\mathrm{p} 20 \text { ou } \\
\geq 28.497 \text { VPD vs } \\
<2.301 \text { VPD) }\end{array}$ & $\mathrm{RR}=1,4 ; \mathrm{IC} 95 \%(0,7-3)$ & $\begin{array}{l}\text { Ajustes para idade, sexo } \\
\text { e configuração da rede } \\
\text { elétrica na vizinhança da } \\
\text { residência. Utilização de } \\
\text { curvas Gaussianas para } \\
\text { ponderar a contagem de } \\
\text { tráfego pela distância à } \\
\text { residência }\end{array}$ \\
\hline $\begin{array}{l}\text { Reynolds et } \\
\text { al., } 2002\end{array}$ & $\begin{array}{l}\text { Estado da } \\
\text { Califórnia, } \\
\text { EUA; 1988- } \\
1994\end{array}$ & $\begin{array}{l}\text { Ecológico } \\
(21.519 \\
\text { census block } \\
\text { groups) }\end{array}$ & $\begin{array}{lr}\text { Incidência } & \text { de } \\
\text { Câncer } & \text { em } \\
\text { geral, } & \\
\text { Leucemia } & \text { e } \\
\text { Glioma } & \end{array}$ & $\begin{array}{l}6988 \text { casos de } \\
\text { Câncer (2443 de } \\
\text { Leucemia e } \\
1351 \quad \text { de } \\
\text { Glioma); (idade } \\
\text { de } 0 \text { a } 14 \text { anos) }\end{array}$ & 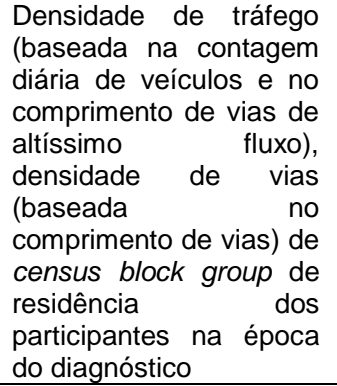 & $\begin{array}{l}\text { Densidade de tráfego } \\
\text { (>p90 vs <p25 ou } \\
>320.701 \text { vs <33.290 } \\
\left.\mathrm{mpd} / \mathrm{milha}^{2}\right) \\
\\
\text { Densidade de vias } \\
(>\mathrm{p} 90 \text { vs }<\mathrm{p} 25 \text { ou } \\
>24,9 \text { vs }<12,3 \text { milhas } \\
\left./ \text { milha }^{2}\right)\end{array}$ & 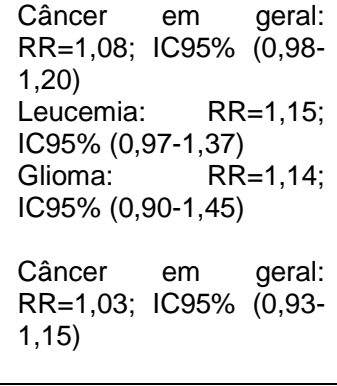 & $\begin{array}{l}\text { Ajustes para idade, sexo, } \\
\text { raça e etnia. A adição da } \\
\text { renda mediana familiar e } \\
\text { da taxa de urbanização } \\
\text { ao modelo de regressão } \\
\text { pouco modificaram os } \\
\text { resultados. Estimativas } \\
\text { populacionais podem } \\
\text { não ser acuradas. Não } \\
\text { se observa gradiente } \\
\text { dose-resposta }\end{array}$ \\
\hline $\begin{array}{l}\text { Reynolds et } \\
\text { al., } 2003\end{array}$ & $\begin{array}{l}\text { Estado da } \\
\text { Califórnia, } \\
\text { EUA; 1988- } \\
1994\end{array}$ & $\begin{array}{l}\text { Ecológico } \\
\text { (census tracts) }\end{array}$ & $\begin{array}{lr}\text { Incidência } & \text { de } \\
\text { Câncer } & \text { em } \\
\text { geral, } & \\
\text { Leucemia } & \text { e } \\
\text { Glioma } & \end{array}$ & $\begin{array}{l}6989 \text { casos de } \\
\text { Câncer (2443 de } \\
\text { Leucemia e } \\
1351 \text { de } \\
\text { Glioma); (idade } \\
\text { de } 0 \text { a } 14 \text { anos) }\end{array}$ & $\begin{array}{lrr}\text { Escore de exposição } \\
\text { (calculado pela } \\
\text { dos proma } \\
\text { concentrações médias } \\
\text { de } 25 \text { poluentes } \\
\text { modeladas para cada } \\
\text { census tract pelas suas } \\
\text { respectivas potências } \\
\text { carcinógenas) } & \text { do } \\
\text { census tract } & \text { de } \\
\text { residência } & \text { dos } \\
\text { participantes na } & \text { época } \\
\text { do diagnóstico } & \end{array}$ & $\begin{array}{l}\text { Escore de exposição } \\
\text { para fontes móveis } \\
\text { (>p90 vs }<\text { p25) }\end{array}$ & $\begin{array}{l}\text { Câncer em } \quad \text { geral: } \\
\text { RR=1,04; IC95\% } \\
\text { 1,14) } \\
\text { Leucemia: } \quad R R=1,18 \text {; } \\
\text { IC95\% }(0,98-1,41) \\
\text { Glioma: } \quad R R=1,02 ; \\
\text { IC95\% }(0,83-1,26)\end{array}$ & $\begin{array}{l}\text { Ajustes para idade, sexo, } \\
\text { raça e etnia. A adição da } \\
\text { renda mediana familiar e } \\
\text { da taxa de urbanização } \\
\text { ao modelo de regressão } \\
\text { pouco modificaram os } \\
\text { resultados. Modelo } \\
\text { ASPEN de dispersão } \\
\text { com uso de dados } \\
\text { meteorológicos e de } \\
\text { emissão. Não houve } \\
\text { gradiente dose-resposta }\end{array}$ \\
\hline $\begin{array}{l}\text { Crosignani et } \\
\text { al., } 2004\end{array}$ & $\begin{array}{l}\text { Província de } \\
\text { Varese, Itália; } \\
\text { 1978-1997 }\end{array}$ & $\begin{array}{l}\text { Caso-controle } \\
\text { de base } \\
\text { populacional }\end{array}$ & $\begin{array}{l}\text { Incidência de } \\
\text { Leucemia }\end{array}$ & $\begin{array}{l}120 \text { casos e } 480 \\
\text { controles; (idade } \\
\text { de } 0 \text { a } 14 \text { anos) }\end{array}$ & $\begin{array}{l}\text { Concentrações médias } \\
\text { modeladas de benzeno } \\
\text { baseadas no endereço } \\
\text { de residência dos } \\
\text { participantes na época } \\
\text { do diagnóstico; distância } \\
\text { de vias de alto fluxo } \\
\text { veicular à residência, } \\
\text { localizadas dentro de }\end{array}$ & $\begin{array}{l}\text { Concentrações de } \\
\text { benzeno }\left(>10 \mu / \mathrm{m}^{3} \text { vs }\right. \\
\left.<0,1 \mu \mathrm{g} / \mathrm{m}^{3}\right) \\
\text { Distância de vias de } \\
\text { alto fluxo de tráfego } \\
\text { (distância }<20 \mathrm{~m} \text { de } \\
\text { vias com } \geq 10.000 \\
\text { VPD vs distância }\end{array}$ & $\begin{array}{l}\mathrm{RR}=3,91 ; \mathrm{IC} 95 \% \quad(1,36- \\
11,27) \\
\\
\mathrm{RR}=2,09 ; \mathrm{IC} 95 \% \quad(0,85- \\
5,12)\end{array}$ & $\begin{array}{l}\text { Ajustes foram feitos } \\
\text { somente para idade e } \\
\text { sexo. Pouca influência } \\
\text { teve o ajuste adicional } \\
\text { para o nível sócio- } \\
\text { econômico do município } \\
\text { de residência dos } \\
\text { participantes. Exposição } \\
\text { avaliada por modelo de }\end{array}$ \\
\hline
\end{tabular}




\begin{tabular}{|c|c|c|c|c|c|c|c|c|}
\hline & & & & & $\begin{array}{l}\text { um raio de } 300 \text { metros } \\
\text { desta }\end{array}$ & $\begin{array}{l}>150 \mathrm{~m} \text { de vias com < } \\
10.000 \text { VPD) }\end{array}$ & & $\begin{array}{l}\text { dispersão Gaussiano } \\
\text { linear (CALINE 4) com } \\
\text { uso de dados de tráfego } \\
\text { e meteorológicos }\end{array}$ \\
\hline $\begin{array}{l}\text { Reynolds et } \\
\text { al., } 2004\end{array}$ & $\begin{array}{l}\text { Estado da } \\
\text { Califórnia, } \\
\text { EUA; 1988- } \\
1997\end{array}$ & $\begin{array}{l}\text { Caso-controle } \\
\text { de base } \\
\text { populacional }\end{array}$ & $\begin{array}{l}\text { Incidência } \\
\text { Câncer } \\
\text { geral, } \\
\text { Leucemia } \\
\text { Neoplasias do } \\
\text { SNC }\end{array}$ & $\begin{array}{l}4396 \text { casos de } \\
\text { Câncer (1728 de } \\
\text { Leucemia e } 746 \\
\text { de Neoplasias } \\
\text { do SNC) e } 8730 \\
\text { controles; (idade } \\
\text { de } 0 \text { a } 4 \text { anos) }\end{array}$ & $\begin{array}{l}\text { Densidade de vias de } \\
\text { alto fluxo veicular } \\
\text { (baseada no } \\
\text { comprimento das vias) e } \\
\text { densidade de tráfego } \\
\text { (baseada na contagem } \\
\text { diária de veículos e no } \\
\text { comprimento de vias de } \\
\text { altíssimo fluxo) dentro } \\
\text { de um raio de } 152 \\
\text { metros do endereço de } \\
\text { residência na época do } \\
\text { nascimento dos } \\
\text { participantes }\end{array}$ & $\begin{array}{l}\text { Densidade de tráfego } \\
\text { (>p90 vs <p29 ou } \\
>276.000 \mathrm{mpd} / \mathrm{milha}^{2} \\
\text { vs } 0 \text { ) }\end{array}$ & 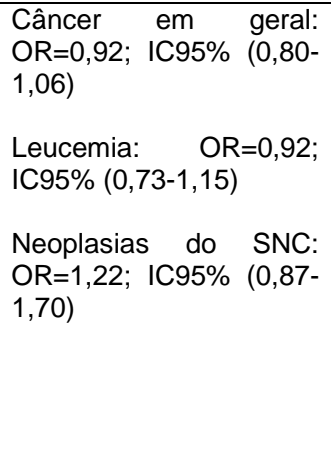 & $\begin{array}{l}\text { Ajustes foram feitos para } \\
\text { idade, gênero e raça / } \\
\text { etnia. As estimativas não } \\
\text { alteraram após ajustes } \\
\text { adicionais para idade } \\
\text { materna, peso ao } \\
\text { nascimento, renda } \\
\text { familiar mediana da } \\
\text { vizinhança e emissões } \\
\text { de benzeno por área do } \\
\text { condado de residência. } \\
\text { Não se observou } \\
\text { gradiente dose-resposta }\end{array}$ \\
\hline $\begin{array}{l}\text { Steffen et al., } \\
2004\end{array}$ & $\begin{array}{l}\text { Nancy, Lille, } \\
\text { Lyon e Paris, } \\
\text { França; 1995- } \\
1999\end{array}$ & $\begin{array}{l}\text { Caso-controle } \\
\text { de base } \\
\text { hospitalar }\end{array}$ & $\begin{array}{l}\text { Incidência de } \\
\text { Leucemia } \\
\text { Aguda }\end{array}$ & $\begin{array}{l}280 \text { casos e } 285 \\
\text { controles; (idade } \\
\text { de } 0 \text { a } 14 \text { anos) }\end{array}$ & $\begin{array}{l}\text { Presença de vias de alto } \\
\text { tráfego em um raio de } \\
50 \text { metros das } \\
\text { residências históricas } \\
\text { dos participantes desde } \\
\text { a concepção até o } \\
\text { diagnóstico ou a } \\
\text { entrevista }\end{array}$ & $\begin{array}{l}\text { Presença de vias de } \\
\text { alto tráfego próximas } \\
\text { às residências (sim vs } \\
\text { não) }\end{array}$ & $\begin{array}{l}\text { Durante a gestação: } \\
\text { OR=0,9; IC95\% } \quad(0,7- \\
1,3) \\
\\
\text { Durante toda a infância: } \\
\text { OR=1,1; IC95\% } \quad(0,8- \\
1,6)\end{array}$ & $\begin{array}{l}\text { Ajustes para sexo, idade, } \\
\text { origem étnica, cidade do } \\
\text { hospital de tratamento e } \\
\text { região administrativa de } \\
\text { moradia. Falta de } \\
\text { critérios objetivos na } \\
\text { avaliação da exposição }\end{array}$ \\
\hline $\begin{array}{l}\text { Visser et al., } \\
2004\end{array}$ & $\begin{array}{l}\text { Amsterdã, } \\
\text { Holanda; } \\
\text { 1989-1997 }\end{array}$ & Ecológico & $\begin{array}{l}\text { Incidência de } \\
\text { Câncer em } \\
\text { geral e dos } \\
\text { seus principais } \\
\text { grupos }\end{array}$ & $\begin{array}{l}5 \text { casos de } \\
\text { Leucemia } \\
\text { Linfóide Aguda; } \\
\text { (idade de } 0 \text { a } 14 \\
\text { anos) }\end{array}$ & $\begin{array}{l}\text { Razão da taxa de } \\
\text { incidência padronizada } \\
\text { observada sobre a } \\
\text { esperada da população } \\
\text { residente dentro de um } \\
\text { raio de } 50 \text { metros do } \\
\text { eixo de vias com alto } \\
\text { Escore de Intensidade } \\
\text { de Tráfego ( } \geq 10.000)\end{array}$ & $\begin{array}{l}\text { Razão da taxa de } \\
\text { incidência } \\
\text { padronizada } \\
\text { observada sobre a } \\
\text { esperada }\end{array}$ & $\begin{array}{l}\text { Neoplasias } \\
\text { hematológicas: } \\
\text { SIR=1,35; IC95\% }(0,44- \\
3,15) \\
\text { Leucemia } \\
\text { Aguda: } \\
\text { SIR=2,5; IC Linfóide } \\
5,9)\end{array}$ & $\begin{array}{l}\text { Taxas de incidência } \\
\text { padronizadas para idade } \\
\text { e gênero. Não houve } \\
\text { ajuste para variáveis } \\
\text { sócio-econômicas e } \\
\text { ocupacionais }\end{array}$ \\
\hline Knox, 2005a & $\begin{array}{l}\text { Reino Unido; } \\
\text { 1966-1980 }\end{array}$ & Ecológico & $\begin{array}{l}\text { Mortalidade } \\
\text { por Câncer em } \\
\text { geral }\end{array}$ & $\begin{array}{l}11.312 \text { casos de } \\
\text { Câncer em } \\
\text { geral; (idade de } \\
0 \text { a } 15 \text { anos) }\end{array}$ & $\begin{array}{l}\text { Razão de emigração e } \\
\text { imigração em relação à } \\
\text { área a menos de } 1 \mathrm{~km} \\
\text { das fontes poluentes. } \\
\text { Análise realizada para } \\
\text { fontes de vários } \\
\text { poluentes diferentes, } \\
\text { sem discriminação das } \\
\text { fontes móveis }\end{array}$ & $\begin{array}{l}\mathrm{CO} \\
\mathrm{PM}_{10} \\
\mathrm{NO}_{x} \\
\text { 1,3-butadieno } \\
\text { Benzeno }\end{array}$ & $\begin{array}{l}R R=3,75 \\
R R=2,49 \\
R R=2,63 \\
R R=3,81 \\
R R=2,12\end{array}$ & $\begin{array}{l}\text { Ausência de ajustes para } \\
\text { potenciais variáveis de } \\
\text { confusão. Exposição } \\
\text { baseada na distância de } \\
\text { fontes com alta emissão } \\
\text { do poluente em relação } \\
\text { às residências dos } \\
\text { participantes desde o } \\
\text { nascimento até a morte }\end{array}$ \\
\hline
\end{tabular}




\begin{tabular}{|c|c|c|c|c|c|c|c|c|}
\hline Knox, 2005b & $\begin{array}{l}\text { Reino Unido; } \\
\text { 1955-1980 }\end{array}$ & Ecológico & $\begin{array}{l}\text { Mortalidade } \\
\text { por Câncer em } \\
\text { geral }\end{array}$ & $\begin{array}{l}12.018 \text { casos de } \\
\text { Câncer em } \\
\text { geral; (idade de } \\
0 \text { a } 15 \text { anos) }\end{array}$ & $\begin{array}{l}\text { Razão de emigração e } \\
\text { imigração em relação à } \\
\text { área a menos de } 1 \mathrm{~km} \\
\text { das fontes poluentes. } \\
\text { Análise realizada para } \\
\text { diversas fontes } \\
\text { poluentes diferentes, } \\
\text { com discriminação das } \\
\text { mesmas }\end{array}$ & $\begin{array}{l}\text { Rodovias de } \\
\text { tráfego }\end{array}$ & $\begin{array}{l}\text { RR=0,91; IC95\% }(0,78- \\
1,05)\end{array}$ & $\begin{array}{l}\text { Ausência de ajustes para } \\
\text { potenciais variáveis de } \\
\text { confusão. Exposição } \\
\text { baseada na distância } \\
\text { das fontes em relação às } \\
\text { residências dos } \\
\text { participantes desde o } \\
\text { nascimento até a morte }\end{array}$ \\
\hline Knox, 2006 & $\begin{array}{l}\text { Reino Unido; } \\
\text { 1955-1980 }\end{array}$ & Ecológico & $\begin{array}{l}\text { Mortalidade } \\
\text { por Câncer em } \\
\text { geral }\end{array}$ & $\begin{array}{l}12.017 \text { casos de } \\
\text { Câncer em } \\
\text { geral; (idade de } \\
0 \text { a } 15 \text { anos) }\end{array}$ & $\begin{array}{l}\text { Razão de emigração e } \\
\text { imigração em relação à } \\
\text { área a menos de } 0,3 \mathrm{~km} \\
\text { das fontes poluentes. } \\
\text { Análise realizada para } \\
\text { diversas fontes } \\
\text { poluentes diferentes, } \\
\text { com discriminação das } \\
\text { mesmas }\end{array}$ & $\begin{array}{l}\text { Rodovias de alto } \\
\text { tráfego }\end{array}$ & $\begin{array}{l}\mathrm{RR}=0,74 \\
\mathrm{RR}=1,92\end{array}$ & $\begin{array}{l}\text { Ausência de ajustes para } \\
\text { potenciais variáveis de } \\
\text { confusão. Exposição } \\
\text { baseada na distância } \\
\text { das fontes em relação às } \\
\text { residências dos } \\
\text { participantes desde o } \\
\text { nascimento até a morte }\end{array}$ \\
\hline $\begin{array}{l}\text { Von Behren et } \\
\text { al., } 2008\end{array}$ & $\begin{array}{l}\text { Estado da } \\
\text { Califórnia, } \\
\text { EUA; 1995- } \\
2002\end{array}$ & $\begin{array}{l}\text { Caso-controle } \\
\text { de base } \\
\text { populacional }\end{array}$ & $\begin{array}{l}\text { Incidência de } \\
\text { Leucemia } \\
\text { Linfóide } \\
\text { Aguda (LLA) }\end{array}$ & $\begin{array}{l}310 \text { casos e } 396 \\
\text { controles; (idade } \\
\text { de } 0 \text { a } 14 \text { anos) }\end{array}$ & $\begin{array}{l}\text { Densidade de tráfego } \\
\text { (baseada na contagem } \\
\text { anual de veículos e no } \\
\text { comprimento de vias de } \\
\text { altíssimo fluxo) dentro } \\
\text { de um raio de } 152 \\
\text { metros do endereço de } \\
\text { residência dos } \\
\text { participantes na época } \\
\text { do nascimento, do } \\
\text { diagnóstico e por toda a } \\
\text { vida até o diagnóstico }\end{array}$ & $\begin{array}{l}\text { Densidade de tráfego } \\
\text { (>p75 vs densidade } \\
\text { zero ou } 91.462 \mathrm{mpd} / \\
\text { milha }^{2} \text { vs } 0 \text { ) }\end{array}$ & $\begin{array}{l}\text { No } \quad \text { nascimento: } \\
\text { OR=1,11; IC95\% }(0,70- \\
1,78) \quad \text { do } \\
\text { Na época } \\
\text { diagnóstico: } \\
\text { OR=1,17; IC95\% }(0,76- \\
1,81) \\
\text { Durante toda a vida: } \\
\text { OR=1,24; IC95\% }(0,74- \\
2,08)\end{array}$ & $\begin{array}{l}\text { Ajustes para idade, } \\
\text { gênero, etnia / raça da } \\
\text { mãe e renda residencial } \\
\text { anual. Observou-se } \\
\text { gradiente dose-resposta } \\
\text { para exposição durante } \\
\text { toda a vida até o } \\
\text { diagnóstico }\end{array}$ \\
\hline $\begin{array}{l}\text { Whitworth et } \\
\text { al., } 2008\end{array}$ & $\begin{array}{l}\text { condados do } \\
\text { nordeste do } \\
\text { Estado do } \\
\text { Texas, EUA; } \\
\text { 1995-2004 }\end{array}$ & $\begin{array}{l}\text { Ecológico } \\
\text { (census tracts) }\end{array}$ & $\begin{array}{l}\text { Incidência de } \\
\text { Leucemia, } \\
\text { LLA, LMA e } \\
\text { Linfoma }\end{array}$ & $\begin{array}{l}670 \text { casos de } \\
\text { Leucemia, } 510 \\
\text { de LLA, 92 de } \\
\text { LMA e } 283 \text { de } \\
\text { Linfoma; (idade } \\
\text { de } 0 \text { a } 19 \text { anos) }\end{array}$ & $\begin{array}{l}\text { Concentrações médias } \\
\text { modeladas dos } \\
\text { poluentes baseadas no } \\
\text { endereço de residência } \\
\text { dos participantes na } \\
\text { época do diagnóstico }\end{array}$ & 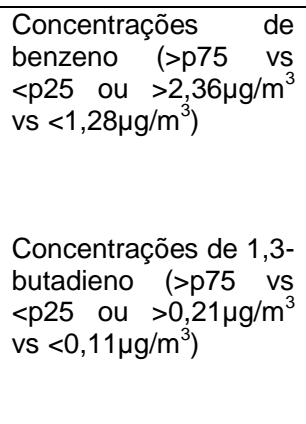 & $\begin{array}{l}\text { Leucemia: RR=1,37; } \\
\text { IC95\% (1,05-1,78) } \\
\text { LLA: RR=1,24; IC95\% } \\
\text { (0,92-1,66) } \\
\text { LMA: RR=2,02; IC95\% } \\
(1,03-3,96) \\
\\
\text { Leucemia: RR=1,40; } \\
\text { IC95\% (1,07-1,81) } \\
\text { LLA: RR=1,32; IC95\% } \\
(0,98-1,77) \\
\text { LMA=1,68; IC95\% }(0,84- \\
\text { 3,35) }\end{array}$ & $\begin{array}{l}\text { Ajustes para idade, } \\
\text { gênero, raça / etnia e } \\
\text { status sócio-econômico } \\
\text { de census tract. } \\
\text { Exposição estimada por } \\
\text { modelo ASPEN de } \\
\text { dispersão com uso de } \\
\text { dados meteorológicos, } \\
\text { de emissão e de outros } \\
\text { fatores e se refere a } \\
\text { fontes móveis, } \\
\text { estacionárias e de área }\end{array}$ \\
\hline
\end{tabular}




\begin{tabular}{|c|c|c|c|c|c|c|c|c|}
\hline $\begin{array}{l}\text { Weng et al., } \\
2008\end{array}$ & $\begin{array}{l}\text { Taiwan; 1995- } \\
2005\end{array}$ & $\begin{array}{l}\text { Caso-controle } \\
\text { de base } \\
\text { populacional }\end{array}$ & $\begin{array}{l}\text { Mortalidade } \\
\text { por Leucemia }\end{array}$ & $\begin{array}{l}308 \text { casos e } 308 \\
\text { controles; (idade } \\
\text { de } 0 \text { a } 14 \text { anos) }\end{array}$ & $\begin{array}{l}\text { Concentrações médias } \\
\text { do poluente no período } \\
\text { de } 1995-2005 \text { do distrito } \\
\text { administrativo de } \\
\text { residência registrada no } \\
\text { certificado de morte dos } \\
\text { participantes }\end{array}$ & $\begin{array}{l}\text { Concentrações de } \\
\mathrm{NO}_{2}(>\mathrm{p} 75 \text { vs }<\text { p25 ou } \\
>26,3 \mu \mathrm{g} / \mathrm{m}^{3} \text { vs }<20,9 \\
\left.\mu \mathrm{g} / \mathrm{m}^{3}\right)\end{array}$ & $\begin{array}{l}\text { OR=2,29; IC95\% }(1,44- \\
3,64)\end{array}$ & $\begin{array}{l}\text { Ajustes para gênero, } \\
\text { anos de nascimento e de } \\
\text { falecimento e índice de } \\
\text { urbanização } \\
\text { município. Exposição } \\
\text { estimada pela média } \\
\text { aritmética das } \\
\text { concentrações médias } \\
\text { anuais das estações de } \\
\text { monitoramento do ar } \\
\text { dentro de cada distrito. } \\
\text { Observou-se gradiente } \\
\text { dose-resposta }\end{array}$ \\
\hline
\end{tabular}

EUA: Estados Unidos da América; IC95\%: Intervalo de Confiança de 95\%; IR: Incidence Ratio; km: quilômetro; LLA: Leucemia Linfóide Aguda; LMA: Leucemia Mielóide Aguda; mpd / milha²: milhas percorridas por dia por milha ao quadrado; $\mathrm{NO}_{2}$ : Dióxido de Nitrogênio; OR: Odds Ratio; RR: Risco Relativo ou Rate Ratio; SIR: Standardized Incidence Ratio; SNC: Sistema Nervoso Central; VPD: Veículos por dia 
A fim de analisar a incidência de leucemia entre 0 e 15 anos de idade e sua relação com a proximidade da residência dos participantes na época do diagnóstico em relação a vias de alto tráfego, HARRISON et al. (1999) utilizou 2 abordagens distintas de estudo, baseando-se em 130 casos dessa moléstia ocorridos entre 1990 e 1994, na região de West Midlands, Reino Unido. Uma com desenho caso-controle, onde se observou risco aumentado de leucemia $[O R=1,61$; IC95\% $(0,90-2,87)]$ associado a morar a menos de 100 metros de tais vias em relação a morar a distâncias maiores. A outra, com desenho ecológico, comparando a incidência observada e a esperada da doença dentro de um raio de 100 metros das vias de alto tráfego, mostrou leve aumento de risco de leucemia [Incidence Ratio [IR=1,16; IC95\% (0,741,73)]. Entretanto, as estimativas de risco não foram ajustadas para potenciais variáveis de confusão, devido à falta de dados disponíveis.

Já PEARSON et al. (2000) utilizou como medida de exposição da poluição do ar pela emissão dos veículos automotivos a densidade veicular da via de maior tráfego dentro de um raio de 453 metros (1500 pés) da residência dos participantes na época do diagnóstico ponderada pela distância, para investigar a sua potencial associação com o desenvolvimento de câncer em geral e de leucemia entre 0 e 14 anos de idade, em estudo caso-controle, na área metropolitana de Denver, Estados Unidos, no período de 1976 a 1983. Risco aumentado de câncer [OR=5,90; IC95\% (1,69-20,56)] e de leucemia [OR=8,26; IC95\% (2,09-32,80)] foi observado na comparação entre as categorias extremas de exposição ( $\geq 20.000$ e $<500$ veículos por dia), sem formação de gradiente dose-resposta, após ajuste somente para idade e gênero. Poucos casos e controles na categoria mais alta de exposição diminuíram a precisão das estimativas de risco.

RAASCHOU-NIELSEN et al. (2001) investigaram a hipótese de que a exposição de longa duração à poluição atmosférica causada por emissões veiculares aumentaria o risco de câncer durante a infância, através de estudo caso-controle, com 1989 casos totais de câncer, constituídos por leucemias, neoplasias do SNC e linfomas, diagnosticados entre 0 nascimento e 14 anos de idade, no período de 1968 e 1991, na Dinamarca. 
A densidade de tráfego e as concentrações acumuladas de $\mathrm{NO}_{2}$ e de benzeno estimadas nos endereços históricos de residência dos participantes durante a gestação e durante a infância foram utilizadas como medidas de exposição. Não se encontrou aumento do risco de câncer e dos tipos específicos estudados associado com a densidade de tráfego, assim como com as concentrações dos poluentes acima durante a gestação e a infância. A exceção foi a observação de risco aumentado de linfoma de $25 \%$ e de $51 \%$, marginalmente significante, ao se dobrar as concentrações de benzeno e $\mathrm{NO}_{2}$, respectivamente, durante a gestação. Esse aumento, porém, se restringiu à doença de Hodgkin, um de seus subtipos, com elevação do risco ao se dobrar as concentrações de $\mathrm{NO}_{2}$ [RR=1,84; IC95\% $\left.(1,21-2,80)\right]$ e de benzeno [RR=2,47; IC95\% (1,17-5,25)], com forte gradiente dose-resposta. Ajustes foram feitos para sexo, idade e período-calendário no pareamento, e para grau de desenvolvimento urbano, região geográfica, tipo de residência, exposição a campos eletromagnéticos, idade materna e ordem de nascimento na análise estatística.

Em seu estudo caso-controle, LANGHOLZ et al. (2002) utilizou a densidade de tráfego ponderada pela distância de todas as ruas dentro de um raio de 453 metros (1500 pés) do endereço de residência dos participantes para avaliar a relação entre a poluição do ar pelo tráfego e o desenvolvimento de leucemia entre 0 e 10 anos de idade, diagnosticada entre 1978 e 1984, na cidade de Los Angeles, Estados Unidos. Não foi observada associação significante [RR=1,4; IC95\% (0,7-3)], na comparação entre os quintis extremos de exposição, sem gradiente dose-resposta, após ajuste, no pareamento, para idade e sexo, e na análise estatística, para configuração da rede elétrica ao redor da residência. Ajuste adicional para outras variáveis (exposições ocupacionais dos pais, a campos eletromagnéticos, entre outras) alteraram muito pouco as estimativas.

Por sua vez, REYNOLDS et al. (2002) desenharam estudo ecológico para investigar a relação entre várias medidas de tráfego, a saber, densidade de veículos, de vias e de tráfego, e as taxas de incidência de câncer em geral, de leucemia e glioma, diagnosticados entre 1988 e 1994, 
no Estado da Califórnia, em nível de census block group (com população média de cerca de 1.400 habitantes). Os resultados evidenciaram risco ausente ou pouco aumentado dos desfechos em relação às medidas de exposição utilizadas, sem formação de gradiente dose-resposta, com as maiores estimativas de risco associadas com a densidade de tráfego. Usando-se tal medida se observou, na comparação entre o maior decil e o menor quartil, aumento de risco de $8 \%$ para câncer em geral [Rate Ratio=1,08; IC95\% (0,98-1,20), de 15\% para leucemia [Rate Ratio=1,15; IC95\% (0,97-1,37)] e de 14\% para glioma [Rate Ratio=1,14; IC95\% 0,90$1,45)$ ], após ajuste para idade, sexo, raça e etnia. A adição da renda mediana familiar e da taxa de urbanização ao modelo de regressão pouco modificaram os resultados.

Com os dados do estudo anterior, REYNOLDS et al. (2003) empreenderam novo estudo ecológico, em nível de census tract, com uso de escore de exposição, uma medida baseada nas concentrações médias modeladas de 25 poluentes e nas suas respectivas potências carcinogênicas, para diferentes fontes emissoras de poluentes. No caso das fontes móveis (que incluía veículos automotores, navios, trens e aviões), observou-se risco muito pouco aumentado de desenvolvimento de câncer [Rate Ratio=1,04; IC95\% (0,95-1,14)] e de glioma [Rate Ratio=1,02; IC95\% $(0,83-1,26)]$ e risco moderadamente elevado de leucemia [Rate Ratio $=1,18$; IC95\% (0,98-1,41)], sem gradiente dose-resposta, na comparação entre o maior decil e o menor quartil. Ajustes foram feitos para idade, sexo, raça e etnia. Renda mediana familiar e taxa de urbanização adicionadas ao modelo não alteraram as estimativas.

Já CROSIGNANI et al. (2004) investigou o efeito das emissões relacionadas ao tráfego sobre a leucemia na faixa etária entre 0 e 14 anos, com o uso de concentrações modeladas de benzeno e medidas de tráfego no local de residência dos participantes na época do diagnóstico como medidas de exposição, em estudo caso-controle, com 120 casos, na Província de Varese, norte de Itália, entre 1978 e 1997. Morar a menos de 20 metros de vias com fluxo de mais de 10.000 veículos por dia (em relação 
a morar a mais de 150 metros de vias com menos de 10.000 veículos por dia) foi associado com o risco de leucemia [RR=2,09; IC95\%(0,85-5,12)] na população estudada, com gradiente dose-resposta. Do mesmo modo, as concentrações de benzeno aumentadas $\left(>10 \mu / \mathrm{m}^{3}\right.$ versus $\left.<0,1 \mu \mathrm{g} / \mathrm{m}^{3}\right)$ foram associadas a risco aumentado do desfecho [RR=3,91; IC95\%(1,36-11,27)], também com padrão dose-resposta. Ajustes foram feitos somente para idade e sexo no pareamento. Teve pouca influência o ajuste adicional para o nível sócio-econômico do município de residência dos participantes.

Utilizando como medidas de exposição da poluição do ar relacionada ao tráfego a densidade de vias de alto fluxo veicular e a densidade de tráfego dentro de um raio de 152 metros (500 pés) do endereço de residência da mãe de cada participante na época do seu nascimento, REYNOLDS et al. (2004) empreenderam estudo caso-controle, no estado da Califórnia, Estados Unidos, visando a investigar a associação entre essas medidas de exposição e o desenvolvimento de câncer total, leucemia e neoplasias do Sistema Nervoso Central, diagnosticados entre 1988 e 1997, em menores de 5 anos. Para câncer total e leucemia, as Odds Ratio obtidas foram, em geral, menores que a unidade e não significantes para as categorias de exposição consideradas. Somente para as neoplasias do SNC, na categoria mais elevada de exposição da densidade de tráfego, a Odds Ratio foi elevada [OR=1,22; IC95\% $(0,87-1,7)]$, na comparação entre as exposições acima do percentil 90 e abaixo do percentil 25, porém sem significância estatística e sem evidência de gradiente dose resposta. Ajustes foram feitos para idade e gênero, por pareamento, e para raça / etnia, na análise estatística. Ajustes adicionais para idade materna, peso ao nascimento, renda familiar mediana da vizinhança e emissões de benzeno por área do condado de residência não alteraram as estimativas de risco.

Visando investigar vários fatores de risco associados com a leucemia aguda, na faixa etária de 0 a 14 anos, entre eles a poluição do ar causada pelo tráfego, STEFFEN et al. (2004) utilizou a presença de vias de alto tráfego dentro de um raio de 50 metros das residências históricas dos participantes, desde a concepção ao diagnóstico, como medida dessa 
exposição, em estudo caso-controle de base hospitalar em algumas cidades da França. Com 280 casos, diagnosticados entre 1995 e 1999, esse estudo não observou risco aumentado e significante de leucemia aguda associado à residência até 50 metros de tais vias durante a gestação da mãe [OR=0,9; IC95\% (0,7-1,3)] e durante a infância [OR=1,1; IC95\% (0,8-1,6)], após ajuste, através de pareamento e análise estatística, para sexo, idade, origem étnica, cidade do hospital de tratamento e região administrativa de moradia. Limitação importante deste estudo foi que a informação sobre as distâncias entre as residências e as vias de alto tráfego foram aquelas relatadas pelas mães dos participantes, portanto sem utilização de critérios objetivos.

Estudo ecológico comparou as taxas de incidência, padronizadas para a idade e gênero, de neoplasias hematológicas, diagnosticadas entre 1989 a 1997, em residentes a até 50 metros de vias de alto tráfego em relação a residentes a distâncias maiores dessas, em Amsterdã, Holanda, na faixa etária de 0 a 14 anos. Verificou-se razão de incidência padronizada aumentada [SIR=1,35; IC95\% $(0,44-1,35)]$, com todos os 5 casos com diagnóstico de leucemia linfóide aguda, que demonstrou risco elevado não significante [SIR=2,5; IC95\% $(0,8-5,9)]$. Não se procedeu a ajuste para o nível sócio-econômico (VISSER et al., 2004).

KNOX (2005a) investigou a relação entre a proximidade da residência na época do nascimento em relação a fontes de diversos poluentes e a mortalidade por câncer na idade de 0 a 15 anos, em estudo ecológico baseado em análise de migração, no Reino Unido, entre 1966 a 1980. Risco aumentado ocorreu entre as crianças residentes ao nascimento até a um quilômetro de fontes com altas emissões de $\mathrm{CO}, \mathrm{MP}_{10}, \mathrm{NO}_{x}$ e 1,3-butadieno, poluentes estes mais associados com fontes móveis. Não houve ajuste para potenciais variáveis de confusão e discriminação das fontes emissoras. Dois outros estudos do mesmo autor (KNOX, 2005b; 2006), com o mesmo banco de dados e metodologia, tipificaram as fontes e as examinaram separadamente. Verificou-se associação positiva entre proximidade a diversas fontes, como rodovias com moderada intensidade de tráfego $(A, B$ class roads), linhas férreas, estações de trem e ônibus, e o desfecho, porém 
ela não foi observada para residência ao nascimento próxima a rodovias de alta intensidade de tráfego. Esse achado incongruente foi justificado por pequeno número de casos e baixa densidade populacional próximo a tais rodovias, assim como por viés na mensuração da exposição.

Utilizando a mesma medida de densidade do tráfego do estudo de REYNOLDS et al. (2004) em 3 diferentes períodos de tempo - no nascimento, no diagnóstico e durante toda a vida -, VON BEHREN et al. (2008) analisou a possível associação entre a poluição do ar pelo tráfego e o desenvolvimento de leucemia linfoblástica aguda (LLA) em estudo casocontrole, com 310 casos, em menores de 15 anos, diagnosticados entre 1995 e 2002, no estado da Califórnia. Comparando os participantes com densidade de tráfego acima do percentil $75 \mathrm{com}$ aqueles com densidade nula, observou-se aumento de risco não significante de LLA associado à residência na época do nascimento [OR=1,11; IC95\% $(0,70-1,78)]$, do diagnóstico [OR=1,17; IC95\% $(0,76-1,81)]$ e à média das exposições nas residências no período do nascimento ao diagnóstico [OR=1,24; IC95\% $(0,74-2,08)]$, após ajuste para idade, gênero, etnia hispânica e raça da mãe, por pareamento, e para renda residencial anual, na análise estatística. Gradiente dose-resposta só ocorreu para a média das exposições ocorridas no período do nascimento ao diagnóstico.

Já WHITWORTH et al. (2008) empreendeu estudo ecológico no nordeste do estado do Texas, Estados Unidos, visando explorar a relação entre as concentrações de benzeno e 1,3-butadieno, em nível de census tract, e a incidência de diversos tipos de câncer linfohematopoético, diagnosticados entre 1995 e 2004, em menores de 20 anos. Aumento de risco associado com a elevação dos níveis de benzeno e de 1,3-butadieno foi observado para leucemia $[R R=1,37$; IC95\% $(1,05-1,78)$ e $R R=1,40$; IC95\% (1,07-1,81), respectivamente], para leucemia linfóide aguda [RR=1,24; IC95\% $(0,92-1,66)$ e $R R=1,32 ;$ IC95\% $(0,98-1,77)]$, para leucemia mielóide aguda [RR=2,02; IC95\% (1,03-3,96) e RR=1,68; IC95\% $(0,84-3,35)]$ e para doença de Hodgkin [RR=1,52; IC95\% $(0,92-2,52)$ e $R R=1,41$; IC95\% $(0,85-2,34)]$, na comparação entre quartis extremos de exposição. Somente 
a leucemia evidenciou gradiente dose-resposta significativo. Ajustes foram feito para idade, gênero, raça / etnia e status sócio-econômico do census tract. Entretanto, as medidas de exposição se referiam a fontes móveis, estacionárias e de área, não as discriminando entre si.

Estudo caso-controle, em Taiwan, investigou a relação entre o risco de morte por leucemia entre o nascimento e 14 anos de idade e a exposição a emissões de exaustão de veículos utilizando a concentração média de $\mathrm{NO}_{2}$ no distrito administrativo de residência dos participantes na época do seu falecimento como marcador da poluição do ar relacionada ao tráfego. Os casos se constituíram de 308 mortes por tal desfecho, ocorridas entre 1995 e 2005, verificando-se aumento do risco de morte por leucemia infantil associado à residência em áreas com maiores níveis de $\mathrm{NO}_{2}$ na atmosfera [OR=2,29; IC95\% (1,44-3,64)], na comparação entre os tercis extremos de exposição, com gradiente dose-resposta, com ajustes por gênero, anos de nascimento e de falecimento, através de pareamento, e por um índice de urbanização, na análise estatística (WENG et al., 2008). 


\section{CURRÍCULOS LATTES}

\section{André de Almeida Ribeiro}

Possui graduação em medicina pela Universidade de São Paulo (2003), especialidade em Clínica Médica pela Universidade Estadual Paulista (2007) e em Medicina do Trabalho pela Faculdade de Medicina de São José do Rio Preto (2009). Atualmente, é médico clínico do Hospital Pérola Byington e médico clínico e do trabalho do Hospital Maternidade Leonor Mendes de Barros, unidades da Secretaria de Estado da Saúde de São Paulo. (Texto informado pelo autor)

Última atualização do currículo em 20/07/2011

Endereço para acessar este CV:

http://lattes.cnpq.br/0218019283318662

\section{Adelaide Cassia Nardocci}

Sou Bacharel em Física pela Universidade Estadual de Londrina (1987), mestre em Engenharia Nuclear pela Coordenação dos Programas de Pós Graduação Em Engenharia (COPPE/UFRJ) (1990) e doutora em Saúde Pública pela Universidade de São Paulo (1999). Tenho pós-doutorado pela Universidade de Bologna (2008) e Livre-docência pela USP (2010).Sou professora associada do Departamento de Saúde Ambiental da Faculdade de Saude Publica da Universidade de São Paulo. Minha atividade de pesquisa atual tem ênfase em Avaliação e Gerenciamento de Riscos Ambientais,em especial: avaliação quantitativa de exposições e riscos de agentes químicos e microbiológicos; gerenciamento de riscos, percepção de riscos; saúde ambiental. (Texto informado pelo autor)

Última atualização do currículo em 07/07/2011

Endereço para acessar este CV:

http://lattes.cnpq.br/7211771211059721 